University of Tennessee Health Science Center

UTHSC Digital Commons

$11-2015$

\title{
Discovery of Novel Tubulin Polymerization Inhibitors and Survivin Inhibitors as Potential Anticancer Agents
}

Min Xiao

University of Tennessee Health Science Center

Follow this and additional works at: https://dc.uthsc.edu/dissertations

Part of the Medicinal and Pharmaceutical Chemistry Commons, and the Pharmaceutics and Drug Design Commons

\section{Recommended Citation}

Xiao, Min , "Discovery of Novel Tubulin Polymerization Inhibitors and Survivin Inhibitors as Potential Anticancer Agents" (2015). Theses and Dissertations (ETD). Paper 299. http://dx.doi.org/10.21007/ etd.cghs.2015.0359.

This Dissertation is brought to you for free and open access by the College of Graduate Health Sciences at UTHSC Digital Commons. It has been accepted for inclusion in Theses and Dissertations (ETD) by an authorized administrator of UTHSC Digital Commons. For more information, please contact jwelch30@uthsc.edu. 


\title{
Discovery of Novel Tubulin Polymerization Inhibitors and Survivin Inhibitors as Potential Anticancer Agents
}

\begin{abstract}
Melanoma is the most dangerous form of skin cancer and accounts for the majority of skin cancer death. Although considerable advances have been made in melanoma treatment in recent years, there are many problems associated with current therapies. Drug resistance to targeted therapies is almost inevitable after short term treatment. Immunotherapies generally have low response rate and the effects vary among patients. Therefore, the need to develop new and more effective treatment for melanoma is high.

The work presented here focuses on discovery of novel anticancer agents for melanoma by targeting two important cancer targets: tubulin and survivin. Microtubules play important role in mitosis and cell division. Cancer cells divide more rapidly than normal cells, and thus are more sensitive to tubulin targeting agents which disrupt mitosis. Targeting tubulin for anticancer treatment has been very successful. Chapter 3 describes our discovery process of a series of novel tubulin polymerization inhibitors. Our lab previously reported a set of 2-aryl-4-benzoyl-imidazoles (ABI) derivatives with potent anti-proliferative activity against melanoma cells and xenografts. A new series of 4-aryl-2-benzoylimidazoles were designed and synthesized after further optimization of the ABI series. The new scaffold reversed the position of the aryl group and benzoyl group on the imidazole ring of $A B I$ structure and thus was named RABI. Those newly synthesized compounds were tested against eight different cancer cells, including multidrug-resistant cancer cell lines. The in vitro results showed that several compounds in this series had excellent anti-proliferative activities. The best compound displayed IC50 value in single-digit nano-molar against several tumor cell lines. In addition, RABI compounds showed advantages in overcoming multiple drug resistance, compared with existing tubulin targeting agents, paclitaxel, colchicine, and vinblastine. Mechanism of action for the RABI compounds was investigated using cell cycle analysis, tubulin polymerization assay, competitive mass spectrometry binding assay, and molecular docking studies. These studies suggested that RABI compounds exerted their anticancer effects by inhibiting tubulin polymerization at the colchicine binding site. The RABI compounds represent promising cancer drug candidates for further development.
\end{abstract}

Another attractive target for anticancer treatment is survivin. The differential expression of survivin between normal differentiated cells and tumor cells and the essential role of survivin in tumor make it an ideal target for cancer. Although survivin is an attractive cancer drug target, the pool of existing survivin inhibitors is quite limited. Thus, it is highly significant to develop new survivin inhibitors. Our attempts to search for new survivin inhibitors were initiated by the identification of UC-112 which turned out to be a potent and selective survivin inhibitor. UC-112 was discovered through virtual screening from a library of compounds. It showed good potency both in vitro and in vivo. Structural modifications of the UC-112 oxyquinoline template generated a number of UC-112 analogs. The new analogs were tested on a panel of cancer cell lines. The results suggested that the new derivatives had strong anticancer activity. Several compounds showed IC50 value in the nano-molar range. The structure-activity relationships were also elucidated through the structural modifications. Our best compounds along with UC-112 were submitted for $\mathrm{NCl}-60$ cancer cell line screening. The results from the screening indicated the best compound in this series improved potency in terms of GI50. The most potent compound also showed good drug-like properties. Mechanism of action for the UC-112 analogs was investigated using Western blot and drug affinity responsive target stability (DARTS) assay. This set of compounds selectively inhibited the expression of survivin over other IAP proteins and also protected survivin from digestion by pronase in the DARTS assay. The most potent compound from the in vitro assay effectively suppressed tumor growth in melanoma xenograft. This novel scaffold represents a new structure template for survivin inhibitors and can be further developed as potential anticancer agents. 


\section{Document Type \\ Dissertation \\ Degree Name \\ Doctor of Philosophy (PhD) \\ Program \\ Pharmaceutical Sciences}

\section{Research Advisor}

Wei Li, Ph.D.

\section{Keywords}

melanoma, RABI, survivin inhibitors, tubulin polymerization inhibitors, UC- 112 analogs

\section{Subject Categories}

Medicinal and Pharmaceutical Chemistry | Medicine and Health Sciences | Pharmaceutics and Drug Design | Pharmacy and Pharmaceutical Sciences 
Discovery of Novel Tubulin Polymerization Inhibitors and Survivin Inhibitors as Potential Anticancer Agents

\author{
A Dissertation \\ Presented for \\ The Graduate Studies Council \\ The University of Tennessee \\ Health Science Center \\ In Partial Fulfillment \\ Of the Requirements for the Degree \\ Doctor of Philosophy \\ From The University of Tennessee
}

By

Min Xiao

December 2015 
Chapter 3 (C) 2015 by American Chemical Society.

Chapter 4 (C) 2015 by Bentham Science Publishers.

Portion of Chapter 5 (C) 2015 by Public Library of Science All other material $\mathbb{C} 2015$ by Min Xiao.

All rights reserved. 


\section{ACKNOWLEDGEMENTS}

I would like to take this opportunity to express my deepest gratitude to my advisor, Dr. Wei Li for his support and guidance through my graduate studies, without which any part of this dissertation would not have been possible. His insightful minds, dedication to research, and diligent working attitude have always inspired me to do good research and become a better scientist.

I would like to extend my thanks to my committee members, Dr. Isaac O. Donkor, Dr. Tomoko Fujiwara, Dr. Richard E. Lee, and Dr. Bob M. Moore for their time and invaluable suggestions throughout my studies. I would also like to thank Dr. Duane D. Miller for his help, stimulating discussion and encouragement during the weekly group meetings.

I would like to give a special thanks to Dr. Jianjun Chen, a former member of our group for teaching me the techniques in organic synthesis. I really appreciate his careful and patient guidance, without which none of my research could have been possible. I would also like to thank Dr. Yan Lu for her valuable suggestions. Whenever I come to her for suggestions, she is always willing to help. I am sincerely thankful to Dr. Jin Wang and Dr. Sunjoo Ahn for performing all the biological studies for the compounds I synthesized.

I am grateful to my colleagues and friends in Memphis. Their support and accompany make my five years Ph.D. life full of joys and memories.

Lastly, I would like to give my sincere gratitude to my parents and my wife. Their continuous support and unconditional love encourage me to be a better self. 


\begin{abstract}
Melanoma is the most dangerous form of skin cancer and accounts for the majority of skin cancer death. Although considerable advances have been made in melanoma treatment in recent years, there are many problems associated with current therapies. Drug resistance to targeted therapies is almost inevitable after short term treatment. Immunotherapies generally have low response rate and the effects vary among patients. Therefore, the need to develop new and more effective treatment for melanoma is high.
\end{abstract}

The work presented here focuses on discovery of novel anticancer agents for melanoma by targeting two important cancer targets: tubulin and survivin. Microtubules play important role in mitosis and cell division. Cancer cells divide more rapidly than normal cells, and thus are more sensitive to tubulin targeting agents which disrupt mitosis. Targeting tubulin for anticancer treatment has been very successful. Chapter 3 describes our discovery process of a series of novel tubulin polymerization inhibitors. Our lab previously reported a set of 2-aryl-4-benzoyl-imidazoles (ABI) derivatives with potent anti-proliferative activity against melanoma cells and xenografts. A new series of 4-aryl-2-benzoyl-imidazoles were designed and synthesized after further optimization of the ABI series. The new scaffold reversed the position of the aryl group and benzoyl group on the imidazole ring of ABI structure and thus was named RABI. Those newly synthesized compounds were tested against eight different cancer cells, including multidrug-resistant cancer cell lines. The in vitro results showed that several compounds in this series had excellent anti-proliferative activities. The best compound displayed $\mathrm{IC}_{50}$ value in single-digit nano-molar against several tumor cell lines. In addition, RABI compounds showed advantages in overcoming multiple drug resistance, compared with existing tubulin targeting agents, paclitaxel, colchicine, and vinblastine. Mechanism of action for the RABI compounds was investigated using cell cycle analysis, tubulin polymerization assay, competitive mass spectrometry binding assay, and molecular docking studies. These studies suggested that RABI compounds exerted their anticancer effects by inhibiting tubulin polymerization at the colchicine binding site. The RABI compounds represent promising cancer drug candidates for further development.

Another attractive target for anticancer treatment is survivin. The differential expression of survivin between normal differentiated cells and tumor cells and the essential role of survivin in tumor make it an ideal target for cancer. Although survivin is an attractive cancer drug target, the pool of existing survivin inhibitors is quite limited. Thus, it is highly significant to develop new survivin inhibitors. Our attempts to search for new survivin inhibitors were initiated by the identification of UC-112 which turned out to be a potent and selective survivin inhibitor. UC-112 was discovered through virtual screening from a library of compounds. It showed good potency both in vitro and in vivo. Structural modifications of the UC-112 oxyquinoline template generated a number of UC-112 analogs. The new analogs were tested on a panel of cancer cell lines. The results suggested that the new derivatives had strong anticancer activity. Several compounds showed $\mathrm{IC}_{50}$ value in the nano-molar range. The structure-activity relationships were also 
elucidated through the structural modifications. Our best compounds along with UC-112 were submitted for NCI-60 cancer cell line screening. The results from the screening indicated the best compound in this series improved potency in terms of $\mathrm{GI}_{50}$. The most potent compound also showed good drug-like properties. Mechanism of action for the UC-112 analogs was investigated using Western blot and drug affinity responsive target stability (DARTS) assay. This set of compounds selectively inhibited the expression of survivin over other IAP proteins and also protected survivin from digestion by pronase in the DARTS assay. The most potent compound from the in vitro assay effectively suppressed tumor growth in melanoma xenograft. This novel scaffold represents a new structure template for survivin inhibitors and can be further developed as potential anticancer agents. 


\section{TABLE OF CONTENTS}

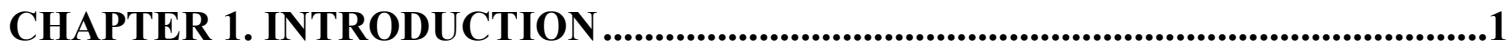

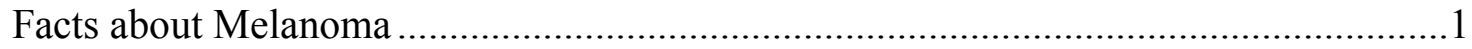

Statistics for Melanoma …..........................................................................

Melanoma Causes and Risk Factors ..................................................................... 1

Major Genetic Recurrent Driver Mutations of Melanoma ......................................

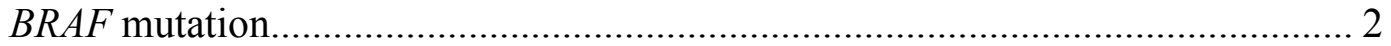

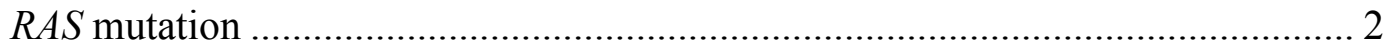

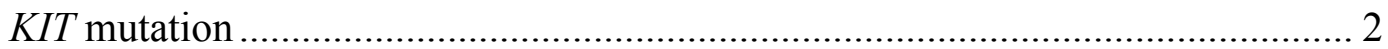

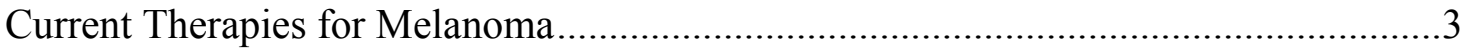

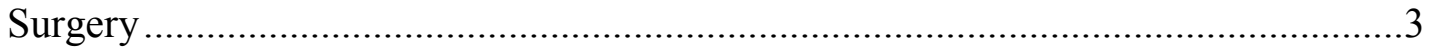

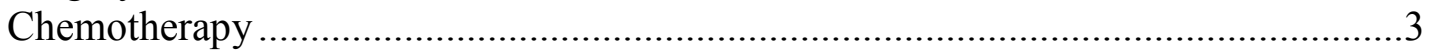

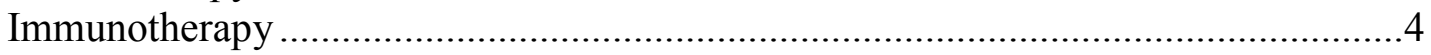

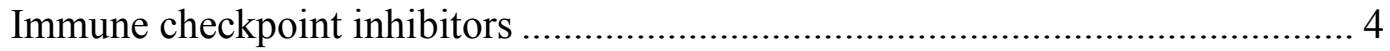

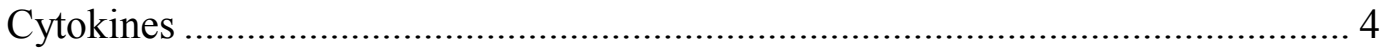

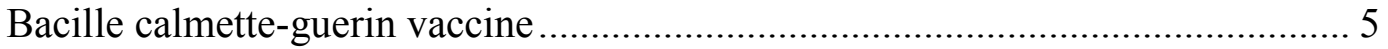

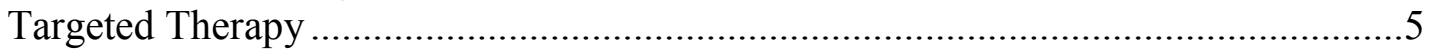

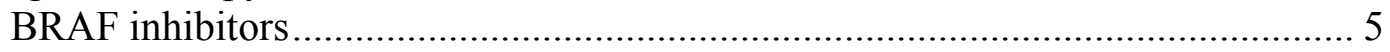

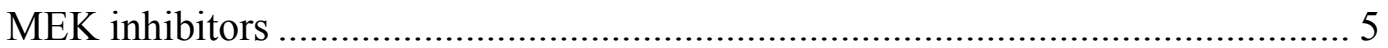

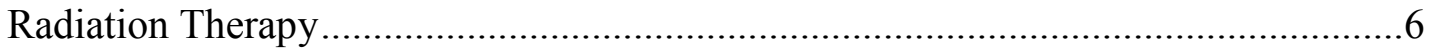

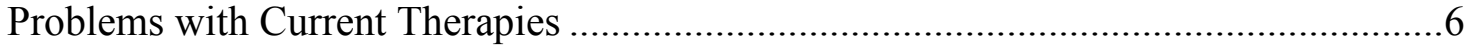

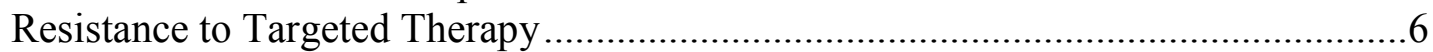

Limitations of Immunotherapy .....................................................................

Tubulin and Survivin as Cancer Drug Targets ........................................................

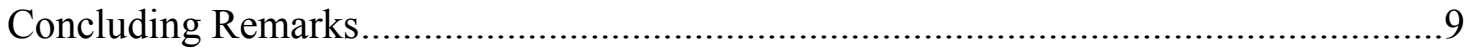

\section{CHAPTER 2. OVERVIEW OF TUBULIN AND TUBULIN}

POLYMERIZATION INHIBITORS …................................................................10

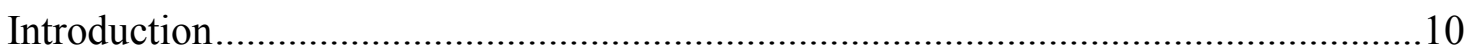

Structure and Functions of Microtubule ................................................................... 10

Binding Sites of Tubulin Targeting Agents ................................................................ 12

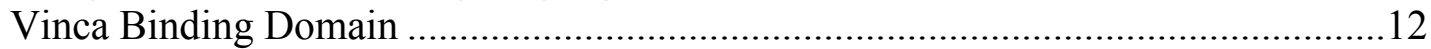

Taxol Binding Domain .................................................................................... 12

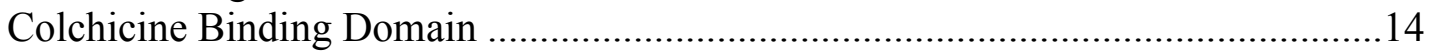

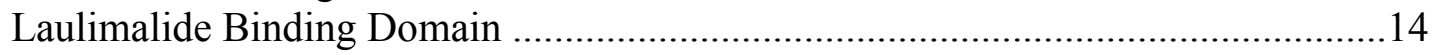

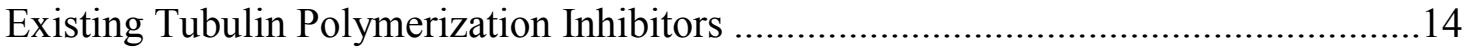

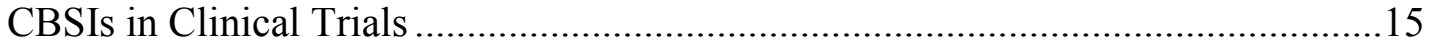

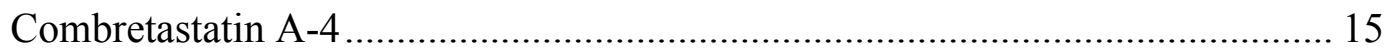

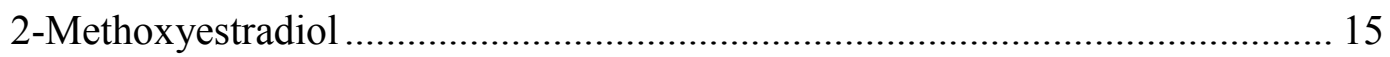

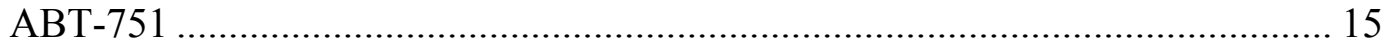

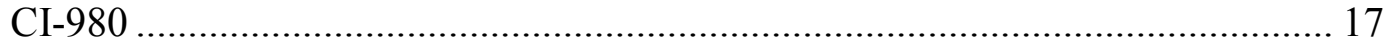

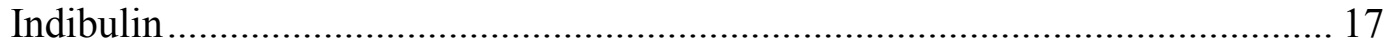

Reported CBSIs in Preclinical Studies .......................................................... 17

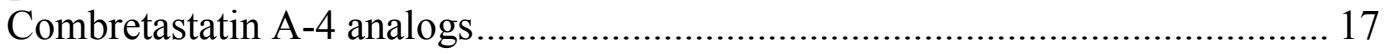




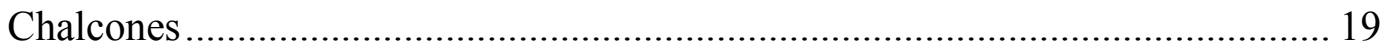

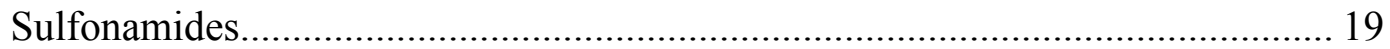

Indole-based compounds .......................................................................... 19

Problems with Existing Tubulin Targeting Agents .....................................................20

Drug Resistance to Tubulin Targeting Agents......................................................20

ATP binding cassette proteins and drug efflux.................................................. 20

Alterations in microtubules .............................................................................. 21

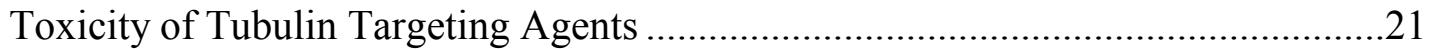

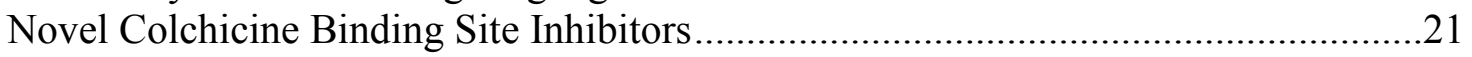

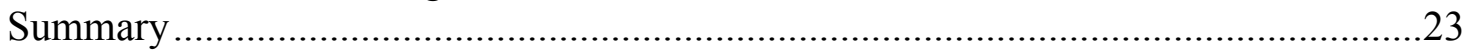

\section{CHAPTER 3. DISCOVERY OF 4-ARYL-2-BENZOYL-IMIDAZOLES AS TUBULIN POLYMERIZATION INHIBITORS WITH POTENT} ANTIPROLIFERATIVE PROPERTIES...........................................................24

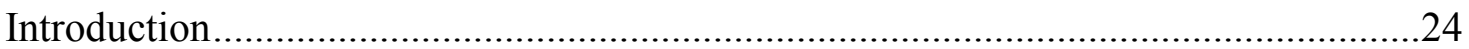

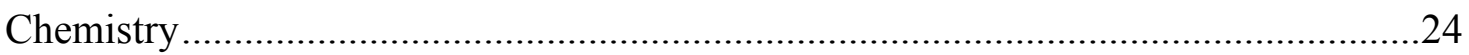

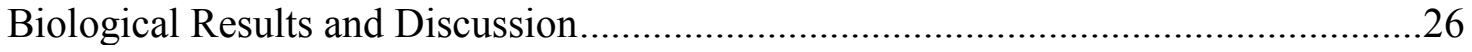

Effect of Substitutions on the A Ring of ABI Analogs ..........................................26

The Ketone Linker Remains Critical for RABI Analogs...........................................30

Effect of Substitutions on the A Ring of RABIs........................................................

Effect of Substitutions on the C Ring of RABIs ........................................................

Effect of Substitutions on the B Ring of RABIs ......................................................33

Effect of RABI Compounds against Multidrug-Resistant Melanoma Cells...............33

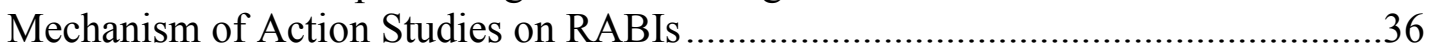

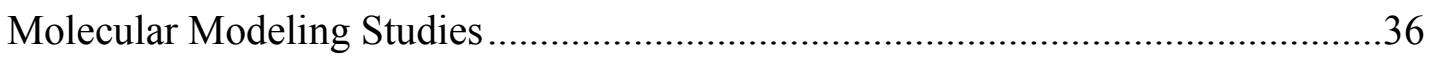

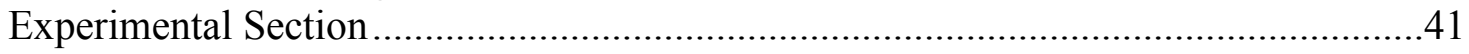

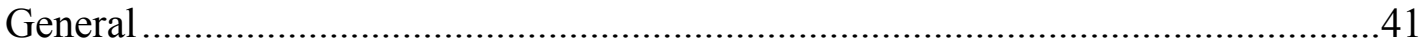

General Procedure for the Preparation of 2a-c........................................................ 41

General Procedure for the Preparation of 3a-c.........................................................4 41

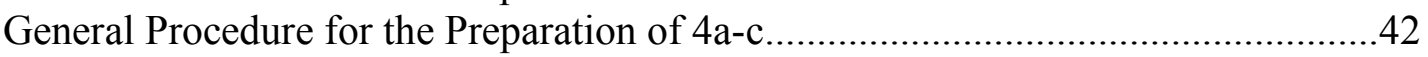

General Procedure for the Preparation of 5a-c........................................................42

General Procedure for the Preparation of 8a-e........................................................43

General Procedure for the Preparation of 11-14 …………......................................43

General Procedure for the Preparation of 15a-c....................................................48

General Procedure for the Preparation of 15d-f......................................................48

General Procedure for the Preparation of $15 \mathrm{~g}-\mathrm{h}$.......................................................49

General Procedure for the Preparation of 18a-c......................................................50

Cell Culture and Cytotoxicity Assay ………………….......................................50

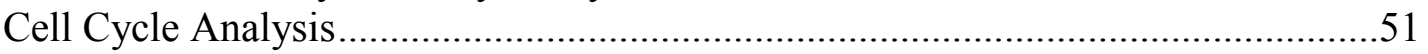

Tubulin Polymerization Assay .................................................................................51

Competitive Mass Spectrometry Binding Assay ………………............................51

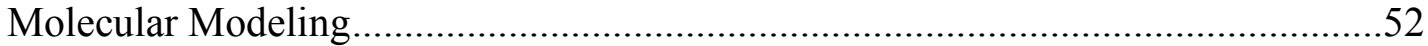

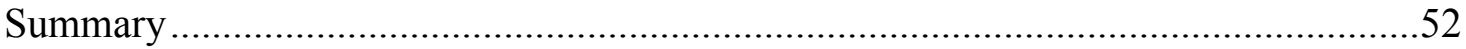


CHAPTER 4. OVERVIEW OF SURVIVIN AND SURVIVIN INHIBITORS .........54

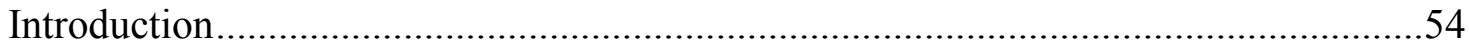

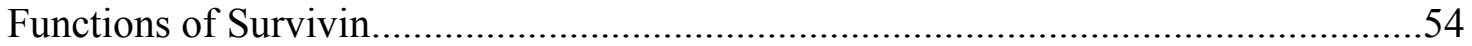

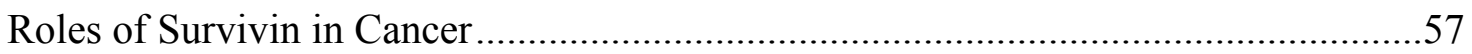

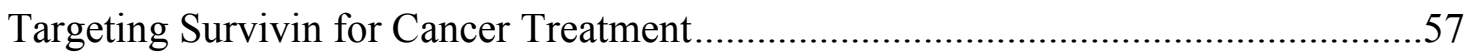

Existing Small-Molecule Survivin Inhibitors ..........................................................58

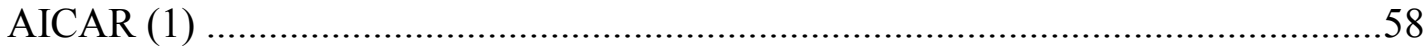

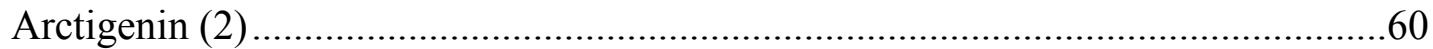

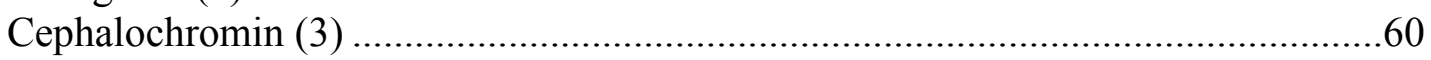

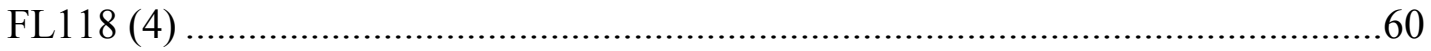

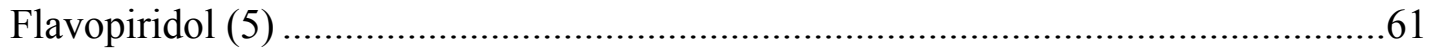

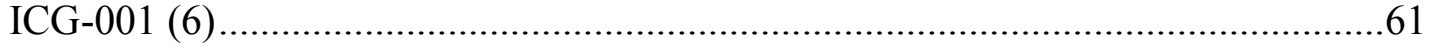

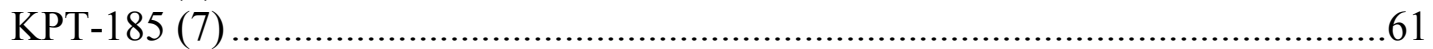

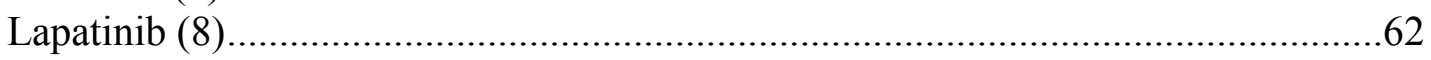

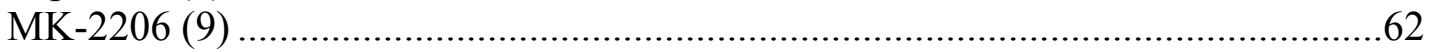

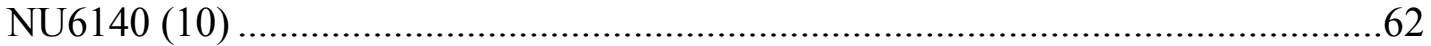

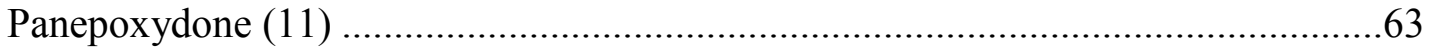

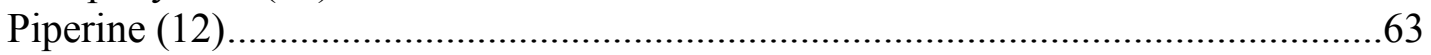

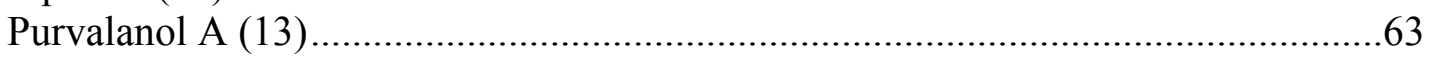

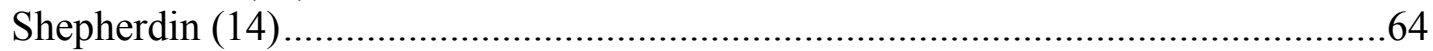

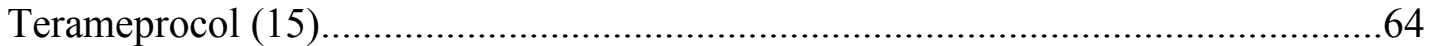

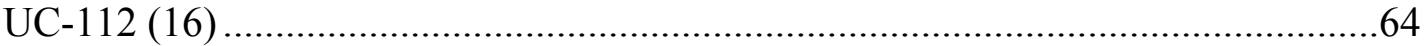

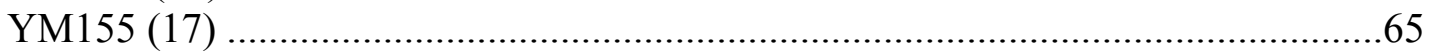

Challenges for Development of Survivin Inhibitors .....................................................65

Conclusion Remarks and Future Directions ………………....................................66

\section{CHAPTER 5. DESIGN, SYNTHESIS AND BIOLOGICAL EVALUATION OF} NOVEL SURVIVIN INHIBITORS ................................................................................67

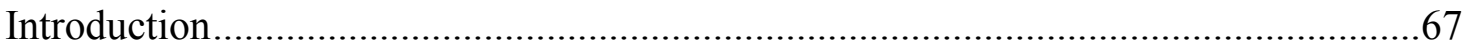

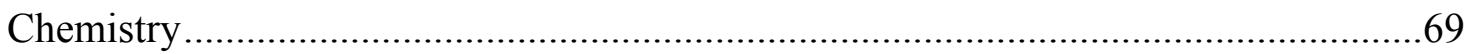

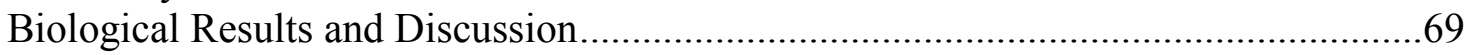

Effect of Substitutions on the C Ring of UC-112 ………….................................75

Effect of Replacing the Phenyl Ring of UC-112 with Other Groups .........................75

Effect of D Ring Modification on UC-112 ……………........................................78

Effect of Chain Length between Oxygen and C Ring of UC-112 Analogs ................78

Effect of Linkers between C Ring and D Ring of UC-112 Analogs ..........................78

UC-112 Analogs Can Overcome Multidrug Resistance ............................................. 81

UC-112 Analogs Show Good Antiproliferative Effects with Selectivity in NCI-

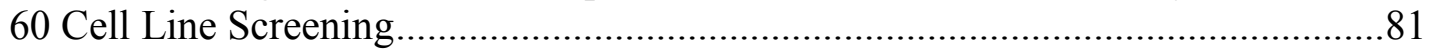

Compound 4g Possesses Good Drug-Like Properties ................................................84

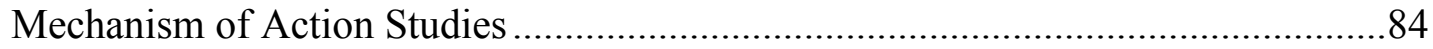

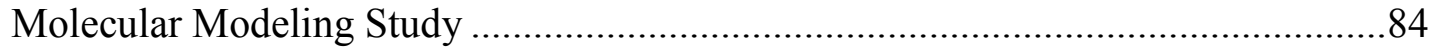

Drug Affinity Responsive Target Stability (DARTS) Assay....................................89

In Vivo Anti-Tumor Efficacy Assessment ..............................................................89

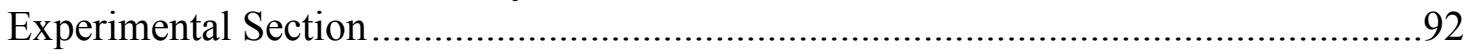

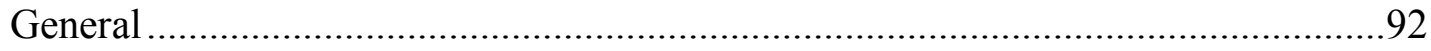


Preparation of 5-Chloromethyl-8-Quinolinol Hydrochloride (2) ...........................92

General Procedure for the Preparation of Compounds (3a-31) ..............................92

General Procure for the Preparation of Compounds $(4 \mathrm{a}-41)$....................................94

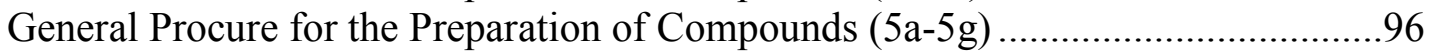

General Procure for the Preparation of Compounds $(6 \mathrm{a}-6 \mathrm{~g})$...................................97

General Procure for the Preparation of Compounds (8a-8b) ...............................98

General Procure for the Preparation of Compounds (9a-9b) ...................................99

General Procure for the Preparation of Compounds (10a-10b) ................................99

General Procure for the Preparation of Compounds (11a-11b) ...............................100

General Procure for the Preparation of Compounds (12a-12b) .............................100

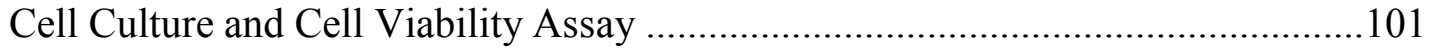

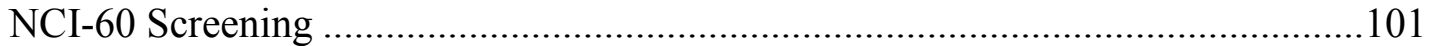

Drug-Like Property Profiling for Compound 4g ................................................... 101

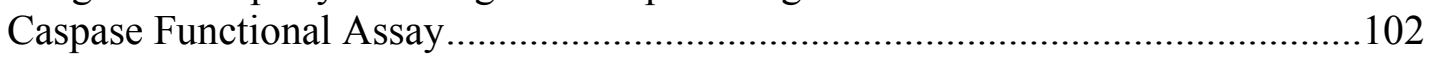

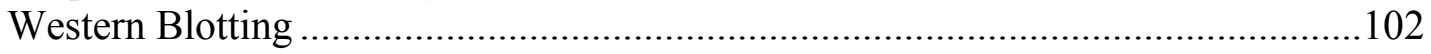

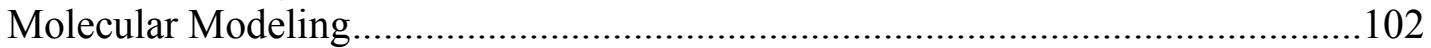

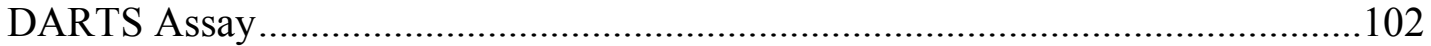

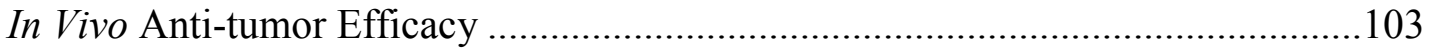

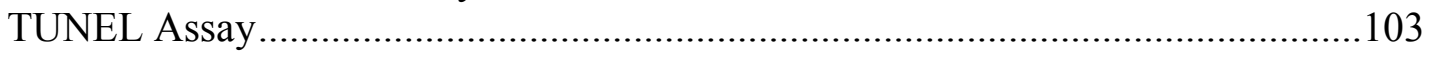

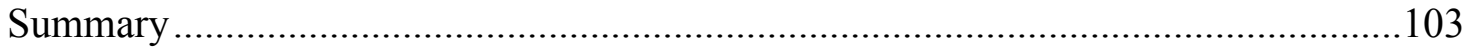

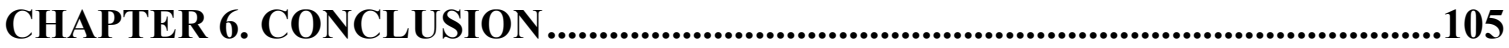

LIST OF REFERENCES ..................................................................................................108

VITA 


\section{LIST OF TABLES}

Table 3-1. In vitro growth inhibitory effects of ABI compounds with A ring substitutions

Table 3-2. In vitro growth inhibitory effects of RABI compounds with methylene linker.

Table 3-3. In vitro growth inhibitory effects of RABI compounds without B ring substitution

Table 3-4. In vitro growth inhibitory effects of RABI compounds with B ring substitution

Table 3-5. In vitro growth inhibitory effects of RABI compounds comparison to other anticancer drugs on multidrug-resistant melanoma cell and parent cell line

Table 5-1 In vitro growth inhibitory effects of UC-112 analogs with $\mathrm{C}$ ring substitutions

Table 5-2. In vitro growth inhibitory effects of C ring modified UC-112 analogs ........77

Table 5-3. In vitro growth inhibitory effects of D ring modified UC-112 analogs........79

Table 5-4.. In vitro growth inhibitory effects of UC-112 analogs with different chain lengths

Table 5-5. In vitro growth inhibitory effects of UC-112 analogs with different linkers

Table 5-6 Aqueous solubility and in vitro metabolism properties of compound $4 \mathrm{~g} . . . .85$

Table 5-7. Cytochrome P450 inhibition effects of compound 4g .85 


\section{LIST OF FIGURES}

Figure 1-1. The mechanisms of acquired resistance to BRAF inhibition........................

Figure 2-1. Structure of microtubule ..................................................................... 11

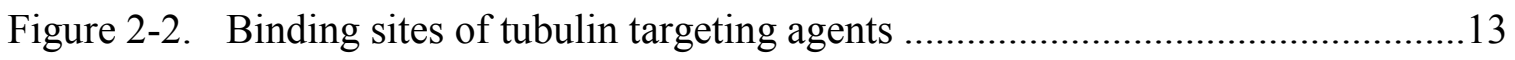

Figure 2-3. Chemical structures of representative CBSIs in clinical trials....................16

Figure 2-4. Chemical structures of reported CBSIs in preclinical studies ....................18

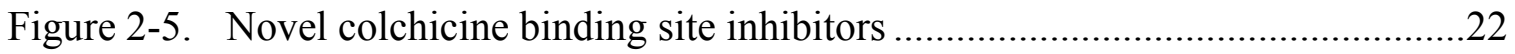

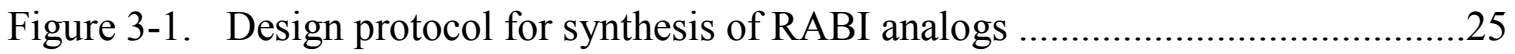

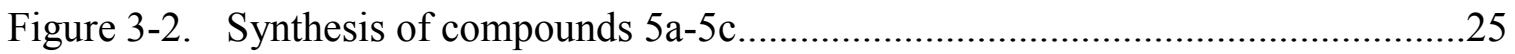

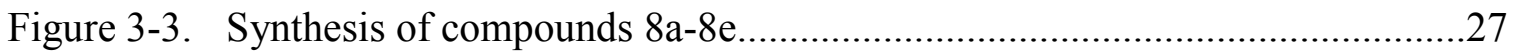

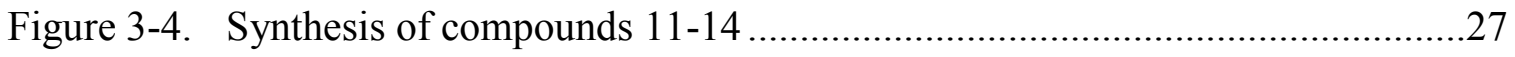

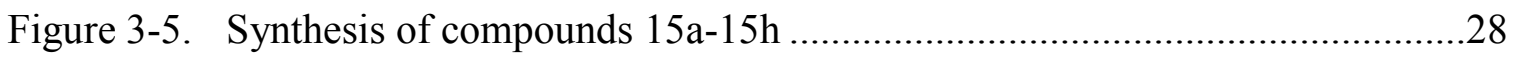

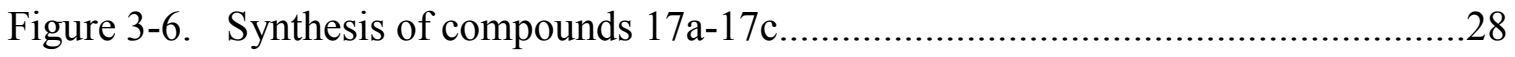

Figure 3-7. Effect of compounds 5a, 12a, 12d, 12e, 15a and $15 \mathrm{~b}$ on cell cycle..............37

Figure 3-8. Effect of RABI compounds on tubulin polymerization in vitro ...................38

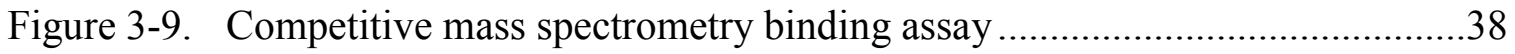

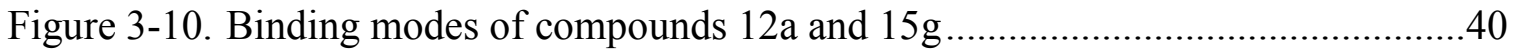

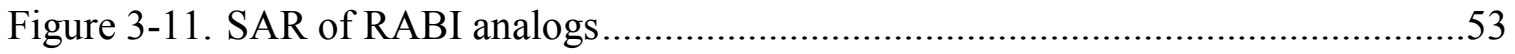

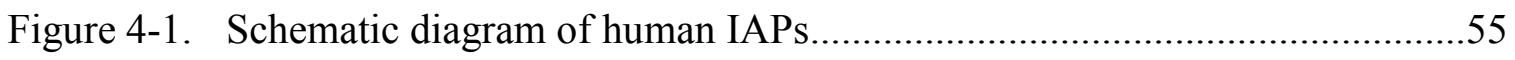

Figure 4-2. Functions of survivin and targets of survivin inhibitors ..........................56

Figure 4-3. Chemical structures of recently developed small-molecule survivin inhibitors

Figure 5-1. Targeted modification to design new UC-1 12 analogs............................68

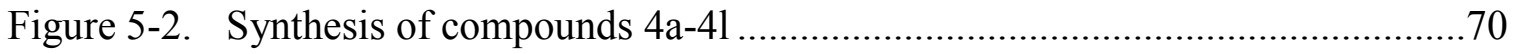

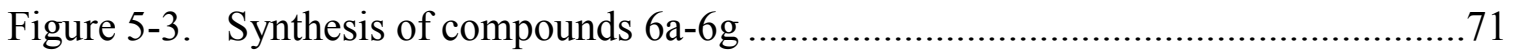




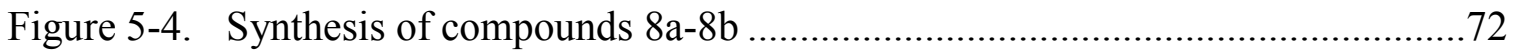

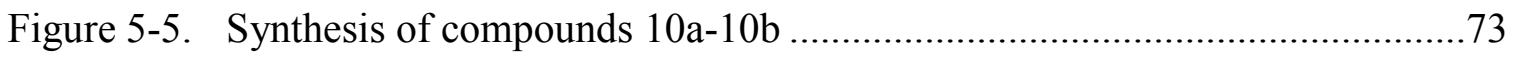

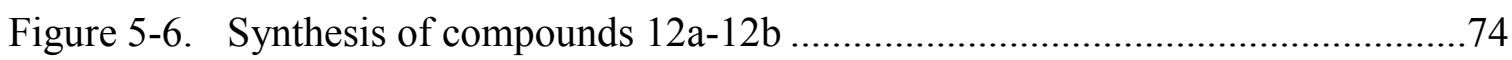

Figure 5-7 Average $\mathrm{GI}_{50}$ data for UC-112, compound $12 \mathrm{c}, 4 \mathrm{c}$ and $4 \mathrm{~g}$ tested in NCI60 anti-proliferative screening ...................................................... 82

Figure 5-8. Heat map showing the $\mathrm{GI}_{50}$ values (nM) for UC-112 and three analogs in the NCI-60 screening

Figure 5-9 Western blotting assay of A375 and PC-3 cells treated with gradient

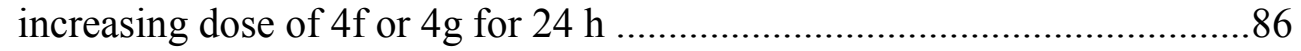

Figure 5-10. Relative in vitro caspases 3/7 activity of human melanoma A375 or human prostate cancer PC-3 cells were evaluated after treatment of UC112 analogs $(1 \mu \mathrm{M})$ for $24 \mathrm{~h}(\mathrm{~N}=3)$.

Figure 5-11. Potential binding pose of UC-112 and compound 4g in the SMAC Nterminus tetra-peptide AVPI binding site of survivin crystal structure (PDB entry: 3UIH).

Figure 5-12. Representative drug affinity responsive target stability (DARTS) results for pronase-digested A375 or M14 cell lysates .......................................90

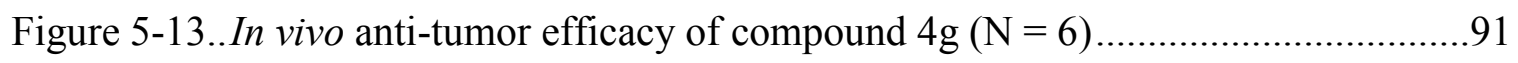

Figure 5-14.. Structure activity relationships of UC-112 analogs ...............................104 


\section{LIST OF ABBREVIATIONS}

$\begin{array}{ll}\text { ABC } & \text { ATP binding cassette } \\ \text { ABI } & \text { 2-aryl-4-benzoyl-imidazoles } \\ \text { ADME } & \text { adsorption, distribution, metabolism and elimination } \\ \text { AICAR } & \text { 5-aminoimidazole-4-carboxamide-1-b-D-ribofuranoside } \\ \text { ATCC } & \text { American type culture collection } \\ \text { ATP } & \text { adenosine triphosphate } \\ \text { BCRP } & \text { breast cancer resistant proteins } \\ \text { BIR } & \text { baculoviral IAP repeat } \\ \text { BIRC5 } & \text { baculoviral inhibitor of apoptosis repeat-containing 5 } \\ \text { CA-4 } & \text { combretastatin A-4 } \\ \text { CA-4P } & \text { combretastatin A-4 phosphate } \\ \text { CBSI } & \text { colchicine binding site inhibitor } \\ \text { CDK } & \text { cyclin-dependent kinase } \\ \text { CPC } & \text { chromosomal passenger complex } \\ \text { CTLA-4 } & \text { cytotoxic T lymphocyte antigen-4 } \\ \text { CYP } & \text { cytochrome P450 } \\ \text { DARTS } & \text { drug affinity responsive target stability } \\ \text { DMEM } & \text { Dulbecco's modified eagle's medium } \\ \text { DMF } & \text { dimethylformamide } \\ \text { DMSO } & \text { dimethyl sulfoxide } \\ \text { DNA } & \text { deoxyribonucleic acid } \\ \text { ESI } & \text { electrospray ionization } \\ \text { FACS } & \text { fluorescence-activated cell sorting } \\ \text { FDA } & \text { food and drug administration } \\ \text { GDP } & \text { guanosine diphosphate } \\ \text { GI } 50 & \text { concentration of 50\% growth inhibition } \\ \text { GTP } & \text { guanosine triphosphate } \\ \text { HBXIP } & \text { hepatitis B X-interacting protein } \\ \text { HMBC } & \text { heteronuclear multiple bond correction spectroscopy } \\ \text { HPLC } & \text { high performance liquid chromatography } \\ \text { IAP } & \text { inhibitor of apoptosis protein } \\ \text { LRP } & \text { lung resistance associated protein } \\ \text { MAPK } & \text { mitogen-activated protein kinase } \\ \text { MDR1 } & \text { multidrug resistance protein 1 } \\ \text { MRP } & \text { multidrug resistance associated protein } \\ \text { NAIP } & \text { NLR family, apoptosis inhibitory protein } \\ \text { NSCLC } & \text { nonsmall cell lung cancer } \\ \text { PAT } & \text { phenyl-aminothiazole } \\ \text { PBS } & \text { phosphate-buffered saline } \\ \text { PD-1 } & \text { programmed cell death-1 } \\ \text { Pgp } & \text { propidium iodide } \\ \text { PI } & \\ \text { PI3K } & \end{array}$


PPIs

RAID

RTK

SAR

SCF

SMART

SRB

TCF

THF

TLC

TMS

TUNEL

UVR

XIAP

2-ME protein-protein interactions

rapid access to intervention development

receptor tyrosine kinase

structure-activity relationships

stem cell factor

4-substituted methoxy benzoylaryl-thiazoles

sulforhodamine B

$\mathrm{T}$ cell factor

tetrahydrofuran

thin layer chromatography

trimethyl silane

terminal deoxynucleotidyl transferase dUTP nick end labeling

ultraviolet radiation

$\mathrm{X}$-linked inhibitor of apoptosis

2-methoxyestradiol 


\section{CHAPTER 1. INTRODUCTION}

\section{Facts about Melanoma}

Melanoma causes the greatest morbidity and mortality of all skin cancers [1]. The blueprint of melanoma statistics, risk factors and major biology mutations is summarized here.

\section{Statistics for Melanoma}

According to the up-to-date data from National Cancer Institute, melanoma is one of the top 10 most common cancers in the United States with steadily increasing rate over the past decade. It is estimated that there will be 73, 870 new cases and 9,940 new death of melanoma in 2015. About 4\% patients develop distal metastasis in the whole melanoma population and poor prognosis is associated with the disease at this stage. The five-year survival rate for metastasis melanoma is only $16.6 \%$, which indicates the aggressiveness of disease and the missing of effective therapeutics.

\section{Melanoma Causes and Risk Factors}

Men with fair complexion and red hair is more likely to develop melanoma with the growing of age, compared with other group of people [2]. Although $40 \%$ of melanoma is considered to be a benign disease, ultraviolet radiation (UVR) remains the leading cause of melanoma. People with heritable factors including the history of sunburn, excessive exposure to UVR, and close relative history of melanoma, multiple benign and unusual moles are at higher risk for the development of melanoma [3].

Melanoma origins from the malignant transformation of melanocytes, which can be found between the epidermis and dermis layer of skin. When the melanocyte begins to grow out of control due to factors like DNA-damage caused by UVR and hereditary gene mutation, it enters to early stage of melanoma (radial growth phase) [3]. Melanoma at this stage hasn't yet contacted with the blood vessel buried deeper and is not able to spread to distal tissues. Comparing with other skin cancers like basal cell carcinoma and squamous cell carcinoma, melanoma has characteristic asymmetry, border irregularity, color variation and large diameter look. When the melanoma cells begin to grow towards vertical direction into papillary dermis, they reach invasive stage of melanoma and further spread to both surrounding and distal tissues (especially lung) through blood or lymph circulation [4]. 


\section{Major Genetic Recurrent Driver Mutations of Melanoma}

Melanoma can be categorized by the histological and anatomic sites of origin into different subtypes like nodular melanoma, uveal melanoma and superficial spreading melanoma. But with the in-depth understanding of the molecular and genetic aspects of melanoma during the recent decades, researchers find that several "driver" mutations are closely associated with the disease progression, prognosis and tumorigenesis [1, 5-7]. Melanoma arises when mutations of these cancer driver genes accumulate and alter the melanocyte cell proliferation, programmed death and differentiation. Target therapies for melanoma have been studied based on these findings in gene mutation status. The landscape of melanoma genomic alteration subtypes are summarized here and respective insights of therapeutic choices are discussed later in brief as well.

\section{BRAF mutation}

$B R A F$ gene codes a serine/threonine kinase, BRAF, which is a part of RAS-RAFMEK-ERK signaling pathway [7-10]. More than 30 mutations of the $B R A F$ gene have been found in most types of cancers with wide variation of abundance. Around $60 \%$ of malignant melanoma patients bear $B R A F$ V600E mutation, which alters the sequence at the hydrophobic activation loop of BRAF and changes the sensitivity of protein to proteasome inhibitors. The wild-type BRAF protein works as homodimer, while the mutant (e.g. V600E, V600K) protein can be activated as monomer [11]. Mutant BRAF protein usually is hyper-activated and thus leads to the over-stimulation of downstream MEK kinase and progressive disease status.

\section{RAS mutation}

About $10 \sim 20 \%$ of melanoma carry $R A S$ mutations and they are considered as the marker for the derivation of malignant melanoma. Among three pro-oncogene of human RAS (HRAS, KRAS, NRAS), NRAS has the most common mutations in melanoma. RAS protein is membrane-bound small GTPase [10, 12-14]. Its active form translocates RAF protein from cytoplasm to plasma membrane and phosphorylates it in response to the extracellular growth factors [5]. RAS protein is among the first onco-proteins studied in human, which plays roles like a "switch" of events determining cell growth, differentiation and survival. Downstream effectors that bind to RAS and trigger signaling cascade include Aiolos transcription factor, RAF proteins, phosphatidylinositol 3-kinase (PI3K), Ral guanine nucleotide dissociation stimulator, PLC $\varepsilon$ and $\mathrm{PKC} \zeta$ [13].

\section{KIT mutation}

Although small portion of melanomas have KIT mutations compared with $B R A F$ or $R A S$ mutations, melanomas arising from mucosal and genital regions commonly have amplifications or activating mutations of KIT, which encode c-KIT (also known as 
CD117), a type III transmembrane receptor tyrosine kinase (RTK) for binding of stem cell factor (SCF) [7, 11, 15]. Upon stimulation, c-KIT will be dimerized, autophosphorylated, and activate several signaling pathways. Interestingly, the response of cKIT to RTK inhibitor imatinib is dependent on the mutation status of KIT gene. It is reported that melanoma patients harboring K642E mutation as well as a 7-codon duplication of exon 11 in KIT achieved durable benefits of imatinib treatment, while patients with mutations on exon $17 \operatorname{did}$ not [15].

\section{Current Therapies for Melanoma}

There are mainly five types of therapies to treat melanoma currently, including surgery, chemotherapy, immunotherapy, targeted therapy, and radiation therapy. In this section, these therapies and the drugs used are reviewed.

\section{Surgery}

Surgery remains the main treatment option for most melanomas. It usually can cure early stage melanomas and thus is the best choice for patients with early stage melanomas. After a diagnosis of melanoma is made, the tumor site will be cut out along with a small amount of normal non-cancerous skin, which is referred as margin [16]. The surgical margins will vary depending on the tumor thickness and also sometimes the location of the tumor. Sometimes, the lymph nodes close to the primary melanoma will also be removed to prevent spreading. Surgery is unlikely to cure metastatic melanoma. Yet surgery is sometimes performed in patients with advanced melanomas either to control the cancer or to help improve quality of life.

\section{Chemotherapy}

Dacarbazine is the primary chemotherapeutical agent used to treat advanced melanoma. Dacarbazine was approved by Food and Drug Administration (FDA) in 1975 and has been used for the treatment of metastatic melanoma for several decades. This agent works by alkylation of DNA via the super active methyl radical formed after activation in vivo. The overall response rate of dacarbazine has fallen over the years [1718]. But it remains the mainstay of many chemotherapy regimens. Since chemotherapeutical drugs generally work by attacking fast-dividing cells, those normal cells that are also dividing fast in our body, such as those in bone marrow, the lining of the mouth and intestine, and the hair follicles, will also be affected, causing many side effects. With the advent of new immunotherapies and targeted drugs which target cancer cells more selectively and have less adverse effects, chemotherapeutical drugs are used less often now. 


\section{Immunotherapy}

Melanoma has long been considered as a promising target for immunotherapy. Currently there are several types of immunotherapies used to treat melanoma patients, which are discussed in the following part.

\section{Immune checkpoint inhibitors}

The most successful immunotherapy up to date has been immune checkpoint inhibition. Checkpoints are essentially molecules on immune cells to control immune response. An important purpose for their existence is to protect normal cells from being attacked. Melanoma and other cancers can escape from immunological attack in many ways involving the checkpoints [3]. Restoring immune response to melanoma by inhibiting checkpoints proves a very effective way to treat melanoma. Two checkpoints, cytotoxic T lymphocyte antigen-4 (CTLA-4) and programmed cell death-1(PD-1), that mediate immune tolerance, have been best studied. CTLA-4 is a molecule expressed on the surface of activated T cells which can obstruct T cells activation. PD-1 is expressed by activated T cells and B cells, while PD-1 ligand, PD-L1, is expressed by antigenpresenting cells. The interaction between PD-1 on T cells and PD-L1 deactivates T cells. Many cancers including melanoma evade immune surveillance by expressing PD-L1 themselves.

Ipilimumab, a CTLA-4 blocking monoclonal antibody, was the first drug to extend survival for patients with metastatic melanoma [19]. It was approved by FDA for the treatment of advanced melanoma in 2011. Anti-PD-1 monoclonal antibodies showed even better effects than ipilimumab in clinical trials [20]. Pembrolizumab, an PD-1 blocking agent, won FDA approval in September 2014 for the treatment of patients with unresectable or metastatic melanoma and disease progression following ipilimumab [21]. Another anti-PD-1 drug, nivolumab, was approved by the FDA for the same indications as pembrolizumab in December 2014.

\section{Cytokines}

Cytokines are small proteins in the body that can boost immune system. Two cytokines, interleukin-2 and interferon-alfa, have been used in clinical for the treatment of melanoma. Interleukin-2 was a type I cytokine which activates cytotoxic T cells. It was approved by the FDA in 1998 for patients with advanced melanoma and represents the first FDA-approved immunotherapy drug. Interleukin-2 has many side effects including severe tiredness, drowsiness, and low blood cell counts, which limit their use [22]. Despite of this, it can produce long-term remissions in some patients [23]. Interferon-alfa has been used both as a single agent after surgery or in combination with other drugs for advanced melanoma treatment [24-25]. The use of interferon-alfa can prevent remaining cancer cells after surgery from growing and spreading. For both interleukin-2 and interferon-alpha to be effective, high doses must be used. But many patients cannot 
tolerate the severe adverse effects associated with high doses. Therefore, they are used less as of now.

\section{Bacille calmette-guerin vaccine}

Cancer vaccines are another type of immunotherapy used in clinical. They are designed to induce immune responses against tumor-specific or tumor-associated antigens, which will encourage the immune system to attack cancer cells containing these antigens. Bacille Calmette-Guerin vaccine is a germ related to the one that causes tuberculosis. It boosts the entire immune system similarly as cytokines. This vaccine is not specific for melanoma cells. It is sometimes used to treat melanomas by directly injecting the vaccine into the tumors [26].

\section{Targeted Therapy}

Targeted therapy of melanoma began with the identification of mutations in BRAF, a serine/threonine protein kinase, by Davies et al in 2002 [9]. It is reported that more than 50\% melanomas have position 600 mutations in BRAF, with V600E mutation being the majority $(80 \%)$ and the next being V600K mutation $[10,27]$. Drugs that target BRAF mutations have been very successful in recent years with three targeted drugs including vemurafenib, dabrafenib, and trametinib, approved by the FDA. The three drugs are discussed in more details in the following part.

\section{BRAF inhibitors}

BRAF plays an important role in the RAS-RAF-MEK-ERK signaling pathway, and regulates many critical cellular functions, such as cell division, proliferation, and apoptosis resistance [28]. Various mutations of BRAF have been identified in melanoma. Vemurafenib works by preferentially inhibiting the active form of BRAF [29] and is the first targeted drug to show substantial efficacy against melanoma [30]. In the phase III clinical trial, vemurafenib induced significant tumor shrinkage in the majority of patients with melanomas bearing $\mathrm{BRAF}^{\mathrm{V} 600 \mathrm{E}}$ mutations and showed advantages over dacarbazine treatment group [8]. This drug was approved by the FDA in 2011 for use in patients with advanced or unresectable melanomas. Dabrafenib, another selective BRAF inhibitor, is the first identified drug that can efficiently treat melanoma with brain metastases [31]. It provided similar clinical benefits as vemurafenib [32]. It was approved by the FDA as a single agent for the treatment of advanced melanoma with $\mathrm{BRAF}^{\mathrm{V} 600 \mathrm{E}}$ mutations in 2013.

\section{MEK inhibitors}

MEK is another member of the MAPK signaling pathway and is in the downstream of RAF. Thus drugs that block MEK protein are also useful in treating 
melanomas with BRAF mutations. MEK inhibitors such as trametinib and selumetinib, showed good responses in clinical trials with melanoma patients [33-34]. Trametinib was approved by the FDA in 2013 as a monotherapy agent for the treatment of metastatic melanoma with BRAF mutations. It is the first orally available, allosteric MEK inhibitor. Many studies have been done to study the combinatory effects of using MEK inhibitors together with other anticancer agents, especially BRAF inhibitors. In one recent clinic trial, co-administration of dabrafenib with trametinib demonstrated improved clinical benefits with fewer toxicities compared with single agent treatment [14].

\section{Radiation Therapy}

Radiation therapy uses high-energy rays to kill tumor cells. It is not often used in the original melanoma that started on the skin. Radiation therapy is sometimes used after surgery to the region where lymph nodes have been removed in order to prevent cancer from recurring. It is often used to relieve symptoms caused by the spread of the melanoma. Some possible side effects include hair loss, fatigue, nausea and weight loss. The side effects can become worse when radiation is given with chemotherapy.

\section{Problems with Current Therapies}

Recent years have witnessed several revolutionary therapeutical advances that have significantly improved the outcomes of melanoma patients. The success lies in immunotherapy and targeted therapy of melanoma with six new anti-melanoma drugs being approved by the FDA in the recent five years. These advances mark the era of immunotherapy and targeted therapy. The new drugs bring considerable clinical benefits to patients with advanced melanomas. However, there are many limitations with these therapies. Problems with current therapies for melanoma are summarized in this section.

\section{Resistance to Targeted Therapy}

The efficacy of BRAF inhibitors like vemurafenib or dabrafenib is restricted to melanomas harboring BRAF mutations. Even in BRAF-mutant patients, drug resistance and disease progression occurred in most cases within 6 months during the treatment [8]. The melanomas that are resistant to BRAF inhibitors often confer resistance to MEK inhibitors such as trametinib or selumetinib as well [12]. It is therefore not surprising that trametinib monotherapy shows minimal clinical activity to patients with acquired resistance to BRAF inhibitors [35].

Mechanisms of resistance to BRAF inhibition include innate resistance and acquired resistance. Innate resistance generally comes from BRAF wild type melanomas. Pretreatment factors including BCL2A1 expression, PTEN loss, and CCND1 activation can cause innate resistance [36]. For acquired resistance, various mechanisms have been

identified, which can be divided into two categories (Figure 1-1): $\mathrm{BRAF}^{\mathrm{V} 600 \mathrm{E}}$-bypass, 


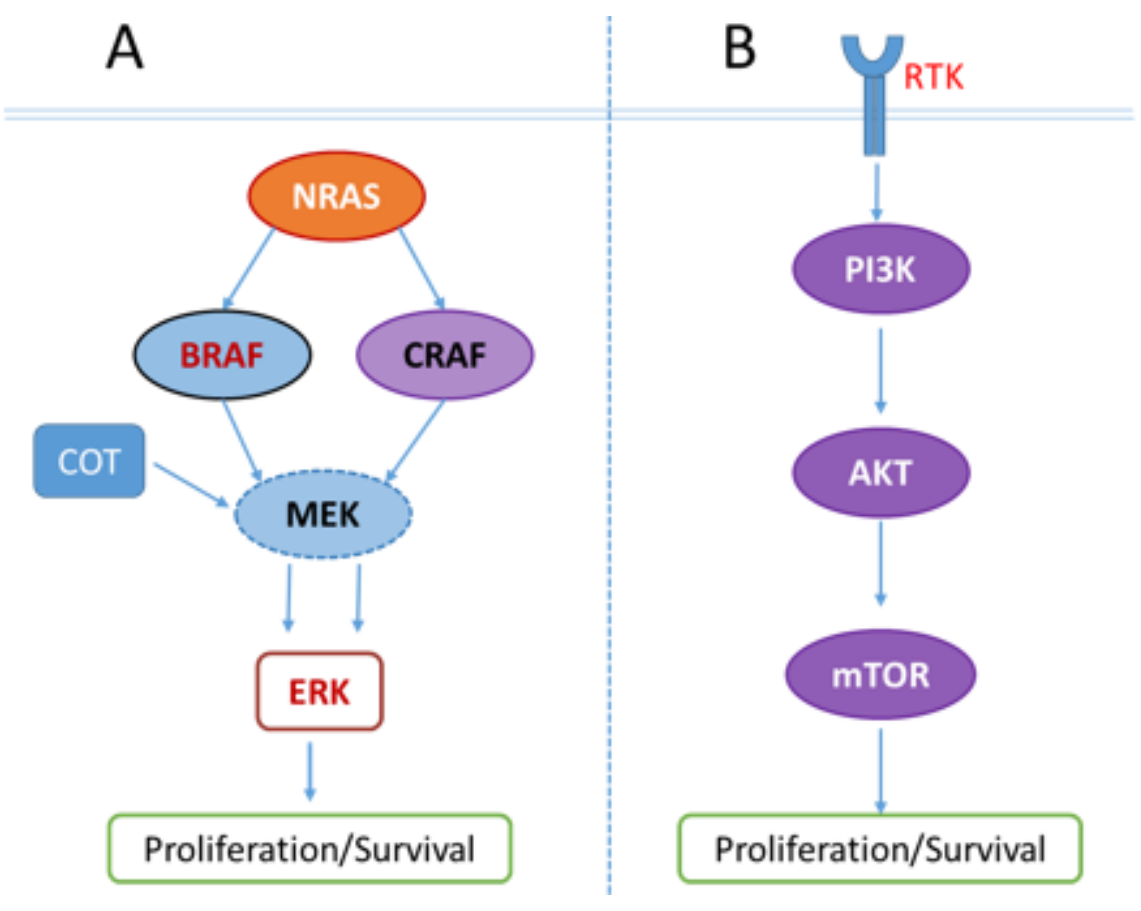

Figure 1-1. The mechanisms of acquired resistance to BRAF inhibition 
mechanisms and MAPK-bypass mechanisms [37-40]. In the first category, MAPK signaling is reactivated. Such mechanisms include MEK1 mutations, COT upregulation and NRAS mutations. MEK1 mutations increase the catalytic activity of MEK and lead to BRAF-independent ERK phosphorylation [41]. COT, is a MEK kinase encoded by gene MAP3K8. The upregulation of COT activates MEK signaling without RAF protein [42]. Although NRAS is in the upstream of BARF, hyperactive or mutant NRAS can restore MAPK signaling through paradoxical activation of CRAF [43]. Many MAPK pathway-independent mechanisms work by activating the PI3K-AKT signaling pathway. This pathway can be activated by the overexpression of receptor tyrosine kinases such as insulin-like growth factor 1 receptor and platelet-derived growth factor receptor beta [44].

\section{Limitations of Immunotherapy}

Although recently approved immunotherapy drugs improve overall survival rate of patients with metastatic melanomas, their clinical benefits are accompanied by several limitations. First, the portion of patients who respond to current immunotherapies is still low. For example, the response rate for ipilimumab is only around $15 \%$, and long-term durability of response occurs in an even smaller set of patients [45]. Another concern with immunotherapies is their side effects. Because these immunotherapies sometimes allow the immune system to attack normal cells in the body, serious side effects can occur to some patients. It was reported that ipilimumab caused hypophysitis in around $17 \%$ of the patients treated with this drug [46-47].

\section{Tubulin and Survivin as Cancer Drug Targets}

Tubulin and survivin share several common features. First, both of them are crucial in the process of cell mitosis and division. During mitosis, proper functioning of microtubule dynamics is required for the correct movements of the duplicated chromosomes and their segregation into two daughter cells [3]. Survivin participates in a multi-protein complex called the chromosomal passenger complex which is essential for accurate sister chromatid segregation and cytokinesis in mitosis [48]. Secondly, both of them are important for the formation and maintenance of tumor cells. Microtubules, as key components of cytoskeleton, are critical for the development and maintenance of tumor cell shape. Survivin is a nodal protein involved in many signaling mechanisms controlling tumor maintenance [49]. Third, blocking tubulin and survivin can both lead to cell apoptosis. Inhibition of microtubule dynamics causes cell cycle arrest and eventually results in cell death by apoptosis. One major function of survivin is inhibition of apoptosis. Blocking of survivin causes induction of apoptosis. These common features make tubulin and survivin important cancer drug targets, which are also the focuses of my research projects in this dissertation. Besides these common features in the two targets, survivin and tubulin are also correlated in many ways [49]. Survivin has been reported to directly modulate microtubule dynamics by binding to polymerized microtubules [50]. Survivin has also been shown to promote drug resistance to microtubule targeting agents [51]. Details about tubulin and tubulin targeting agents will 
be presented in Chapter 2. Survivin and its inhibitors will also be discussed in details in Chapter 4.

\section{Concluding Remarks}

Melanoma is an extremely complex disease with many gene mutations and signaling pathways involved. The huge complexity of this disease may account for its poor prognosis and survival rate at metastatic stage. Although tremendous research work has been done to find better treatments for melanoma, especially metastatic melanoma, for the past several decades, major successes are elusive until recently. Notable therapeutic advances in immunotherapy and targeted therapy of melanoma have been made in recent five years, which significantly improve the outcomes of patients with advanced melanoma. Despite of these advances, it should be recognized that the majority of patients with advanced melanoma still die of this disease. Besides, there are many limitations with the new therapies, such as drug resistance to targeted therapies and low response rate to immunotherapies. Therefore, the need to find new treatments for melanoma is still high. To fulfill this need, we have done a lot of work to develop novel, potent anticancer agents for melanoma treatment. I will describe these efforts in the next several chapters. 


\section{CHAPTER 2. OVERVIEW OF TUBULIN AND TUBULIN POLYMERIZATION INHIBITORS}

\section{Introduction}

Microtubule is critical in the process of mitosis, making it an important therapeutic target for anticancer drugs. Many successful microtubule-targeted agents have been discovered and used in clinical for decades, such as paclitaxel and vinca alkaloids. However, there are certain problems with existing tubulin targeting agents which limit their usages. Considerable research efforts are underway to develop novel microtubuletargeted agents with high potency and selectivity and less toxicity.

In this chapter, we first describe the structure and functions of microtubule and different binding sites of tubulin. Then we review current tubulin polymerization inhibitors and problems with these agents. Several novel colchicine domain binding agents previously developed in our group are also discussed.

\section{Structure and Functions of Microtubule}

Microtubules are long, filamentous, tube-shaped protein polymers which are composed of heterodimers of $\alpha$-tubulin and $\beta$-tubulin (Figure 2-1). The heterodimers first assemble to form a microtubule nucleus. Then more dimers are added head to tail at both ends to form a cylinder structure with 13 protofilaments [52]. Each microtubule has two ends, one end is designated as $(+)$ end with $\beta$-tubulin exposed to the solvents, the other end is designated as (-) end with $\alpha$-tubulin exposed to the solvents. Both $\alpha$-tubulin and $\beta$ tubulin can bind to a molecule of guanosine triphosphate (GTP) [53]. GTP-tubulins form a short region at both ends of microtubule called GTPcap, which prevents microtubule from disassembly. Tubulin dimer adds to the end of microtubule only at GTP-bound state. The hydrolysis of tubulin-bound GTP to guanosine diphosphate (GDP) will destabilize microtubule, leading to depolymerization. The switch from growing or paused state to shortening state is called 'catastrophe'; the switch of opposite direction is called "rescue".

Microtubule is a key component of cytoskeleton and is involved in many cellular processes. It is critical in cell shape maintenance, intracellular transportation, and cell division and mitosis. The functional diversity of microtubule is accomplished in several ways: through the binding of various regulatory proteins to soluble tubulin and to the microtubule surfaces and ends; by expression of different tubulin isotypes; and through several post-translational modifications of tubulin [52]. The biological functions of microtubules are largely determined by their polymerization dynamics [54]. Microtubules have two types of non-equilibrium dynamics. One type of dynamic behavior is called 'dynamic instability', which is a process in which microtubule ends switch between growth and shortening phases. The two ends of a microtubule are not the same in terms of instability. The plus end grows and shortens more rapidly than the minus end. The 


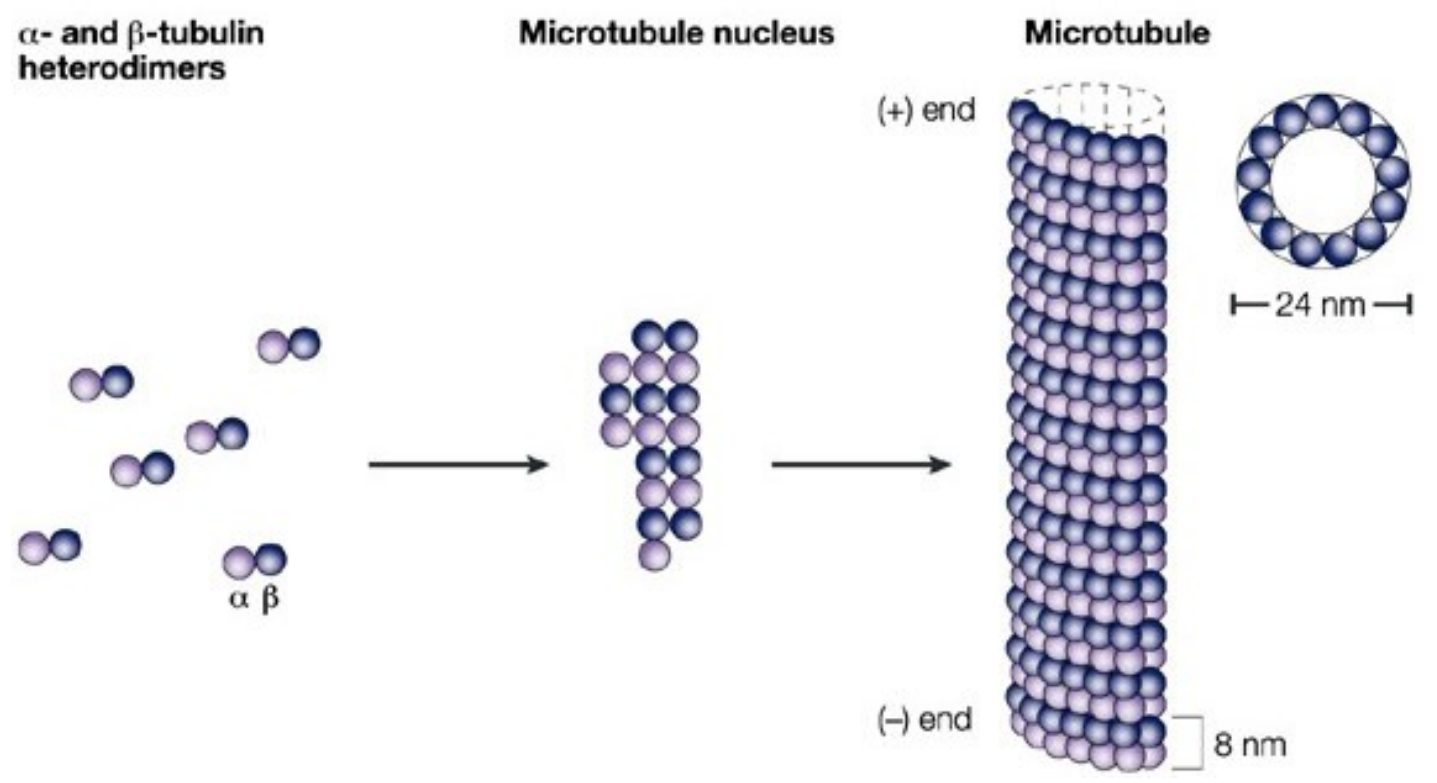

Figure 2-1. Structure of microtubule

Reprinted with permission from Macmillan Publishers Ltd. Jordan, M. A.; Wilson, L. Microtubules as a target for anticancer drugs. Nat Rev Cancer, 2004, 4(4), 253-265. 
second dynamic behavior is called 'treadmilling'. It is essentially net growth at one end of microtubule balanced by the shortening at the opposite end. It involves the intrinsic flow of tubulin subunits from one end to the opposite one. This behavior is very common both in cells and in vitro and is very important in mitosis [55].

\section{Binding Sites of Tubulin Targeting Agents}

Tubulin targeting agents are classified into two main groups: microtubule stabilizing agents and microtubule destabilizing agents, based on their effects on microtubule polymer mass at high concentrations [56]. Microtubule stabilizing agents inhibit tubulin depolymerization at high concentrations and include several compounds such as the taxanes, paclitaxel, docetaxel and cabazitaxel, the epothilones, ixabepilone, patupilone and sagopilone, cyclostreptin, dictyostatin, eleutherobins, discodermolide, sarcodictyins, rhazinilam, laulimalide, and peloruside A. Microtubule destabilizing agents inhibit tubulin polymerization when present at high concentrations and this type of agents include the vinca alkaloids, vinblastine, vincristine, and vindesine, the dolastatins, eribulin, maytansinoids, and spongistatin, cryptophycins, halichondrins, estramustine, colchicine and its analogues, podophyllotoxin, combretastatins, 2-methoxyestradiol, phenylahistins, steganacins and curacins. These tubulin targeting agents are known to interact with at least four binding sites: the vinca binding domain, the taxol binding domain, the colchicine binding domain, and the laulimalide binding domain. The four binding sites as shown in Figure 2-2 are discussed in details in the following subsections.

\section{Vinca Binding Domain}

The vinca alkaloids, identified more than 50 years ago [57] were originally isolated from periwinkle plant Catharanthus rosea and are the oldest family of tubulin targeting agents. The cancer chemotherapeutical potential of vinca alkaloids was discovered by research groups at both Eli Lilly Research Laboratories and at the University of Western Ontario in the 1950s [52]. The vinca alkaloids were used widely for the single-agent treatment for childhood and adult hematological malignancies. They were very successful in the treatment of childhood leukemia and were regarded as the "wonder drugs". The vinca alkaloids bind to a distinct region called the vinca-binding domain located at the $\beta$-subunit of tubulin dimers. They generally bind at the ends of tubulin but do not copolymerize into microtubules. Vinblastine was found to introduce a wedge at the interface of two $\alpha, \beta$-tubulin heterodimers and such interference prevents tubulin assembly [58].

\section{Taxol Binding Domain}

Paclitaxel, a complex molecule that was isolated from the bark of the yew tree in 1967 by Monroe Wall and Mansukh Wani [59]. The development of paclitaxel was slow until Peter Schiff and Susan Horwitz made the surprising discovery that paclitaxel 


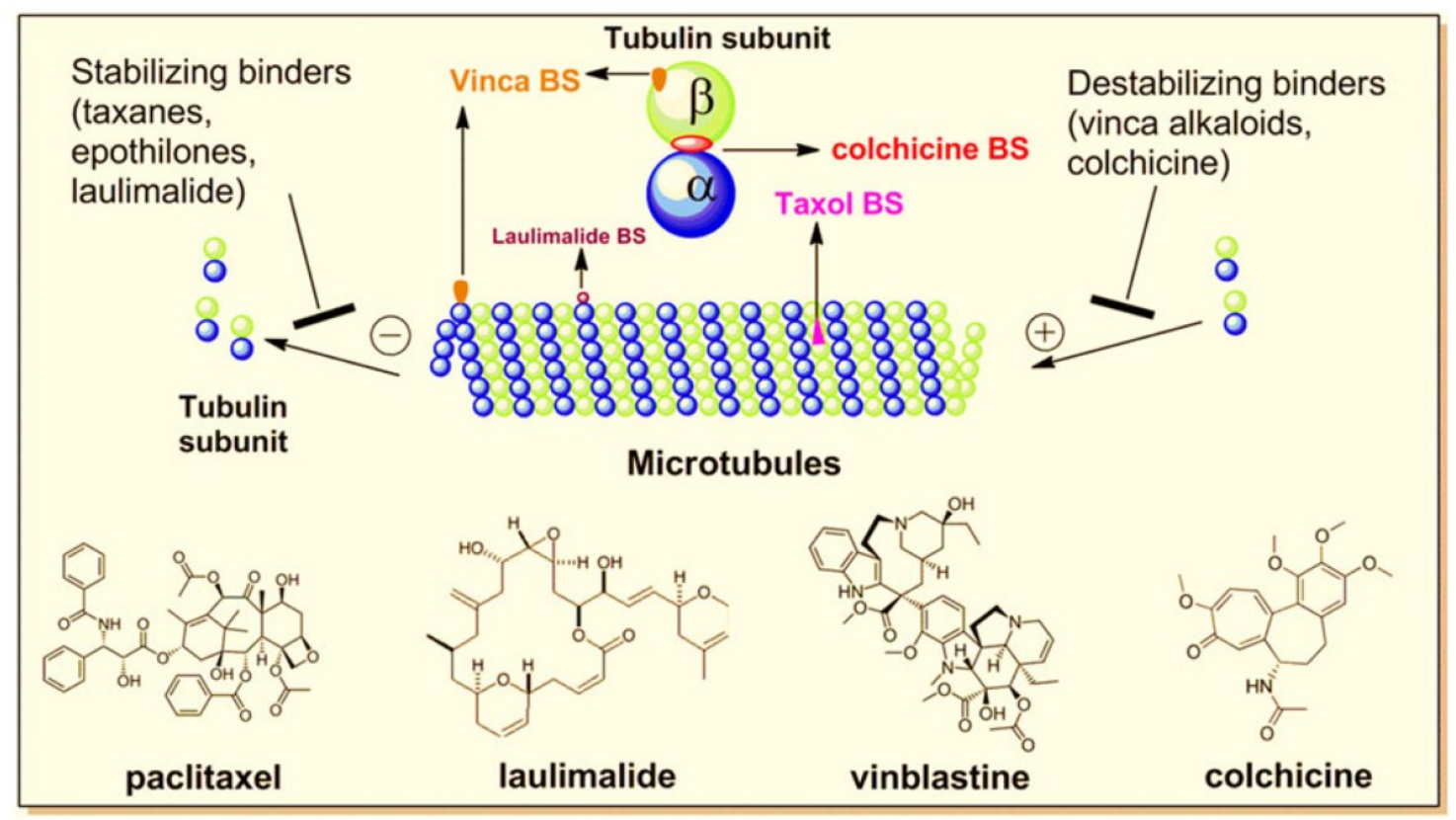

Figure 2-2. Binding sites of tubulin targeting agents

Reprinted with permission from Springer. Lu, Y.; Chen, J.; Xiao, M.; Li, W.; Miller, D. D. An overview of tubulin inhibitors that interact with the colchicine binding site. Pharm Res, 2012, 29(11), 2943-2971. 
stimulated tubulin polymerization which is totally different from vinca alkaloids that inhibit tubulin polymerization [60]. In 1995, paclitaxel was approved for its clinical use for the treatment of cancer. A lot of semisynthetic analogues have been made since then. Successful examples include docetaxel and cabazitaxel. Paclitaxel and its analogues are among the most important additions to the chemotherapeutic arsenal. The binding site of paclitaxel is located at the inner surface of the $\beta$-subunit [61]. It is presumed that paclitaxel exerts its effects of stabilizing the microtubule and increasing tubulin polymerization by inducing a conformational change in tubulin [62]. Such conformational change increases the affinity of one tubulin molecule for its neighboring tubulin molecules.

\section{Colchicine Binding Domain}

Colchicine was extracted from the poisonous meadow saffron Colchicum autumnale $L$ and is a tubulin destabilizing agents. Colchicine binds to soluble tubulin and forms a tubulin-colchicine complex [63-64], which can be incorporated into microtubules. It has been shown that binding of colchicine to a site located on $\beta$-tubulin causes a steric clash between colchicine and $\alpha$-tubulin, which prevents curved tubulin from adopting a straight conformation. This is the possible mechanism of colchicine's activity in inhibiting tubulin assembly. Colchicine has been clinically used to treat gout for many years, but neither colchicine nor other colchicine site binding agents have been approved for the treatment of cancer until now. Research efforts are now ongoing to develop agents targeting colchicine binding site for cancer treatment.

\section{Laulimalide Binding Domain}

Laulimalide is a structurally novel cancer therapeutic lead isolated from Pacific marine sponges [65]. It stabilizes microtubule and enhances tubulin assembly in a similar mode of action as taxol. It was reported that laulimalide was unable to inhibit the binding of radiolabeled paclitaxel to tubulin polymer [66], which means it binds to a novel binding site distinct from that of paclitaxel. Laulimalide would be the first example of a ligand for this site.

\section{Existing Tubulin Polymerization Inhibitors}

Existing tubulin polymerization inhibitors are consisted of two groups of agents: vinca domain-binding agents and colchicine domain-binding agents. Among vinca domain-binding agents, there are several drugs that have been approved for cancer treatment, including vinblastine, vincristine, vinorelbine, vinflunine and vindesine [56]. However, none colchicine binding site inhibitor (CBSI) has been approved by FDA for clinical use in the treatment of cancer. Therefore, there is strong need to develop novel anticancer drugs targeting colchicine binding site, which is also the focus of our research. In the following part, representative reported CBSIs will be reviewed. 


\section{CBSIs in Clinical Trials}

In this section, we discuss several CBSIs in clinical trials (Figure 2-3).

\section{Combretastatin A-4}

Combretastatin A-4 (CA-4) was extracted from the bark of the South African willow Combretum caffrum and is a potent tubulin and cell growth inhibitor [67]. Although CA-4 exhibits potent anti-proliferative activity, its poor aqueous solubility impinged its clinical development. Combretastatin A-4 phosphate (CA-4P), which is the phosphate form and a prodrug of CA-4, was developed to resolve the solubility issue. CA-4P is dephosphorylated to its active metabolite CA-4 in vivo. There are several phase II clinical trials going on for the use of CA-4P in the treatment of anaplastic thyroid cancer, non-small cell lung cancer, and relapsed ovarian cancer [68].

\section{2-Methoxyestradiol}

2-Methoxyestradiol (2-ME) is an endogenous estrogen metabolite, formed by hepatic cytochrome P450 2-hydroxylation of $\beta$-estradiol and 2-O-methylation via catechol O-methyltransferase. 2-ME showed potent inhibition of angiogenesis and tumor growth [69]. Many studies have been done to elucidate the mechanism for the cytotoxic effects of 2-ME [70-71]. Competitive binding studies with $\left[{ }^{3} \mathrm{H}\right]$ colchicine suggested that 2-ME inhibited tubulin polymerization by interacting with the colchicine binding site on tubulin [72-73]. Because of the potent antiangiogenic activity and tubulin polymerization inhibition of 2-ME, several clinical trials for using 2-ME in the treatment of prostate cancer, breast cancer and multiple myeloma have been performed [74-76]. Some of the adverse effects of 2-ME include fatigue, nausea, diarrhea, neuropathy, edema, and dyspnea in these clinical studies.

\section{ABT-751}

ABT-751, also known as E7010, was first reported by Yoshino, et al in 1992 [77]. It is a novel sulfonamide antimitotic agent which was shown to inhibit microtubule assembly by binding to the colchicine site on tubulin [78]. Such inhibition leads to cell cycle arrest at the G2/M phase, resulting in cellular apoptosis. ABT-751 was shown to be active against several cancer cell lines that were resistant to vincristine, doxorubicin and cisplatin because it is not a substrate for the multiple drug resistance transporter. It also displayed good in vivo activity against various human tumor xenografts. Several clinical trials for using ABT-751 as a single agent treatment or in combination with other agents have been completed [79-81]. Some dose-limiting toxicities of ABT-751 found in the clinical trials include abdominal pain, constipation, and fatigue. 


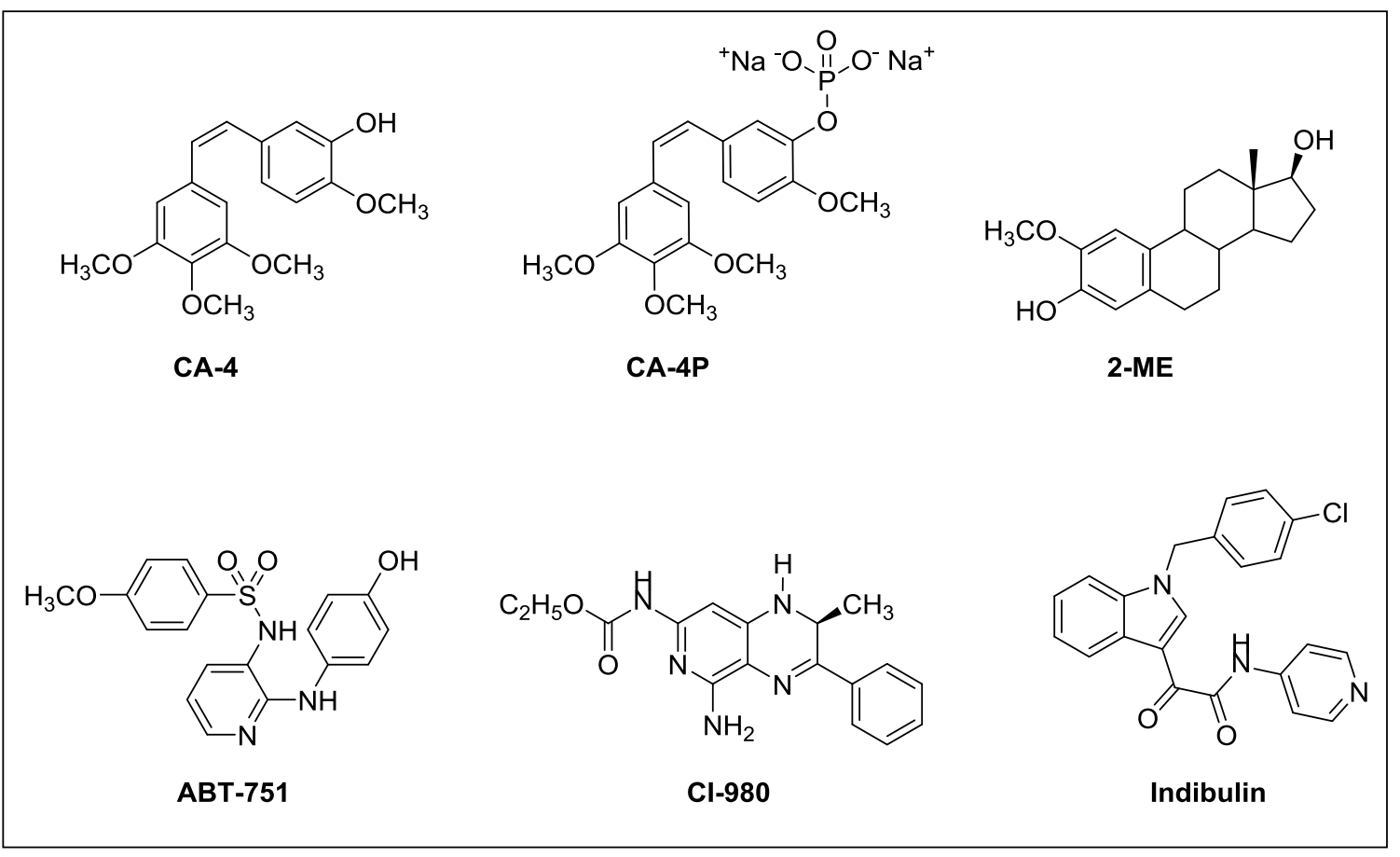

Figure 2-3. Chemical structures of representative CBSIs in clinical trials 


\section{CI-980}

CI-980 is a novel synthetic antimicrotubule agent belonging to the class of 1,2dihydropyrido [3, 4-b] pyrazines. CI-980 bears a chiral center and is the S-isomer form. The R-isomer NSC 613863 also showed inhibitory effects of tubulin polymerization and tumor cell growth, but the S-isomer CI-980 was more potent [82]. Treatment of cancer cells with CI-980 caused arrest in the M-phase of the cell cycle, leading to cell death subsequently. This agent has a wide spectrum of antitumor activity, including leukemia, melanoma, sarcoma, mammary adenocarcinoma, and colon adenocarcinomas. It has entered phase II clinical trial. Neurotoxicity is one major adverse effect of this agent. It can cause a significant but reversible decline in recent memory functioning [83]. So the cognitive function of patients taking this agent should be closely monitored.

\section{Indibulin}

Indibulin, N-(pyridin-4-yl)-[1-(4-chlorbenzyl)-indol-3-yl]-glyoxyl-amide, was identified through a cell-based screening to discover cytotoxic compounds [62]. It is a potent microtubule destabilizing agent and blocks cell cycle at G2/M phase specifically. This compound exhibited potent anti-proliferative activity against a series of human cancer cell lines including SKOV3 ovarian cancer, U87 glioblastoma, and ASPC-1 pancreatic cancer cells. Animal experiment showed that treatment of rats bearing Yoshida AH13 sarcomas with indibulin induced complete tumor regression without systemic toxicity observed. Indibulin did not have the neurotoxicity which is associated with tubulin targeting agents like paclitaxel or vincristine. It has been found to be able to discriminate between mature neuronal tubulin and immature neuronal or nonneuronal tubulin [84]. This agent is currently in phase II clinical trials.

\section{Reported CBSIs in Preclinical Studies}

With the rapid development of colchicine binding site inhibitors, many structures that showed excellent potency and drug-like properties for their preclinical applications have been reported. In this section, we will summarize several classes of CBSIs reported in preclinical studies. Representative structures for each class are shown in Figure 2-4.

\section{Combretastatin A-4 analogs}

Although CA-4 showed potent anti-proliferative activities, two major problems impinged the clinical development of this drug. The first problem of CA-4 is its poor aqueous solubility. The other one is due to the cis-olefinic bridge which represents a weak point for metabolic stability. The cis-olefinic conformation can easily isomerize to the trans- olefinic conformation, which is an inactive form of CA-4. Many CA-4 analogs have been developed to overcome the above two problems. Replacement of the olefinic bridge with a sulfonate linker generates compound 1. It is a potent inhibitor of tubulin 
<smiles>COc1cc(S(=O)(=O)Oc2ccc3[nH]ccc3c2)cc(OC)c1OC</smiles>

1<smiles>COc1ccc(-c2oc(=O)[nH]c2-c2cc(OC)c(OC)c(OC)c2)cc1N</smiles>

4<smiles>COc1ccc(OC)c(C(=O)/C(C)=C/c2ccc(N(C)C)cc2)c1</smiles>

MDL-27048 (7)<smiles>[X]c1cc(OC)c(OC)c(OC)c1</smiles>

10: $\mathrm{X}=\mathrm{S}$

11: $\mathrm{X}=\mathrm{CH}_{2}$

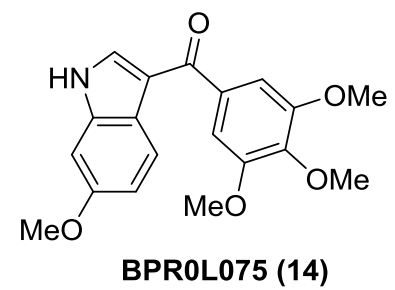<smiles>COc1ccc(-c2c(-c3cc(OC)c(OC)c(OC)c3)ncn2C)cc1N</smiles>

2<smiles>COc1cc(-c2nn[nH]c2-c2ccc(N)cc2)cc(OC)c1OC</smiles>

5<smiles>COc1ccc(-c2ncoc2-c2cc(OC)c(OC)c(OC)c2)cc1N</smiles>

3

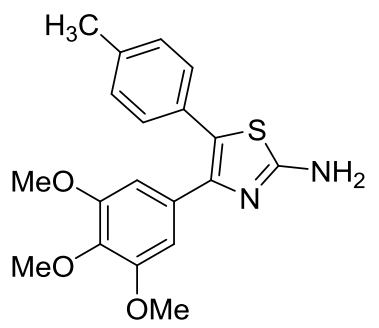

6<smiles>COc1cc(OC)c(C(=O)C=Cc2cn(C)c3ccccc23)c(OC)c1</smiles>

JAI-51 (8)<smiles>COC(=O)c1[nH]c2ccc(Br)cc2c1C(=O)c1cc(OC)c(OC)c(OC)c1</smiles>

12<smiles>Cc1ccc(S(=O)(=O)Nc2cc(-c3ccc(C#N)s3)ccc2C)cc1</smiles>

ELR510444 (9)

$\mathrm{MeO}$<smiles>Cc1ccc2[nH]c(C(=O)c3ccccc3)cc2c1</smiles>

D-64131 (13)

Figure 2-4. Chemical structures of reported CBSIs in preclinical studies 
polymerization and tumor cell growth. This compound was also active against Pglycoprotein (Pgp) overexpressing cancer cell lines. A number of CA-4 analogs that uses a heterocyclic ring as the linker have also been prepared to restrict the cis-conformation. Imidazole (2), 1, 3-oxazole (3), oxazolone (4), triazole (5) and 2-aminothiazole (6) linkers have been tried to improve drug-like properties [85]. Compound $\mathbf{2}$ is the first CA4 analog that shows potent oral antitumor activity in vivo. Compounds 6 exhibited antiproliferative activity at picomolar concentrations against several tested cancer cell lines [86]. Among the linkers, certain five-membered ring systems seem to be the best option for modification.

\section{Chalcones}

Chalcone compounds are characterized by bearing an aromatic ketone and an enone as the central core. They can be found in many natural products and exhibit various biological activities including anti-cancer, anti-inflammatory, and anti-fungi [87-89]. A number of studies have shown chalcone compounds are potent microtubule destabilizing agents that bind to the colchicine binding site, which is possible mechanism for their anticancer activities [90-91]. The biological activities of chalcones are largely attributed to $\alpha, \beta$-unsaturated ketone moiety, thus modifications on chalcone scaffold mainly focus on the two terminal aromatic rings in the screening of active chalcones. MDL-27048 (7) and JAI-51 (8) are two examples. MDL-27048 is a potent reversible microtubule inhibitor that interacts with the colchicine binding site [92-93]. JAI-51 acted as a microtubule destabilizing agent and an inhibitor of the Pgp and exhibited strong potency in glioblastoma models [94].

\section{Sulfonamides}

Sulfonamide drugs have been used in clinical for many years because of their various biological activities such as antibacterial, antidiabetic, and antiviral activities. Many novel sulfonamides analogs have been reported to show strong antitumor activity in recent years. ELR510444 (9) is a novel microtubule disrupting agent that directly interacts with the colchicine binding site on tubulin [95]. It potently inhibited cell proliferation with an $\mathrm{IC}_{50}$ value of $30.9 \mathrm{nM}$ in MDA-MB-231 cells and disrupted endothelial cell shape at a low concentration of $30 \mathrm{nM}$. In vivo study demonstrated that ELR510444 provided significant antitumor efficacy with minimal side effects at daily dose of $6 \mathrm{mg} / \mathrm{kg}$. One good thing about ELR510444 is that it does not serve as a substrate of the Pgp transporter and thus can possibly circumvent clinically relevant drug resistance.

\section{Indole-based compounds}

Many clinically used drugs contain an indole ring in their structures. The indole ring is also a structural component of a number of antimitotic agents. A series of tubulin 
polymerization inhibitors that bear indole moiety have been reported. Arythioindole analogs containing 3-(3, 4, 5-trimethoxyphenyl) thio moiety were potent tubulin polymerization inhibitors [96-97]. Compound $\mathbf{1 0}$ was one of the most potent one among reported arythioindole derivatives. It inhibited the growth of MCF-7 cells at $\mathrm{IC}_{50}$ of 13 nM. Compounds 11 and 12 which replaced the sulfur linker of compound 10 with methylene linker and ketone linker were also reported as potent tubulin assembly inhibitors. In terms of growth inhibitory effect of MCF-7 cells, sulfur linker was slightly better or equivalent than ketone linker, while methylene linker was significantly less effective.

2-Aroylindoles is another indole-containing scaffold reported as tubulin assembly inhibitors. D-64131 (13) was discovered as a potent antitumor agent from a series of synthetic 2-aroylindole derivatives [98]. It displayed high cytotoxicity in $\mathrm{HeLa} / \mathrm{KB}$ cervical, SKOV3 ovarian, and U373 astrocytoma carcinoma cell lines. It acts by interfering with the mitotic spindle and destabilizing microtubules, leading to the arrest in $\mathrm{G} 2 / \mathrm{M}$ phase of the cell cycle. It also showed excellent oral antitumor activity in MEXF 989 model. BPR0L075 (14) is another potent tubulin polymerization inhibitor belonging to this scaffold [99]. It exhibited strong cytotoxic activity in a panel of cancer cell lines, including several KB-derived multidrug resistant cell lines, with $\mathrm{IC}_{50}$ values in singledigit nano-molar ranges. BPR0L075 also displayed potent activity against the growth of xenograft tumors including gastric carcinoma MKN-45 and human cervical carcinoma KB.

\section{Problems with Existing Tubulin Targeting Agents}

Two major problems associated with existing tubulin targeting agents are development of drug resistance and the significant toxicity. In the following part, mechanisms of drug resistance and toxicities of these agents are discussed.

\section{Drug Resistance to Tubulin Targeting Agents}

It is crucial to understand the mechanisms of resistance to microtubule-targeted agents in order to develop novel compounds that can overcome multidrug resistance. Two known mechanisms for these agents are presented in the following subsections.

\section{ATP binding cassette proteins and drug efflux}

The main resistance mechanism of inherent or developed resistance to microtubule-targeted agents is a family of membrane-associated transporters called ATP binding cassette (ABC) transporters [56]. These membrane efflux pumps are overexpressed in many cancer cell lines. Pgp, which is encoded by the human multidrug resistance protein 1(MDR1) gene, was the first one identified in the $\mathrm{ABC}$ transporter class [100]. The Pgp pump works by actively effluxing antimitotic agents out of cell, 
thereby decreasing intracellular drug concentrations and leading to cross resistance to these drugs. Considerable efforts are ongoing to develop novel tubulin targeting agents that are not substrates of these pumps [101-102].

\section{Alterations in microtubules}

Another mechanism of resistance comes from alterations of the target, the tubulinmicrotubule complex. Modifications of microtubules can affect the binding of microtubule-targeted agents to the target. Microtubules are consisted of at least 13 isotypes of $\alpha$-tubulin and $\beta$-tubulin. The overexpression of class III $\beta$-tubulin is an indicator of resistance to microtubule-targeted agents such as taxanes [56].

\section{Toxicity of Tubulin Targeting Agents}

Besides drug resistance, the other major problem of tubulin targeting agents is their toxicity. Neurological toxicity is the chief issue associated with many tubulin targeting agents [103]. The mechanism why these agents are preferentially toxic to nervous system is not clearly understood yet. However, two possible reasons can partially explain it. First, tubulin is relatively abundant in neurons. Secondly, it is important to keep an intact, functional microtubule cytoskeleton for adequate nerve conduction [56]. Myeloid toxicity is another frequently observed adverse effect with microtubule-binding agents [104]. The possible mutagenic properties of microtubule-binding agents and the increase in the risk of secondary tumors by these agents is also a concern. It has been described that chromosomal instability and an aneuploid-prone phenotype were correlated with response to taxanes [105-106].

\section{Novel Colchicine Binding Site Inhibitors}

Up to now, no antitubulin drug targeting colchicine binding site has entered the market. Many research efforts are underway to search novel anticancer agents that interact with colchicine binding site. Our group is one of them. We have discovered several new scaffolds of tubulin polymerization inhibitors as shown in Figure 2-5. A series of 4-substituted methoxy benzoylaryl-thiazoles (SMART) were first discovered based on lead compounds 2-arylthiazolidine-4-carboxylic acid amides [107].In order to improve the aqueous solubility of SMART compounds, 2-aryl-4-benzoyl imidazoles (ABI) and phenyl-aminothiazole (PAT) series were made [108-109]. The ABI scaffold replaced the thiazole ring in SMART structure with imidazole ring, which is more hydrophilic and has improved aqueous solubility. The PAT template inserted an amino linkage between the A ring and B ring of SMART structure. Further optimization of these templates is ongoing is our group. 


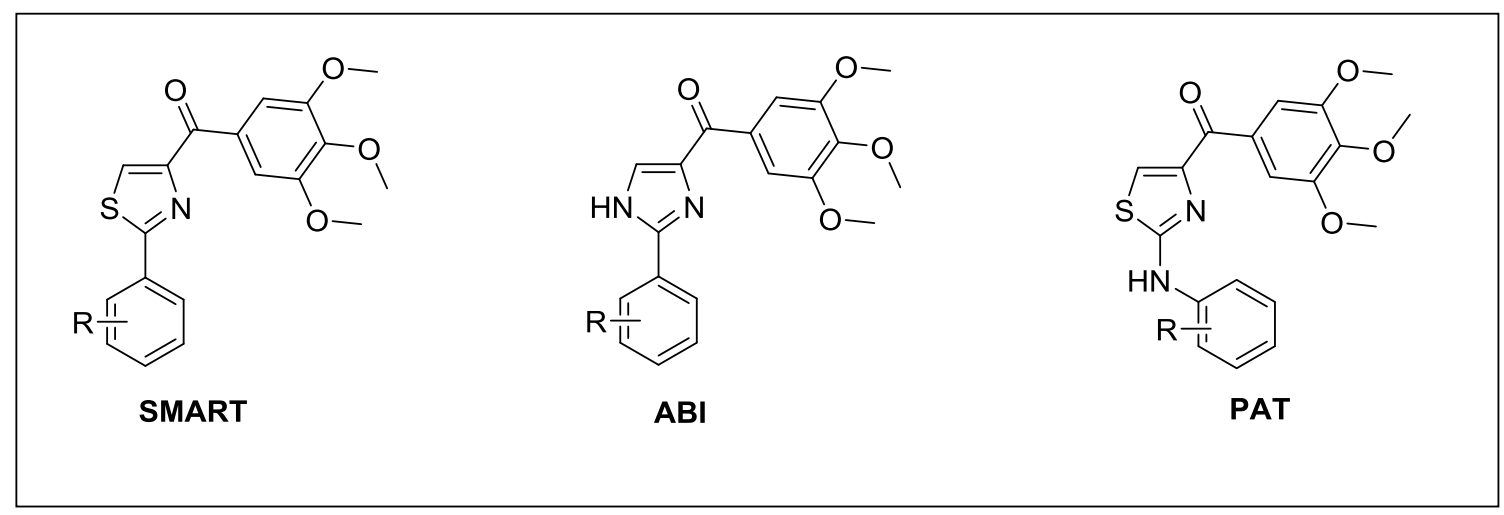

Figure 2-5. Novel colchicine binding site inhibitors 


\section{Summary}

Microtubules are among the most successful anticancer drug targets. A number of drugs that target microtubule dynamics have been approved by FDA for cancer treatment, including the taxanes, paclitaxel, docetaxel and cabazitaxel, and vinca alkaloids such as vinblastine, vincristine and vinorelbine. However, there are several limitations with these drugs. First, they generally have poor aqueous solubility. Secondly, they suffer from different mechanisms of resistance. The structural complexities of taxanes and vinca alkaloids make them difficult to be modified. Colchicine binding site agents have simpler structures and are more feasible for modification. Furthermore, several preclinical studies suggested that colchicine binding site inhibitors have less susceptibility to ABC transporter mediated drug resistance [110-111]. Many anticancer agents that interact with the colchicine binding domain have been developed, yet none of them have been approved for clinical use. The need to develop more effective, less toxic colchicine binding site inhibitors is strong. In Chapter 3, our recent efforts in developing novel potent anticancer agents that interact with colchicine binding site will be described. 


\section{CHAPTER 3. DISCOVERY OF 4-ARYL-2-BENZOYL-IMIDAZOLES AS TUBULIN POLYMERIZATION INHIBITORS WITH POTENT ANTIPROLIFERATIVE PROPERTIES*}

\section{Introduction}

We previously reported the discovery of $\mathrm{ABI}$ analogs targeting the colchicine binding site in tubulin as potent anti-proliferative agents. [108, 112-116] Compared with existing tubulin-targeting agents such as paclitaxel, colchicine, or vinblastine, ABI compounds have comparable in vitro and in vivo potency but can effectively circumvent several clinically relevant multidrug resistant mechanisms, including drug resistance mediated by Pgp, multidrug resistance-associated proteins (MRPs), and breast cancer resistant proteins (BCRP). [113-114] ABI compounds have also shown excellent oral bioavailability [113], a potential advantage over existing tubulin inhibitors which can only be administrated by intravenous injection. To further optimize the potency of ABI analogues and to gain further insight in their structure-activity relationships (SAR), we designed and synthesized several new series of ABI analogs (summarized in Figure 3-1) by introducing three major changes to the parental ABI scaffold as described below.

First, we varied the substitutions at the para-position on the A-ring of ABI analogs. This was accomplished by using previously established synthetic strategies. $[108,112,115]$ Second, we reversed the two major substitutions on the B-ring to produce the 4-aryl-2-benzoyl-imidazoles (reverse ABI, or RABI) compounds. We developed a one-pot synthetic strategy to synthesize RABI analogs in good yields based on the literature for synthesizing similar scaffold. [117] Finally, we systematically incorporated additional substitutions in the B-ring of the RABI analogs to determine molecular shape/conformational requirements for their anticancer potency. Biological testing of those RABI compounds revealed their excellent anti-proliferative activity against several cancer cell lines including multidrug-resistant cancer cell lines. Mechanism of action of RABIs was investigated using cell cycle analysis, tubulin polymerization assay, competitive mass spectrometry binding assay and molecular modeling. These studies showed that their antitumor activity was achieved through the antimitotic effect by the inhibition of tubulin polymerization, similar to their parental ABI analogs.

\section{Chemistry}

The general synthesis of the A ring modified analogs (5a-c) of ABI compounds is outlined in Figure 3-2 using the same protocol as the method reported previously. [108, $112,115]$ The general synthesis of the substituted imidazoles (8a-e) is shown in Figure

*Modified with permission. Xiao, M.; Ahn, S.; Wang, J.; Chen, J.; Miller, D. D.; Dalton, J. T.; Li, W. Discovery of 4-Aryl-2-benzoyl-imidazoles as tubulin polymerization inhibitor with potent anti-proliferative properties. J Med Chem, 2013, 56(8), 3318-3329. 


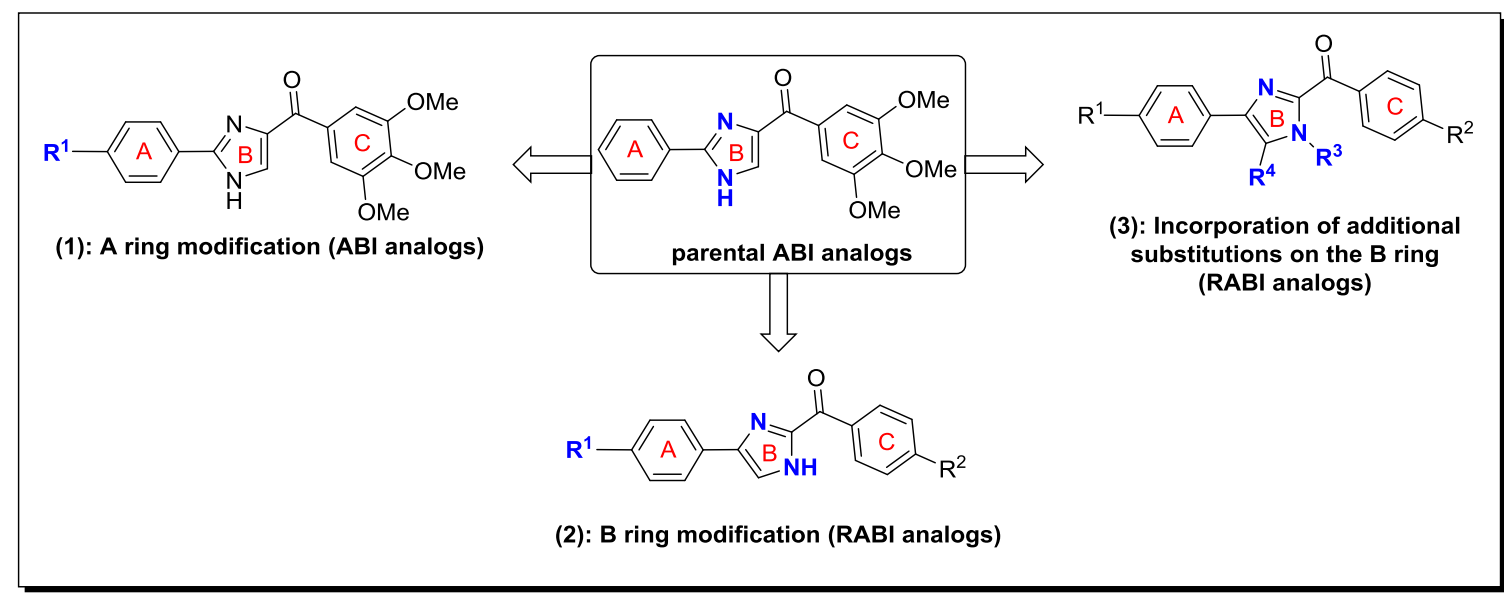

Figure 3-1. Design protocol for synthesis of RABI analogs

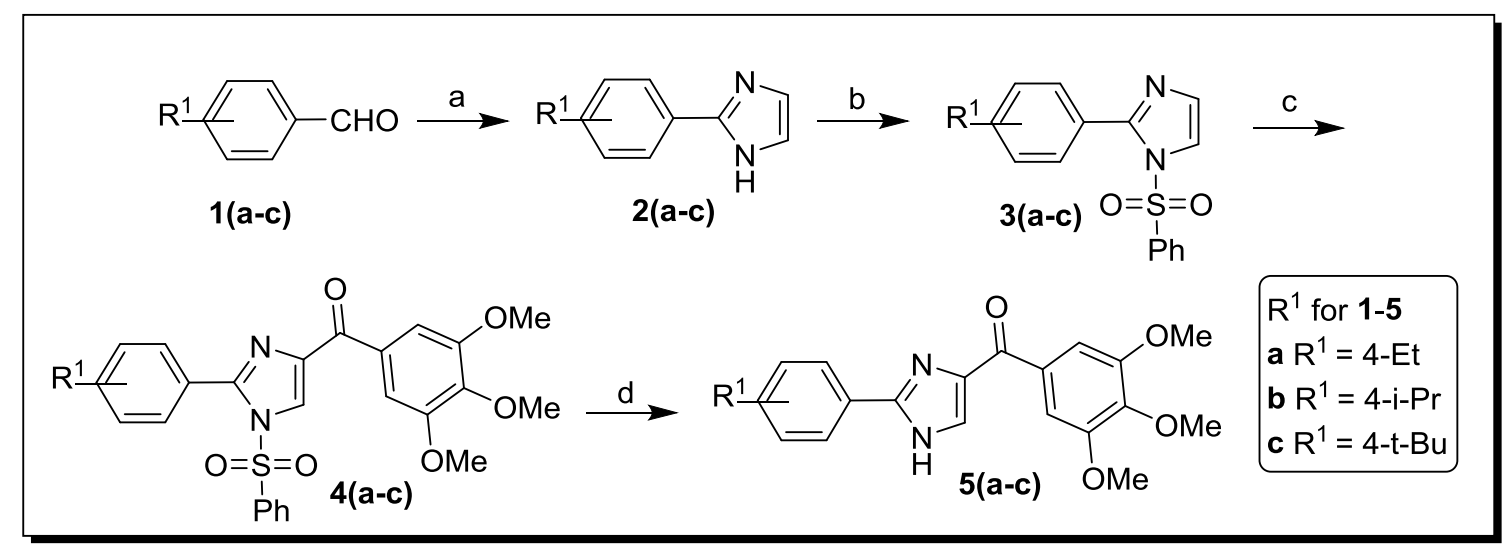

Figure 3-2. Synthesis of compounds 5a-5c

Reagents and conditions: (a) oxalaldehyde, $\mathrm{NH}_{4} \mathrm{OH}, \mathrm{EtOH}, 0{ }^{\circ} \mathrm{C}$-rt; (b) $\mathrm{NaH}, \mathrm{PhSO}_{2} \mathrm{Cl}$, THF, $0{ }^{\circ} \mathrm{C}-\mathrm{rt}$; (c) t-BuLi, substituted benzoyl chloride, THF, $-78^{\circ} \mathrm{C}$; (d) $\mathrm{Bu}_{4} \mathrm{NF}$, THF, rt. 
3-3. A series of diketones (7a-e) [118] in ethanol reacted with 3, 4, 5-trimethoxy benzeneacetaldehyde $\mathbf{6}$ and ammonium hydroxide to generate a series of substituted imidazoles. [119] RABI compounds (11-14) were synthesized utilizing a one-pot, onestep reaction, which is outlined in Figure 3-4. [117] The arylglyoxal [120] reacts with 3, 4,5-trimethoxyphenyl glyoxal in the presence of ammonium acetate in ethanol to give four products with similar yields around $20 \%$ in one pot. The ratio of compounds 12a-i to 13a-i is approximately 1:1. Two dimensional ${ }^{1} \mathrm{H}^{13} \mathrm{C}$ heteronuclear multiple bond correction spectroscopy (HMBC) NMR experiments were used to distinguish the structures between 12a-i and 13a-i. Strategies to incorporate additional substitutions on the B-ring of the RABI compounds are shown in Figure 3-5. In Figure 3-5, there are three conditions to introduce substitution to the N1-position. In condition a, compound 12a react with methyl iodide, ethyl bromide, and benzyl bromide in the presence of sodium hydride in anhydrous THF to generate compounds 15a-c. [115] In condition $\mathbf{b}$, compound 12a reacts with $n$-propyl iodide, $i$-propyl iodide and cyclopentyl bromide in the presence of potassium carbonate in acetonitrile to generate compounds 15d-f. [121122] In condition $\mathbf{c}$, copper iodide, cesium carbonate and a ligand are used to introduce a pyridine ring or a thiophene ring to N1-position of compound 12a to make compounds 15g-h. [123] A similar method to that in Figure 3-4 was employed to synthesize a series of 5-substituted RABI compounds (17a-c) as shown in Figure 3-6.

\section{Biological Results and Discussion}

All the compounds were evaluated for their cytotoxicity in human melanoma cell lines and prostate cancer cell lines. Colchicine, vinblastine and docetaxel, the well-known antimitotic agents were included in the assays, serving as positive controls and as basis for comparison.

\section{Effect of Substitutions on the A Ring of ABI Analogs}

As shown in Table 3-1, compound 5a (average $\mathrm{IC}_{50}=18 \mathrm{nM}$ ) maintained potent activity in most cancer cells compared with compound $\mathbf{5 d a}[108,114]$ (average $\mathrm{IC}_{50}=10$ $\mathrm{nM}$ ) which has a methyl substitution on A ring para position. Introducing a larger isopropyl group (5b, average $\mathrm{IC}_{50}=254 \mathrm{nM}$ ) into this position on the A ring caused a 20fold decrease of potency compared with compound 5da. Further increasing the size of this substitution using a tert butyl group to this position resulted in a 100-fold loss of activity compared with $\mathbf{5 d a}$. The activity trend in terms of para substitution in this A ring is $\mathrm{Me}>\mathrm{Et}>\mathrm{H}>i-\mathrm{Pr}>t$ - $\mathrm{Bu}$, clearly suggesting a relatively small binding pocket to the receptor around the A-ring, with a methyl group being the optimal size. Since A ring modification did not generate a more potent compound than $\mathbf{5 d a}$, we decided to design and synthesize analogs by modifying the B ring. 


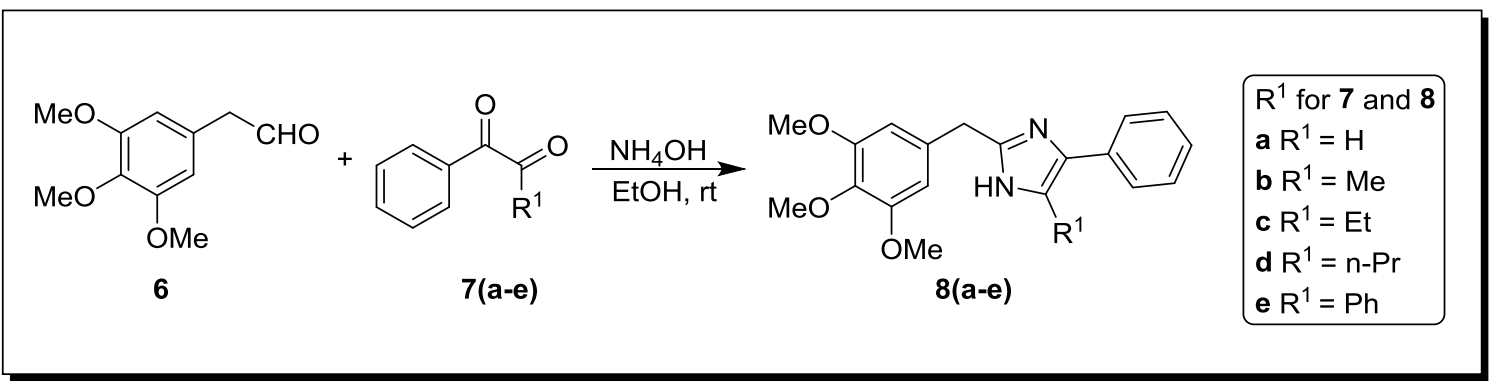

Figure 3-3. Synthesis of compounds 8a-8e

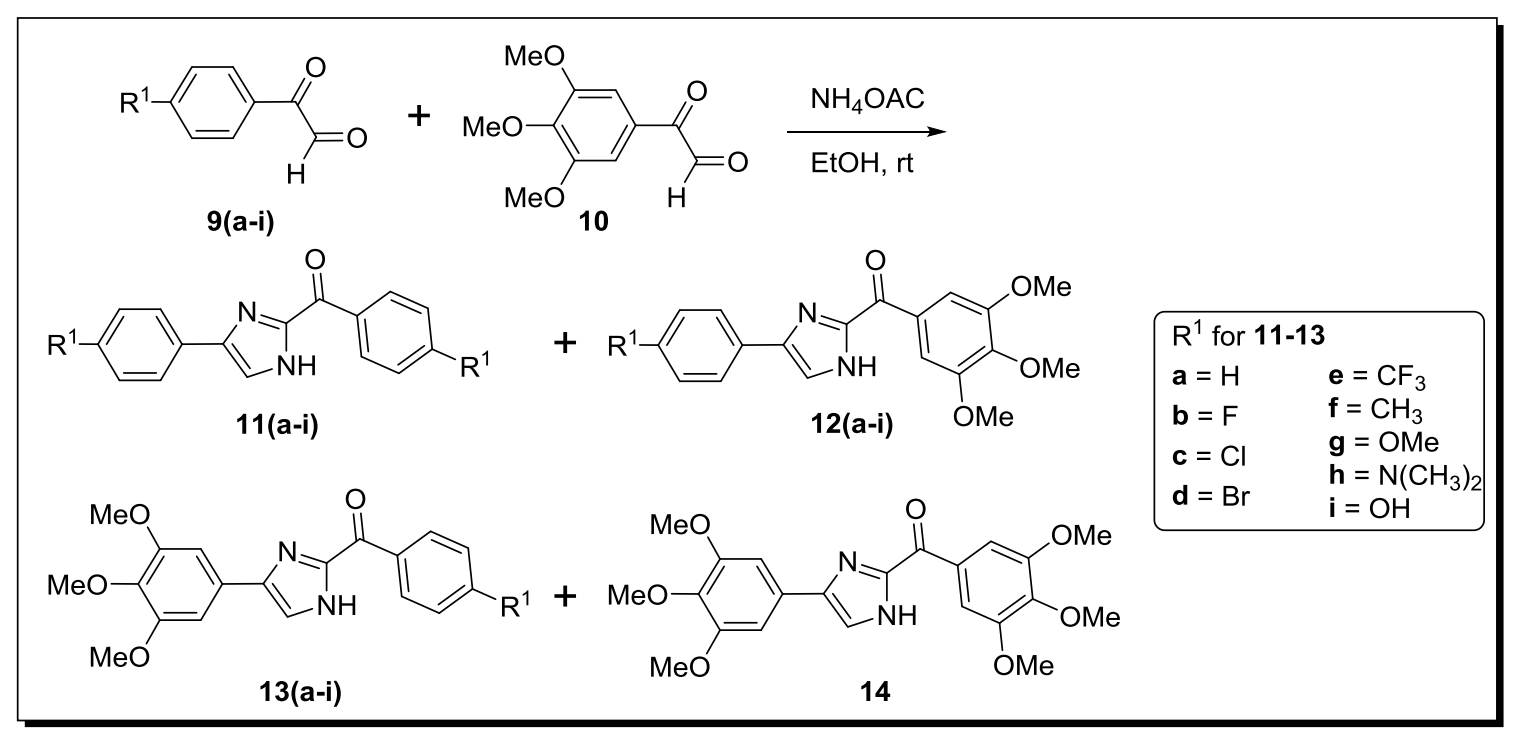

Figure 3-4. Synthesis of compounds 11-14 


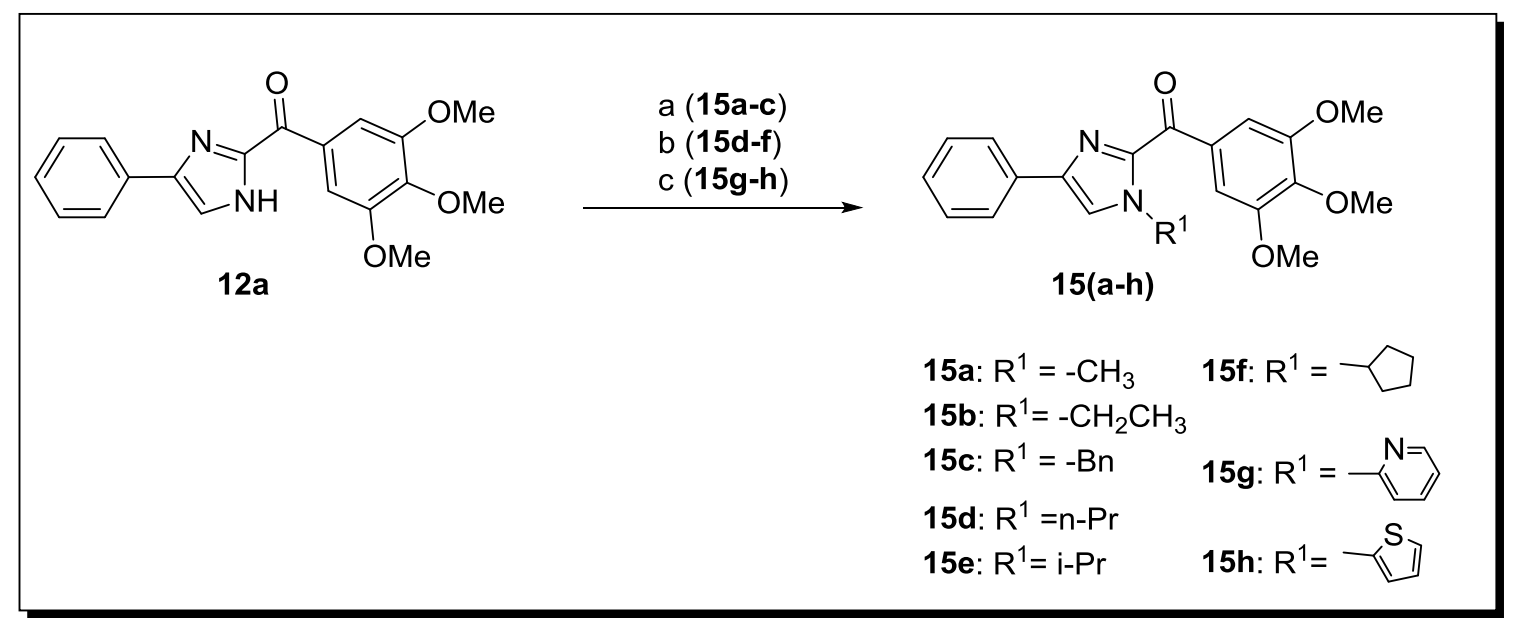

Figure 3-5. Synthesis of compounds 15a-15h Reagents and conditions: (a) $\mathrm{NaH}, \mathrm{CH}_{3} \mathrm{I}$ for $\mathbf{1 5 a}, \mathrm{CH}_{3} \mathrm{CH}_{2} \mathrm{Br}$ for $15 \mathbf{b}$ and $\mathrm{BnBr}$ for $\mathbf{1 5 c}$; (b) $\mathrm{K}_{2} \mathrm{CO}_{3}, \mathrm{ACN}, \mathrm{CH}_{3} \mathrm{CH}_{2} \mathrm{CH}_{2} \mathrm{I}$ for $\mathbf{1 5 d},\left(\mathrm{CH}_{3}\right)_{2} \mathrm{CHI}$ for $15 \mathrm{e}$ and cyclopentyl bromide for 15f; (c) $\mathrm{CuI}, \mathrm{Cs}_{2} \mathrm{CO}_{3}, \mathrm{DMF}$, Ligand, 2-bromo-pyridine for 15g, 2-bromothiophene for $15 \mathrm{~h}$.

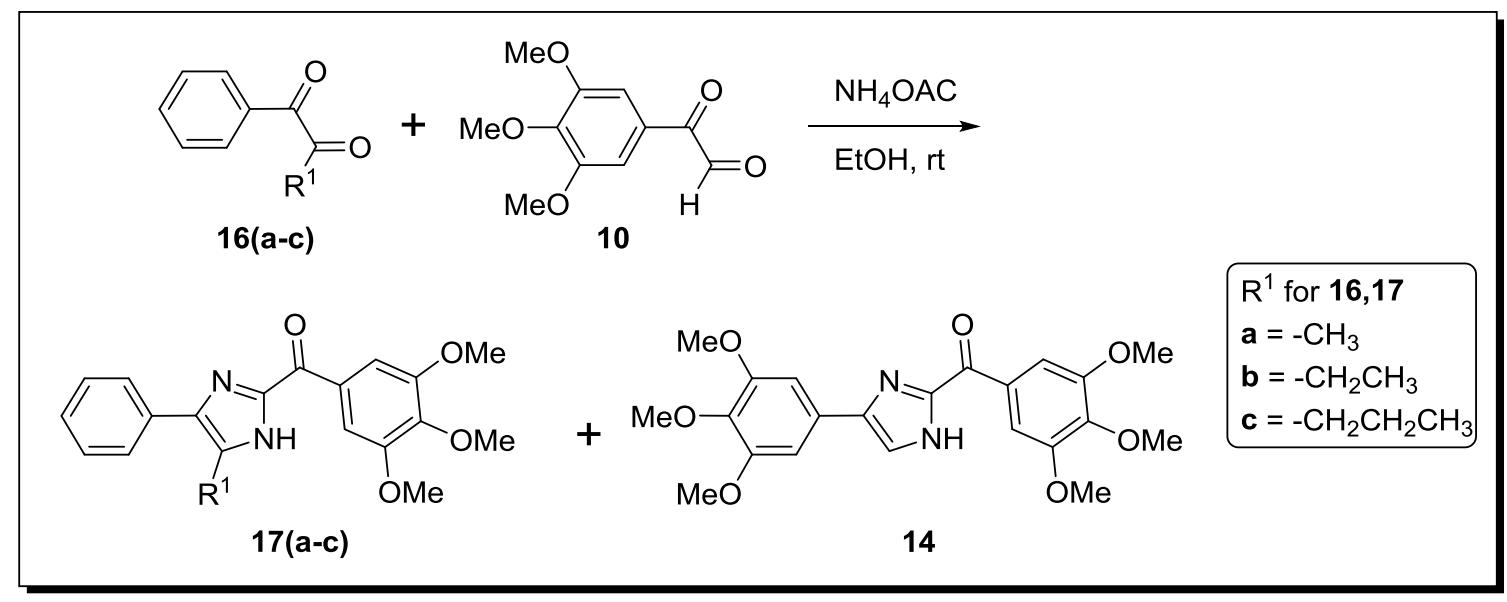

Figure 3-6. Synthesis of compounds 17a-17c 
Table 3-1. In vitro growth inhibitory effects of ABI compounds with A ring substitutions

\begin{tabular}{|c|c|c|c|c|c|c|c|c|c|c|}
\hline \multirow[b]{2}{*}{ Structure } & \multirow[b]{2}{*}{ ID } & \multirow[b]{2}{*}{$\mathbf{R}^{1}$} & \multicolumn{7}{|c|}{$\mathrm{IC}_{50} \pm \operatorname{SEM}(\mathrm{nM})$} & \multirow[b]{2}{*}{$\begin{array}{c}\text { Average } \\
\text { IC }_{50}\end{array}$} \\
\hline & & & LNCaP & PC3 & PPC1 & DU145 & A375 & $\begin{array}{c}\text { MDA-MB } \\
-435 \\
\end{array}$ & $\begin{array}{c}\text { MDA-MB } \\
\text {-435/LCC- } \\
\text { 6MDR1 } \\
\end{array}$ & \\
\hline & $5 \mathbf{a a}$ & $\mathrm{H}$ & $152 \pm 35$ & $288 \pm 30$ & $133 \pm 6$ & $196 \pm 29$ & $160 \pm 20$ & ND & ND & 186 \\
\hline & $5 \mathrm{da}$ & $\mathrm{Me}$ & $12 \pm 1$ & $9 \pm 0.4$ & $15 \pm 1$ & $11 \pm 0.1$ & $9 \pm 2$ & $5 \pm 1$ & $11 \pm 2$ & 10 \\
\hline & $5 \mathbf{a}$ & Et & $9 \pm 1$ & $13 \pm 1$ & $15 \pm 1$ & $25 \pm 2$ & $14 \pm 5$ & $25 \pm 4$ & $27 \pm 3$ & 18 \\
\hline & $5 b$ & i-Pr & $171 \pm 34$ & $136 \pm 20$ & $173 \pm 0.3$ & $482 \pm 40$ & ND & $312 \pm 4$ & $250 \pm 4$ & 254 \\
\hline OMe & $5 c$ & $\mathrm{t}-\mathrm{Bu}$ & $423 \pm 71$ & $436 \pm 115$ & $294 \pm 2$ & $1698 \pm 400$ & ND & $3691 \pm 60$ & $3074 \pm 50$ & 1603 \\
\hline
\end{tabular}

Note: ND: Not Determined. Dr. Sunjoo Ahn and Dr. Jin Wang performed the biological testing in this table. 


\section{The Ketone Linker Remains Critical for RABI Analogs}

We previously reported that a ketone linker is essential for the activity of the parental ABI and its related analogs [107]. To test whether this is still a critical requirement, we synthesized five RABI analogs containing a methylene linker instead of a carbonyl linker (Figure 3-3). The biological activity of these five compounds was shown in Table 3-2. All of them were basically inactive, consistent with results reported previously which indicated the essential role of the carbonyl linker.

\section{Effect of Substitutions on the A Ring of RABIs}

After confirming the essential role of the carbonyl linker in the RABI analogs, we converted the methylene linker to carbonyl linker using a slightly modified approach as shown in Figure 3-4 and produced RABI analogs 11-13. All RABI compounds were evaluated for their anti-proliferative activity and the results were shown in Table 3-3. Compound 12a was most potent with $\mathrm{IC}_{50}$ values ranging from 6 to $24 \mathrm{nM}$. Introducing an electron withdrawing group with increasing sizes to the para position on the A ring (4fluro, 4-chloro, 4-bromo and 4-trifluromethyl) generally decreased activity (compare 12b-e with 12a). Among the three halogen substituted RABI compounds, the trend of activity was $\mathrm{F}<\mathrm{Cl}<\mathrm{Br}$. Introduction of an electron donating group such as methyl to the compound maintained the activity $\left(\mathbf{1 2 f}, \mathrm{IC}_{50}: 10-27 \mathrm{nM}\right)$, while the introduction of methoxy and dimethylamino group caused loss of activity to some extent $\left(\mathbf{1 2 g}, \mathrm{IC}_{50}\right.$ : 30 $210 \mathrm{nM} ; \mathbf{1 2 h}, \mathrm{IC}_{50}$ : 96-263 nM). Compound 12i with phenol group as A ring was the least potent one among compounds 12a-12i. These results are consistent with the SAR identified in the parental ABI analogs (Table 3-1 and earlier studies [108, 115]).

\section{Effect of Substitutions on the C Ring of RABIs}

Several RABI compounds (11a-11i) which did not have the 3, 4, 5-trimethoxy moiety on $\mathrm{C}$ ring showed poor activity as shown in Table 3-3. The RABI compounds with unsubstituted phenyl ring as $\mathrm{A}$ ring and $\mathrm{C}$ ring caused complete loss of activity (11a, $\left.\mathrm{IC}_{50}>50 \mu \mathrm{M}\right)$. Compounds with a single halogen substituent in the para position of $\mathrm{A}$ and $\mathrm{C}$ rings lost activity completely ( $\mathrm{IC}_{50}>5 \mu \mathrm{M}$ for $\mathbf{1 1 b}-\mathbf{d}$ ). When methyl, methoxy, trifluoromethyl, dimethylamino, or hydroxyl was introduced to the para position of the A and $\mathrm{C}$ rings, the activity was also lost. All these results suggested the essential role of 3 , 4, 5-trimethoxy substituents on the $\mathrm{C}$ ring. Interestingly, when 3,4,5-trimethoxy group was put on the A ring, the activity of two compounds 13a and 13d returned to some extent (13a, IC 50 : 195-5770 nM; 13d, IC 50 : 131-429 nM) even though there is no 3,4,5trimethoxy substituents on $\mathrm{C}$ ring, perhaps suggesting that the orientation of the compound changed when binding to tubulin. One results worth noting is that when 3,4 , 5-trimethoxy group was introduced to both A ring and $\mathrm{C}$ ring, the activity was lost completely. This is consistent with results in previous sections that a bulky A-ring containing a 3, 4, 5-trimethoxy moiety cannot be tolerated at the receptor. 
Table 3-2. In vitro growth inhibitory effects of RABI compounds with methylene linker

\begin{tabular}{|c|c|c|c|c|c|}
\hline \multirow[b]{2}{*}{ Structure } & \multirow[b]{2}{*}{ ID } & \multirow[b]{2}{*}{$\mathbf{R}^{1}$} & \multicolumn{3}{|c|}{$\mathrm{IC}_{50} \pm \operatorname{SEM}(\mu \mathrm{M})$} \\
\hline & & & A375 & $\begin{array}{c}\text { MDA-MB- } \\
435\end{array}$ & $\begin{array}{l}\text { MDA-MB- } \\
\text { 435/LCC- } \\
\text { 6MDR1 }\end{array}$ \\
\hline & $8 \mathbf{a}$ & $\mathrm{H}$ & $10.2 \pm 0.4$ & ND & ND \\
\hline & $8 b$ & $\mathrm{Me}$ & $>50$ & ND & ND \\
\hline & $8 c$ & $\mathrm{Et}$ & ND & $>50$ & $>50$ \\
\hline & 8d & $\mathrm{n}-\mathrm{Pr}$ & ND & $10.9 \pm 0.1$ & $15.9 \pm 0.2$ \\
\hline & $8 e$ & $\mathrm{Ph}$ & ND & $>50$ & $>50$ \\
\hline
\end{tabular}

Note: ND: Not Determined. Dr. Jin Wang performed the biological testing in this table. 
Table 3-3. In vitro growth inhibitory effects of RABI compounds without B ring substitution

\begin{tabular}{|c|c|c|c|c|c|c|c|c|c|c|c|}
\hline \multirow[b]{2}{*}{ Structure } & \multirow[b]{2}{*}{ ID } & \multirow[b]{2}{*}{$\mathbf{R}^{1}$} & \multirow[b]{2}{*}{$\mathbf{R}^{2}$} & \multicolumn{8}{|c|}{$\mathrm{IC}_{50} \pm \operatorname{SEM}(\mathrm{nM})$} \\
\hline & & & & LNCaP & PC3 & PPC1 & DU145 & A375 & WM164 & $\begin{array}{c}\text { MDA-MB- } \\
435\end{array}$ & $\begin{array}{c}\text { MDA-MB- } \\
\text { 435/LCC } \\
\text {-6MDR1 }\end{array}$ \\
\hline \multirow{23}{*}{$=$} & 11a & $\mathrm{H}$ & $\mathrm{H}$ & $>50000$ & $>50000$ & $>50000$ & $>50000$ & $>50000$ & $>50000$ & $>50000$ & $>50000$ \\
\hline & $11 \mathrm{~b}$ & $\mathrm{~F}$ & $\mathrm{~F}$ & $>50000$ & $>50000$ & $>50000$ & $>50000$ & $>50000$ & $>50000$ & $>50000$ & $>50000$ \\
\hline & $11 \mathrm{c}$ & $\mathrm{Cl}$ & $\mathrm{Cl}$ & $>50000$ & $>50000$ & $>50000$ & $>50000$ & $\begin{array}{l}35674 \pm \\
665\end{array}$ & $>50000$ & $>50000$ & $>50000$ \\
\hline & 11d & $\mathrm{Br}$ & $\mathrm{Br}$ & $\begin{array}{l}16930 \pm \\
6183\end{array}$ & $\begin{array}{l}18940 \pm \\
1068\end{array}$ & $\begin{array}{l}13210 \pm \\
706\end{array}$ & $\begin{array}{l}25490 \pm \\
5144\end{array}$ & $24960 \pm 35$ & $\begin{array}{l}26320 \pm \\
211\end{array}$ & $\begin{array}{l}14355 \pm \\
178\end{array}$ & \multirow{2}{*}{$\begin{array}{l}17814 \pm \\
155 \\
26460 \pm \\
533\end{array}$} \\
\hline & $11 \mathrm{e}$ & $\mathrm{CF}_{3}$ & $\mathrm{CF}_{3}$ & $>50000$ & $>50000$ & $>50000$ & $>50000$ & $>50000$ & $>50000$ & $>50000$ & \\
\hline & $11 \mathrm{f}$ & $\mathrm{Me}$ & $\mathrm{Me}$ & $\begin{array}{l}3762 \pm \\
1720\end{array}$ & $5159 \pm 386$ & $2405 \pm 308$ & $6541 \pm 460$ & $2535 \pm 30$ & $3693 \pm 18$ & $3020 \pm 23$ & $3271 \pm 33$ \\
\hline & $11 \mathrm{~g}$ & $\mathrm{OMe}$ & $\mathrm{OMe}$ & $\begin{array}{l}6419 \pm \\
4365\end{array}$ & $\begin{array}{l}23370 \pm \\
1471\end{array}$ & $\begin{array}{l}38150 \pm \\
2325\end{array}$ & $9839 \pm 503$ & $>50000$ & $>50000$ & $>50000$ & $>50000$ \\
\hline & $11 \mathrm{~h}$ & $\mathrm{~N}\left(\mathrm{CH}_{3}\right)_{2}$ & $\mathrm{~N}\left(\mathrm{CH}_{3}\right)_{2}$ & $\mathrm{ND}$ & $\mathrm{ND}$ & ND & ND & $>50000$ & $>50000$ & $>50000$ & $>50000$ \\
\hline & $11 \mathrm{i}$ & $\mathrm{OH}$ & $\mathrm{OH}$ & $\mathrm{ND}$ & ND & ND & ND & $38769 \pm 97$ & $\begin{array}{l}48218 \pm \\
113\end{array}$ & $\begin{array}{l}47986 \pm \\
104\end{array}$ & $21421 \pm 93$ \\
\hline & $12 a$ & $\mathrm{H}$ & $3,4,5-(\mathrm{OMe})_{3}$ & $6 \pm 1$ & $14 \pm 1$ & $13 \pm 0.3$ & $22 \pm 2$ & $9 \pm 6$ & $14 \pm 3$ & $24 \pm 3$ & $11 \pm 2$ \\
\hline & $12 \mathrm{~b}$ & $\mathrm{~F}$ & $3,4,5-(\mathrm{OMe})_{3}$ & $114 \pm 7$ & $196 \pm 6$ & $134 \pm 0.1$ & $353 \pm 10$ & $197 \pm 15$ & $298 \pm 13$ & $320 \pm 14$ & $263 \pm 10$ \\
\hline & $12 \mathrm{c}$ & $\mathrm{Cl}$ & $3,4,5-(\mathrm{OMe})_{3}$ & $22 \pm 6$ & $64 \pm 7$ & $51 \pm 1$ & $125 \pm 12$ & $51 \pm 13$ & $63 \pm 11$ & $106 \pm 15$ & $75 \pm 11$ \\
\hline & 12d & $\mathrm{Br}$ & $3,4,5-(\mathrm{OMe})_{3}$ & $15 \pm 5$ & $33 \pm 2$ & $30 \pm 1$ & $66 \pm 2$ & $29 \pm 7$ & $31 \pm 4$ & $58 \pm 14$ & $43 \pm 11$ \\
\hline & $12 \mathrm{e}$ & $\mathrm{CF}_{3}$ & $3,4,5-(\mathrm{OMe})_{3}$ & $47 \pm 35$ & $93 \pm 3$ & $74 \pm 2$ & $210 \pm 18$ & $123 \pm 18$ & $143 \pm 8$ & $120 \pm 15$ & $175 \pm 9$ \\
\hline & $12 \mathrm{f}$ & $\mathrm{CH}_{3}$ & $3,4,5-(\mathrm{OMe})_{3}$ & $13 \pm 1$ & $19 \pm 1$ & $18 \pm 0.3$ & $30 \pm 4$ & $13 \pm 2$ & $14 \pm 3$ & $27 \pm 11$ & $21 \pm 5$ \\
\hline & $12 \mathrm{~g}$ & $\mathrm{OMe}$ & $3,4,5-(\mathrm{OMe})_{3}$ & $30 \pm 14$ & $61 \pm 4$ & $54 \pm 1$ & $210 \pm 147$ & $33 \pm 8$ & $41 \pm 12$ & $55 \pm 9$ & $59 \pm 18$ \\
\hline & $12 \mathrm{~h}$ & $\mathrm{~N}\left(\mathrm{CH}_{3}\right)_{2}$ & $3,4,5-(\mathrm{OMe})_{3}$ & $96 \pm 6$ & $118 \pm 17$ & $120 \pm 12$ & $263 \pm 16$ & $141 \pm 23$ & $129 \pm 19$ & $200 \pm 20$ & $162 \pm 12$ \\
\hline & $12 \mathrm{i}$ & $\mathrm{OH}$ & $3,4,5-(\mathrm{OMe})_{3}$ & $219 \pm 101$ & $155 \pm 23$ & $122 \pm 6$ & $518 \pm 10$ & $487 \pm 35$ & $549 \pm 24$ & $669 \pm 31$ & $455 \pm 29$ \\
\hline & 13a & $3,4,5-(\mathrm{OMe})_{3}$ & $\mathrm{H}$ & $195 \pm 91$ & $632 \pm 42$ & $408 \pm 11$ & $1301 \pm 264$ & $1023 \pm 23$ & $1273 \pm 30$ & $4606 \pm 78$ & $5770 \pm 63$ \\
\hline & 13d & $3,4,5-(\mathrm{OMe})_{3}$ & $\mathrm{Br}$ & $131 \pm 175$ & $371 \pm 247$ & $106 \pm 3$ & $429 \pm 0.2$ & $136 \pm 12$ & $177 \pm 16$ & $186 \pm 11$ & $161 \pm 11$ \\
\hline & $13 g$ & $3,4,5-(\mathrm{OMe})_{3}$ & $\mathrm{OMe}$ & $708 \pm 334$ & $\begin{array}{l}10390 \pm \\
6646\end{array}$ & $5685 \pm 325$ & $>50000$ & $\begin{array}{l}35414 \pm \\
106\end{array}$ & $36007 \pm 98$ & $10956 \pm 96$ & $11428 \pm 87$ \\
\hline & $13 \mathrm{~h}$ & $3,4,5-(\mathrm{OMe})_{3}$ & $\mathrm{~N}\left(\mathrm{CH}_{3}\right)_{2}$ & ND & ND & ND & ND & $\begin{array}{l}47878 \pm \\
563\end{array}$ & $46131 \pm 98$ & $29175 \pm 88$ & $\begin{array}{l}40618 \pm \\
112\end{array}$ \\
\hline & $\begin{array}{c}13 i \\
14\end{array}$ & $\begin{array}{l}3,4,5-(\mathrm{OMe})_{3} \\
3,4,5-(\mathrm{OMe})_{3}\end{array}$ & $\begin{array}{c}\mathrm{OH} \\
3,4,5-(\mathrm{OMe})_{3}\end{array}$ & $\begin{array}{l}\text { ND } \\
>50000\end{array}$ & $\begin{array}{l}\text { ND } \\
>50000\end{array}$ & $\begin{array}{l}\text { ND } \\
>50000\end{array}$ & $\begin{array}{l}\text { ND } \\
>50000\end{array}$ & $\begin{array}{l}>50000 \\
>50000\end{array}$ & $\begin{array}{l}>50000 \\
>50000\end{array}$ & $\begin{array}{l}>50000 \\
>50000\end{array}$ & $\begin{array}{l}>50000 \\
>50000\end{array}$ \\
\hline
\end{tabular}

Note: ND: Not Determined. Dr. Sunjoo Ahn and Dr. Jin Wang performed the biological testing in this table. 


\section{Effect of Substitutions on the B Ring of RABIs}

Modifications on the B ring in two different sites were investigated: the N1- and 5-position of the imidazole ring. Introducing methyl, ethyl, or propyl at the 5-position of the imidazole ring resulted in inactive compounds (17a-c) as shown in Table 3-4. A trend in activity for the substituted alkyl groups: $\mathrm{Me}>\mathrm{Et}>\mathrm{Pr}$, was also observed, which suggests big bulky groups at this position are detrimental to activity. In contrast, when different substitution groups were introduced to the N1-position of the imidazole ring, the activity was maintained with only minimal loss compared with the parent compound, 12a. First some alkyl groups were tried on the N1-position including methyl, ethyl, $n$ propyl, $i$-propyl and cyclopentyl groups. Introduction of methyl did not affect the activity compared with 12a (15a, IC $\left.\mathrm{I}_{50}: 9-26 \mathrm{nM}\right)$, while the activity began to lose as the size of the alkyl groups increased, suggesting that a bulky alkyl group at this position was unfavorable. Benzyl group, which was also a relatively big group at the N1-position of the imidazole ring, decreased the activity $\left(\mathbf{1 5 c}, \mathrm{IC}_{50}\right.$ : 34-160 nM). Surprisingly, when the substituents were changed from alkyl groups to heterocyclic rings, the 'effect of big size' disappeared. The introduction of a pyridine ring to the N1-position generated a very potent compound with $\mathrm{IC}_{50}$ ranging from 6 to $37 \mathrm{nM}$. The introduction of a thiophene ring also produced a potent compound with $\mathrm{IC}_{50}$ ranging from 8 to $20 \mathrm{nM}$. The excellent activity of $15 \mathrm{~g}$ and $\mathbf{1 5 h}$ promises the future optimization at this position using other ring systems.

\section{Effect of RABI Compounds against Multidrug-Resistant Melanoma Cells}

Pgp-mediated drug efflux represents a major mechanism for cancer cells to prevent the buildup of effective intracellular drug concentrations. We have previously shown that the parent ABI analogs can effectively overcome a variety of clinically relevant multidrug resistant mechanisms including Pgp-mediated drug resistance. [113114] To determine whether the new RABI analogs maintain this ability, we compared the activity of the RABI compounds against multidrug-resistant melanoma cells (MDA-MB435/LCCMDR1) and their parental nonresistant cancer cells (MDA-MB-435). This pair of cell lines have been well validated and widely used to assess abilities of drugs overcoming Pgp-mediated multidrug resistance. [124-127] Compound 12a, 12d and 12e together with colchicine, vinblastine and paclitaxel were tested on both the multidrug resistant melanoma cells and their parental melanoma cell lines (Table 3-5). Compound 12a, 12d and 12e showed much better resistance index $(0.5$ for 12a, 0.7 for $12 \mathbf{d}, 0.8$ for 12e) than colchicine (58.5), vinblastine (27.5) and paclitaxel (69.3). Although colchicine, vinblastine, and paclitaxel showed excellent activity in nonresistant melanoma cell lines, they were much less potent in resistant melanoma cell lines. In contrast, compounds 12a, 12d and 12e showed comparable or even better activity against Pgp-overexpressed melanoma cells than their parental, nonresistant melanoma cells. 
Table 3-4. In vitro growth inhibitory effects of RABI compounds with B ring substitution

\begin{tabular}{|c|c|c|c|c|c|c|c|c|c|c|c|}
\hline \multirow[b]{2}{*}{ Structure } & \multirow[b]{2}{*}{ ID } & \multirow[b]{2}{*}{$\mathbf{R}^{1}$} & \multirow[b]{2}{*}{$\mathbf{R}^{2}$} & \multicolumn{8}{|c|}{$I_{50} \pm \operatorname{SEM}(\mathrm{nM})$} \\
\hline & & & & LNCaP & PC3 & PPC1 & DU145 & A375 & WM164 & $\begin{array}{c}\text { MDA- } \\
\text { MB-435 }\end{array}$ & $\begin{array}{c}\text { MDA- } \\
\text { MB- } \\
\text { 435/LCC } \\
\text {-6MDR1 }\end{array}$ \\
\hline & $15 a$ & $\mathrm{Me}$ & $\mathrm{H}$ & $10 \pm 1$ & $16 \pm 1$ & $13 \pm 0.2$ & $26 \pm 3$ & $9 \pm 2$ & $33 \pm 5$ & $16 \pm 2$ & $18 \pm 2$ \\
\hline & $15 b$ & $\mathrm{Et}$ & $\mathrm{H}$ & $29 \pm 20$ & $25 \pm 4$ & $30 \pm 8$ & $66 \pm 2$ & $28 \pm 3$ & $16 \pm 3$ & $26 \pm 3$ & $33 \pm 4$ \\
\hline & $15 \mathrm{c}$ & $\mathrm{Bn}$ & $\mathrm{H}$ & $66 \pm 6$ & $72 \pm 5$ & $77 \pm 2$ & $160 \pm 41$ & $104 \pm 17$ & $34 \pm 7$ & $94 \pm 18$ & $156 \pm 18$ \\
\hline & $15 d$ & $\mathrm{n}-\mathrm{Pr}$ & $\mathrm{H}$ & $49 \pm 10$ & $26 \pm 6$ & $10 \pm 4$ & $72 \pm 13$ & $42 \pm 3$ & $14 \pm 3$ & $37 \pm 2$ & $44 \pm 4$ \\
\hline & $15 \mathrm{e}$ & i-Pr & $\mathrm{H}$ & $62 \pm 8$ & $53 \pm 9$ & $15 \pm 3$ & $114 \pm 20$ & $38 \pm 4$ & $23 \pm 5$ & $18 \pm 3$ & $44 \pm 4$ \\
\hline & $15 f$ & & $\mathrm{H}$ & $51 \pm 6$ & $56 \pm 1$ & $63 \pm 4$ & $167 \pm 16$ & $135 \pm 13$ & $56 \pm 13$ & $134 \pm 15$ & $161 \pm 19$ \\
\hline & $15 \mathrm{~g}$ & 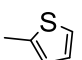 & $\mathrm{H}$ & $20 \pm 5$ & $11 \pm 3$ & $8 \pm 2$ & $37 \pm 6$ & $14 \pm 3$ & $6 \pm 1$ & $11 \pm 3$ & $15 \pm 5$ \\
\hline & $15 h$ & & $\mathrm{H}$ & ND & ND & ND & ND & $20 \pm 2$ & $8 \pm 2$ & $25 \pm 3$ & $27 \pm 3$ \\
\hline $\mathrm{MeO}$ & $17 \mathbf{a}$ & $\mathrm{H}$ & $\mathrm{Me}$ & $938 \pm 65$ & $\begin{array}{l}1617 \pm \\
144\end{array}$ & $860 \pm 5$ & $\begin{array}{l}2001 \pm \\
163\end{array}$ & $\begin{array}{l}1302 \pm \\
106\end{array}$ & $\begin{array}{l}1897 \pm \\
116\end{array}$ & $\begin{array}{l}1634 \pm \\
102\end{array}$ & $\begin{array}{l}1586 \pm \\
104\end{array}$ \\
\hline & $17 b$ & $\mathrm{H}$ & Et & $\begin{array}{l}2029 \pm \\
880\end{array}$ & $\begin{array}{l}3654 \pm \\
192\end{array}$ & $\begin{array}{l}2078 \pm \\
90\end{array}$ & $\begin{array}{l}5079 \pm \\
635\end{array}$ & $\begin{array}{l}2151 \pm \\
48\end{array}$ & $\begin{array}{l}5514 \pm \\
35\end{array}$ & $\begin{array}{l}8795 \pm \\
23\end{array}$ & $\begin{array}{l}5114 \pm \\
27\end{array}$ \\
\hline & $17 \mathrm{c}$ & $\mathrm{H}$ & $\mathrm{n}-\mathrm{Pr}$ & $\begin{array}{l}3094 \pm \\
330\end{array}$ & $\begin{array}{l}12360 \pm \\
7566\end{array}$ & $\begin{array}{l}11410 \pm \\
5918\end{array}$ & $\begin{array}{l}16350 \pm \\
6724\end{array}$ & $\begin{array}{l}36977 \pm \\
73\end{array}$ & $\begin{array}{l}19595 \pm \\
91\end{array}$ & $\begin{array}{l}30540 \pm \\
103\end{array}$ & $\begin{array}{l}14270 \pm \\
362\end{array}$ \\
\hline
\end{tabular}

Note: ND: Not Determined. Dr. Sunjoo Ahn and Dr. Jin Wang performed the biological testing in this table. 
Table 3-5. In vitro growth inhibitory effects of RABI compounds comparison to other anticancer drugs on multidrug-resistant melanoma cell and parent cell line

\begin{tabular}{cccc}
\hline & \multicolumn{3}{c}{ IC50 $\mathbf{\text { SEM }}$ (nM) } \\
\cline { 2 - 4 } ID & MDA-MB-435 & $\begin{array}{c}\text { MDA-MB- } \\
\text { 435/LCC- } \\
\text { 6MDR1 }\end{array}$ & $\begin{array}{c}\text { Resistance } \\
\text { Index }\end{array}$ \\
\hline 12a & $24 \pm 3$ & $11 \pm 2$ & 0.5 \\
12d & $58 \pm 14$ & $43 \pm 11$ & 0.7 \\
12e & $27 \pm 11$ & $21 \pm 5$ & 0.8 \\
colchicine & $11 \pm 2$ & $643 \pm 9$ & 58.5 \\
vinblastine & $0.4 \pm 0.1$ & $11 \pm 1$ & 27.5 \\
paclitaxel & $4 \pm 1$ & $277 \pm 41$ & 69.3 \\
\hline
\end{tabular}

Note: Dr. Jin Wang performed the biological testing in this table. 


\section{Mechanism of Action Studies on RABIs}

Since the parental ABI analogs kill cancer cells by inhibiting mitotic process, we hypothesized that RABIs maintain their mechanism of action. To test this hypothesis, we first performed the cell cycle analysis after the treatment of RABIs on PC3 cells. Cell cycle distribution was determined by propidium iodide (PI) staining. Treated cells were fixed with $70 \%$ ice-cold ethanol and the fixed cells were stained with PI in the presence of RNase A. Cell cycle distribution was analyzed by fluorescence-activated cell sorting (FACS) analysis. Compounds 5a, 12a, 12d, 12f, 15a, and 15b were treated on PC3 cells for $24 \mathrm{~h}$. Four different concentrations 1, 10, 50, and $100 \mathrm{nM}$ of each compound were chosen to examine the dose effect. Results indicated that RABIs arrest cells in the G2/M phase (Figure 3-7A). In the vehicle treated group, about $18 \%$ of PC3 cells were distributed in the G2/M phase. RABIs increased the proportion of cells in G2/M phase up to $70 \%$ approximately in a concentration-dependent manner (Figure 3-7B). The potency of the different concentrations in arresting cells in the G2/M phase positively correlated with in vitro cell growth inhibitory activity.

Based on their effect on cell cycle distribution, we next investigated the effect on tubulin polymerization of RABI analogs. To determine the effect of drug on tubulin polymerization, a fluorescence-enhanced tubulin polymerization assay kit was used. The control drug, vinblastine inhibited tubulin polymerization and destabilized microtubule, while paclitaxel promoted microtubule stability (Figure 3-8). RABI compounds, 12a and 15a inhibited tubulin polymerization as the tubulin destabilizer, vinblastine in a concentration-dependent manner (Figure 3-8) and 15a showed more potent inhibitory effect than 12a. In the competitive mass spectrometry binding assay, the amount of unbound colchicine in the presence or absence of any competitor would explain whether there is the competition of compounds and colchicine to bind in tubulin. 12a and 15g competed effectively with colchicine for tubulin binding (Figure 3-9) with potency similar to podophyllotoxin. Vinblastine, the negative control, did not inhibit colchicine binding to tubulin. Collectively, these data confirmed that new RABI analogs maintain their anti-mitotic mechanisms of action, most likely binding to the colchicine binding site in tubulin, as is the case for the parental ABI analogs. [114-115]

\section{Molecular Modeling Studies}

One surprising results from the analysis of the SAR for the RABI analogs is that incorporating a 5- or 6-membered heterocyclic ring substitution at the N1-position in the B-ring produced highly active compounds, while both similar-sized alkyl substitutions or a larger benzyl substitution resulted in significantly reduced activity (Table 3-4). To better understand how the N1-substituted RABI analogues interact with tubulin, the potential binding modes for two of the most potent compounds, 12a and 15g, were investigated at colchicine binding site in tubulin dimer using Schrodinger 2011 molecular modeling suite (Schrodinger, Inc., New York, NY). Both compounds were docked into two different tubulin crystal structure (PDB ID code: $1 \mathrm{SA} 0$ or $3 \mathrm{HKD}$ ), representing two potential binding geometries for colchicine site ligands. Interestingly, non-substituted 
A
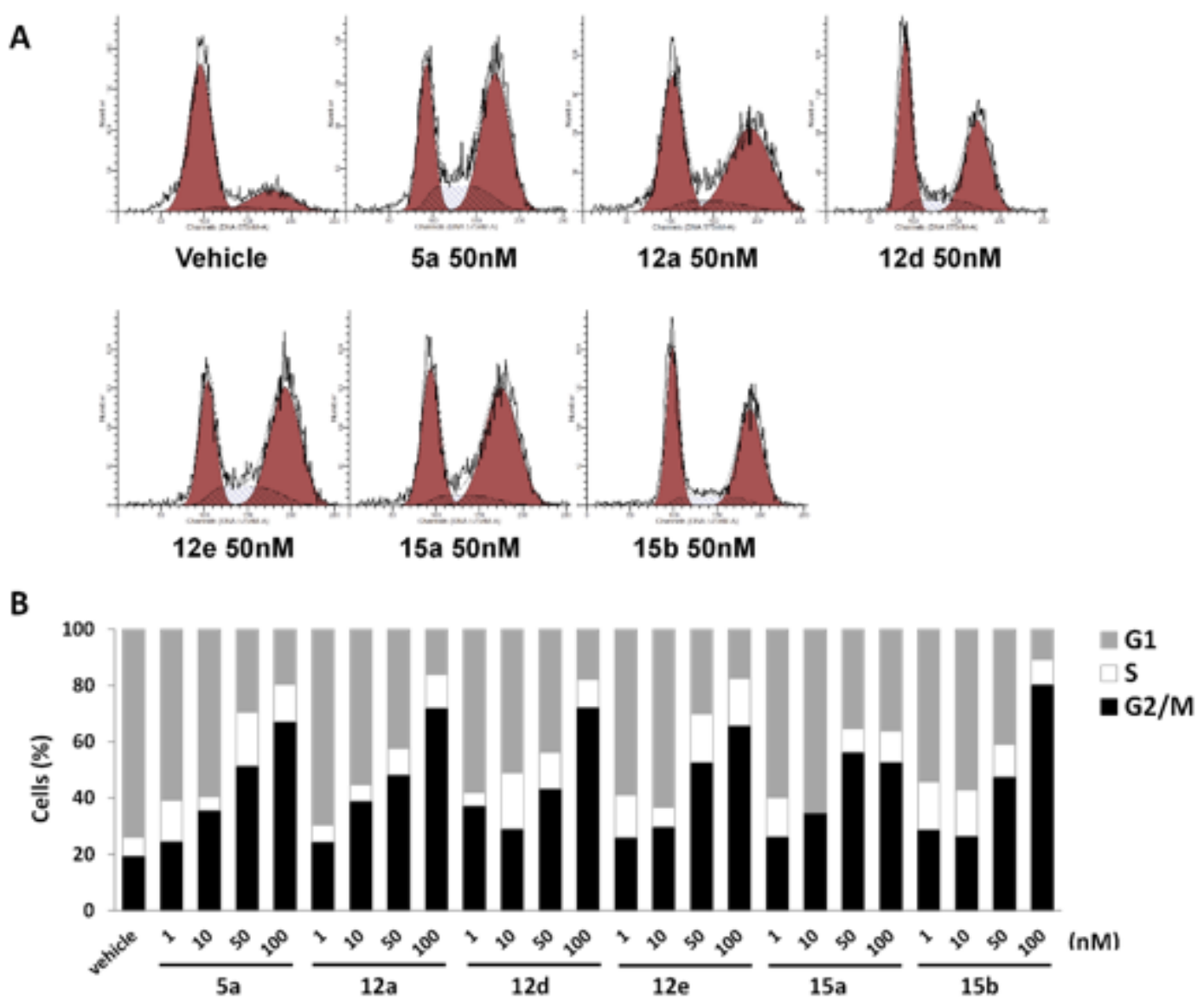

Figure 3-7. Effect of compounds 5a, 12a, 12d, 12e, 15a and $15 b$ on cell cycle Note: Dr. Sunjoo Ahn performed the experiments for this figure. 

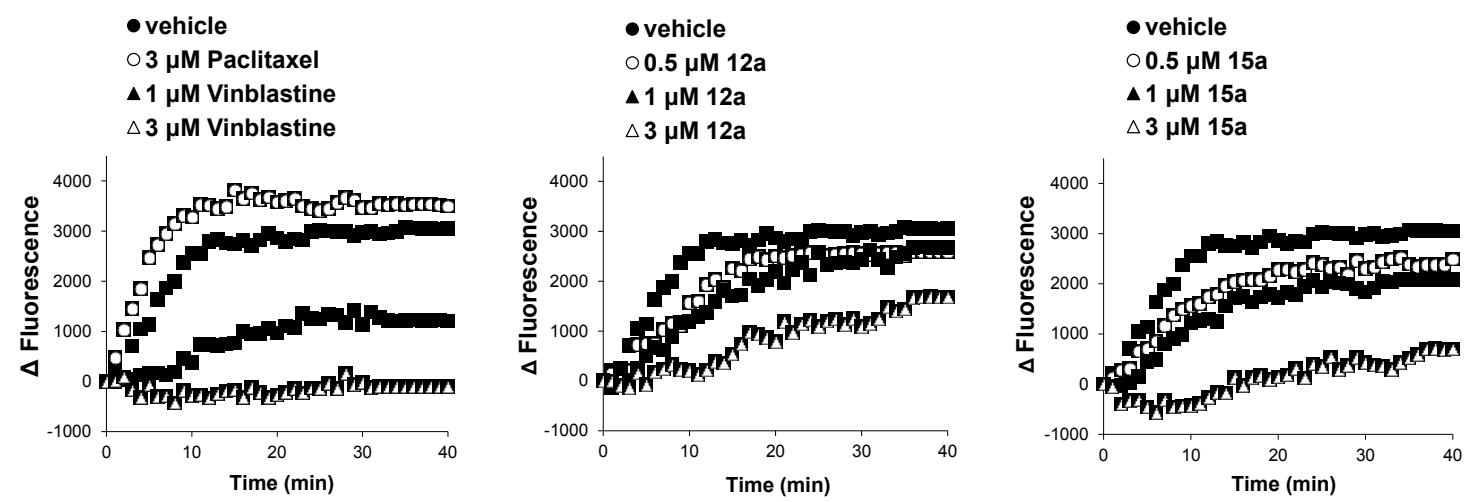

Figure 3-8. Effect of RABI compounds on tubulin polymerization in vitro

Note: Dr. Sunjoo Ahn performed the experiments for this figure.

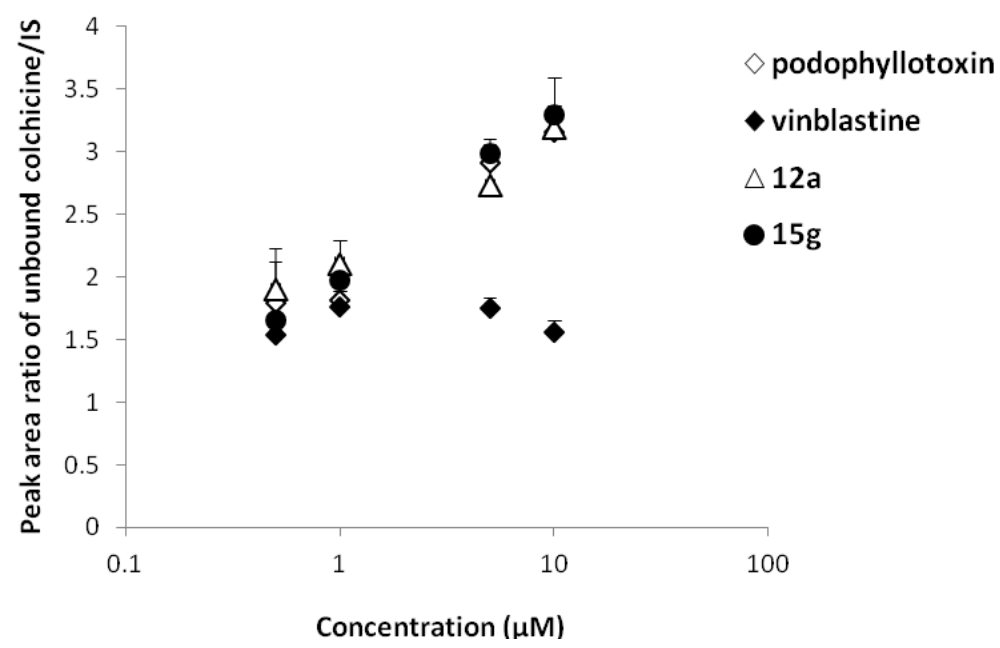

Figure 3-9. Competitive mass spectrometry binding assay

RABI compounds competitively bound to the colchicine-binding site on tubulin.

Podophyllotoxin is a known ligand binding to the colchicine site in tubulin and serves as a positive control. Vinblastine binds to a different site in tubulin and serves as a negative control.

Note: Dr. Sunjoo Ahn performed the experiments for this figure. 
RABI analog 12a demonstrated best glide docking score of -9.2 in 3 HKD compared with a score of -6.4 in 1SA0, while substituted RABI analog 15g showed best glide score of 9.0 in $1 \mathrm{SA} 0$ and could not fit into the binding pocket of $3 \mathrm{HKD}$.

The overview of the binding site of 12a and TN-16 (native ligand of 3HKD) is shown in Figure 3-10A. This binding pocket is located on the interface between the $\alpha$ and $\beta$-subunits of the tubulin dimer and extended slightly out of the $\beta$-subunit.[128-129] Figure 3-10B illustrated the close view of the potential binding pose. Generally, 12a (green stick) overlapped well with TN-16 (blue stick). The A ring of 12a went deep into the pocket and overlapped very well with the first phenyl ring of TN-16. There are very little space between the A-ring and its surrounding amino acids in the $\beta$-subunit (Figure 3-10B), and this explains why little tolerance is allowed for larger substitution in the Aring for both $\mathrm{ABI}$ and $\mathrm{RABI}$ compounds. The imidazole ring overlapped well with the pyrrolidinedione ring of TN-16. A potential hydrogen bond is formed between the imidazole NH of 12a and VAL238 in $\beta-H 7$ (Figure 3-10B), similar to the one formed between the native ligand TN-16 and VAL238 in $\beta-\mathrm{H} 7$. This hydrogen bond stabilized the interaction of 12a with the binding pocket. The 3, 4, 5-trimethoxybenzoyl group (C ring) of 12a extends toward the $\alpha / \beta$-tubulin interface, similar to the mode of the active parental ABI analogs.[112, 115]

Unlike 12a which does not possess a large N1-substitution, the much "fatter" RABI 15g cannot fit into the cylinder shaped binding pocket in $3 \mathrm{HKD}$, but dock reasonably well into the shallower pocket in 1SA0. The potential binding mode of $\mathbf{1 5 g}$ was shown in Figure 3-10C and Figure 3-10D. Figure 3-10C showed the general view of the binding site of $\mathbf{1 5 g}$ and the native ligand colchicine in $1 \mathrm{SA} 0$. Figure 3-10D illustrated the closed view of the potential binding pose. Interestingly, in this binding mode, part of $15 \mathrm{~g}$ (green stick) overlapped well with the native ligand colchicine (blue stick), while the original A ring of $\mathbf{1 5 g}$ extended out of the colchicine binding pocket into the $\alpha / \beta$-tubulin interface. The pyridine ring substitute on the N1- position occupied the site where the 7-membered ring in colchicine binds, while the 3,4,5-trimethoxybenzoyl group (C ring) of 15g overlapped very well with the 3,4,5-trimethoxyphenyl ring in colchicine. A hydrogen bond between the oxygen of 4-OMe in $\mathbf{1 5 g}$ and SH group of $\beta$ CYS241 stabilized the interaction. A similar hydrogen bond was also observed between the oxygen of one methoxy group in colchicine and SH of $\beta$-CYS241. This binding mode is well consistent with the SAR observed for substituted RABI compounds: a smaller, alkyl substitution could not fill this region of the binding pocket and lacks the planar geometry required for binding, while too large benzyl substitution could not fit into the pocket and also lacks the needed geometry. A 5- or 6-membered heterocyclic ring has the desirable shape and size to fit into the pocket well. These data also suggest that while the original "A ring" may not be critical for binding when a suitable N1-substitution is present, an optimized substitution replacing this original A ring moiety may take advantage of the added interactions between the ligand and receptor and provide even better ligand than $\mathbf{1 5 g}$. 
A

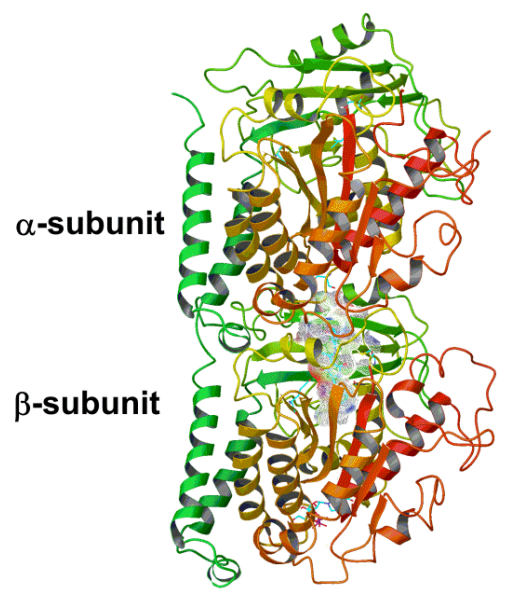

C

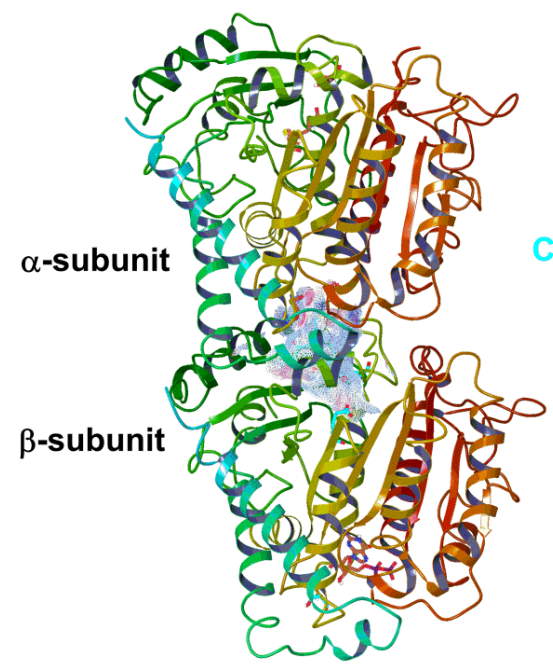

B

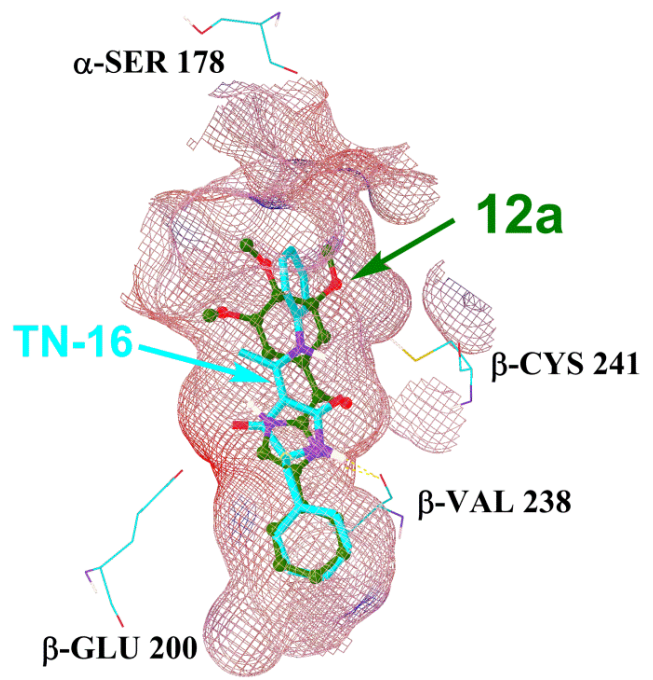

D

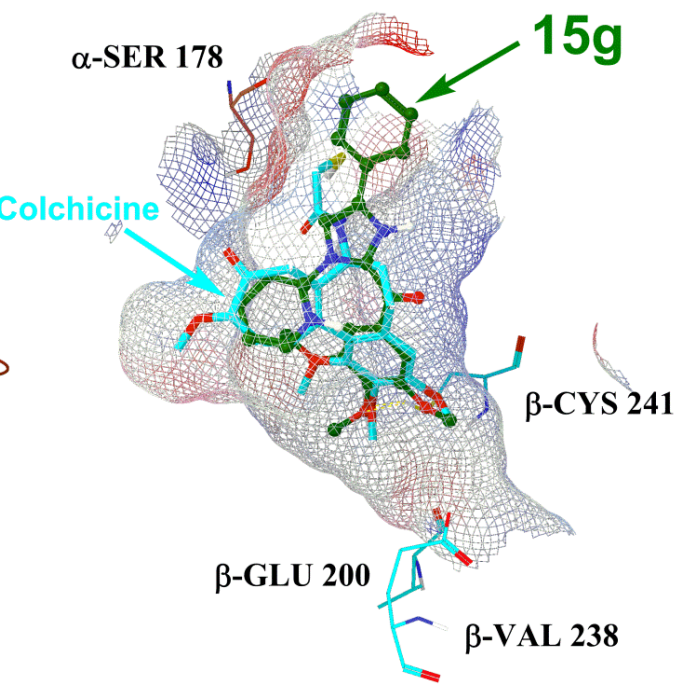

Figure 3-10. Binding modes of compounds 12a and 15g

(A) The overview of the binding modes of 12a and the native ligand TN-16 in tubulin crystal structure $3 \mathrm{HKD}$. (B) The close view of the potential binding pose of 12a and TN16 in 3 HKD. (C) The overview of the binding modes of $\mathbf{1 5 g}$ and the native ligand colchicine in tubulin crystal structure 1SA0.(D) The close view of the potential binding pose of $15 \mathrm{~g}$ and colchicine in $1 \mathrm{SA} 0$.

Note: Dr. Jin Wang performed the studies for this figure. 


\section{Experimental Section}

\section{General}

All reagents were purchased from Sigma-Aldrich Chemical Co., Fisher Scientific (Pittsburgh, PA), Alfa Aesar (Ward Hill, MA), and AK Scientific (Mountain View, CA) and were used without further purification. Routine thin layer chromatography (TLC) was performed on aluminum-backed Uniplates (Analtech, Newark, DE). NMR spectra were obtained on a Varian Inova-500 spectrometer (Agilent Technologies, Santa Clara, CA) or a Bruker Ascend 400 (Billerica, MA) spectrometer. Chemical shifts are reported as parts per million (ppm) relative to TMS in $\mathrm{CDCl}_{3}$. High Resolution Mass spectra were collected on a Waters Xevo G2-S Tof instrument. The purity of the final compounds was tested via Agilent series HPLC system (Agilent 1100 Series, Agilent 1100 Chemstation, Agilent Technology Co, Ltd.) installed with a photodiode array detector. Four RP-HPLC methods were conducted using a Phenomenex $5 \mu \mathrm{m} \mathrm{C}-18$ column $(250 \mathrm{~mm} \times 4.6 \mathrm{~mm})$ at ambient temperature and a flow rate of $1.0 \mathrm{~mL} / \mathrm{min}$. HPLC1: solvent A (water) and solvent B (methanol), 0-30 min 90\% B. HPLC2: solvent A (water) and solvent B (methanol), 0-30 min 85\% HPLC3: solvent A (water) and solvent B (methanol), 0-30 min 80\% B. HPLC4: solvent A (water) and solvent B (methanol), 0-15 min 50-100\% B (linear gradient), $15-25$ min $100 \%$ B, $25-28$ min $100-50 \%$ B, 28-33 min 50\% B. UV detection at $254 \mathrm{~nm}$. Purities of the compounds were established by careful integration of areas for all peaks detected and are reported for each compound in the following section.

\section{General Procedure for the Preparation of 2 a-c}

To a solution of appropriate benzaldehyde $\mathbf{1}(100 \mathrm{mmol})$ in ethanol $(350 \mathrm{~mL})$ at 0 ${ }^{\circ} \mathrm{C}$ was added a solution of $40 \%$ oxalaldehyde in water $(12.8 \mathrm{~mL}, 110 \mathrm{mmol})$ and a solution of $29 \%$ ammonium hydroxide in water $(1000 \mathrm{mmol}, 140 \mathrm{~mL})$. After stirring for 2-3 days at room temperature, the reaction mixture was concentrated and the residue was subjected to flash column chromatography with dichloromethane as eluent to yield the titled compound as a yellow powder. Yield: $20-40 \%$.

\section{General Procedure for the Preparation of 3a-c}

To a solution of 2-aryl-1H-imidazole $2(20 \mathrm{mmol})$ in anhydrous THF $(200 \mathrm{~mL})$ at $0^{\circ} \mathrm{C}$ was added sodium hydride $(60 \%$ dispersion in mineral oil, $1.2 \mathrm{~g}, 30 \mathrm{mmol})$ and stirred for $30 \mathrm{~min}$. Benzenesulfonyl chloride $(2.82 \mathrm{~mL}, 22 \mathrm{mmol})$ was added, and the reaction mixture was stirred overnight. After dilution by $100 \mathrm{~mL}$ of saturated $\mathrm{NaHCO}_{3}$ solution (aqueous), the reaction mixture was extracted by ethyl acetate $(500 \mathrm{~mL})$. The organic layer was dried over magnesium sulfate and concentrated. The residue was purified by flash column chromatography (hexane: ethyl acetate 2:1) to give a pale solid. Yield: $40-50 \%$. 


\section{General Procedure for the Preparation of $4 a-c$}

To a solution of 2-aryl-1-(phenylsulfonyl)-1H-imidazole $(6.0 \mathrm{mmol}) \mathbf{3}$ in anhydrous THF $(30 \mathrm{~mL})$ at $-78^{\circ} \mathrm{C}$ was added $1.7 \mathrm{M}$ tert-butyl lithium in pentane $(5.3 \mathrm{~mL}$, $9.0 \mathrm{mmol}$ ) and stirred for $10 \mathrm{~min}$. Appropriate substituted benzoyl chloride $(7.2 \mathrm{mmol})$ was added at $-78{ }^{\circ} \mathrm{C}$ and stirred for overnight. The reaction mixture was diluted with 100 $\mathrm{mL}$ of saturated $\mathrm{NaHCO}_{3}$ solution (aqueous) and extracted by ethyl acetate $(200 \mathrm{~mL})$. The organic layer was dried over magnesium sulfate and concentrated. The residue was purified by flash column chromatography (hexane: ethyl acetate $4: 1$ ) to give a white solid. (Note. Due to the limited amount of starting material or the difficulty of separation, the following products formed in this step were used without further purification as a mixture for the next step. Yield: $15 \%-40 \%$.

\section{General Procedure for the Preparation of 5a-c}

To a solution of aryl (2-aryl-1-(phenylsulfonyl)-1H-imidazol-4-yl) methanone (2.0 mmol) 4 in THF (20.0 mL) was added 1.0 M tetrabutyl ammoniumfluoride (4.0 $\mathrm{mmol}$ ) and stirred overnight. The reaction mixture was diluted by $50 \mathrm{~mL}$ of saturated $\mathrm{NaHCO}_{3}$ solution (aqueous) and extracted by ethyl acetate $(100 \mathrm{~mL})$. The organic layer was dried over magnesium sulfate and concentrated. The residue was purified by flash column chromatography (hexane: ethyl acetate 3:1) or recrystallized from water and methanol to give a white solid. Yield: $80-95 \%$.

(2-(4-Ethylphenyl)-1H-imidazol-4-yl)(3, 4, 5-trimethoxyphenyl) methanone (5a). ${ }^{1} \mathrm{H}$ NMR $\left(500 \mathrm{MHz}, \mathrm{CDCl}_{3}\right) \delta 10.40(\mathrm{br}, 1 \mathrm{H}), 7.92(\mathrm{~d}, \mathrm{~J}=8.0 \mathrm{~Hz}, 2 \mathrm{H}), 7.85(\mathrm{~s}, 1 \mathrm{H})$, $7.36(\mathrm{~d}, \mathrm{~J}=8.0 \mathrm{~Hz}, 2 \mathrm{H}), 7.27(\mathrm{~s}, 2 \mathrm{H}), 3.99(\mathrm{~s}, 3 \mathrm{H}), 3.97(\mathrm{~s}, 6 \mathrm{H}), 2.75(\mathrm{q}, \mathrm{d}=7.5 \mathrm{~Hz}, 2 \mathrm{H})$, $1.313(\mathrm{t}, \mathrm{d}=7.5 \mathrm{~Hz}, 3 \mathrm{H})$; Exact Mass for $\mathrm{C}_{21} \mathrm{H}_{22} \mathrm{~N}_{2} \mathrm{O}_{4}: 366.158$; HRMS: $[\mathrm{M}+\mathrm{H}]^{+}: 367.1764$; HPLC1: $t_{R} 4.97$ min, purity $97.8 \%$.

(2-(4-Isopropylphenyl)-1H-imidazol-4-yl)(3, 4, 5-trimethoxyphenyl) methanone (5b). ${ }^{1} \mathrm{H} \mathrm{NMR}\left(500 \mathrm{MHz}, \mathrm{CDCl}_{3}\right) \delta 10.38(\mathrm{br}, 1 \mathrm{H}), 7.82(\mathrm{~d}, \mathrm{~J}=8.0 \mathrm{~Hz}, 2 \mathrm{H})$, $7.75(\mathrm{~s}, 1 \mathrm{H}), 7.38(\mathrm{~d}, \mathrm{~J}=8.0 \mathrm{~Hz}, 2 \mathrm{H}), 7.15(\mathrm{~s}, 2 \mathrm{H}), 3.88(\mathrm{~s}, 3 \mathrm{H}), 3.86(\mathrm{~s}, 6 \mathrm{H}), 2.90(\mathrm{~m}$, $1 \mathrm{H}), 1.331(\mathrm{~d}, \mathrm{~d}=6.5 \mathrm{~Hz}, 6 \mathrm{H})$; Exact Mass for $\mathrm{C}_{22} \mathrm{H}_{24} \mathrm{~N}_{2} \mathrm{O}_{4}: 380.1700$; HRMS: $[\mathrm{M}+\mathrm{H}]^{+}$: 381.1818; HPLC1: $t_{R} 5.26$ min, purity $97.5 \%$.

(2-(4-Tertbutylphenyl)-1H-imidazol-4-yl)(3, 4, 5-trimethoxyphenyl) methanone (5c). ${ }^{1} \mathrm{H} \mathrm{NMR}\left(500 \mathrm{MHz}, \mathrm{CDCl}_{3}\right) \delta 10.42(\mathrm{br}, 1 \mathrm{H}), 7.94(\mathrm{~d}, \mathrm{~J}=8.0 \mathrm{~Hz}, 2 \mathrm{H})$, $7.84(\mathrm{~s}, 1 \mathrm{H}), 7.54(\mathrm{~d}, \mathrm{~J}=8.0 \mathrm{~Hz}, 2 \mathrm{H}), 7.25(\mathrm{~s}, 2 \mathrm{H}), 3.98(\mathrm{~s}, 3 \mathrm{H}), 3.96(\mathrm{~s}, 6 \mathrm{H}), 1.385(\mathrm{~s}$, 9H); Exact Mass for $\mathrm{C}_{23} \mathrm{H}_{26} \mathrm{~N}_{2} \mathrm{O}_{4}: 394.1900$; HRMS: [M+H] $]^{+}: 395.2054$; HPLC2: $\mathrm{t}_{\mathrm{R}} 7.75$ $\min$, purity $>99 \%$. 


\section{General Procedure for the Preparation of 8a-e}

To a solution of the aldehyde $6(5 \mathrm{mmol})$ in ethanol $(20 \mathrm{~mL})$ at $0^{\circ} \mathrm{C}$ was added the phenyl alkyl dione $7(5.5 \mathrm{mmol})$ and a solution of $29 \%$ ammonium hydroxide in water ( $50 \mathrm{mmol}, 7 \mathrm{~mL}$ ). After stirring for 2-3 days at room temperature, the reaction mixture was concentrated and the residue was subjected to flash column chromatography with dichloromethane as eluent to yield the titled compound as a yellow powder. Yield: 20$30 \%$.

5-Phenyl-2-(3, 4, 5-trimethoxybenzyl)-1H-imidazole and 4-phenyl-2-(3, 4, 5trimethoxybenzyl)-1H-imidazole (8a). ${ }^{1} \mathrm{H}$ NMR $(500 \mathrm{MHz}$, Chloroform- $d$ ) $\delta 7.91-$ $7.62(\mathrm{~m}, 2 \mathrm{H}), 7.43-7.34(\mathrm{~m}, 2 \mathrm{H}), 7.27-7.21(\mathrm{~m}, 2 \mathrm{H}), 6.51(\mathrm{~s}, 2 \mathrm{H}), 4.12(\mathrm{~s}, 2 \mathrm{H}), 3.86$ $(\mathrm{s}, 3 \mathrm{H}), 3.84(\mathrm{~s}, 6 \mathrm{H})$; Exact Mass for $\mathrm{C}_{19} \mathrm{H}_{20} \mathrm{~N}_{2} \mathrm{O}_{3}: 324.1500$; HRMS: $[\mathrm{M}+\mathrm{H}]^{+}: 325.1684$.

5-Methyl-4-phenyl-2-(3, 4, 5-trimethoxybenzyl)-1H-imidazole and 4-methyl5-phenyl-2-(3, 4, 5-trimethoxybenzyl)-1H-imidazole (8b). ${ }^{1} \mathrm{H}$ NMR $(500 \mathrm{MHz}$, Chloroform- $d$ ) $\delta 7.55(\mathrm{~d}, J=7.6 \mathrm{~Hz}, 2 \mathrm{H}), 7.43-7.37(\mathrm{~m}, 2 \mathrm{H}), 7.25(\mathrm{~d}, J=6.7 \mathrm{~Hz}, 1 \mathrm{H})$, 6.49 (s, 2H), 4.03 (s, 2H), $3.84(\mathrm{~d}, J=1.3 \mathrm{~Hz}, 3 \mathrm{H}), 3.81$ (d, $J=1.2 \mathrm{~Hz}, 6 \mathrm{H}), 2.42$ (s, 3H); Exact Mass for $\mathrm{C}_{20} \mathrm{H}_{22} \mathrm{~N}_{2} \mathrm{O}_{3}: 338.1600$; HRMS: $[\mathrm{M}+\mathrm{H}]^{+}: 339.1799$.

5-Ethyl-4-phenyl-2-(3,4,5-trimethoxybenzyl)-1H-imidazole and 4-ethyl-5phenyl-2-(3,4,5-trimethoxybenzyl)-1H-imidazole (8c). ${ }^{1} \mathrm{H}$ NMR $(500 \mathrm{MHz}$, Chloroform- $d$ ) $\delta 8.47(\mathrm{~s}, 0.42 \mathrm{H}), 8.39(\mathrm{~s}, 0.58 \mathrm{H}), 7.86-7.62(\mathrm{~m}, 2 \mathrm{H}), 7.41(\mathrm{~m}, 2 \mathrm{H}), 7.35$ - $7.31(\mathrm{~m}, 1 \mathrm{H}), 6.54(\mathrm{~m}, 2 \mathrm{H}), 4.10(\mathrm{~m}, 2 \mathrm{H}), 3.90-3.83(\mathrm{~m}, 9 \mathrm{H}), 2.79(\mathrm{~m}, 2 \mathrm{H}), 1.38-$ $1.17(\mathrm{~m}, 3 \mathrm{H})$; Exact Mass for $\mathrm{C}_{21} \mathrm{H}_{24} \mathrm{~N}_{2} \mathrm{O}_{3}: 352.1800$; HRMS: $[\mathrm{M}+\mathrm{H}]^{+}: 353.1912$.

4-Phenyl-5-propyl-2-(3,4,5-trimethoxybenzyl)-1H-imidazole and 5-phenyl-4propyl-2-(3,4,5-trimethoxybenzyl)-1H-imidazole (8d). ${ }^{1} \mathrm{H}$ NMR $(400 \mathrm{MHz}$, Chloroform- $d$ ) $\delta 8.63(\mathrm{~s}, 0.48 \mathrm{H}), 8.50(\mathrm{~s}, 0.52 \mathrm{H}), 7.70-7.64(\mathrm{~m}, 1 \mathrm{H}), 7.41(\mathrm{~m}, 3 \mathrm{H}), 7.37$ $-7.32(\mathrm{~m}, 1 \mathrm{H}), 6.52(\mathrm{~d}, J=1.3 \mathrm{~Hz}, 2 \mathrm{H}), 4.08(\mathrm{~d}, J=5.1 \mathrm{~Hz}, 2 \mathrm{H}), 3.87(\mathrm{~m}, 3 \mathrm{H}), 3.86-$ $3.84(\mathrm{~m}, 6 \mathrm{H}), 2.73(\mathrm{~m}, 2 \mathrm{H}), 1.88-1.75(\mathrm{~m}, 1 \mathrm{H}), 1.64(\mathrm{~m}, 1 \mathrm{H}), 0.98(\mathrm{~m}, 3 \mathrm{H})$; Exact Mass for $\mathrm{C}_{22} \mathrm{H}_{26} \mathrm{~N}_{2} \mathrm{O}_{3}$ : 366.1900; HRMS: [M+H] $]^{+}: 367.2011$.

4, 5-Diphenyl-2-(3,4,5-trimethoxybenzyl)-1H-imidazole (8e). ${ }^{1} \mathrm{H}$ NMR (400 $\mathrm{MHz}$, Chloroform- $d$ ) $\delta 7.44-7.36(\mathrm{~m}, 4 \mathrm{H}), 7.28-7.20(\mathrm{~m}, 6 \mathrm{H}), 6.50(\mathrm{~s}, 2 \mathrm{H}), 4.08(\mathrm{~s}$, $2 \mathrm{H}), 3.78(\mathrm{~m}, 9 \mathrm{H})$; Exact Mass for $\mathrm{C}_{25} \mathrm{H}_{24} \mathrm{~N}_{2} \mathrm{O}_{3}$ : 400.1800; HRMS: [M+H] $]^{+}: 401.1977$.

\section{General Procedure for the Preparation of 11-14}

To ammonium acetate $(10 \mathrm{mmol})$ in ethanol $(5 \mathrm{ml})$ and water $(0.3 \mathrm{ml})$ was added arylglyoxal hydrate 9 (1 mmol) in ethanol $(5 \mathrm{ml})$ and 3, 4, 5-trimethoxyphenyl glyoxal hydrate $10(1 \mathrm{mmol})$ in ethanol $(10 \mathrm{ml})$. The mixture was stirred at room temperature for $30-45 \mathrm{~min}$. The reaction was stopped after the consumption of the starting material monitored by TLC. The mixture was then extracted with ethyl acetate. The organic layer was washed with brine, dried over anhydrous sodium sulfate and concentrated to get the 
crude product. The crude was purified by flash chromatography (dichloromethane: methanol 50:1).

Phenyl-(4-phenyl-1H-imidazol-2-yl) methanone and phenyl-(5-phenyl-1Himidazol-2-yl) methanone (11a). ${ }^{1} \mathrm{H}$ NMR (500 MHz, DMSO-d6): d 13.80 (s, 0.25H), $13.63(\mathrm{~s}, 1 \mathrm{H}), 8.60$ (d, J = 7.76 Hz, 2H), 8.47 (d, J = 7.7 Hz, 0.5H,),8.08 (s, 1H,), 7.97 (d, $\mathrm{J}=7.95 \mathrm{~Hz}, 0.5 \mathrm{H}), 7.94(\mathrm{~d}, \mathrm{~J}=7.64 \mathrm{~Hz}, 2 \mathrm{H}), 7.79(\mathrm{~s}, 0.25 \mathrm{H}), 7.69(\mathrm{t}, \mathrm{J}=7.1 \mathrm{~Hz}, 1 \mathrm{H})$, $7.66(\mathrm{t}, \mathrm{J}=7.6 \mathrm{~Hz}, 0.25 \mathrm{H}), 7.60(\mathrm{t}, \mathrm{J}=7.6 \mathrm{~Hz}, 2 \mathrm{H}), 7.57(\mathrm{t}, \mathrm{J}=8.1 \mathrm{~Hz}, 0.5 \mathrm{H}), 7.47(\mathrm{t}, \mathrm{J}=$ $7.55 \mathrm{~Hz}, 0.5 \mathrm{H}), 7.42(\mathrm{t}, \mathrm{J}=7.7 \mathrm{~Hz}, 2 \mathrm{H}), 7.37(\mathrm{t}, \mathrm{J}=7.1 \mathrm{~Hz}, 0.25 \mathrm{H}), 7.28(\mathrm{t}, \mathrm{J}=7.3 \mathrm{~Hz}$, $1 \mathrm{H}$ ); Exact Mass for $\mathrm{C}_{16} \mathrm{H}_{12} \mathrm{~N}_{2} \mathrm{O}$ : 248.095; HRMS: [M+H] $]^{+}: 249.1058$; HPLC4: $\mathrm{t}_{\mathrm{R}} 10.83$ min, purity $97.6 \%$.

(4-Fluorophenyl)(4-(4-fluorophenyl)-1H-imidazol-2-yl)methanone and (4fluorophenyl)(5-(4-fluorophenyl)-1H-imidazol-2-yl)methanone (11b). ${ }^{1} \mathrm{H}$ NMR (400 $\mathrm{MHz}$, Chloroform-d) $\delta 10.68(\mathrm{~s}, 1 \mathrm{H}), 10.52(\mathrm{~s}, 1 \mathrm{H}), 8.93-8.82(\mathrm{dd}, \mathrm{J}=5.89,8.64 \mathrm{~Hz}$, 2H), $8.72(\mathrm{dd}, J=5.60,8.70 \mathrm{~Hz}, 0.39 \mathrm{H}), 7.89(\mathrm{dd}, J=5.39,8.72 \mathrm{~Hz}, 2 \mathrm{H}), 7.63(\mathrm{dd}, \mathrm{J}=$ $5.05,8.25 \mathrm{~Hz}, 0.46 \mathrm{H}), 7.59(\mathrm{~d}, \mathrm{~J}=2.2 \mathrm{~Hz}, 0.29 \mathrm{H}), 7.55(\mathrm{~d}, \mathrm{~J}=2.8 \mathrm{~Hz}, 1 \mathrm{H}) 7.25-7.20$ $(\mathrm{m}, 2 \mathrm{H}), 7.20-7.13(\mathrm{~m}, 2 \mathrm{H})$; Exact Mass for $\mathrm{C}_{16} \mathrm{H}_{10} \mathrm{~F}_{2} \mathrm{~N}_{2} \mathrm{O}: 284.0761$; HRMS: $[\mathrm{M}+\mathrm{H}]^{+}$: 285.0830; HPLC4: $t_{R} 13.97$ min, purity $98.0 \%$.

(4-Chlorophenyl)(4-(4-chlorophenyl)-1H-imidazol-2-yl)methanone and (4chlorophenyl)(5-(4-chlorophenyl)-1H-imidazol-2-yl)methanone(11c). ${ }^{1} \mathrm{H}$ NMR (400 MHz, Chloroform-d) $\delta 10.70(\mathrm{~s}, 0.65 \mathrm{H}), 10.55(\mathrm{~s}, 1 \mathrm{H}), 8.78(\mathrm{~d}, J=8.65 \mathrm{~Hz}, 2 \mathrm{H}), 8.63$ $(\mathrm{s}, 1 \mathrm{H}), 7.87(\mathrm{~s}, 2 \mathrm{H}), 7.66-7.52(\mathrm{~m}, 5 \mathrm{H}), 7.50-7.39(\mathrm{~m}, 2 \mathrm{H})$; Exact Mass for C16H10Cl2N2O: 316.017; HRMS: [M+H]+: 317.0292; HPLC4: tR 16.30 min, purity $98.8 \%$.

4-Bromophenyl-(4-(4-bromophenyl)-1H-imidazol-2-yl)ketone and 4bromophenyl-(5-(4-bromophenyl)-1H-imidazol-2-yl)methanoe(11d). ${ }^{1} \mathrm{H}$ NMR (500 MHz, DMSO-d6) $\delta$ 13.91(s, 0.16H),13.73 (s, 1H), $8.51(\mathrm{~d}, \mathrm{~J}=8.4 \mathrm{~Hz}, 2 \mathrm{H}), 8.42(\mathrm{~d}, \mathrm{~J}=$ $8.3 \mathrm{~Hz}, 0.32 \mathrm{H}), 8.16(\mathrm{~s}, 1 \mathrm{H}), 7.93(\mathrm{~d}, \mathrm{~J}=8.15 \mathrm{~Hz}, 0.32 \mathrm{H}), 7.89(\mathrm{~d}, \mathrm{~J}=8.35 \mathrm{~Hz}, 2 \mathrm{H}), 7.83$ $(\mathrm{d}, \mathrm{J}=8.45 \mathrm{~Hz}, 2 \mathrm{H}), 7.80(\mathrm{~d}, \mathrm{~J}=8.4 \mathrm{~Hz}, 0.32 \mathrm{H}), 7.79(\mathrm{~s}, 0.16 \mathrm{H}), 7.67(\mathrm{~d}, \mathrm{~J}=8.05 \mathrm{~Hz}$, $0.32 \mathrm{H}), 7.62(\mathrm{~d}, \mathrm{~J}=8.35 \mathrm{~Hz}, 2 \mathrm{H})$; Exact Mass for $\mathrm{C}_{16} \mathrm{H}_{10} \mathrm{Br}_{2} \mathrm{~N}_{2} \mathrm{O}$ : 403.916; HRMS: $[\mathrm{M}+\mathrm{H}]^{+}:$404.9241; HPLC4: $\mathrm{t}_{\mathrm{R}} 16.53 \mathrm{~min}$, purity $95.5 \%$.

(4-(Trifluoromethyl) phenyl)(4-(4-(trifluoromethyl)phenyl)-1H-imidazol-2yl)methanone and (4-(trifluoromethyl)phenyl)(5-(4-(trifluoromethyl)phenyl)-1Himidazol-2-yl)methanone (11e). ${ }^{1} \mathrm{H}$ NMR $(400 \mathrm{MHz}$, Chloroform-d) $\delta 10.83$ (s, 0.38H), $10.60(\mathrm{~s}, 1 \mathrm{H}), 8.78(\mathrm{~d}, J=8.19 \mathrm{~Hz}, 2 \mathrm{H}), 8.64(\mathrm{~d}, J=8.13 \mathrm{~Hz}, 0.48 \mathrm{H}), 7.93(\mathrm{~d}, J=8.34$ $\mathrm{Hz}, 2 \mathrm{H}), 7.76(\mathrm{~d}, J=8.56 \mathrm{~Hz}, 2 \mathrm{H}), 7.66-7.59(\mathrm{~m}, 3 \mathrm{H})$; Exact Mass for $\mathrm{C}_{18} \mathrm{H}_{10} \mathrm{~F}_{6} \mathrm{~N}_{2} \mathrm{O}$ : 384.0697; HRMS: $[\mathrm{M}+\mathrm{H}]^{+}:$385.0790; HPLC1: $\mathrm{t}_{\mathrm{R}} 7.76 \mathrm{~min}$, purity $98.3 \%$.

p-Tolyl(4-p-tolyl-1H-imidazol-2-yl)methanone and p-tolyl(5-p-tolyl-1Himidazol-2-yl)methanone(11f). ${ }^{1} \mathrm{H}$ NMR $(400 \mathrm{MHz}$, Chloroform-d) $\delta 10.96$ (s, 1H), $10.73(\mathrm{~s}, 1 \mathrm{H}), 8.71(\mathrm{~d}, J=8.26 \mathrm{~Hz}, 2 \mathrm{H}), 8.54(\mathrm{~d}, J=8.23 \mathrm{~Hz}, 2 \mathrm{H}), 7.82(\mathrm{~d}, J=8.11 \mathrm{~Hz}$, 2H), $7.67-7.49(\mathrm{~m}, 4 \mathrm{H}), 7.37(\mathrm{t}, J=7.62,7.62 \mathrm{~Hz}, 4 \mathrm{H}), 7.30(\mathrm{~s}, 1 \mathrm{H}), 7.28(\mathrm{~s}, 2 \mathrm{H}), 7.26$ 
$(\mathrm{s}, 1 \mathrm{H}), 2.49(\mathrm{~d}, J=4.52 \mathrm{~Hz}, 6 \mathrm{H}), 2.42(\mathrm{~d}, J=4.95 \mathrm{~Hz}, 6 \mathrm{H})$; Exact Mass for $\mathrm{C}_{18} \mathrm{H}_{16} \mathrm{~N}_{2} \mathrm{O}$ : 276.1263; HRMS: $[\mathrm{M}+\mathrm{H}]^{+}:$277.1385; HPLC3: tR 10.27 min, purity $98.7 \%$.

(4-Methoxyphenyl)(4-(4-methoxyphenyl)-1H-imidazol-2-yl)methanone and (4-methoxyphenyl)(5-(4-methoxyphenyl)-1H-imidazol-2-yl)methanone $(11 \mathrm{~g}) \cdot{ }^{1} \mathrm{H}$ NMR (400 MHz, Chloroform-d) $\delta 10.50$ (s, 1H), 10.38 (s, 1H), 8.77 (d, $J=8.90 \mathrm{~Hz}, 2 \mathrm{H})$, $8.60(\mathrm{~d}, J=8.89 \mathrm{~Hz}, 2 \mathrm{H}), 7.77(\mathrm{~s}, 1 \mathrm{H}), 7.75(\mathrm{~s}, 1 \mathrm{H}), 7.48(\mathrm{~d}, J=8.75 \mathrm{~Hz}, 1 \mathrm{H}), 7.45-$ $7.36(\mathrm{~m}, 2 \mathrm{H}), 7.03-6.87(\mathrm{~m}, 5 \mathrm{H}), 3.86(\mathrm{~s}, 2 \mathrm{H}), 3.85(\mathrm{~s}, 2 \mathrm{H}), 3.84(\mathrm{~s}, 2 \mathrm{H}), 3.80(\mathrm{~s}, 2 \mathrm{H})$, $3.79(\mathrm{~s}, 2 \mathrm{H})$; Exact Mass for $\mathrm{C}_{18} \mathrm{H}_{10} \mathrm{~F}_{6} \mathrm{~N}_{2} \mathrm{O}: 384.0697$; HRMS: $[\mathrm{M}+\mathrm{H}]^{+}$: 385.0790 ; HPLC2: $t_{R} 6.05 \mathrm{~min}$, purity $97.2 \%$.

(4-(Dimethylamino)phenyl)(4-(4-(dimethylamino)phenyl)-1H-imidazol-2yl)methanone and (4-(dimethylamino)phenyl)(5-(4-(dimethylamino)phenyl)-1Himidazol-2-yl)methanone(11h). ${ }^{1} \mathrm{H}$ NMR (500 MHz, DMSO-d6) $\delta 13.17$ (s, 0.35H), $13.12(\mathrm{~s}, 1 \mathrm{H}),, 8.64(\mathrm{~d}, J=8.95 \mathrm{~Hz}, 2 \mathrm{H}), 8.50(\mathrm{~d}, J=8.95 \mathrm{~Hz}, 1 \mathrm{H}), 7.80-7.69(\mathrm{~m}, 4 \mathrm{H})$, $7.50(\mathrm{~s}, 1 \mathrm{H}), 6.82(\mathrm{~d}, J=8.99 \mathrm{~Hz}, 2 \mathrm{H}), 6.76(\mathrm{t}, J=7.70,7.70 \mathrm{~Hz}, 5 \mathrm{H}), 3.07(\mathrm{~s}, 6 \mathrm{H}), 3.05$ $(\mathrm{s}, 4 \mathrm{H}), 2.95(\mathrm{~s}, 4 \mathrm{H}), 2.93(\mathrm{~s}, 6 \mathrm{H}))$; Exact Mass for $\mathrm{C}_{18} \mathrm{H}_{10} \mathrm{~F}_{6} \mathrm{~N}_{2} \mathrm{O}$ : 384.0697; HRMS: $[\mathrm{M}+\mathrm{H}]^{+}:$385.0790; HPLC1: tR $5.43 \mathrm{~min}$, purity $95.3 \%$.

(4-Hydroxyphenyl)(4-(4-hydroxyphenyl)-1H-imidazol-2-yl)methanone and (4-hydroxyphenyl)(5-(4-hydroxyphenyl)-1H-imidazol-2-yl)methanone(11i). ${ }^{1} \mathrm{H}$ NMR (500 MHz, DMSO-d6) $\delta 13.37$ (s, 0.37H), 13.29 (s, 1H), 10.39 (s, 1H), $9.46(\mathrm{~s}, 1 \mathrm{H}), 8.60$ $(\mathrm{d}, J=7.88 \mathrm{~Hz}, 3 \mathrm{H}), 8.47(\mathrm{~s}, 1 \mathrm{H}), 7.79(\mathrm{~s}, 2 \mathrm{H}), 7.73(\mathrm{~d}, J=7.48 \mathrm{~Hz}, 4 \mathrm{H}), 7.55(\mathrm{~s}, 1 \mathrm{H})$, $6.92(\mathrm{~d}, J=8.02 \mathrm{~Hz}, 4 \mathrm{H}), 6.81(\mathrm{~d}, J=8.03 \mathrm{~Hz}, 4 \mathrm{H})$; Exact Mass for $\mathrm{C}_{16} \mathrm{H}_{12} \mathrm{~N}_{2} \mathrm{O}_{3}$ : 280.0800; HRMS: $[\mathrm{M}+\mathrm{H}]^{+}: 281.0967$; HPLC2: $\mathrm{t}_{\mathrm{R}} 3.54 \mathrm{~min}$, purity $99.8 \%$.

(4-Phenyl-1H-imidazol-2-yl)(3,4,5-trimethoxyphenyl)methanone and (5phenyl-1H-imidazol-2-yl)(3,4,5-trimethoxyphenyl)methanone (12a). ${ }^{1} \mathrm{H}$ NMR (400 $\mathrm{MHz}$, Chloroform-d) $\delta 10.63(\mathrm{~s}, 0.48 \mathrm{H}), 10.47(\mathrm{~s}, 1 \mathrm{H}), 8.19(\mathrm{~s}, 2 \mathrm{H}), 7.98(\mathrm{~s}, 1 \mathrm{H}), 7.82(\mathrm{t}$, $J=1.67,1.67 \mathrm{~Hz}, 1 \mathrm{H}), 7.81(\mathrm{t}, J=1.11,1.11 \mathrm{~Hz}, 1 \mathrm{H}), 7.60-7.53(\mathrm{~m}, 1 \mathrm{H}), 7.51(\mathrm{~d}, J=$ $1.97 \mathrm{~Hz}, 1 \mathrm{H}), 7.46-7.30(\mathrm{~m}, 3 \mathrm{H}), 7.29-7.22(\mathrm{~m}, 1 \mathrm{H}), 3.95(\mathrm{~s}, 5 \mathrm{H}), 3.91(\mathrm{~s}, 3 \mathrm{H}), 3.91$ $(\mathrm{s}, 3 \mathrm{H}), 3.89(\mathrm{~s}, 1 \mathrm{H})$; Exact Mass for $\mathrm{C}_{19} \mathrm{H}_{18} \mathrm{~N}_{2} \mathrm{O}_{4}: 338.1267$; HRMS: $[\mathrm{M}+\mathrm{H}]^{+}: 339.1423$; HPLC2: $t_{R} 6.40$ min, purity $95.0 \%$.

(4-(4-Fluorophenyl)-1H-imidazol-2-yl)(3,4,5-trimethoxyphenyl)methanone and (5-(4-fluorophenyl)-1H-imidazol-2-yl)(3,4,5-trimethoxyphenyl)methanone (12b). ${ }^{1} \mathrm{H}$ NMR (400 MHz, Chloroform-d) $\delta 10.60(\mathrm{~s}, 0.30 \mathrm{H}), 10.46(\mathrm{~s}, 1 \mathrm{H}), 8.15$ (s, 2H), 7.97 $(\mathrm{s}, 1 \mathrm{H}), 7.77(\mathrm{dd}, J=5.35,8.90 \mathrm{~Hz}, 2 \mathrm{H}), 7.58-7.50(\mathrm{dd}, \mathrm{J}=5.10,8.20 \mathrm{~Hz}, 0.47 \mathrm{H}), 7.48$ $(\mathrm{s}, 0.46 \mathrm{H}), 7.46(\mathrm{~s}, 1 \mathrm{H}), 7.45(\mathrm{~s}, 1 \mathrm{H}), 7.10-7.02(\mathrm{~m}, 2 \mathrm{H}), 3.94(\mathrm{~s}, 6 \mathrm{H}), 3.92(\mathrm{~s}, 3 \mathrm{H})$, $3.91(\mathrm{~s}, 2 \mathrm{H}), 3.89(\mathrm{~s}, 1 \mathrm{H})$; Exact Mass for $\mathrm{C}_{19} \mathrm{H}_{17} \mathrm{FN}_{2} \mathrm{O}_{4}$ : 356.1172; HRMS: $[\mathrm{M}+\mathrm{H}]^{+}$: 357.1245 ; HPLC2: $\mathrm{t}_{\mathrm{R}} 6.90 \mathrm{~min}$, purity $99.3 \%$.

(4-(4-Chlorophenyl)-1H-imidazol-2-yl)(3,4,5-trimethoxyphenyl)methanone and (5-(4-chlorophenyl)-1H-imidazol-2-yl)(3,4,5-trimethoxyphenyl)methanone (12c). ${ }^{1} \mathrm{H}$ NMR (400 MHz, Chloroform-d) $\delta 10.57(\mathrm{~s}, 0.33 \mathrm{H}), 10.45(\mathrm{~s}, 1 \mathrm{H}), 8.15(\mathrm{~s}, 2 \mathrm{H}), 7.97$ $(\mathrm{s}, 0.49 \mathrm{H}), 7.81-7.68(\mathrm{~m}, 2 \mathrm{H}), 7.51-7.47(\mathrm{~m}, 1 \mathrm{H}), 7.36-7.30(\mathrm{~m}, 2 \mathrm{H}), 3.94(\mathrm{~s}, 6 \mathrm{H})$, 
3.91 (s, 3H), 3.89 (s, 0.75H); Exact Mass for $\mathrm{C}_{19} \mathrm{H}_{17} \mathrm{ClN}_{2} \mathrm{O}_{4}$ : 372.0877; HRMS: [M+H] ${ }^{+}$: 373.0992; HPLC4: $t_{R} 15.76$ min, purity $95.6 \%$.

(4-(4-Bromophenyl)-1H-imidazol-2-yl)(3,4,5-

trimethoxyphenyl)methanoneand (5-(4-bromophenyl)-1H-imidazol-2-yl)(3,4,5trimethoxyphenyl)methanone(12d). ${ }^{1} \mathrm{H}$ NMR $(400 \mathrm{MHz}$, Chloroform-d) $\delta 10.77$ (s, $0.36 \mathrm{H}), 10.59(\mathrm{~s}, 1 \mathrm{H}), 8.24(\mathrm{~s}, 2 \mathrm{H}), 8.06(\mathrm{~s}, 1 \mathrm{H}), 7.78(\mathrm{~d}, J=1.86 \mathrm{~Hz}, 1 \mathrm{H}), 7.76(\mathrm{~d}, J=$ $1.98 \mathrm{~Hz}, 1 \mathrm{H}), 7.69-7.47(\mathrm{~m}, 4 \mathrm{H}), 4.03(\mathrm{~s}, 6 \mathrm{H}), 4.01(\mathrm{~s}, 3 \mathrm{H}), 4.00(\mathrm{~s}, 2 \mathrm{H}), 3.99(\mathrm{~s}, 1 \mathrm{H})$; Exact Mass for $\mathrm{C}_{19} \mathrm{H}_{17} \mathrm{BrN}_{2} \mathrm{O}_{4}: 416.0372$; HRMS: $[\mathrm{M}+\mathrm{H}]^{+}: 417.0496$; HPLC1: $\mathrm{t}_{\mathrm{R}} 6.37$ min, purity $96.7 \%$.

(4-(4-(Trifluoromethyl)phenyl)-1H-imidazol-2-yl)(3,4,5trimethoxyphenyl)methanone and (5-(4-(trifluoromethyl)phenyl)-1 H-imidazol-2yl)(3,4,5trimethoxyphenyl)methanone (12e). ${ }^{1} \mathrm{H}$ NMR (400 MHz, Chloroform-d) $\delta$ $10.90(\mathrm{~s}, 0.16 \mathrm{H}), 10.67(\mathrm{~s}, 1 \mathrm{H}), 8.26(\mathrm{~s}, 2 \mathrm{H}), 8.08(\mathrm{~s}, 0.36 \mathrm{H}), 8.01(\mathrm{~d}, J=7.30 \mathrm{~Hz}, 2 \mathrm{H})$, 7.80-7.88 (m, 0.79H), $7.76-7.62(\mathrm{~m}, 3 \mathrm{H}), 4.08-3.95(\mathrm{~m}, 11 \mathrm{H})$; Exact Mass for $\mathrm{C}_{20} \mathrm{H}_{17} \mathrm{~F}_{3} \mathrm{~N}_{2} \mathrm{O}_{4}$ : 406.114; HRMS: [M+H] $]^{+}$: 407.1319; HPLC2: $\mathrm{t}_{\mathrm{R}} 9.60$ min, purity $95.1 \%$.

(4-p-Tolyl-1H-imidazol-2-yl)(3,4,5-trimethoxyphenyl)methanone and (5-ptolyl-1H-imidazol-2-yl)(3,4,5-trimethoxyphenyl)methanone (12f). ${ }^{1} \mathrm{H}$ NMR (400 MHz, Chloroform-d) $\delta 10.57$ (s, 0.77H), $10.44(\mathrm{~s}, 1 \mathrm{H}), 8.18(\mathrm{~s}, 2 \mathrm{H}), 7.96(\mathrm{~s}, 1 \mathrm{H}), 7.71(\mathrm{~d}$, $J=1.87 \mathrm{~Hz}, 1 \mathrm{H}), 7.69(\mathrm{~d}, J=1.88 \mathrm{~Hz}, 1 \mathrm{H}), 7.47(\mathrm{~d}, J=2.44 \mathrm{~Hz}, 2 \mathrm{H}), 7.22(\mathrm{~s}, 1 \mathrm{H}), 7.16$ $(\mathrm{s}, 1 \mathrm{H}), 3.94(\mathrm{~s}, 6 \mathrm{H}), 3.92(\mathrm{~s}, 3 \mathrm{H}), 3.90(\mathrm{~s}, 3 \mathrm{H}), 3.89(\mathrm{~s}, 2 \mathrm{H})$; Exact Mass for $\mathrm{C}_{20} \mathrm{H}_{20} \mathrm{~N}_{2} \mathrm{O}_{4}$ : 352.1423; HRMS: $[\mathrm{M}+\mathrm{H}]^{+}: 353.1527$; HPLC1: $\mathrm{t}_{\mathrm{R}} 5.63$ min, purity $95.9 \%$.

(4-(4-Methoxyphenyl)-1H-imidazol-2-yl)(3,4,5-trimethoxyphenyl)methanone and (5-(4-methoxyphenyl)-1H-imidazol-2-yl)(3,4,5-trimethoxyphenyl)methanone (12g). ${ }^{1} \mathrm{H}$ NMR (400 MHz, Chloroform-d) $\delta 10.60(\mathrm{~s}, 1 \mathrm{H}), 10.50$ (s, 1H), $8.27(\mathrm{~s}, 2 \mathrm{H})$, $8.05(\mathrm{~s}, 1 \mathrm{H}), 7.84(\mathrm{~s}, 1 \mathrm{H}), 7.82(\mathrm{~s}, 1 \mathrm{H}), 7.59(\mathrm{~d}, J=8.87 \mathrm{~Hz}, 1 \mathrm{H}), 7.54(\mathrm{~d}, J=1.90 \mathrm{~Hz}$, $1 \mathrm{H}), 7.51(\mathrm{~d}, J=2.31 \mathrm{~Hz}, 1 \mathrm{H}), 7.05-6.97(\mathrm{~m}, 4 \mathrm{H}), 4.04(\mathrm{~s}, 5 \mathrm{H}), 4.01(\mathrm{~s}, 3 \mathrm{H}), 4.00(\mathrm{~s}$, $3 \mathrm{H}), 3.98(\mathrm{~s}, 2 \mathrm{H}), 3.89(\mathrm{~s}, 2 \mathrm{H}), 3.88(\mathrm{~s}, 3 \mathrm{H})$; Exact Mass for $\mathrm{C}_{20} \mathrm{H}_{20} \mathrm{~N}_{2} \mathrm{O}_{5}$ : 368.1372; HRMS: $[\mathrm{M}+\mathrm{H}]^{+}: 369.1572$; HPLC4: $\mathrm{t}_{\mathrm{R}} 13.78$ min, purity $96.5 \%$.

(4-(4-(Dimethylamino)phenyl)-1H-imidazol-2-yl)(3,4,5trimethoxyphenyl)methanone and (5-(4-(dimethylamino)phenyl)-1H-imidazol-2yl)(3,4,5-trimethoxyphenyl)methanone (12h). ${ }^{1} \mathrm{H}$ NMR $(500 \mathrm{MHz}$, Chloroform-d) $\delta$ $10.67(\mathrm{~s}, 1 \mathrm{H}), 10.54(\mathrm{~s}, 0.49 \mathrm{H}), 8.28(\mathrm{~s}, 1 \mathrm{H}), 8.03(\mathrm{~s}, 2 \mathrm{H}), 7.78(\mathrm{~s}, 1 \mathrm{H}), 7.76(\mathrm{~s}, 1 \mathrm{H}), 7.53$ $(\mathrm{d}, J=8.79 \mathrm{~Hz}, 2 \mathrm{H}), 7.50(\mathrm{~d}, J=1.56 \mathrm{~Hz}, 1 \mathrm{H}), 6.78(\mathrm{~m}, 4 \mathrm{H}), 4.03(\mathrm{~s}, 4 \mathrm{H}), 3.99(\mathrm{~s}, 8 \mathrm{H})$, $3.97(\mathrm{~s}, 3 \mathrm{H}), 3.04$ (s, $6 \mathrm{H}), 3.02(\mathrm{~s}, 4 \mathrm{H})$; Exact Mass for $\mathrm{C}_{21} \mathrm{H}_{23} \mathrm{~N}_{3} \mathrm{O}_{4}$ : 381.1689; HRMS: $[\mathrm{M}+\mathrm{H}]^{+}: 382.1842$; $\mathrm{HPLC} 1: \mathrm{t}_{\mathrm{R}} 5.53$ min, purity $96.0 \%$.

(4-(4-Hydroxyphenyl)-1H-imidazol-2-yl)(3,4,5-trimethoxyphenyl)methanone and (5-(4-hydroxyphenyl)-1H-imidazol-2-yl)(3,4,5trimethoxyphenyl)methanone)(12i). ${ }^{1} \mathrm{H}$ NMR (500 MHz, Chloroform-d) $\delta 11.19$ (s, $1 \mathrm{H}), 10.75(\mathrm{~s}, 1 \mathrm{H}), 8.23(\mathrm{~s}, 2 \mathrm{H}), 7.98(\mathrm{~s}, 2 \mathrm{H}), 7.77(\mathrm{~s}, 1 \mathrm{H}), 7.75(\mathrm{~s}, 1 \mathrm{H}), 7.54(\mathrm{~d}, J=5.13$ $\mathrm{Hz}, 3 \mathrm{H}), 7.49$ (s, 1H), 6.90 (t, J=9.24, $9.24 \mathrm{~Hz}, 4 \mathrm{H}), 4.01$ (s, 6H), 3.99 (s, 3H), 3.97 (s, 
5H), 3.96 (s, 3H); Exact Mass for $\mathrm{C}_{19} \mathrm{H}_{18} \mathrm{~N}_{2} \mathrm{O}_{5}: 354.1216$; HRMS: [M+H] $]^{+}$: 355.1378 ; HPLC2: $t_{R} 4.46$ min, purity $98.1 \%$.

Phenyl(4-(3,4,5-trimethoxyphenyl)-1H-imidazol-2-yl)methanone and phenyl(5-(3,4,5-trimethoxyphenyl)-1H-imidazol-2-yl)methanone(13a). ${ }^{1} \mathrm{H}$ NMR (400 MHz, Chloroform- $d$ ) $\delta 10.67(\mathrm{~s}, 1 \mathrm{H}), 10.51(\mathrm{~s}, 1 \mathrm{H}), 8.68-8.63(\mathrm{~m}, 2 \mathrm{H}), 8.53-8.49(\mathrm{~m}$, $1 \mathrm{H}), 7.62-7.53(\mathrm{~m}, 2 \mathrm{H}), 7.53-7.44(\mathrm{~m}, 5 \mathrm{H}), 7.04(\mathrm{~s}, 2 \mathrm{H}), 6.75(\mathrm{~s}, 1 \mathrm{H}), 3.89(\mathrm{~s}, 6 \mathrm{H})$, $3.89(\mathrm{~s}, 3 \mathrm{H}), 3.83(\mathrm{~s}, 2 \mathrm{H}), 3.82(\mathrm{~s}, 3 \mathrm{H})$; Exact Mass for $\mathrm{C}_{19} \mathrm{H}_{18} \mathrm{~N}_{2} \mathrm{O}_{4}$ : 338.1267; HRMS: $[\mathrm{M}+\mathrm{H}]^{+}: 339.1348 ;$ HPLC2: $\mathrm{t}_{\mathrm{R}} 5.23 \mathrm{~min}$, purity $97.4 \%$.

(4-Bromophenyl)(4-(3,4,5-trimethoxyphenyl)-1H-imidazol-2-yl)methanone and (4-bromophenyl)(5-(3,4,5-trimethoxyphenyl)-1H-imidazol-2-yl)methanone(13d). ${ }^{1} \mathrm{H}$ NMR (400 MHz, Chloroform- $d$ ) $\delta 10.66(\mathrm{~s}, 1 \mathrm{H}), 10.57(\mathrm{~s}, 1 \mathrm{H}), 8.72-8.62(\mathrm{~m}, 2 \mathrm{H})$, $8.56-8.50(\mathrm{~m}, 1 \mathrm{H}), 7.80-7.75(\mathrm{~m}, 1 \mathrm{H}), 7.75-7.67(\mathrm{~m}, 4 \mathrm{H}), 7.57(\mathrm{q}, J=2.04 \mathrm{~Hz}, 2 \mathrm{H})$, $7.12(\mathrm{~s}, 2 \mathrm{H}), 6.82(\mathrm{~s}, 1 \mathrm{H}), 3.99(\mathrm{~s}, 6 \mathrm{H}), 3.98(\mathrm{~s}, 4 \mathrm{H}), 3.93(\mathrm{~s}, 2 \mathrm{H}), 3.92$ (s, 3H); Exact Mass for $\mathrm{C}_{19} \mathrm{H}_{17} \mathrm{BrN}_{2} \mathrm{O}_{4}$ : 416.0372; HRMS: [M+H] $]^{+}$: 417.0454; HPLC2: tR 7.28 min, purity $97.9 \%$.

(4-Methoxyphenyl)(4-(3,4,5-trimethoxyphenyl)-1H-imidazol-2-yl)methanone and (4-methoxyphenyl)(5-(3,4,5-trimethoxyphenyl)-1H-imidazol-2yl)methanone(13g). ${ }^{1} \mathrm{H}$ NMR $(400 \mathrm{MHz}$, Chloroform- $d$ ) $\delta 10.80(\mathrm{~s}, 1 \mathrm{H}), 10.66(\mathrm{~s}, 1 \mathrm{H})$, $8.87-8.79(\mathrm{~m}, 2 \mathrm{H}), 8.73-8.67(\mathrm{~m}, 1 \mathrm{H}), 7.56(\mathrm{~d}, J=1.83 \mathrm{~Hz}, 1 \mathrm{H}), 7.53(\mathrm{~d}, J=2.32 \mathrm{~Hz}$, 1H), 7.14 (s, 2H), 7.05 (dd, J=3.59, $8.90 \mathrm{~Hz}, 3 \mathrm{H}), 6.83$ (s, 1H), 3.99 (s, 6H), 3.96 (s, $3 \mathrm{H}), 3.95(\mathrm{~s}, 3 \mathrm{H}), 3.94(\mathrm{~s}, 2 \mathrm{H}), 3.92(\mathrm{~s}, 2 \mathrm{H}), 3.91(\mathrm{~s}, 3 \mathrm{H})$; Exact Mass for $\mathrm{C}_{20} \mathrm{H}_{20} \mathrm{~N}_{2} \mathrm{O}_{5}$ : 368.1372; HRMS: $[\mathrm{M}+\mathrm{H}]^{+}: 369.1494$; HPLC2: $\mathrm{t}_{\mathrm{R}} 5.94 \mathrm{~min}$, purity $97.4 \%$.

(4-(Dimethylamino) phenyl)(4-(3,4,5-trimethoxyphenyl)-1H-imidazol-2yl)methanone and (4-(dimethylamino)phenyl)(5-(3,4,5-trimethoxyphenyl)-1Himidazol-2-yl)methanone(13h). ${ }^{1} \mathrm{H}$ NMR (400 MHz, Chloroform- $d$ ) $\delta 11.20(\mathrm{~s}, 1 \mathrm{H})$, $10.94(\mathrm{~s}, 1 \mathrm{H}), 8.94-8.75(\mathrm{~m}, 2 \mathrm{H}), 8.74-8.61(\mathrm{~m}, 1 \mathrm{H}), 7.54(\mathrm{~s}, 1 \mathrm{H}), 7.50(\mathrm{~s}, 1 \mathrm{H}), 7.15$ $(\mathrm{d}, J=2.41 \mathrm{~Hz}, 2 \mathrm{H}), 6.86(\mathrm{~s}, 1 \mathrm{H}), 6.76(\mathrm{dd}, J=5.30,9.05 \mathrm{~Hz}, 3 \mathrm{H}), 3.99(\mathrm{~s}, 7 \mathrm{H}), 3.93$ (s, $4 \mathrm{H}), 3.91(\mathrm{~s}, 6 \mathrm{H}), 3.14(\mathrm{~s}, 6 \mathrm{H}), 3.13(\mathrm{~s}, 4 \mathrm{H})$; Exact Mass for $\mathrm{C}_{21} \mathrm{H}_{23} \mathrm{~N}_{3} \mathrm{O}_{4}$ : 381.1689; HRMS: $[\mathrm{M}+\mathrm{H}]^{+}: 382.1842$; HPLC1: $\mathrm{t}_{\mathrm{R}} 4.82 \mathrm{~min}$, purity $97.8 \%$.

(4-Hydroxyphenyl)(4-(3,4,5-trimethoxyphenyl)-1H-imidazol-2-yl)methanone and (4-hydroxyphenyl)(5-(3,4,5-trimethoxyphenyl)-1H-imidazol-2yl)methanone(13i). ${ }^{1} \mathrm{H}$ NMR $(500 \mathrm{MHz}$, Chloroform- $d) \delta 11.81(\mathrm{~s}, 1 \mathrm{H}), 11.45(\mathrm{~s}, 1 \mathrm{H})$, $8.62-8.44(\mathrm{~m}, 2 \mathrm{H}), 8.39-8.19(\mathrm{~m}, 2 \mathrm{H}), 7.53(\mathrm{~d}, J=31.95 \mathrm{~Hz}, 2 \mathrm{H}), 7.07$ (s, 2H), 6.82 $(\mathrm{dd}, J=12.16,30.47 \mathrm{~Hz}, 6 \mathrm{H}), 3.90(\mathrm{~s}, 5 \mathrm{H}), 3.88(\mathrm{~s}, 8 \mathrm{H}), 3.84(\mathrm{~s}, 6 \mathrm{H})$; Exact Mass for $\mathrm{C}_{19} \mathrm{H}_{18} \mathrm{~N}_{2} \mathrm{O}_{5}$ : 354.1216; HRMS: [M+H] $]^{+}: 355.1339$; HPLC1: $\mathrm{t}_{\mathrm{R}} 4.00 \mathrm{~min}$, purity $97.4 \%$.

3,4,5-Trimethoxyphenyl-(4-(3,4,5-trimethoxyphenyl)-1H-imidazol-2yl)methanone and 3,4,5-trimethoxyphenyl-(5-(3,4,5-trimethoxyphenyl)-1H-imidazol2-yl)methanone(14). ${ }^{1} \mathrm{H}$ NMR (400 MHz, Chloroform-d) $\delta 10.76$ (s, 0.40H), 10.61 (s, $1 \mathrm{H}), 8.20(\mathrm{~s}, 2 \mathrm{H}), 7.95(\mathrm{~s}, 1 \mathrm{H}), 7.48(\mathrm{~d}, J=1.90 \mathrm{~Hz}, 0.40 \mathrm{H}), 7.47(\mathrm{~d}, J=2.34 \mathrm{~Hz}, 1 \mathrm{H})$, 7.06 (s, 2H), 6.75 (s, 1H), 3.93 (s, 5H), 3.91 (d, J=0.84 Hz, 4H), 3.89 (s, 1H), 3.87 (s, 
$2 \mathrm{H}), 3.86(\mathrm{~s}, 5 \mathrm{H}) 3.83(\mathrm{~s}, 1 \mathrm{H}), 3.82(\mathrm{~s}, 2 \mathrm{H})$; Exact Mass for $\mathrm{C}_{22} \mathrm{H}_{24} \mathrm{~N}_{2} \mathrm{O}_{7}$ : 428.1584;

HRMS: $[\mathrm{M}+\mathrm{H}]^{+}$: 429.1677; HPLC3: $\mathrm{t}_{\mathrm{R}}$ 9.60min, purity $96.4 \%$.

\section{General Procedure for the Preparation of 15a-c}

To a solution of 12a (135 mg, $0.4 \mathrm{mmol})$ in THF $(10 \mathrm{~mL})$ in ice-bath was added sodium hydride ( $60 \%$ dispersion in mineral oil, $28 \mathrm{mg}, 0.60 \mathrm{mmol})$ followed by adding methyl iodide ( $85 \mathrm{mg}, 0.60 \mathrm{mmol}$ ) (for 15a) or ethyl iodide $(93 \mathrm{mg}, 0.60 \mathrm{mmol}$ ) (for 15b)or benzyl bromide $(102 \mathrm{mg}, 0.60 \mathrm{mmol}$ ) (for $\mathbf{1 5 c}$ ). The resulting reaction mixture was stirred overnight under reflux condition. After dilution by $50 \mathrm{ml}$ of saturated $\mathrm{NaHCO}_{3}$ solution (aqueous), the reaction mixture was extracted by ethyl acetate $(100 \mathrm{ml})$. The organic layer was dried over magnesium sulfate and concentrated. The residue was purified by flash column chromatography.

\section{(1-Methyl-4-phenyl-1H-imidazol-2-yl)(3,4,5-trimethoxyphenyl)methanone} (15a). ${ }^{1} \mathrm{H}$ NMR $(500 \mathrm{MHz}$, Chloroform-d) $\delta 7.97$ (d, $J=2.38 \mathrm{~Hz}, 2 \mathrm{H}), 7.85$ (d, $J=6.01$ $\mathrm{Hz}, 2 \mathrm{H}), 7.46-7.39(\mathrm{~m}, 3 \mathrm{H}), 7.28(\mathrm{~d}, J=2.39 \mathrm{~Hz}, 1 \mathrm{H}), 4.16-4.10(\mathrm{~m}, 3 \mathrm{H}), 3.99(\mathrm{~d}, J=$ $2.82 \mathrm{~Hz}, 9 \mathrm{H})$; Exact Mass for $\mathrm{C}_{20} \mathrm{H}_{20} \mathrm{~N}_{2} \mathrm{O}_{4}: 352.1423$; HRMS: [M+H] $]^{+}: 353.1527$; HPLC1: $\mathrm{t}_{\mathrm{R}} 6.03$ min, purity $96.4 \%$.

\section{(1-Ethyl-4-phenyl-1H-imidazol-2-yl)(3,4,5-}

trimethoxyphenyl)methanone(15b). ${ }^{1} \mathrm{H}$ NMR $(400 \mathrm{MHz}$, Chloroform-d) $\delta 7.95$ (s, 2H), $7.89-7.83(\mathrm{~m}, 2 \mathrm{H}), 7.51(\mathrm{~s}, 1 \mathrm{H}), 7.43(\mathrm{t}, J=7.61,7.61 \mathrm{~Hz}, 2 \mathrm{H}), 7.36-7.31(\mathrm{~m}, 1 \mathrm{H})$, $4.56(\mathrm{q}, J=7.19,7.19,7.19 \mathrm{~Hz}, 2 \mathrm{H}), 3.99(\mathrm{~s}, 6 \mathrm{H}), 3.98(\mathrm{~s}, 3 \mathrm{H}), 1.30(\mathrm{t}, \mathrm{J}=7.19,7,19 \mathrm{~Hz}$, $3 \mathrm{H}$ ); Exact Mass for $\mathrm{C}_{21} \mathrm{H}_{22} \mathrm{~N}_{2} \mathrm{O}_{4}$ : 366.158; HRMS: $[\mathrm{M}+\mathrm{H}]^{+}: 367.1725$; HPLC1: $\mathrm{t}_{\mathrm{R}} 6.47$ min, purity $97.1 \%$.

\section{(1-Benzyl-4-phenyl-1H-imidazol-2-yl)(3,4,5-}

trimethoxyphenyl)methanone(15c). ${ }^{1} \mathrm{H}$ NMR $(500 \mathrm{MHz}$, Chloroform-d) $\delta 7.94$ (d, $J=$ $1.70 \mathrm{~Hz}, 2 \mathrm{H}), 7.84$ (d, $J=7.73 \mathrm{~Hz}, 2 \mathrm{H}), 7.47-7.28$ (m, 9H), 5.74 (s, 2H), 3.98 (s, 9H); Exact Mass for $\mathrm{C}_{26} \mathrm{H}_{24} \mathrm{~N}_{2} \mathrm{O}_{4}$ : 428.1736; HRMS: $[\mathrm{M}+\mathrm{H}]^{+}: 429.1931$; HPLC1: $\mathrm{t}_{\mathrm{R}} 6.70 \mathrm{~min}$, purity $95.4 \%$.

\section{General Procedure for the Preparation of 15d-f}

To a solution of 12a (135 $\mathrm{mg}, 0.4 \mathrm{mmol})$ in ACN $(10 \mathrm{~mL})$ was added potassium carbonate $(82 \mathrm{mg}, 0.60 \mathrm{mmol}$ ) followed by $n$-propyl iodide $(82 \mathrm{mg}, 0.48 \mathrm{mmol})$ (for $15 \mathrm{~d}$ ) or i-propyl iodide ( $82 \mathrm{mg}, 0.48 \mathrm{mmol}$ ) (for 15e) or cyclopentyl bromide (72 $\mathrm{mg}, 0.48$ $\mathrm{mmol}$ ) (for 15f). The resulting reaction mixture was stirred overnight under reflux condition. After dilution by $50 \mathrm{ml}$ of saturated $\mathrm{NaHCO}_{3}$ solution (aqueous), the reaction mixture was extracted by ethyl acetate $(100 \mathrm{ml})$. The organic layer was dried over magnesium sulfate and concentrated. The residue was purified by flash column chromatography. 
(4-Phenyl-1-propyl-1H-imidazol-2-yl)(3,4,5-

trimethoxyphenyl)methanone(15d). ${ }^{1} \mathrm{H}$ NMR $(500 \mathrm{MHz}$, Chloroform- $d) \delta 7.94$ (s, 2H), $7.90-7.82(\mathrm{~m}, 2 \mathrm{H}), 7.47(\mathrm{~s}, 1 \mathrm{H}), 7.42(\mathrm{t}, J=7.67 \mathrm{~Hz}, 2 \mathrm{H}), 7.34-7.28(\mathrm{~m}, 1 \mathrm{H}), 4.51-$ 4.40 (m, 2H), 3.98 (d, $J=1.49 \mathrm{~Hz}, 9 \mathrm{H}), 1.96$ (h, $J=7.40 \mathrm{~Hz}, 2 \mathrm{H}), 1.03$ (t, $J=7.42 \mathrm{~Hz}$, $3 \mathrm{H}$ ); Exact Mass for $\mathrm{C}_{22} \mathrm{H}_{24} \mathrm{~N}_{2} \mathrm{O}_{4}: 380.1700$; HRMS: [M+H] $]^{+}: 381.1897$; HPLC1: $\mathrm{t}_{\mathrm{R}} 6.88$ min, purity $98.0 \%$.

\section{(1-Isopropyl-4-phenyl-1H-imidazol-2-yl)(3,4,5-}

trimethoxyphenyl)methanone(15e). ${ }^{1} \mathrm{H}$ NMR $(400 \mathrm{MHz}$, Chloroform- $d) \delta 7.79(\mathrm{~s}, 3 \mathrm{H})$, $7.78-7.73(\mathrm{~m}, 1 \mathrm{H}), 7.57(\mathrm{~s}, 1 \mathrm{H}), 7.34(\mathrm{dd}, J=6.87,8.44 \mathrm{~Hz}, 2 \mathrm{H}), 7.25-7.21(\mathrm{~m}, 1 \mathrm{H})$, $5.66-5.21(\mathrm{~m}, 1 \mathrm{H}), 3.89(\mathrm{~s}, 9 \mathrm{H}), 1.52(\mathrm{~s}, 6 \mathrm{H})$; Exact Mass for $\mathrm{C}_{22} \mathrm{H}_{24} \mathrm{~N}_{2} \mathrm{O}_{4}: 380.1700$; HRMS: $[\mathrm{M}+\mathrm{H}]^{+}: 381.1937$; HPLC1: $\mathrm{t}_{\mathrm{R}} 6.90$ min, purity $98.3 \%$.

(1-Cyclopentyl-4-phenyl-1H-imidazol-2-yl)(3,4,5trimethoxyphenyl)methanone(15f). ${ }^{1} \mathrm{H}$ NMR $(500 \mathrm{MHz}$, Chloroform- $d) \delta 7.90-7.82$ (m, 4H), $7.61(\mathrm{~d}, J=1.7 \mathrm{~Hz}, 1 \mathrm{H}), 7.42(\mathrm{td}, J=7.7,1.7 \mathrm{~Hz}, 2 \mathrm{H}), 7.33-7.28(\mathrm{~m}, 1 \mathrm{H}), 5.88$ -5.32 (m, 1H), 3.98 (t, $J=1.9 \mathrm{~Hz}, 9 \mathrm{H}), 2.64-2.20$ (m, 2H), $2.00-1.77$ (m, 6H); Exact Mass for $\mathrm{C}_{24} \mathrm{H}_{26} \mathrm{~N}_{2} \mathrm{O}_{4}$ : 406.1893; HRMS: [M+H] $]^{+}: 407.2103$; HPLC1: $\mathrm{t}_{\mathrm{R}} 8.07$ min, purity $98.3 \%$.

\section{General Procedure for the Preparation of 15g-h}

Under inert atmosphere, a Schlenk flask was charged with $\mathrm{Cs}_{2} \mathrm{CO}_{3}(260 \mathrm{mg}, 0.8$ $\mathrm{mmol}), \mathrm{CuI}(76 \mathrm{mg}, 0.4 \mathrm{mmol})$, ligand $(0.4 \mathrm{mmol})$, compound 12a (135 mg, $0.4 \mathrm{mmol})$, 2-pyrimidyl bromide (124 mg, $0.8 \mathrm{mmol}$ ) (for 15g) or 2-bromothiophene (130 $\mathrm{mg}, 0.8$ $\mathrm{mmol}$ ) (for $\mathbf{1 5 h}$ ) and DMF (5 mL). The reaction mixture was stirred for $30 \mathrm{~min}$ at room temperature, and then heated to $110^{\circ} \mathrm{C}$ for 2 days. The reaction mixture was monitored by TLC. After the starting material was completely consumed, the reaction was stopped and the mixture was cooled to room temperature. The reaction mixture was directly passed through a plug of silica gel. After being rinsed with ethyl acetate, the combined filtrate was washed with saturated brine. After the organic layer was dried by sodium sulfate, it was concentrated. The residue was purified by column chromatography on silica gel to provide the desired product.

(4-Phenyl-1-(pyridin-2-yl)-1H-imidazol-2-yl)(3,4,5trimethoxyphenyl)methanone (15g). ${ }^{1} \mathrm{H}$ NMR $(500 \mathrm{MHz}$, Chloroform- $d$ ) $\delta 8.59$ (dt, $J=$ $1.70,4.33 \mathrm{~Hz}, 1 \mathrm{H}), 7.91$ (ddt, $J=1.67,3.99,7.42 \mathrm{~Hz}, 3 \mathrm{H}), 7.86(\mathrm{~d}, J=1.52 \mathrm{~Hz}, 2 \mathrm{H})$, $7.82(\mathrm{~d}, J=1.57 \mathrm{~Hz}, 1 \mathrm{H}), 7.48-7.40(\mathrm{~m}, 4 \mathrm{H}), 7.34(\mathrm{td}, J=1.38,7.27 \mathrm{~Hz}, 1 \mathrm{H}), 3.98(\mathrm{~d}, J$ $=1.62 \mathrm{~Hz}, 3 \mathrm{H}), 3.96(\mathrm{~d}, J=1.41 \mathrm{~Hz}, 6 \mathrm{H})$. Exact Mass for $\mathrm{C}_{24} \mathrm{H}_{21} \mathrm{~N}_{3} \mathrm{O}_{4}: 415.1500$; HRMS: $[\mathrm{M}+\mathrm{H}]^{+}:$: 416.1692; HPLC1: $\mathrm{t}_{\mathrm{R}} 4.85$ min purity, $97.9 \%$.

(4-Phenyl-1-(thiophen-2-yl)-1H-imidazol-2-yl)(3,4,5trimethoxyphenyl)methanone (15h). ${ }^{1} \mathrm{H}$ NMR $(500 \mathrm{MHz}$, Chloroform- $d$ ) $\delta 7.87-7.76$ (m, 4H), 7.52 (d, $J=1.84 \mathrm{~Hz}, 1 \mathrm{H}), 7.37$ (td, $J=1.83,7.63,8.06 \mathrm{~Hz}, 2 \mathrm{H}), 7.30-7.23$ (m, 2H), 7.06 (dd, $J=1.95,3.59 \mathrm{~Hz}, 1 \mathrm{H}), 6.97$ (dp, $J=1.70,5.60 \mathrm{~Hz}, 1 \mathrm{H}), 3.89$ (d, $J=1.94$ 
$\mathrm{Hz}, 3 \mathrm{H}), 3.88(\mathrm{~d}, J=1.95 \mathrm{~Hz}, 6 \mathrm{H})$; Exact Mass for $\mathrm{C}_{23} \mathrm{H}_{20} \mathrm{~N}_{2} \mathrm{O}_{4} \mathrm{~S}: 420.1100$; HRMS: $[\mathrm{M}+\mathrm{H}]^{+}: 421.1298$; HPLC1: $\mathrm{t}_{\mathrm{R}} 6.33$ min, purity $98.2 \%$.

\section{General Procedure for the Preparation of 18a-c}

To ammonium acetate $(10 \mathrm{mmol})$ in ethanol $(5 \mathrm{ml})$ and water $(0.3 \mathrm{ml})$ was added phenyl alkyl diones 17(a-c) (1 mmol) in ethanol (5 ml) and 3, 4, 5-trimethoxyphenyl glyoxal hydrate $\mathbf{1 0}(1 \mathrm{mmol})$ in ethanol $(10 \mathrm{ml})$. The mixture was stirred at room temperature for 30-45 min. The reaction was stopped after the consumption of the starting material monitored by TLC. The mixture was then extracted with ethyl acetate. The organic layer was washed with brine, dried over anhydrous sodium sulfate and concentrated to get the crude product. The crude was purified by flash chromatography.

(5-Methyl-4-phenyl-1H-imidazol-2-yl)(3,4,5-trimethoxyphenyl)methanone and (4-methyl-5-phenyl-1H-imidazol-2-yl)(3,4,5-trimethoxyphenyl)methanone (18a). ${ }^{1} \mathrm{H}$ NMR (400 MHz, Chloroform-d) $\delta 10.43$ (s, 0.59H), $10.32(\mathrm{~s}, 1 \mathrm{H}), 8.24(\mathrm{~s}, 2 \mathrm{H}), 8.05$ $(\mathrm{s}, 1 \mathrm{H}), 7.87-7.71(\mathrm{~m}, 3 \mathrm{H}), 7.62-7.38(\mathrm{~m}, 6 \mathrm{H}), 4.02(\mathrm{~s}, 5 \mathrm{H}), 4.01(\mathrm{~s}, 3 \mathrm{H}), 3.99(\mathrm{~s}, 2 \mathrm{H})$, $3.98(\mathrm{~s}, 2 \mathrm{H}), 3.95(\mathrm{~s}, 2 \mathrm{H}), 2.64(\mathrm{~s}, 3 \mathrm{H}), 2.56(\mathrm{~s}, 1 \mathrm{H})$; Exact Mass for $\mathrm{C}_{19} \mathrm{H}_{17} \mathrm{ClN}_{2} \mathrm{O}_{4}$ : 372.0877; HRMS: $[\mathrm{M}+\mathrm{H}]^{+}: 373.0992$; HPLC2: t $6.42 \mathrm{~min}$, purity $95.4 \%$.

(5-Ethyl-4-phenyl-1H-imidazol-2-yl)(3, 4, 5-trimethoxyphenyl)methanone and (4-ethyl-5-phenyl-1H-imidazol-2-yl)(3,4,5-trimethoxyphenyl)methanone (18b). ${ }^{1} \mathrm{H}$ NMR (400 MHz, Chloroform-d) $\delta 10.85(\mathrm{~s}, 1 \mathrm{H}), 8.28(\mathrm{~s}, 2 \mathrm{H}), 8.15(\mathrm{~s}, 1 \mathrm{H}), 7.75$ (m, $1 \mathrm{H}), 7.45-7.30(\mathrm{~m}, 5 \mathrm{H}), 4.00(\mathrm{~m}, 9 \mathrm{H}), 3.05(\mathrm{~m}, 2 \mathrm{H}), 1.40(\mathrm{~m}, 3 \mathrm{H})$; Exact Mass for $\mathrm{C}_{19} \mathrm{H}_{17} \mathrm{ClN}_{2} \mathrm{O}_{4}: 372.0877$; HRMS: [M+H] $]^{+}: 373.0992$; HPLC1: $\mathrm{t}_{\mathrm{R}} 5.37$ min, purity $96.3 \%$.

(4-Phenyl-5-propyl-1H-imidazol-2-yl)(3,4,5-trimethoxyphenyl)methanone and (5-phenyl-4-propyl-1H-imidazol-2-yl)(3,4,5-trimethoxyphenyl)methanone(18c). ${ }^{1} \mathrm{H}$ NMR (400 MHz, Chloroform-d) $\delta 10.52(\mathrm{~s}, 0.52 \mathrm{H}), 10.47(\mathrm{~s}, 1 \mathrm{H}), 8.24(\mathrm{~s}, 2 \mathrm{H}), 8.14$ $(\mathrm{s}, 1 \mathrm{H}), 7.78(\mathrm{~d}, J=7.39 \mathrm{~Hz}, 2 \mathrm{H}), 7.60-7.43(\mathrm{~m}, 5 \mathrm{H}), 7.36(\mathrm{t}, J=7.40,7.40 \mathrm{~Hz}, 1 \mathrm{H})$, $4.01(\mathrm{~s}, 5 \mathrm{H}), 4.00(\mathrm{~s}, 3 \mathrm{H}), 3.99(\mathrm{~s}, 4 \mathrm{H}), 3.00-2.93(\mathrm{t}, \mathrm{J}=7.40,7.40 \mathrm{~Hz}, 2 \mathrm{H}), 2.84(\mathrm{t}, J=$ 7.50, $7.50 \mathrm{~Hz}, 1 \mathrm{H}), 1.94-1.87(\mathrm{~m}, 1 \mathrm{H}), 1.87-1.78(\mathrm{~m}, 2 \mathrm{H}), 1.07(\mathrm{t}, J=7.33,7.33 \mathrm{~Hz}$, $3 \mathrm{H}), 0.98-0.92(\mathrm{t}, \mathrm{J}=7.10,7.10 \mathrm{~Hz}, 1 \mathrm{H})$; Exact Mass for $\mathrm{C}_{19} \mathrm{H}_{17} \mathrm{ClN}_{2} \mathrm{O}_{4}: 372.0877$; HRMS: $[\mathrm{M}+\mathrm{H}]^{+}: 373.0992$; HPLC: $\mathrm{t}_{\mathrm{R}} 12.46 \mathrm{~min}$, purity $96.1 \%$.

\section{Cell Culture and Cytotoxicity Assay}

We examined the anti-proliferative activity of the RABI compounds in four human melanoma cell lines (A375 and WM-164, MDA-MB-435 and MDA-MB435/LCC6MDR1) and four human prostate cancer cell lines (LNCaP, DU 145, PC-3, and PPC-1). All these cell lines were purchased from ATCC (American Type Culture Collection, Manassas, VA). Melanoma cells were cultured in DMEM (Cellgro Mediatech

Inc., Herndon, VA), and prostate cancer cells were cultured in RPMI 1640 (Cellgro 
Mediatech, Inc., Herndon, VA) supplemented with 10\% fetal bovine serum (Cellgro Mediatech). Cultures were maintained at $37^{\circ} \mathrm{C}$ in a humidified atmosphere containing $5 \%$ $\mathrm{CO}_{2}$. Then 1000-5000 cells were plated into each well of 96-well plates depending on growth rate and exposed to different concentrations of a test compound for $48 \mathrm{~h}$ (fast growing melanoma cells) or $96 \mathrm{~h}$ (slow growing prostate cancer cells) in three-five replicates. Cell numbers at the end of the drug treatment were measured by the sulforhodamine B (SRB) assay. Briefly, the cells were fixed with 10\% trichloroacetic acid and stained with $0.4 \% \mathrm{SRB}$, and the absorbances at $540 \mathrm{~nm}$ were measured using a plate reader (DYNEX Technologies, Chantilly VA). Percentages of cell survival versus drug concentrations were plotted, and the $\mathrm{IC}_{50}$ (concentration that inhibited cell growth by $50 \%$ of untreated control) values were obtained by nonlinear regression analysis using GraphPad Prism (GraphPad Software, San Diego, CA).

\section{Cell Cycle Analysis}

Cell cycle distribution was determined by propidium iodide (PI) staining. Treated cells were washed with PBS and fixed with $70 \%$ ice-cold ethanol overnight. Fixed cells were then stained with $20 \mu \mathrm{g} / \mathrm{mL}$ of PI in the presence of RNase A $(300 \mu \mathrm{g} / \mathrm{mL})$ at $37^{\circ} \mathrm{C}$. for $30 \mathrm{~min}$. Cell cycle distribution was analyzed by fluorescence-activated cell sorting (FACS) analysis core services at the University of Tennessee Health Science Center, TN.

\section{Tubulin Polymerization Assay}

The drug effects on tubulin polymerization were determined using a fluorescenceenhanced tubulin polymerization assay kit (Cytoskeleton, cat\# BK011P). Porcine brain tubulin $(0.56 \mathrm{mg},>99 \%$ pure) was mixed with test compounds and incubated in $50 \mu \mathrm{L}$ of tubulin buffer ( $80 \mathrm{mM}$ PIPES, $2.0 \mathrm{mM} \mathrm{MgCl}_{2}, 0.5 \mathrm{mM}$ EGTA, $1 \mathrm{mM} \mathrm{GTP}$, and $10 \mu \mathrm{M}$ fluorescent reporter) with $10 \%$ glycerol at $37{ }^{\circ} \mathrm{C}$. The assay was monitored every $1 \mathrm{~min}$ for 40 min by the SYNERGY 4 Microplate Reader (Bio-Tek Instruments, Winooski, VT) at the excitation wavelength 340 to $360 \mathrm{~nm}$ and emission 410 to 460 in kinetic mode. Polymerization is measured by fluorescence enhancement.

\section{Competitive Mass Spectrometry Binding Assay}

The binding site of $\mathbf{1 2 a}$ and $\mathbf{1 5 g}$ in tubulin protein was evaluated by the competitive mass spectrometry binding assay as previously described [130]. Briefly, colchicine $(1.2 \mu \mathrm{M})$ was incubated with bovine brain tubulin $(1.0 \mathrm{mg} / \mathrm{mL})$ in the incubation buffer [ $80 \mathrm{mM}$ piperazine-N,N'-bis(2-ethanesulfonic acid) (PIPES), $2.0 \mathrm{mM}$ magnesium chloride $\left(\mathrm{MgCl}_{2}\right), 0.5 \mathrm{mM}$ ethylene glycol tetra acetic acid (EGTA), pH 6.9] at $37^{\circ} \mathrm{C}$ for $1 \mathrm{~h}$. Different concentrations $(0.5-10 \mu \mathrm{M})$ of podophyllotoxin (positive control), 12a, 15g, and vinblastine (negative control) were used to compete with the binding of colchicine to tubulin. After $1 \mathrm{~h}$ incubation, the amount of unbound colchicine was obtained from the filtrate by ultrafiltration (Amicon Ultra-0.5 Centrifugal Filter Unit 
with Ultracel-30 membrane, Millipore, Billerica, MA). The amount of unbound colchicine in the presence or absence of any competitor was measured. Each experiment was performed in triplicate.

\section{Molecular Modeling}

All molecular modeling studies were performed with Schrodinger Molecular Modeling Suite 2011 (Schrodinger LLC, New York, NY) running on a Dell Linux workstation. We selected tubulin complex with TN16 (PDB code: 3HKD) and tubulin complex with colchicine (PDB code: 1SA0) as our modeling system. RABIs were built and prepared using the Ligprep module, and they were docked into the TN16 site and colchicine site by the Glide module in the Schrodinger Suite. The best docking complexes were subject to restricted molecular dynamics to release any strains by using the Macromodel module with OPLS-2005 force field. The ligand and its surrounding residues within $15 \AA$ were allowed to move freely while the outer atoms are frozen.

\section{Summary}

Novel RABI analogs were designed and synthesized based on rational structural modification of previous ABI analogs. SAR (Figure 3-11) was investigated by introducing different substituents into the A, B and C rings. Several RABIs showed excellent anti-proliferative activity which was comparable to existing tubulin-targeting agents such as paclitaxel, colchicine, or vinblastine but could overcome Pgp-mediated multiple drug resistance effectively. Among them compound 12a was the most potent one with $\mathrm{IC}_{50}$ in the low nano-molar range, while compound $\mathbf{1 5 g}$ provided very interesting insights in future optimization of these analogs. Mechanism of action studies confirmed that RABI analogs maintain their ability to inhibit tubulin polymerization at colchicine binding site and arrest cells in G2/M phase. These results strongly suggest that novel RABI analogs can be further developed as a promising antitumor agent for the more efficacious treatment of advanced cancers. 
B ring, substitutions on 5- position ruin activity. Substitutions on N1- position are well tolerated. Bulky groups on N1- position are not good for activity.

Heterocyclic ring such as pyridine on N1-position is good for activity.

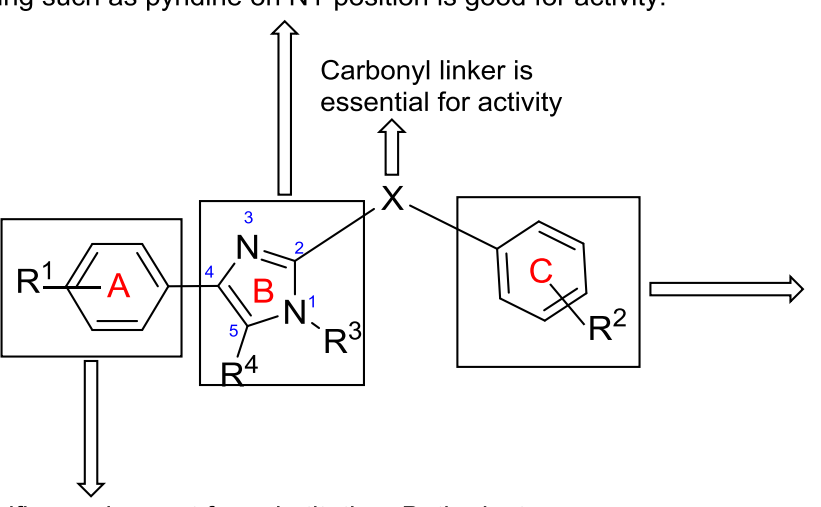

C ring, 3, 4, 5-trimethoxy substituents are essential for activity

A ring, no specific requirement for substitution. Both electron donating and electron withdrawing groups decrease activity compared with non-substituted $A$ ring.

Figure 3-11. SAR of RABI analogs 


\section{CHAPTER 4. OVERVIEW OF SURVIVIN AND SURVIVIN INHIBITORS*}

\section{Introduction}

Survivin, an anti-apoptotic protein, was discovered by Grazia Ambrosini and Dario C. Altieri in 1997 [131]. Survivin is a member of the inhibitor of apoptosis proteins (IAP) family of which there are eight members: NAIP (NLR family, apoptosis inhibitory protein), c-IAP1, c-IAP2, XIAP (X-linked inhibitor of apoptosis), livin, ILP-2, Apollon, and survivin (Figure 4-1) [132-135]. Each member contains at least a single baculoviral IAP repeat (BIR) domain at the N-terminus region [132]. Survivin is encoded by baculoviral inhibitor of apoptosis repeat-containing 5 (BIRC5), so it is also called BIRC5. Compared with other IAPs that contain multiple domains, survivin is structurally unique because it contains only one single BIR domain. It is the smallest member of the IAP family, has a molecule weight of $16.5 \mathrm{kDa}$, and contains 142 amino acid residues [136137]. Unlike other IAPs that are expressed in both cancerous and normal cells, survivin is expressed only in the vast majority of neoplasms but not in most normal differentiated tissues $[49,138-140]$. Survivin also contributes to tumor formation and maintenance because of its functional properties $[48,141]$. Therefore, targeting survivin represents a very attractive strategy in cancer drug discovery. However, due to the requirement of efficiently disrupting protein-protein interactions which typically have large interface areas, the development of small-molecule survivin inhibitors have been very challenging. Thus the number of currently available survivin inhibitors is small. In addition, most of these inhibitors target other biomolecules and ultimately reduce the level of survivin, rather than directly interact with survivin protein itself. Despite these challenges and limitations, developing new potent and selective small-molecule survivin inhibitors will be important in both basic science and translational research to develop them into potentially effective, broad-spectrum therapeutic agents. In this chapter, we first describe the functions of survivin, its role in cancer progression and potential therapy. Then we focus on recently developed small-molecule survivin inhibitors. Challenges for developing survivin inhibitors and future direction will also be covered.

\section{Functions of Survivin}

The main established functions of survivin are the regulation of cell mitosis and the inhibition of apoptosis as illustrated in Figure 4-2. Survivin plays an essential role in cell mitosis [142], during which survivin regulates cell division through a multiprotein complex called chromosomal passenger complex (CPC) as shown in Figure 4-2. In this complex, survivin is associated with other regulators of cytokinesis including aurora kinase B, INCENP, and borealin [143-145]. CPC is essential for accurate

*Reprinted with permission. Xiao, M.; Li, W. Recent Advances on Small-Molecule Survivin Inhibitors. Curr Med Chem, 2015, 22(9), 1136-1146. 


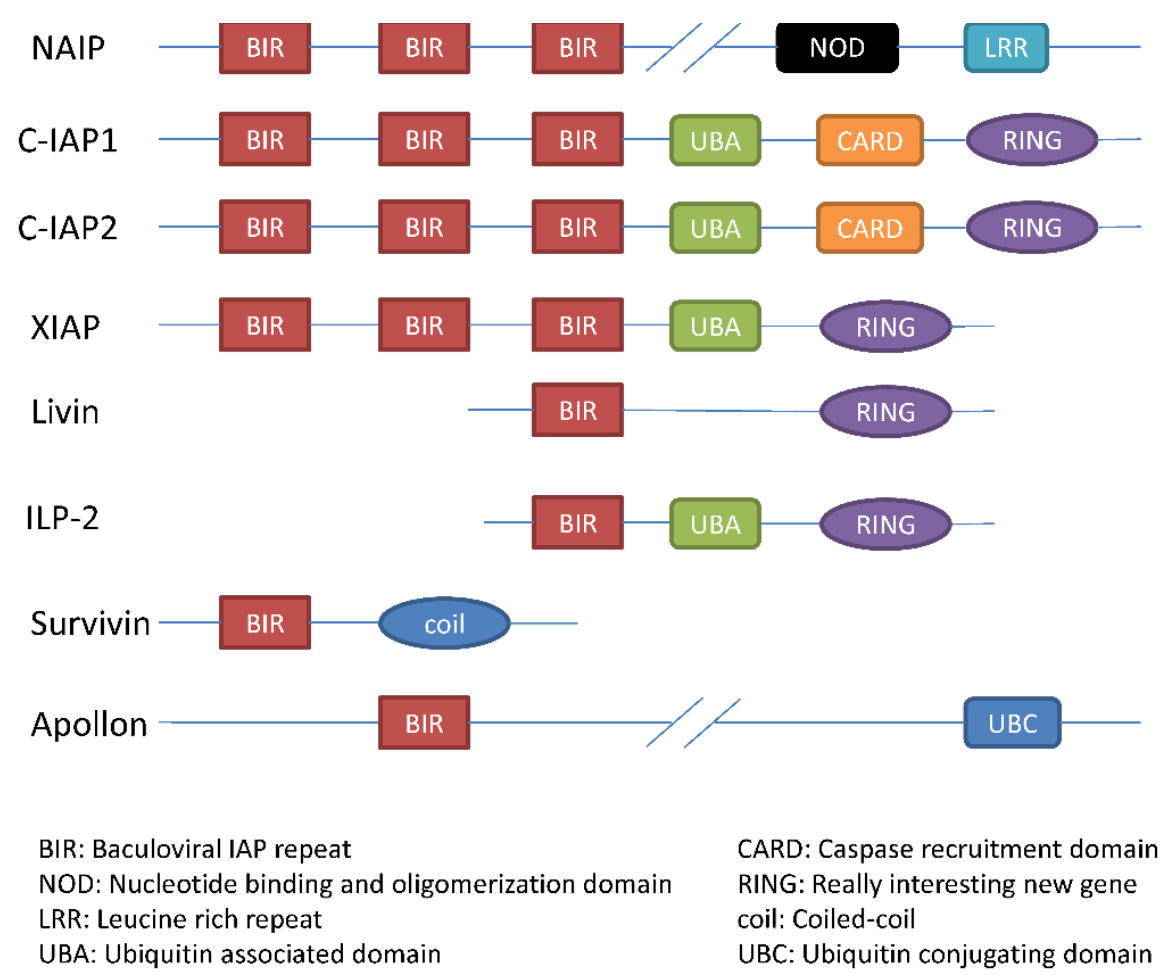

Figure 4-1. Schematic diagram of human IAPs 


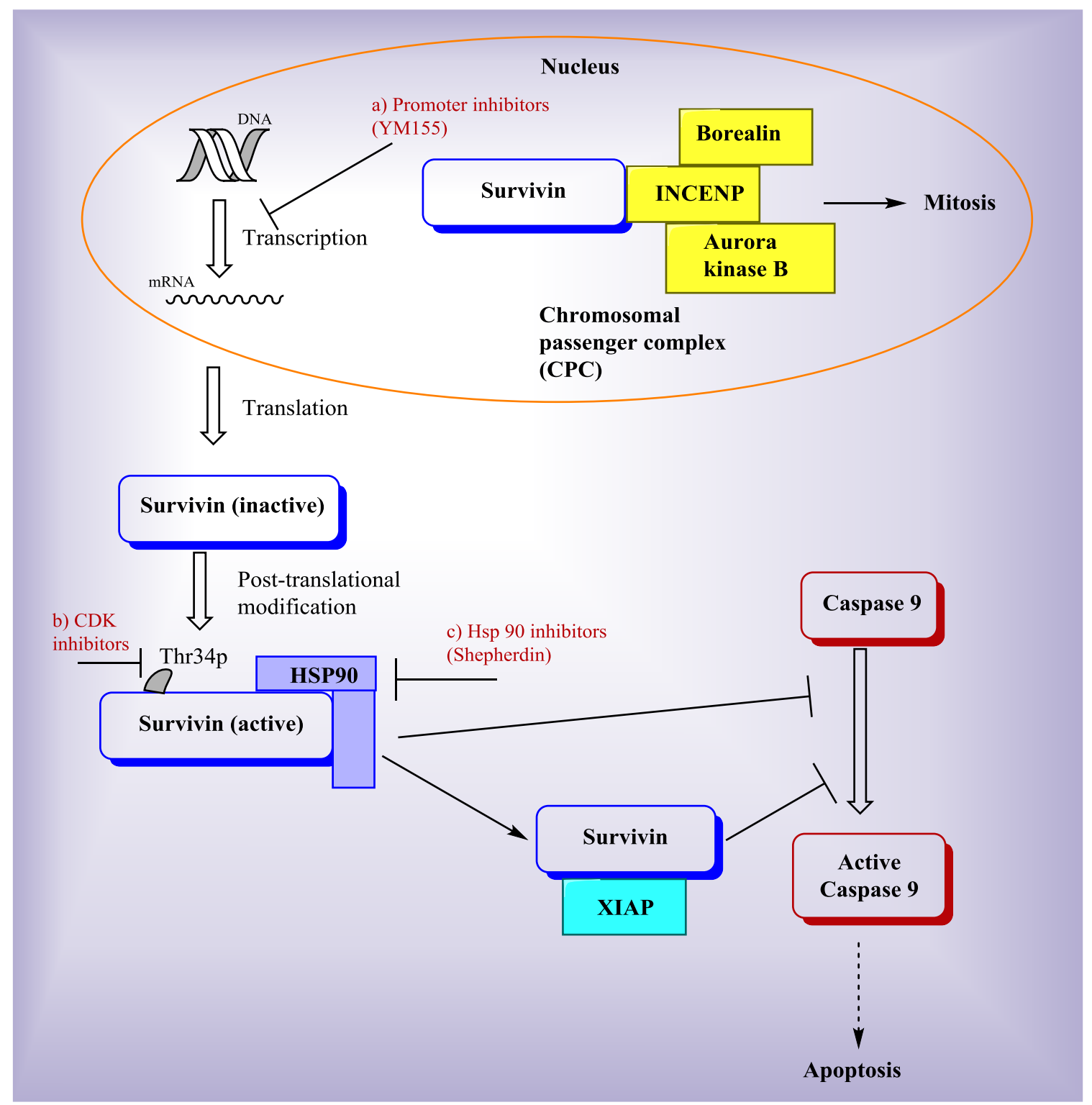

Figure 4-2. Functions of survivin and targets of survivin inhibitors 
chromosome segregation and cytokinesis. Survivin and its molecular partners in the CPC fundamentally control genetic stability of cells [146]. Survivin has also been shown to be associated with regulating microtubule dynamics [147-149]. Survivin stabilizes the microtubules, thereby contributing to the formation of the bipolar spindle [149]. Similar to other members in the IAP family, one main function of survivin is inhibition of apoptosis as shown in Figure 4-2 [150-153]. Although it has been confirmed that survivin inhibits apoptosis, the exact mechanism of inhibition is still under debate over two major theories. One theory is that survivin directly binds to caspases and subsequently inhibits apoptosis. The interaction between survivin and the effector caspases has been reported by several groups [150-151]. The second theory is that survivin inhibits caspase activity through indirect mechanisms to inhibit apoptosis [30, 154-155]. One example proposes that survivin binds to XIAP to form a complex that inhibits the activation of caspase-9 $[30,154]$. In another example, a survivin-hepatitis B $\mathrm{X}$-interacting protein (HBXIP) complex binds to procaspase-9 to suppress apoptosis [155].

\section{Roles of Survivin in Cancer}

Both the functions of promoting cell proliferation and inhibiting apoptosis contribute to the formation and maintenance of tumors. Because the expression level of survivin in normal cells and malignant cells is largely different, survivin can be used as a tumor biomarker [156-158]. Many studies have confirmed that survivin is overexpressed in a variety of cancers (e.g., lung, breast, pancreatic, and melanoma) [159-162]. Survivin has also been shown to be responsible for multiple types of drug resistance [163-166].

For example, it has been reported that taxol-treated HeLa cells show an increased level of survivin expression, which provides a cell survival pathway to counteract taxol-induced apoptosis [147]. Overexpression of survivin has also been reported in prostate cancer and thyroid cancer cells that are resistant to cisplatin treatment [167-168]. Because survivin is crucial in the process of carcinogenesis, knockout of survivin impedes the development of cancer. A recent study showed that loss of survivin in the prostate epithelium inhibited the progression of prostatic premalignant lesions to adenocarcinoma in the Pten-deletion mouse model [169]. The study confirms the role of survivin in cancer progression.

\section{Targeting Survivin for Cancer Treatment}

Survivin has been proposed as an attractive target for selective cancer treatment because of its unique attributes [170]. The following features are some reasons that targeting survivin is a good strategy. First, the expression of survivin is typically very high in tumor cells but very low or even undetectable in normal adult tissues [49] . This feature is highly significant, because it provides selectivity, a major problem for current cancer drug development. Second, the functions of survivin contribute to the formation and maintenance of tumors [171], so targeting survivin will be very effective for treating cancer. Furthermore, survivin has been shown to be associated with resistance to multiple types of cancer therapies [172-174]. Targeting survivin can help overcome the multidrug 
resistance which is the one of the major reasons many therapeutic agents fail in clinic. However, there are also significant challenges associated with using survivin as a drug target. Small-molecule survivin inhibitors have to disrupt the protein-protein interaction between survivin and other proteins, which could be difficult because most interfaces in protein-protein interactions (PPIs) are not well suitable for effective small molecule binding [175]. Despite the difficulties for small molecules to disrupt protein-protein interactions, there are some successful PPI inhibitors [176], including tirofiban (targeting the integrins) and maraviroc (targeting CCR5-gp120 interactions) which are already on the market [177-178]. Those successes are probably attributed to the fact that most PPIs have "hot spots" which are small parts of the interface that are essential for high-affinity binding [179]. Small-molecule PPI inhibitors can either interact with those hot spots or bind to allosteric sites to cause conformational change that will prevent protein-ligand binding, which will result to the desired disruption of protein-protein interactions. In the case of developing small-molecule survivin inhibitors, the Ala-Val-Pro-Ile (AVPI) peptide binding region has been proposed as a hot spot for small molecule inhibition [180-181]. Therefore, targeting survivin is tractable for cancer treatment in spite of the challenges.

Many survivin inhibitors have been reported in the literature. These survivin inhibitors are mainly composed of six categories: antisense oligonucleotides, dominantnegative mutant, ribozymes, small interfering RNAs, cancer vaccine, and small-molecule inhibitors. Several reviews have been published covering the six categories of survivin inhibitors in general [136, 182-183], but no review specifically focuses on smallmolecule survivin inhibitors, which is the focus of this review. As we discussed earlier, most existing survivin inhibitors do not directly bind and interact with survivin protein itself, instead, they usually target other biomolecules and ultimately reduce survivin expression. Figure 4-2 shows three representative examples. The first example is YM155 which inhibits survivin by inhibiting survivin gene promoter on the transcriptional level [184]. The second example is represented by cyclin-dependent kinase (CDK) inhibitors. For example, the CDK inhibitor flavopiridol inhibits survivin phosphorylation on Thr34 which leads to progressive loss of survivin expression [185]. The last example shown in Figure 4-2 for indirect targeting survivin are Hsp90 inhibitors which disrupt the interaction between survivin and Hsp90, destabilize survivin protein and ultimately lead to survivin degradation. In the following sections, we will discuss each reported smallmolecule survivin inhibitor (arranged alphabetically) in detail (Figure 4-3).

\title{
Existing Small-Molecule Survivin Inhibitors
}

\begin{abstract}
AICAR (1)
The nonpeptidic, small-molecule 5-aminoimidazole-4-carboxamide-1-b-Dribofuranoside (AICAR) as a structurally novel inhibitor of Hsp90 was developed through a combined structure- and dynamics-based computational design [186]. AICAR mimics the binding and functional properties of the peptidic antagonist of the survivin-
\end{abstract}




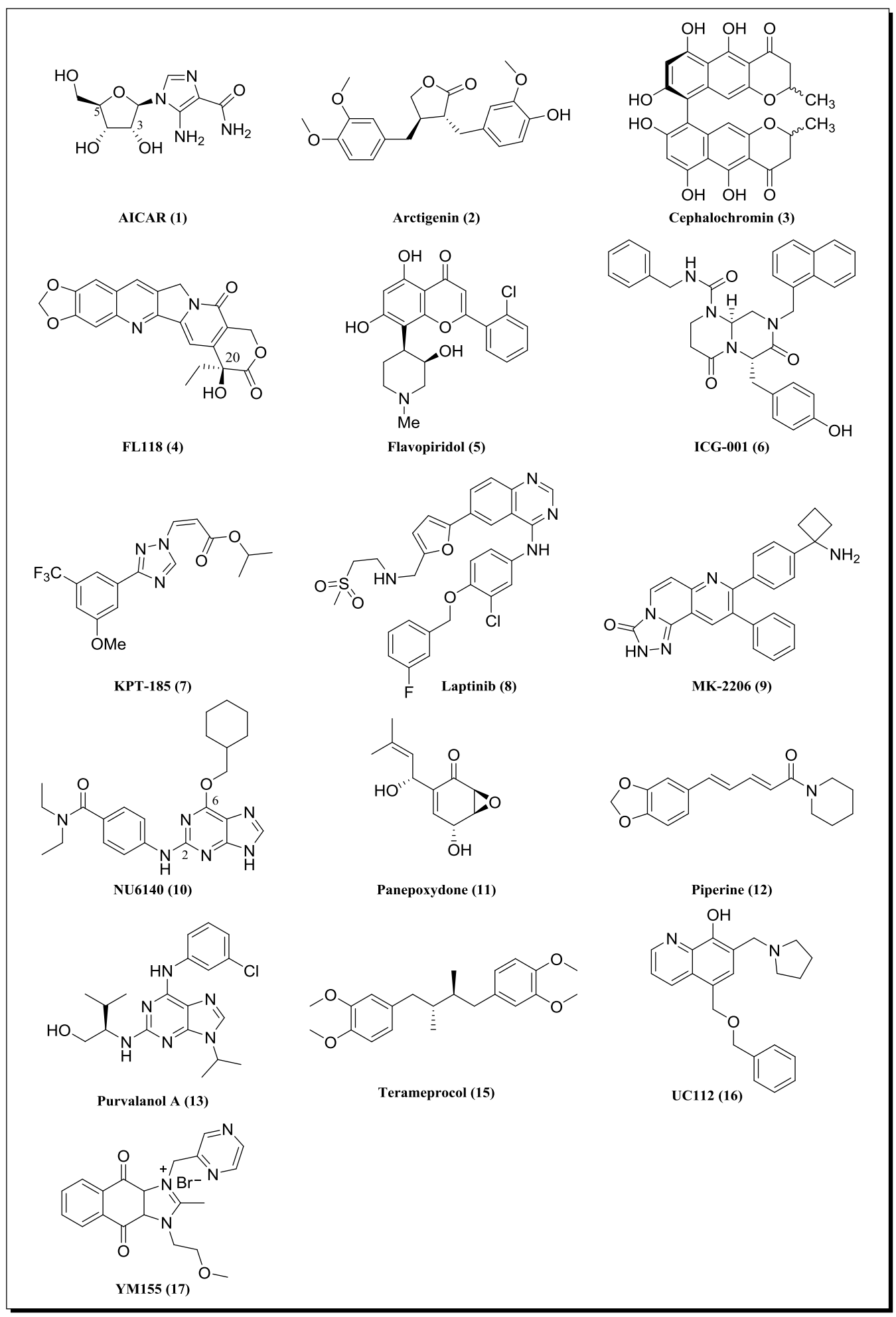

Figure 4-3. Chemical structures of recently developed small-molecule survivin inhibitors 
Hsp90 complex, shepherdin. The AICAR/Hsp90 interaction studies revealed that AICAR is involved in direct contacts with Asp93 of Hsp90 through the two hydroxyl groups on position 3 and 5 of the ribose ring, suggesting that replacement of these residues with other polar groups may strengthen the interaction. This is also true for the polar substituents on the imidazole ring. AICAR has been shown to exhibit excellent antiproliferative activities in multiple cancer cell lines including DU145, JR8 and Hela cells. While AICAR is very potent in inhibiting the growth of tumor cells, it does not affect the proliferation of normal human fibroblasts. AICAR exerts its anticancer activities by inhibiting the chaperone function with destabilization of multiple Hsp90 client proteins, including survivin [186].

\section{Arctigenin (2)}

Arctigenin, a ligand isolated from the seeds of Arctium lappa, shows antiproliferative activities against a series of cancers [187-188]. A study illustrates the mechanism of its anticancer effect [188]. The results showed that arctigenin executed its antitumor effect by inhibiting STAT3 phosphorylation and survivin expression. The level of survivin was significantly reduced in arctigenin-treated ovarian cancer cells. Arctigenin has also been shown to sensitize tumor cells to cisplatin treatment by inhibiting survivin [187].

\section{Cephalochromin (3)}

Cephalochromin, a compound isolated from the fermented broth of Cosmospora vilior YMJ89051501 [189], is used as an antibacterial. It has been reported that cephalochromin can inhibit cell growth and induce apoptosis in human lung cancer cells with an $\mathrm{IC}_{50}$ value of $2.8 \mu \mathrm{M}$ [189]. Cephalochromin was found to exert its antitumor effect by downregulating several anti-apoptotic proteins, including survivin. The expression level of survivin was significantly reduced in cephalochromin-treated A549 lung cancer cells compared with untreated cells. Due to the survivin suppression effect, caspases- $8,-9$, and -3 are activated, which is responsible for the induced apoptosis. The anti-proliferative effect of cephalochromin reveals the therapeutical potential of this antibacterial agent in treating cancer.

\section{FL118 (4)}

FL118 was first reported by Ling et al. in 2012 [190]. FL118 was identified through high throughput screening of compound libraries following in vitro and in vivo analysis. FL118 can inhibit cancer cell growth in a concentration of less than $1 \mathrm{nM}$. It has shown excellent antitumor activity in a series of cancer cell lines including HCT116 colon cancer cells, A549 lung cancer cells, MCF7 breast cancer cells, and PC-3 prostate cancer cells. Its antitumor activity results from inhibiting survivin promoter activity and survivin gene expression. [190] The superior anticancer activity of FL118 largely 
depends on its steric configuration. FL118 which has an $R$-configuration has much better activity than its analog FL113 with an $S$-configuration. In addition, the free hydroxyl group on position 20 of FL118 is essential for activity. Esterification of the hydroxyl group on position 20 resulted in almost complete loss of activity. The study also demonstrated that FL118 can inhibit expression of other cancer-associated IAPs such as Mcl-1, XIAP, and cIAP2, further enhancing its anticancer activity. The in vivo studies indicated that FL118 has excellent antitumor efficacy without significant toxicity [190]. The antitumor activity of FL118 highly depends on its primary structure and steric configuration [191]. The superior efficacy and selectivity hold significant promise for the further clinical development of FL188 and its core structure-derived analogs.

\section{Flavopiridol (5)}

Flavopiridol is a broad spectrum, cyclin-dependent kinase (CDK) inhibitor. In the study by Nathan et al., flavopiridol caused progressive loss of survivin expression by inhibiting survivin phosphorylation on Thr34 when incubated with HeLa cells [185]; Thr34 phosphorylation of survivin is a critical requirement for survivin function [192]. Sequential treatment with flavopiridol and other anticancer agents enhanced anticancer activity both in breast carcinoma MCF-7 cells and SCID/bg mice bearing MCF-7 xenograft tumors [185]. A recent study showed that flavopiridol inhibited human uterine leiomyoma growth both in vitro and in a xenograft model [193]. Flavopiridol is now in Phase II clinical trial [194-195]. In one phase II clinical trial of flavopiridol, the combination of flavopiridol and cisplatin treatment showed clinical activity in platin resistant and sensitive ovarian/primary peritoneal cancers [195].

\section{ICG-001 (6)}

ICG-001 is a small-molecule inhibitor of $\beta$-catenin/T cell factor (TCF)-mediated transcription [196]. It has been shown that the survivin gene is mediated by $\mathrm{TCF} / \beta-$ catenin. The treatment of SW480 and HCT116 colon cancer cells with ICG-001clearly showed the inhibition of survivin gene transcription. The survivin inhibition effect was also observed in the SW620 xenograft tumors in the ICG-001-treated group. The inhibition of survivin expression results in induction of apoptosis, which causes tumor growth inhibition. Because survivin is up-regulated in most cancer cells but not in normal tissues, ICG-001 increases caspase activity in colon carcinoma cell lines (SW480 or HCT116) but not in normal colonic epithelial cells [196]. The specificity and strong potency of ICG-001 promise it to be a new anticancer therapeutic agent.

\section{KPT-185 (7)}

KPT-185, a selective inhibitor of nuclear export, has been shown to be effective in several cancers including pancreatic cancer, acute myeloid leukemia, mantle cell lymphoma, and nonsmall cell lung cancer (NSCLC) [197-200]. KPT-185 can 
significantly induce growth inhibition and apoptosis of tumor cells. A recent study showed that the survivin level is downregulated in KPT-185-treated NSCLC cell lines. The survivin level was also suppressed in an NSCLC H1975 xenograft model when treated with KPT-185 [200]. The survivin inhibition effect of KPT-185 contributes to its antitumor efficacy. Although KPT-185 has strong cytotoxicity, it is not suitable for in vivo use due to poor PK properties, while its analog KPT-330 which attaches a 2pyrazinyl hydrazinyl group to the carbonyl group and replace the methoxy substitution on the phenyl ring with a trifluoromethyl group compared with the structure of KPT-185, has comparable potency as KPT-185 and optimal PK properties [201].

\section{Lapatinib (8)}

Lapatinib, a potent small-molecule inhibitor of ErbB1 and ErbB2 tyrosine kinases, has been shown to markedly suppress survivin expression and subsequently induce apoptosis when treated in ErbB2-overexpressing breast cancer cell lines, such as BT 474 [202]. The inhibition of survivin by lapatinib is primarily posttranslational through the promoted ubiquitin-proteasome degradation of the survivin protein. The observation that the protein levels of His-tagged surviving, which are under the transcriptional control of a heterologous promoter and endogenous survivin are equally downregulated in response to lapatinib provides evidence for a posttranslational mechanism by which lapatinib regulates survivin. Lapatinib causes synergistic effects when used with other cytotoxic agents such as sorafenib [203]. Lapatinib is now in Phase 3 clinical trial [204-205].

\section{MK-2206 (9)}

MK-2206, a novel allosteric inhibitor of Akt [206-207], has strong anticancer efficacy in a series of cancer cells [206-207]. It has been show that Akt phosphorylation is associated with the formation of survivin/XIAP complex. Deactivating Akt phosphorylation can lead to downregulation of survivin [208]. As an Akt inhibitor, MK2206 suppresses survivin. In a study, the level of survivin was reduced both in GEO cancer cells and GEO cell xenograft model when treated with MK-2206, which led to increased cancer cell death via apoptosis [209]. MK-2206 is now actively evaluated as a new anticancer agent and is now in Phase II clinical trial.

\section{NU6140 (10)}

NU6140, (4-(6-cyclohexylmethoxy-9Hpurin-2-ylamino)-N, N-diethyl-benzamide) is a novel CDK inhibitor developed by Davies et al. in 2002 through structure-based design [210]. Structure-activity relationships for this compound indicate that a cyclic hydrophobic substituent at $\mathrm{O}^{6}$-poisiton such as cyclohexylmethyl is optimal and the extended groups at $\mathrm{N}^{2}$-position increased potency and selectivity. It has been shown that CDK1-mediated phosphorylation of survivin on Thr34 is essential for the cytoprotective 
function of survivin [192]. As a CDK inhibitor, NU6140 induced a concentrationdependent decrease in the level of survivin protein when treated in HeLa Cells. In addition, the level of the active, Thr34-phosphorylated form of survivin was reduced in a concentration-dependent manner after HeLa cells were treated with NU6140 [211]. Because the CDK inhibitor NU6140 can inhibit the expression and phosphorylation of survivin, a combination treatment of taxol and NU6140 in HeLa cells causes a synergistic effect on tumor growth inhibition. [211]

\section{Panepoxydone (11)}

Panepoxydone, a secondary metabolite isolated from an edible mushroom, has long been known for its antibacterial effect. Studies have shown that panepoxydone interferes with NF-kB, which can lead to tumor inhibition [212-213]. Panepoxydone caused significant growth inhibition in MCF-7 and TNBC cell lines MDA-MB-231, MDA-MB-468, and MDA-MB-453 [213]. The induction of apoptosis is one main factor contributing to tumor cell growth inhibition. Mechanism of action studies showed that the survivin level in the panepoxydone-treated cells was reduced, which was responsible for inducing apoptosis. The strong antitumor effect of panepoxydone promises its further development.

\section{Piperine (12)}

Piperine, an alkaloid from black pepper, inhibited the growth of several colon cancer cell lines [214]. The mechanism of action studies showed that the survivin protein levels in piperine-treated HT-29 colon carcinoma cell were reduced compared with untreated cells. The survivin inhibition effect of piperine may account for the inhibition of apoptosis and cell growth observed in piperine-treated cancer cells. Piperine can also sensitize cancer cells to other chemotherapeutical agents due to its survivin inhibition effect [215-216].

\section{Purvalanol A (13)}

Purvalanol A is p34 ${ }^{\text {cdc2 }}$-specific CDK inhibitor. Studies have shown that elevated p34 ${ }^{\mathrm{cdc} 2}$ kinase activity can lead to increased survivin expression [147]. Purvalanol A as a p34 ${ }^{\text {cdc2 }}$-specific inhibitor not only inhibit Cdc2 activity, but also suppress survivin expression [217]. Purvalanol A can inhibit the mitotic phosphorylation of survivin on Thr34, which causes protein destruction of survivin and blockage of its function. The hyperphosphorylation of survivin on Thr34 has been found to be associated with the drug resistance of taxol in tumor cells [218]. Co-administration of taxol with purvalanol A suppressed the hyperactivity of survivin imposed by taxol, which helped overcome the taxol drug resistance [147]. Purvalanol A can also inhibit ABCB1 transporter and cause synergistic effects when used in combination with other anticancer drugs that are ABCB1 substrates [219]. 


\section{Shepherdin (14)}

Shepherdin, a novel antagonist of the survivin-Hsp90 complex, was discovered by Janet et al. in 2005 [220]. Shepherdin is actually the survivin sequence K79-L87 (KHSSGCAFL). It was named shepherdin because it binds to the "shepherding" chaperone Hsp90. Binding assay results revealed that shepherdin was bound to the $\mathrm{N}$ domain of Hsp90, while no specific binding of shepherdin to the C domain of Hsp90 was observed. Shepherdin disrupts the interaction between survivin and Hsp90 through the ATP binding pocket of Hsp90. Shepherdin can also destabilize survivin and several other client proteins of Hsp90, such as Akt, CDK6, and telomerase, which cause cancer cell death via apoptotic and nonapoptotic mechanisms. Shepherdin has very good selectivity, because it does not affect normal cells while maintaining excellent antitumor activity [220]. Shepherdin can sensitize tumor cells to different cytotoxic drugs because of its survivin suppression effect. For example, shepherdin sensitized imatinib mesylateresistant chronic myelogenous leukemia cells to hydroxyurea or doxorubicin in a recent study [215]. Current clinical development is through the Rapid Access to Intervention Development (RAID) program at the National Cancer Institute.

\section{Terameprocol (15)}

Terameprocol, meso-tetra-O-methyl nordihydroguaiaretic acid, also known as M4N, has been reported to inhibit HIV transactivation [221]. Terameprocol was made based on 3'-O-methylnordihydroguaiaretic acid, which was isolated from larrea tridentata. Subsequent studies showed that terameprocol as a transcription inhibitor can inhibit tumor growth by inhibiting expression of Cdc2 and survivin [222-223]. In the study of Chang et al. [223], terameprocol-treated C3 cells showed downregulation of $\mathrm{Cdc} 2$ and survivin expression. The observation that $\mathrm{C} 3$ cells transfected with $\mathrm{Cdc} 2$ and survivin were resistant to terameprocol-induced cell arrest or death confirmed the tumor growth inhibition mechanisms of terameprocol. Terameprocol significantly enhanced the sensitivity of nonsmall-cell lung carcinoma cells to radiation therapy in the study of Sun et al [224]. Now terameprocol is in Phase I clinical trial [225-226]. The clinical results have shown that this agent has an excellent safety profile in cervical intraepithelial neoplasia, making it a promising candidate for anticancer treatment [225].

\section{UC-112 (16)}

UC-112 was recently reported by our group as a potent and selective survivin inhibitor [180]. It was identified through a similarity-based virtual screening in which the three-dimensional shape of the AVPI peptide in the survivin-Smac crystal complex was used as the template for searching hit structures, followed by biological validation. UC112 showed broad anti-proliferative activities as indicated by NCI-60 cell line screening and preliminary in vivo studies in an A375 melanoma tumor model. Interestingly, preliminary studies showed that UC-112 selectively downregulated survivin level with minimal effects on other members of IAPs. [180] This compound may represent a unique 
scaffold for the development of new selective survivin inhibitors. Further modifications of this compound are currently being carried out.

\section{YM155 (17)}

YM155, 1-(2-Methoxyethyl)-2-methyl-4,9-dioxo-3-(pyrazin-2-ylmethyl)-4,9dihydro-1H-naphtho[2,3-d]imidazolium bromide, a small-molecule survivin inhibitor, was first discovered by Astellas Pharma in 2007 [184]. It suppresses survivin gene promoter in PC-3 and PPC-1 human HRPC cell lines at $10 \mathrm{nmol} / \mathrm{L}$ in cell based proliferation assay. It also shows very good selectivity of survivin over other IAPs. In the study of Nakahara et al., YM155 suppressed survivin expression but had little effect on the expression of other IAPs even up to $100 \mathrm{nmol} / \mathrm{L}$. YM155 induced tumor regression in PC-3 xenografted tumor model [184]. YM155 can help overcome drug resistance in tumors when used with other chemotherapeutical agents. For example, YM155 reversed rapamycin resistance in rapamycin-resistant renal cell carcinoma [227], and the combination of YM155 and cisplatin induced apoptosis and tumor regression in cisplatinresistant ovarian cancer cells [228]. YM155 is now in Phase II clinical trial [229-230]. Recent studies have shown that YM155 is a substrate of the Pgp [231], suggesting that it may suffer from multidrug resistance in its later clinical use.

\section{Challenges for Development of Survivin Inhibitors}

Although survivin is a very promising target for cancer treatment and many studies have been carried out to develop survivin inhibitors, the pool of existing survivin inhibitors is still relatively small. Several problems limit the development of effective survivin inhibitors. Unlike an enzyme or a receptor molecule located on the cell surface, survivin is not a traditional target. Survivin is a nodal protein involved in multiple processes of cancer cell proliferation, including mitosis, apoptosis and autophagy. It also interferes with various molecules such as Hsp90, Borealin, INCENP, aurora B kinase and capases. Therefore, it is a significant challenge and is very critical to unambiguously confirm that the drug action is resulted from survivin-specific inhibition. Because of such challenges, currently it is difficult to evaluate the effectiveness and target specificity of survivin inhibitors accurately via high throughput assays. The lack of suitable assays to identify survivin inhibition by high throughput screenings is one main factor to impede the development of potent and selective survivin inhibitors. Moreover, recent studies have shown that survivin exists in certain types of normal cells, mainly hematopoietic and immune systems [232]. Potential side effects will be a concern for those normal cells. Although clinical studies of survivin inhibitors to date have shown that targeting survivin does not cause toxic side effects, the prolonged use of survivin inhibitors should still be carefully studied because of the emerging role of survivin in regulating functions in normal cells. 


\section{Conclusion Remarks and Future Directions}

The results from studies in the past fifteen years provide convincing evidence that survivin is a promising target for cancer therapy treatment. As discussed in this review, survivin distinguishes itself by its unique functional properties, preferentially expressed in most human cancer cells, and involves in a myriad of cellular functions. Survivin contributes to tumor formation and progression which makes survivin a promising cancer drug target. Although there are significant challenges in developing effective survivin inhibitors and the number of small-molecule survivin inhibitors is still very limited, several potent survivin inhibitors have entered clinical trials, including flavopiridol, lapatinib, terameprocol, MK-2206 and YM155. Most of them have shown positive initial results, suggesting it is feasible to develop small-molecule inhibitors as efficacious anticancer drugs. Lapatinib is the most promising one among them, which is now in phase 3 trials. Currently the lack of a survivin-specific assay is limiting the development of novel small-molecule survivin inhibitors. Developing optimized assays will greatly accelerate research in this field. In addition, further investigations of differential mechanisms regulating survivin expression and functions in tumor and normal cells will be critical to develop novel strategies for selective survivin inhibition by small molecules. Finally, it is well recognized that the efficacy of any single agent including a survivin inhibitor may be limited due to high heterogeneity and plasticity in tumor cells. Not surprisingly, the combination of survivin inhibitors and other traditional chemotherapeutical agents have been evaluated and shown enhanced clinical efficacy, indicating the inhibition of survivin can enhance the efficacy of other agents. Thus the next direction will be developing the best combinations of survivin inhibitors with other existing chemotherapeutical agents for the most efficacious strategy 


\section{CHAPTER 5. DESIGN, SYNTHESIS AND BIOLOGICAL EVALUATION OF NOVEL SURVIVIN INHIBITORS*}

\section{Introduction}

Survivin is a unique member of inhibitor of apoptosis protein (IAP) family.[131] It is overexpressed in most human cancer cells, but is rarely expressed in adult differentiated tissues.[49, 140, 150, 233] This attribute distinguishes survivin from other IAPs which are usually expressed in both cancer and normal cells. Survivin promotes cell proliferation and inhibits apoptosis, [143, 148, 150-152] facilitates angiogenesis in tumors, $[138,234-235]$ and its expression has been shown to strongly correlate with multiple mechanisms of drug resistance.[167-168, 236] Therefore, survivin is widely considered to be an ideal cancer drug target. Several molecules in different categories including antisense oligonucleotides, dominant-negative mutants, ribozymes, small interfering RNAs, cancer vaccines and small molecules have been identified as survivin inhibitors.[136] However, due to the challenging requirement to efficiently disrupt protein-protein interactions, the pool of existing small molecule survivin inhibitors is quite small.[182] The efficacy of those survivin inhibitors is also limited.[136] For example, the reported clinical candidate, small molecule survivin inhibitor YM155 has been shown to be a substrate of Pgp drug efflux pump, which suggests that YM155 has limited efficacy in multiple drug resistant phenotypes.[231] Therefore, it is highly significant to develop new survivin inhibitors that can overcome multidrug resistance, which is an important goal of our research.

We recently discovered that UC-112, [5-((benzyloxy)methyl)-7-(pyrrolidin-1ylmethyl)quinolin-8-ol], is a potent, selective survivin inhibitor (Figure 5-1).[180] UC112 inhibits tumor cell growth in several cancer cell lines in vitro and suppresses melanoma tumor growth in vivo. [180] Mechanistic studies indicated that UC-112 selectively inhibits survivin expression and induces strong cancer cell apoptosis. In order to further optimize this unique oxyquinoline scaffold and explore its SAR, we designed several focused sets of new UC-112 analogs (Figure 5-1). We introduced four major modifications to the structure of UC-112. First, we modified the $\mathrm{C}$ ring moiety by introducing substitutions to the phenyl ring or replacing it with other groups. Secondly, we modified the $\mathrm{D}$ ring moiety with other cyclic amines. We also explored different chain lengths between the oxygen linker and the $\mathrm{C}$ ring moiety. Finally, the linker between the $\mathrm{B}$ ring and the $\mathrm{C}$ ring was modified. By performing these targeted modifications, a series of novel UC-112 analogs were obtained.

Modified with permission. Xiao, M.; Wang, J.; Lin, Z.; Lu, Y.; Li, Z.; White, S. W.; Miller, D. D.; Li, W. Design, Synthesis and Structure-Activity Relationship Studies of Novel Survivin Inhibitors with Potent Anti-Proliferative Properties. PLoS One, 2015, 10(6), e0129807. 


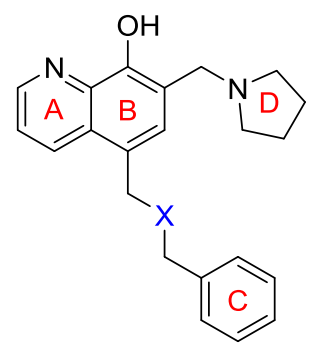

(4) Optimize the linker

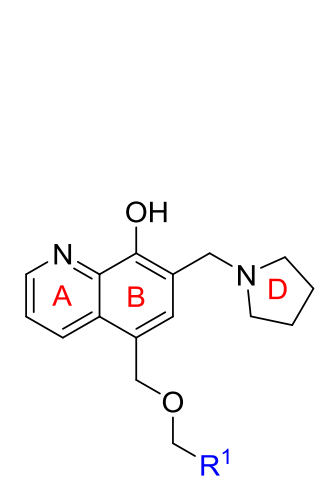

(1) C ring modification

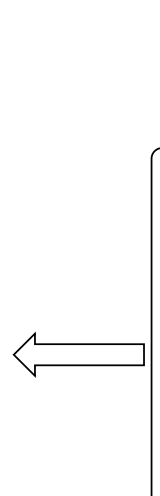

parental compound UC-112

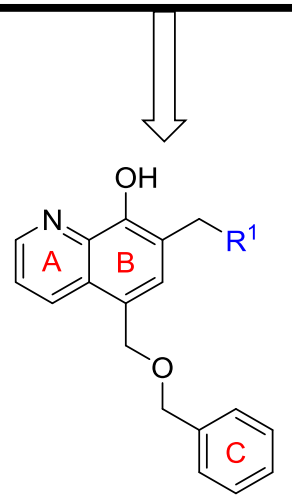

(2) D ring modification

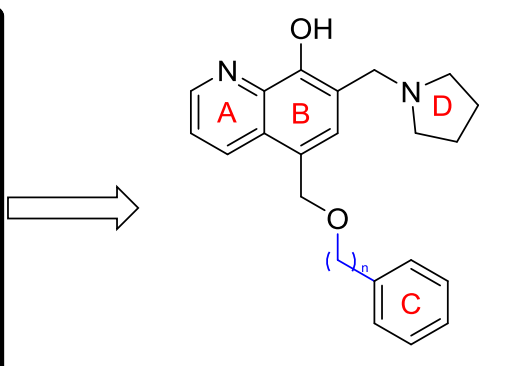

(3) Optimize chain length

Figure 5-1. Targeted modification to design new UC-112 analogs 
Biological evaluation of these new analogs revealed their excellent antiproliferative activity against several cancer cell lines including multidrug resistant phenotypes. Mechanism of action studies confirmed that these new UC-112 analogs maintained their mechanisms of action by selectively downregulating the level of survivin among other IAP family proteins. Preliminary in vivo evaluation for the most active compound demonstrated its efficacy against human melanoma tumor growth.

\section{Chemistry}

The general synthesis of C ring substituted UC-112 analogs (4a-4l) is outlined in Figure 5-2. First 8-hydroxyquinoline reacted with formaldehyde and catalytic zinc chloride in concentrated hydrochloric acid to generate salt 2.[237] This step introduced a chloromethyl group to the 5-position of quinoline ring. Then salt 2 was allowed to react with different substituted benzyl alcohols to form ethers 3a-3l, by two different methods. Ethers $\mathbf{3 b} \mathbf{b} \mathbf{3 e}$ and ethers $\mathbf{3 h}-\mathbf{3 l}$ were synthesized using step $\mathrm{b}$ in which substituted benzyl alcohols were allowed to react with salt $\mathbf{2}$ in the presence of sodium hydride in anhydrous THF. Ethers 3a, 3f and $\mathbf{3 g}$ were synthesized through step c and step d. In step c, substituted benzyl alcohols reacted directly with salt $\mathbf{2}$ with heating to form different salts which were converted to free base by adjusting $\mathrm{pH}$ with $\mathrm{NH}_{4} \mathrm{OH}$ solution in step d.[238] The synthesized ethers were then submitted to Mannich reaction with paraformaldehyde and pyrrolidine in ethanol to form the final compounds $4 \mathbf{a}$ to 41 .[239] Compounds $\mathbf{6 a - 6 g}$ with the $\mathrm{C}$ ring moiety in UC-112 replaced by different functional groups were prepared as Figure 5-3 shown. The ethers $\mathbf{5 a - 5} \mathbf{g}$ were first synthesized using similar approach as shown in Figure 5-2. Then these ethers were converted to 6a-6g via the Mannich reaction. The synthesis of D ring modified UC-112 analogs $\mathbf{8 a}$ and $\mathbf{8 b}$ is shown in Figure 5-4. Salt 2 first reacted with benzyl alcohol to form intermediate 7, which was allowed to react with piperidine or morpholine via the Mannich reaction to form compounds $\mathbf{8 a}$ and 8b. Compounds 10a and 10b which have different chain lengths between oxygen and the phenyl ring from parent compound UC-112 were made using the method shown in Figure 5-5. First salt 2 reacted with 2-phenylethanol and 3-phenyl-1-propanol respectively to form $9 \mathbf{a}$ and $\mathbf{9 b}$, which then underwent the Mannich reaction with paraformaldehyde and pyrrolidine to form compounds 10a and 10b. Finally, compounds 12a and 12b, which have different linkers between the $B$ ring and $C$ ring as compared to the parent compound were made (Figure 5-6). First salt $\mathbf{2}$ reacted with benzyl mercaptan or N-benzymethylamine to form intermediates 11a and 11b. Then 11a and 11b underwent the Mannich reaction to form compounds 12a and 12b.

\section{Biological Results and Discussion}

All UC-112 analogs were evaluated for their cytotoxicity in a panel of human cancer cell lines including melanoma (A375, MDA-MB-435 and its multidrug resistant daughter line MDA-MB-435/LCC6MDR1) and prostate cancer (PC-3). UC-112 was also included in the assays, serving as positive control and basis for comparison. These in vitro biological results are summarized and discussed in detail in the following sections. 


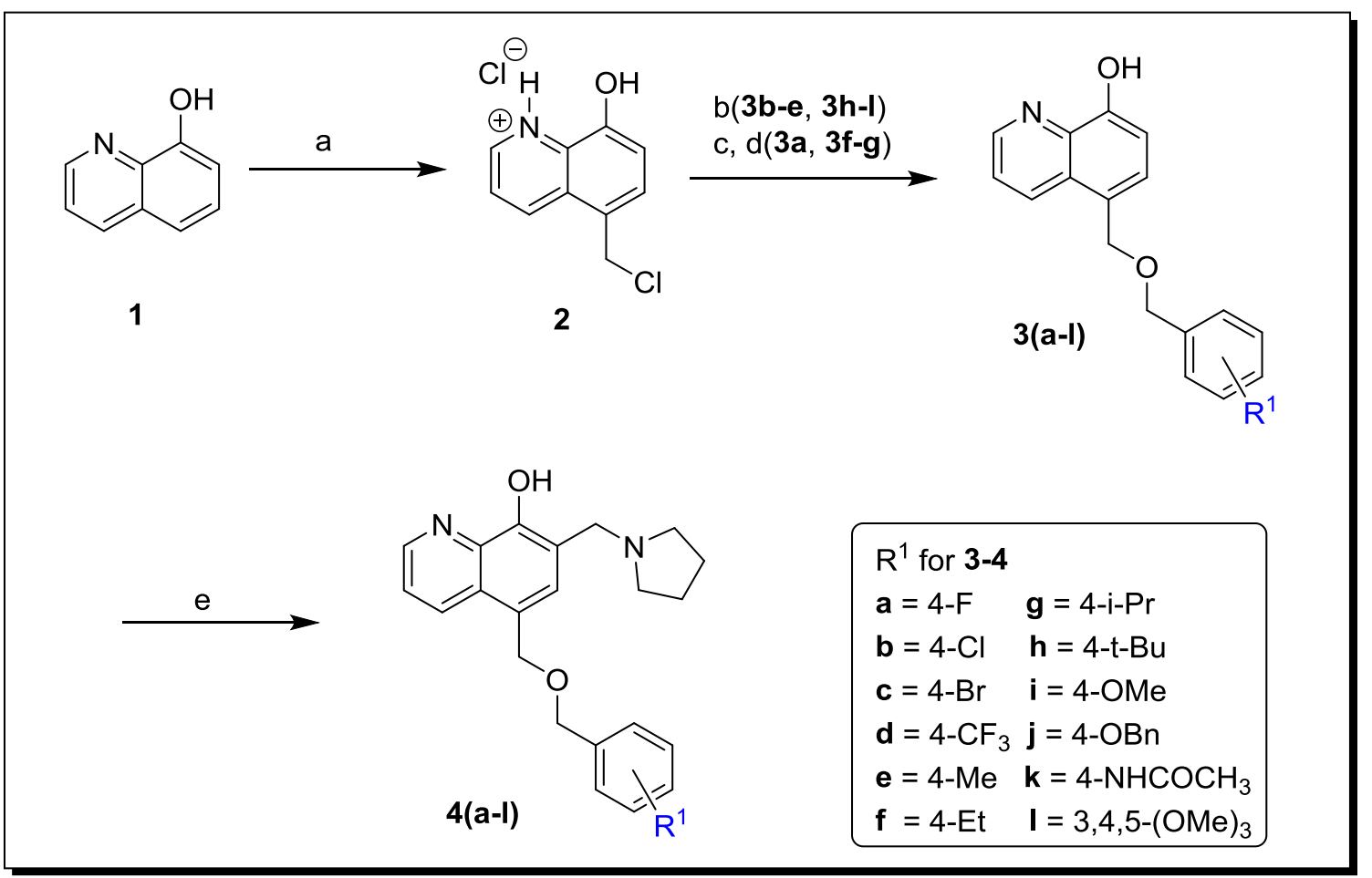

Figure 5-2. Synthesis of compounds $4 \mathrm{a}-41$

Reagents and conditions: (a) conc. $\mathrm{HCl}, \mathrm{ZnCl}_{2}$, $\mathrm{HCHO}\left(37 \%\right.$ in $\left.\mathrm{H}_{2} \mathrm{O}\right)$; (b) substituted benzyl alcohol, $\mathrm{NaH}$, THF, reflux; (c) substituted benzyl alcohol, $110{ }^{\circ} \mathrm{C}$; (d) $\mathrm{NH}_{4} \mathrm{OH}$, $\mathrm{H}_{2} \mathrm{O}, \mathrm{Et}_{2} \mathrm{O}, \mathrm{pH} 8-10$; (e) paraformaldehyde, pyrrolidine, EtOH, reflux. 


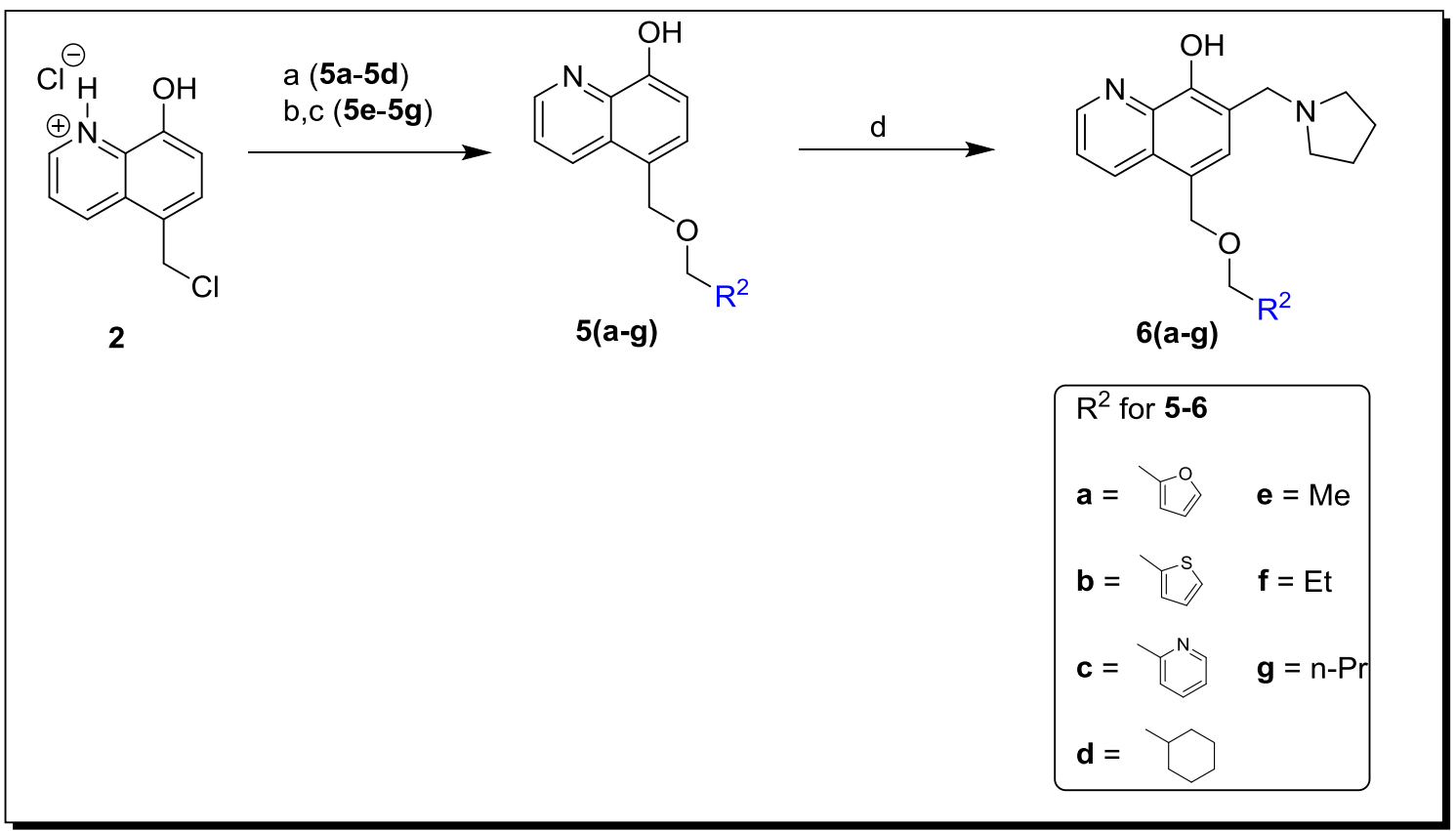

Figure 5-3. Synthesis of compounds 6a-6g

Reagents and conditions: (a) $\mathrm{R}^{2} \mathrm{CH}_{2} \mathrm{OH}, \mathrm{NaH}$, THF, reflux; (b) $\mathrm{R}^{2} \mathrm{CH}_{2} \mathrm{OH}, 110{ }^{\circ} \mathrm{C}$; (c) $\mathrm{NH}_{4} \mathrm{OH}, \mathrm{H}_{2} \mathrm{O}, \mathrm{Et}_{2} \mathrm{O}$, pH 8-10; (d) paraformaldehyde, pyrrolidine,EtOH, reflux. 


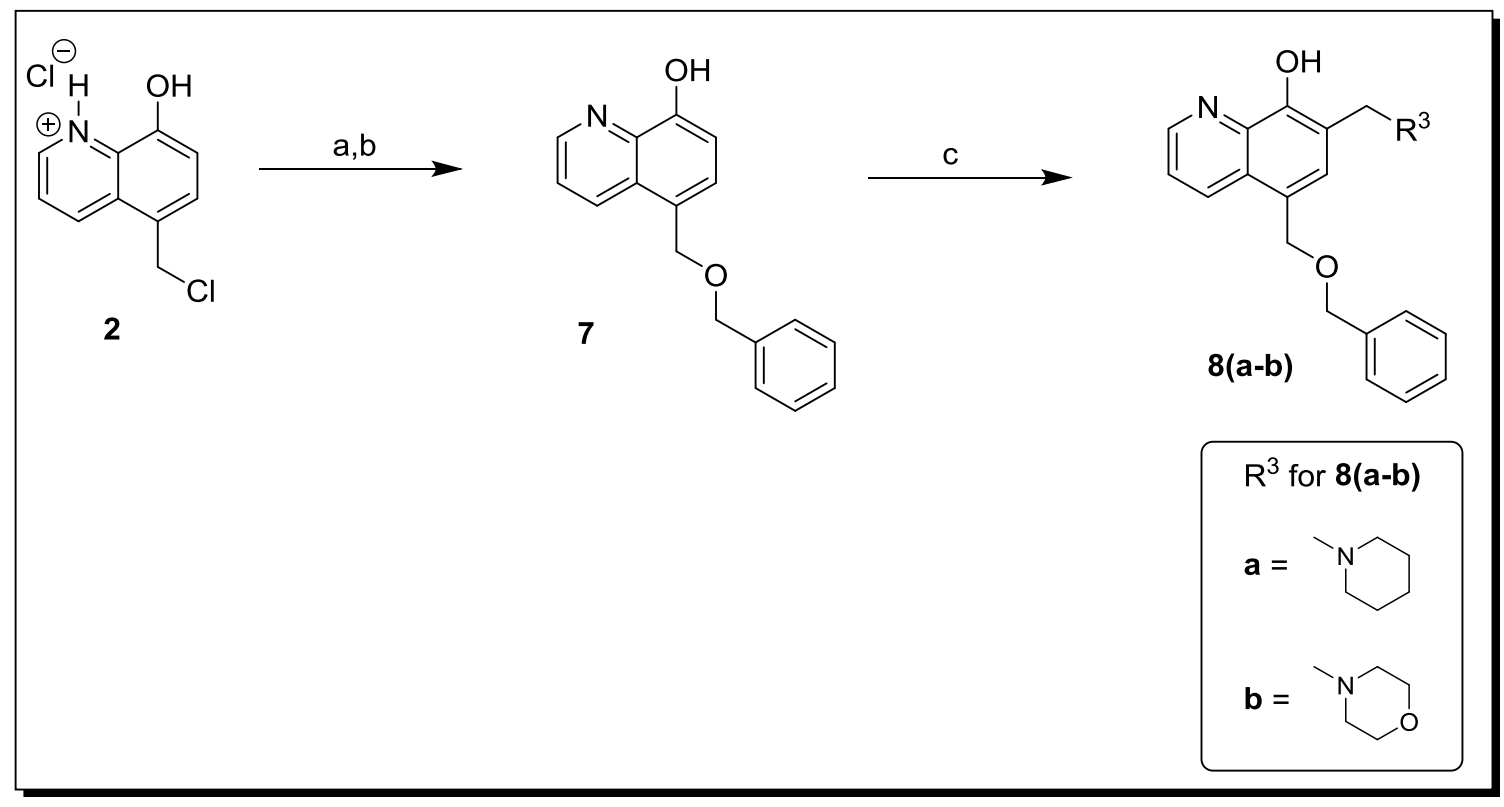

Figure 5-4. Synthesis of compounds 8a-8b

Reagents and conditions: (a) benzyl alcohol, $110{ }^{\circ} \mathrm{C}$; (b) $\mathrm{NH}_{4} \mathrm{OH}, \mathrm{H}_{2} \mathrm{O}, \mathrm{Et}_{2} \mathrm{O}, \mathrm{pH} 8-10$; (c) paraformaldehyde, piperidine for $\mathbf{8 a}$, morpholine for $\mathbf{8 b}, \mathrm{EtOH}$, reflux. 


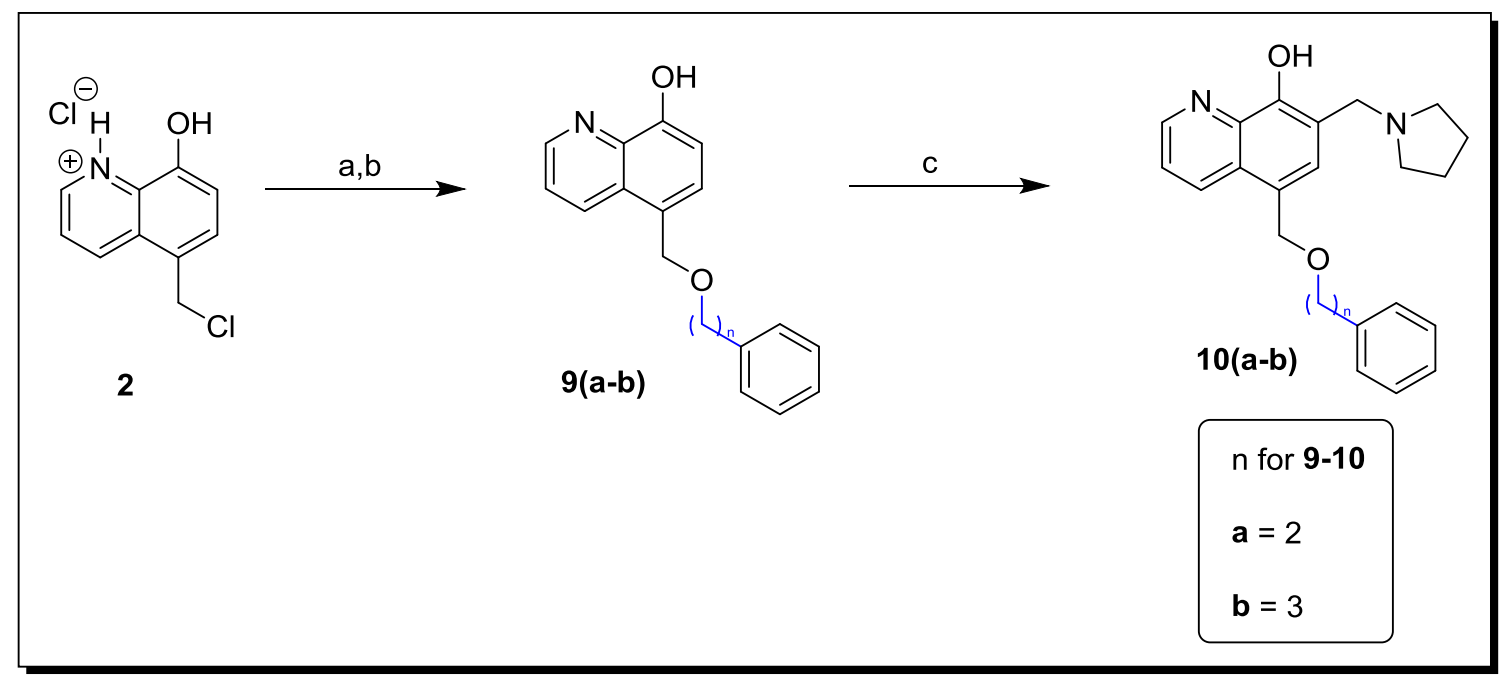

Figure 5-5. Synthesis of compounds 10a-10b

Reagents and conditions: (a) 2-phenylethanol for 9a, 3-phenyl-1-propanol for $9 \mathbf{b}, 110^{\circ} \mathrm{C}$; (b) $\mathrm{NH}_{4} \mathrm{OH}, \mathrm{H}_{2} \mathrm{O}, \mathrm{Et}_{2} \mathrm{O}, \mathrm{pH} 8-10$; (c) paraformaldehyde, pyrrolidine, EtOH, reflux. 


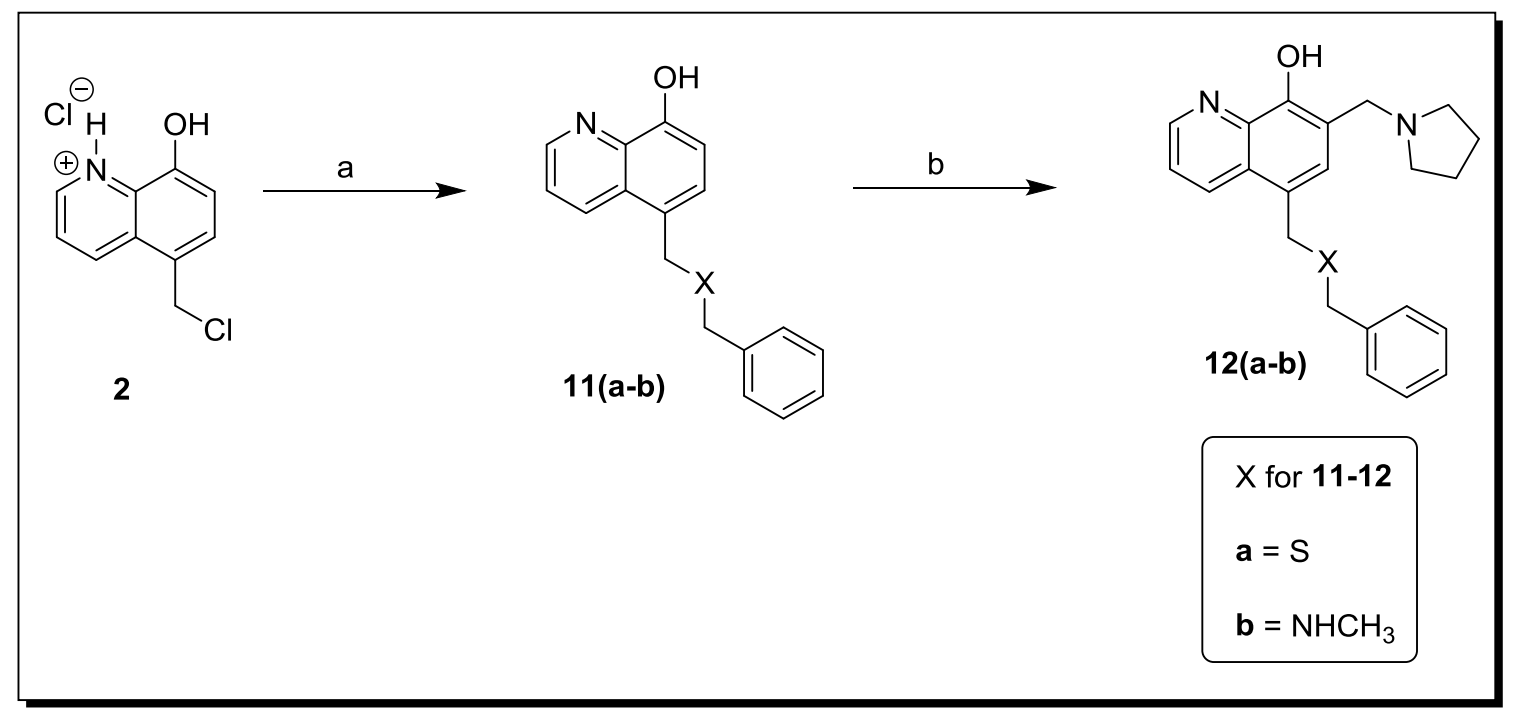

Figure 5-6. Synthesis of compounds 12a-12b

Reagents and conditions: (a) benzyl mercaptan for 11a, N-Benzylmethylamine for 11b, $\mathrm{NaH}$, THF, reflux; (b) paraformaldehyde, pyrrolidine,EtOH, reflux. 


\section{Effect of Substitutions on the C Ring of UC-112}

The in vitro activity for compounds $\mathbf{4 a - 4 l}$ which have substitutions on the $\mathrm{C}$ ring of UC-112 is shown in Table 5-1. Most compounds in this table are more active than the parent compound UC-112, suggesting that introduction of substitutions to the $\mathrm{C}$ ring moiety in UC-112 is favorable. Introducing a fluoro group (4a) to the phenyl ring caused the increase of activity in three of the four cancer cell lines tested $(1.5 \mu \mathrm{M}$ vs $1.9 \mu \mathrm{M}$ in A375, $1.8 \mu \mathrm{M}$ vs $2.1 \mu \mathrm{M}$ in MDA-MB-435 and $0.7 \mu \mathrm{M}$ vs $1.6 \mu \mathrm{M}$ in PC-3). Introducing a chloro substitution (4b) resulted in even better activity in all four cell lines tested. A bromo substitution (4c) further increased activity. Introduction of an electron withdrawing group, trifluoromethyl (4d), also resulted in an increase in activity against all the cell lines. As the size of substitution increases from fluoro to bromo substitutions, a general trend of increased activity was observed (i.e. IC $_{50}$ in MDA-MB-435 cell line.

4a: $1.8 \mu \mathrm{M}$; $4 \mathbf{b}: 1.1 \mu \mathrm{M}$; $4 \mathbf{c}: 1.0 \mu \mathrm{M})$. This trend is also true for electron donating group substituted analogs 4e-4g (i.e. IC50 in MDA-MB-435/LCC6MDR1 cell line. 4e: $4.1 \mu \mathrm{M}$; 4f: $2.7 \mu \mathrm{M}$; $\mathbf{4 g}$ : $1.8 \mu \mathrm{M}$ ). But the tert-butyl group substituted compound $\mathbf{4 h}$ does not further increase activity compared to iso-propyl group substituted compound $\mathbf{4 g}$, indicating there is probably a size limit for effective binding to survivin. In addition, several polar groups which are hydrogen bond acceptors were also tested. However, as Table 5-1 shows, compounds 4i-4l do not increase activity significantly compared to parent compound UC-112. Compounds $\mathbf{4 j}$ and $\mathbf{4 k}$ even had decreased activity compared to UC-112 (i.e. $\mathrm{IC}_{50}$ in MDA-MB-435/LCC6MDR1 cell line. $\mathbf{4 j}: 12.1 \mu \mathrm{M} ; \mathbf{4 k}: 5.5 \mu \mathrm{M}$; UC-112: $3.2 \mu \mathrm{M})$, suggesting that a bulky substitution is unfavorable. Among all the compounds in this table, compounds $\mathbf{4 c}, \mathbf{4 d}$ and $\mathbf{4 g}$ are the most potent ones, indicating that the introduction of a hydrophobic group to the para-position of $\mathrm{C}$ ring is favorable for increased activity.

\section{Effect of Replacing the Phenyl Ring of UC-112 with Other Groups}

After we tried different substitutions on the phenyl ring of UC-112, we replaced the phenyl ring with other groups to further optimize UC-112. Here, we tried seven different groups which included furan ring, thiophene ring, pyridine ring, cyclohexyl ring, methyl group, ethyl group, and $n$-propyl group. The in vitro activity for the seven $\mathrm{C}$ ring modified UC-112 analogs is shown in Table 5-2. In this table, compounds 6a, $6 \mathbf{b}$ and 6c were less active than UC-112 (i.e. $\mathrm{IC}_{50}$ in A375 cell line. 6a: $2.7 \mu \mathrm{M} ; 6$ 6b: $2.5 \mu \mathrm{M}$; 6c: $8.4 \mu \mathrm{M}$; UC-112: $1.9 \mu \mathrm{M}$ ), indicating that replacing the phenyl ring with other heterocyclic rings decreases activity. Replacing the phenyl ring with a cyclohexyl ring resulted in an increase in activity in A375 and MDA-MB-435 cell lines. In order to see whether a ring is required at the $\mathrm{C}$ ring position of $\mathrm{UC}-112$ for activity, compounds $\mathbf{6 e}, \mathbf{6} \mathbf{f}$ and $\mathbf{6 g}$ with only aliphatic chains were synthesized. All these compounds decreased activity compared to parent compound UC-112 (i.e. $\mathrm{IC}_{50}$ in A375 cell line. 6e: $6.1 \mu \mathrm{M}$; 6f: $5.0 \mu \mathrm{M}$; $6 \mathrm{~g}$ : $3.0 \mu \mathrm{M}$; UC-112: $1.9 \mu \mathrm{M}$ ), suggesting a ring system is required at the $\mathrm{C}$ ring position of UC-112. For compounds $6 \mathbf{e}, \mathbf{6 f}$ and $\mathbf{6 g}$, there is a general trend for activity. As the length of the aliphatic chain increases, the activity increases as well. This trend is probably due to the existence of a hydrophobic pocket in the binding site, which 
Table 5-1 In vitro growth inhibitory effects of $\mathrm{UC}-112$ analogs with $\mathrm{C}$ ring substitutions

\begin{tabular}{|c|c|c|c|c|c|}
\hline \multirow[b]{2}{*}{ ID } & \multicolumn{4}{|c|}{$I_{C_{50}} \pm \operatorname{SEM}(\mu M)$} & \multirow[b]{2}{*}{$\begin{array}{l}\text { Resistance } \\
\text { Index }\end{array}$} \\
\hline & A375 & $\begin{array}{l}\text { MDA- } \\
\text { MB-435 }\end{array}$ & $\begin{array}{c}\text { MDA-MB- } \\
\text { 435/LCC6MD } \\
\text { R1 }\end{array}$ & PC-3 & \\
\hline $4 a$ & $1.5 \pm 0.2$ & $1.8 \pm 0.3$ & $4.4 \pm 0.7$ & $0.7 \pm 0.2$ & 2.4 \\
\hline $4 b$ & $1.5 \pm 0.3$ & $1.1 \pm 0.1$ & $2.4 \pm 0.5$ & $0.9 \pm 0.1$ & 2.2 \\
\hline $4 c$ & $0.9 \pm 0.2$ & $1.0 \pm 0.2$ & $1.8 \pm 0.6$ & $0.7 \pm 0.3$ & 1.8 \\
\hline $4 d$ & $0.9 \pm 0.3$ & $1.0 \pm 0.4$ & $1.9 \pm 0.5$ & $1.0 \pm 0.1$ & 1.9 \\
\hline $4 e$ & $1.7 \pm 0.3$ & $2.3 \pm 0.5$ & $4.1 \pm 2.0$ & $1.1 \pm 0.2$ & 1.8 \\
\hline $4 f$ & $0.9 \pm 0.1$ & $0.9 \pm 0.1$ & $2.7 \pm 1.0$ & $0.9 \pm 0.1$ & 3.0 \\
\hline $4 g$ & $0.9 \pm 0.1$ & $0.8 \pm 0.2$ & $1.8 \pm 0.4$ & $0.7 \pm 0.1$ & 2.3 \\
\hline $4 h$ & $1.1 \pm 0.4$ & ND & $1.5 \pm 0.7$ & $1.5 \pm 0.3$ & ND \\
\hline $4 i$ & $1.8 \pm 0.2$ & $1.5 \pm 0.4$ & $3.8 \pm 0.6$ & $1.0 \pm 0.4$ & 2.5 \\
\hline $4 \mathbf{j}$ & $2.8 \pm 0.1$ & ND & $12.1 \pm 0.5$ & ND & ND \\
\hline $4 \mathbf{k}$ & $4.7 \pm 0.8$ & ND & $5.5 \pm 1.3$ & ND & ND \\
\hline 41 & $2.8 \pm 0.4$ & $3.6 \pm 1.0$ & $>30$ & $1.6 \pm 0.3$ & $>8.3$ \\
\hline UC-112 & $1.9 \pm 0.6$ & $2.1 \pm 0.3$ & $3.2 \pm 0.5$ & $1.6 \pm 1.0$ & 1.5 \\
\hline YM-155 & ND & 0.003 & $>10$ & ND & $>2941$ \\
\hline
\end{tabular}

Notes: ND: Not Determined. Resistance index is calculated by dividing $\mathrm{IC}_{50}$ values on multidrug-resistant cell line MDA-MB-435/LCC6MDR1 by $\mathrm{IC}_{50}$ values on the matching sensitive parental cell line MDA-MB-435. Dr. Jin Wang performed the biological testing in this table. 
Table 5-2. In vitro growth inhibitory effects of $\mathrm{C}$ ring modified UC-112 analogs

\begin{tabular}{cccccc}
\hline & \multicolumn{5}{c}{ IC50 \pm SEM $(\boldsymbol{\mu M})$} \\
\cline { 2 - 5 } ID & $\mathbf{A 3 7 5}$ & $\begin{array}{c}\text { MDA- } \\
\text { MB-435 }\end{array}$ & $\begin{array}{c}\text { MDA-MB- } \\
\text { 435/LCC6 } \\
\text { MDR1 }\end{array}$ & PC-3 & $\begin{array}{c}\text { Resistance } \\
\text { Index }\end{array}$ \\
\hline $\mathbf{6 a}$ & $2.7 \pm 0.3$ & $3.1 \pm 0.3$ & $15.3 \pm 3.1$ & $27.5 \pm 2.0$ & 4.9 \\
$\mathbf{6 b}$ & $2.5 \pm 0.5$ & $1.9 \pm 0.9$ & $4.2 \pm 0.2$ & $3.4 \pm 0.7$ & 2.2 \\
$\mathbf{6 c}$ & $8.4 \pm 1.5$ & $8.0 \pm 2.2$ & $>30$ & $>30$ & $>3.8$ \\
$\mathbf{6 d}$ & $1.0 \pm 0.1$ & $1.3 \pm 0.6$ & $\mathrm{ND}$ & $\mathrm{ND}$ & $\mathrm{ND}$ \\
$\mathbf{6 e}$ & $6.1 \pm 0.7$ & $5.1 \pm 2.1$ & $\mathrm{ND}$ & $\mathrm{ND}$ & $\mathrm{ND}$ \\
$\mathbf{6 f}$ & $5.0 \pm 0.3$ & $5.9 \pm 1.2$ & $\mathrm{ND}$ & $\mathrm{ND}$ & $\mathrm{ND}$ \\
$\mathbf{6 g}$ & $3.0 \pm 0.5$ & $4.9 \pm 1.3$ & $\mathrm{ND}$ & $\mathrm{ND}$ & $\mathrm{ND}$ \\
$\mathbf{U C - 1 1 2}$ & $1.9 \pm 0.6$ & $2.1 \pm 0.3$ & $3.2 \pm 0.5$ & $1.6 \pm 1.0$ & 1.5 \\
\hline
\end{tabular}

Note: ND: Not Determined. Dr. Jin Wang performed the biological testing in this table. 
is consistent with previous observation that introduction of a hydrophobic substitution with bigger space occupation on the phenyl ring is favorable for activity.

\section{Effect of D Ring Modification on UC-112}

Following $\mathrm{C}$ ring modification in the above, we went on with $\mathrm{D}$ ring modification of UC-112. We tried to replace the pyrrolidine ring with two different cyclic amines: piperidine and morpholine at current stage. The in vitro activity for the two $\mathrm{D}$ ring modified compounds $\mathbf{8 a}$ and $\mathbf{8 b}$ is show in Table 5-3.Compound 8a showed slightly better activity than the parent compound, while compound $\mathbf{8 b}$ was less active than UC112 (i.e. $\mathrm{IC}_{50}$ in $\mathrm{A} 375$ cell line. 8a: $1.1 \mu \mathrm{M}$; 8b: $5.0 \mu \mathrm{M}$; UC-112: $1.9 \mu \mathrm{M}$ ). This observation means the replacement of pyrrolidine ring in $\mathrm{UC}-112$ with a piperidine ring maintains activity, while replacing pyrrolidine ring with morpholine ring decreases activity. Both compounds $\mathbf{8 a}$ and $\mathbf{8 b}$ can effectively inhibit the growth of resistant cell line MDA-MB-435/LCC6MDR1, suggesting that they can overcome the Pgp-mediated multiple drug resistance. The difference in activity between $\mathbf{8 a}$ and $\mathbf{8 b}$ indicates that the $\mathrm{D}$ ring position of UC-112 is an important site that further optimization can be carried out.

\section{Effect of Chain Length between Oxygen and C Ring of UC-112 Analogs}

The chain length between oxygen linker and $\mathrm{C}$ ring in the parent compound UC112 is one carbon. We tried to test the importance of chain length by increasing the carbon numbers. Two compounds $\mathbf{1 0 a}$ and $\mathbf{1 0 b}$ were prepared and their in vitro activity is shown in Table 5-4. Both compounds 10a and 10b were less active than the parental compound, especially the activity against resistant cell line MDA-MB-435/LCC6MDR1 reduced from 3.2 to $15 \sim 20 \mu \mathrm{M}$, suggesting that increasing the chain length was not a favorable modification for increasing activity.

\section{Effect of Linkers between C Ring and D Ring of UC-112 Analogs}

After the D ring modification, we went on to optimize the linker. We made two compounds 12a and 12b with two different linkers from the parent compound. The in vitro activity of those tow compounds is shown in Table 5-5. Compound 12a which bears a sulfur linker shows increased activity compared with UC-112 (i.e. $1.4 \mu \mathrm{M}$ vs 1.9 $\mu \mathrm{M}$ in A375 cell line), meaning sulfur linker here is favorable. Compound $\mathbf{1 2 b}$ which contains a methylamine linker was less active (i.e. $7.1 \mu \mathrm{M}$ vs $1.9 \mu \mathrm{M}$ in A375 cell line), indicating that a methylamine linker is unfavorable. Both compounds 12a and 12b have small resistance indexes. Their activity in the resistant cell line MDA-MB435/LCC6MDR1 is comparable with that in the parental cell line MDA-MB-435. While two compounds can't determine the optimized linker, at least they give us some information about the activity requirement of the linker which is very useful for further optimization. 
Table 5-3. In vitro growth inhibitory effects of $D$ ring modified UC-112 analogs

\begin{tabular}{|c|c|c|c|c|c|}
\hline \multirow[b]{2}{*}{ ID } & \multicolumn{4}{|c|}{$\mathrm{IC}_{50} \pm \operatorname{SEM}(\mu \mathrm{M})$} & \multirow[b]{2}{*}{$\begin{array}{l}\text { Resistance } \\
\text { Index }\end{array}$} \\
\hline & A375 & $\begin{array}{c}\text { MDA- } \\
\text { MB-435 }\end{array}$ & $\begin{array}{c}\text { MDA-MB- } \\
\text { 435/LCC6 } \\
\text { MDR1 }\end{array}$ & PC-3 & \\
\hline $8 \mathbf{a}$ & $1.1 \pm 0.1$ & $1.3 \pm 0.2$ & $2.1 \pm 0.6$ & $1.3 \pm 0.3$ & 1.6 \\
\hline $8 b$ & $5.0 \pm 1.6$ & $4.8 \pm 0.5$ & $3.5 \pm 1.0$ & ND & 0.7 \\
\hline UC-112 & $1.9 \pm 0.6$ & $2.1 \pm 0.3$ & $3.2 \pm 0.5$ & $1.6 \pm 1.0$ & 1.5 \\
\hline
\end{tabular}

Note: ND: Not Determined. Dr. Jin Wang performed the biological testing in this table.

Table 5-4.. In vitro growth inhibitory effects of UC-112 analogs with different chain lengths

\begin{tabular}{ccccc}
\hline & \multicolumn{3}{c}{ IC $50 \pm$ SEM $(\boldsymbol{\mu M})$} & \\
\cline { 2 - 4 } ID & $\mathbf{A 3 7 5}$ & $\begin{array}{c}\text { MDA-MB- } \\
\mathbf{4 3 5}\end{array}$ & $\begin{array}{c}\text { MDA-MB- } \\
\mathbf{4 3 5} / \text { LCC- } \\
\mathbf{6 M D R 1}\end{array}$ & $\begin{array}{c}\text { Resistance } \\
\text { Index }\end{array}$ \\
\hline $\mathbf{1 0 a}$ & $2.8 \pm 0.9$ & $2.9 \pm 0.2$ & $15.0 \pm 2.5$ & 5.2 \\
$\mathbf{1 0 b}$ & $2.4 \pm 0.7$ & $2.3 \pm 0.8$ & $20.0 \pm 1.6$ & 8.7 \\
UC-112 & $1.9 \pm 0.6$ & $2.1 \pm 0.3$ & $3.2 \pm 0.5$ & 1.5 \\
\hline
\end{tabular}

Notes: ND: Not Determined. Dr. Jin Wang performed the biological testing in this table. 
Table 5-5. In vitro growth inhibitory effects of UC-112 analogs with different linkers

\begin{tabular}{|c|c|c|c|c|c|}
\hline \multirow[b]{2}{*}{ ID } & \multicolumn{4}{|c|}{$\mathrm{IC}_{50} \pm \operatorname{SEM}(\mu \mathrm{M})$} & \multirow[b]{2}{*}{$\begin{array}{l}\text { Resistance } \\
\text { Index }\end{array}$} \\
\hline & A375 & $\begin{array}{l}\text { MDA- } \\
\text { MB-435 }\end{array}$ & $\begin{array}{c}\text { MDA-MB- } \\
\text { 435/LCC6M } \\
\text { DR1 } \\
\end{array}$ & PC-3 & \\
\hline $12 \mathbf{a}$ & $1.4 \pm 0.3$ & $1.4 \pm 0.2$ & $2.9 \pm 0.6$ & $1.1 \pm 0.1$ & 2.1 \\
\hline $12 b$ & $7.1 \pm 0.7$ & $6.2 \pm 1.4$ & $8.0 \pm 1.0$ & $2.5 \pm 0.6$ & 1.3 \\
\hline UC-112 & $1.9 \pm 0.6$ & $2.1 \pm 0.3$ & $3.2 \pm 0.5$ & $1.6 \pm 1.0$ & 1.5 \\
\hline
\end{tabular}

Notes: ND: Not Determined. Dr. Jin Wang performed the biological testing in this table. 


\section{UC-112 Analogs Can Overcome Multidrug Resistance}

In order to determine whether the new analogs we made can overcome multidrug resistance, we compared the activity of those analogs against multidrug resistant melanoma cells (MDA-MB-435/LCCMDR1) and their parental sensitive cancer cells (MDA-MB-435). This pair of cell lines have been well validated and widely used to assess abilities of drugs overcoming Pgp-mediated multidrug resistance.[124, 126-127] Our three best compounds $\mathbf{4 c}, \mathbf{4 d}$ and $\mathbf{4 g}$ together with the most successful small molecule survivin inhibitor YM155 were tested on both the multidrug resistant melanoma cells and their parental cells (Table 5-1). The resistance index is calculated by dividing the $\mathrm{IC}_{50}$ value of the resistant cell line by $\mathrm{IC}_{50}$ value of the sensitive parental cell line. So the smaller this value, the better resistance overcoming effect obtained. As this table shows, compounds $\mathbf{4 c}, \mathbf{4 d}$ and $\mathbf{4 g}$ all have very small resistance indexes $(1.8,1.9$ and 2.3 respectively). Their activity in the resistant cell line is comparable with that in the parental cell line. For existing survivin inhibitor, YM155, although it is very potent in parental cell line ( $\mathrm{IC}_{50}$ at $3 \mathrm{nM}$ ), its activity in resistant cell line is considerably lower ( $\mathrm{IC}_{50}$ is higher than $10 \mu \mathrm{M}$, resistance index is higher than 2941). This data indicates that the new UC-112 analogs can circumvent Pgp-mediated multidrug resistance and are distinct from that of YM-155.

\section{UC-112 Analogs Show Good Antiproliferative Effects with Selectivity in NCI-60 Cell Line Screening}

UC-112 and three potent analogs $\mathbf{4 c}, \mathbf{4 g}$ and $\mathbf{1 2 a}$ were submitted to NCI for its one-concentration $(10 \mu \mathrm{M})$ screening against the NCI-60 cell lines. All four compounds showed good activity and were selected for the subsequent five doses testing to determine their growth inhibition potency $\left(\mathrm{GI}_{50}\right)$ in the NCI-60 cell lines. As shown in Figure 5-7, structure modification from UC-112 to our best compound $\mathbf{4 g}$ has improved the average $\mathrm{GI}_{50}$ by nearly four times $(2.2 \mu \mathrm{M}$ for $\mathrm{UC}-112 \nu$ s. $0.5 \mu \mathrm{M}$ for $\mathbf{4 g})$.

The heat map in Figure 5-8 summarizes the compound growth inhibition pattern which is characterized by the $\mathrm{GI}_{50}$ mean values from NCI-60 screening. UC-112 and its new analogs showed interesting selective growth inhibition behavior within the NCI 60 cell lines. The $\mathrm{GI}_{50}$ value of compound $\mathbf{4 g}$ in renal cancer cell line UO-31 was as low as $52.5 \mathrm{nM}$. Interestingly, two other cell lines, HCT-15 (colon cancer) and NCI/ADR-RES (ovarian cancer), were also particularly sensitive to the treatment of UC-112 and its analogs, with lowest $\mathrm{GI}_{50}$ value (highest activity) for compound $\mathbf{4 g}$ at $46.8 \mathrm{nM}$ and 50.1 $\mathrm{nM}$, respectively. Since colorectal adenocarcinoma HCT-15 cells intrinsically expresses moderate levels of Pgp, multidrug resistance associated protein (MRP) and lung resistance associated protein (LRP) [240], and ovarian cancer NCI/ADR-RES cells are naturally over-expressing MDR1 and resistant to various chemotherapies including doxorubicin [241], these data have supported our findings that UC-112 and its analogs could effectively overcome the multidrug resistance in vitro. 


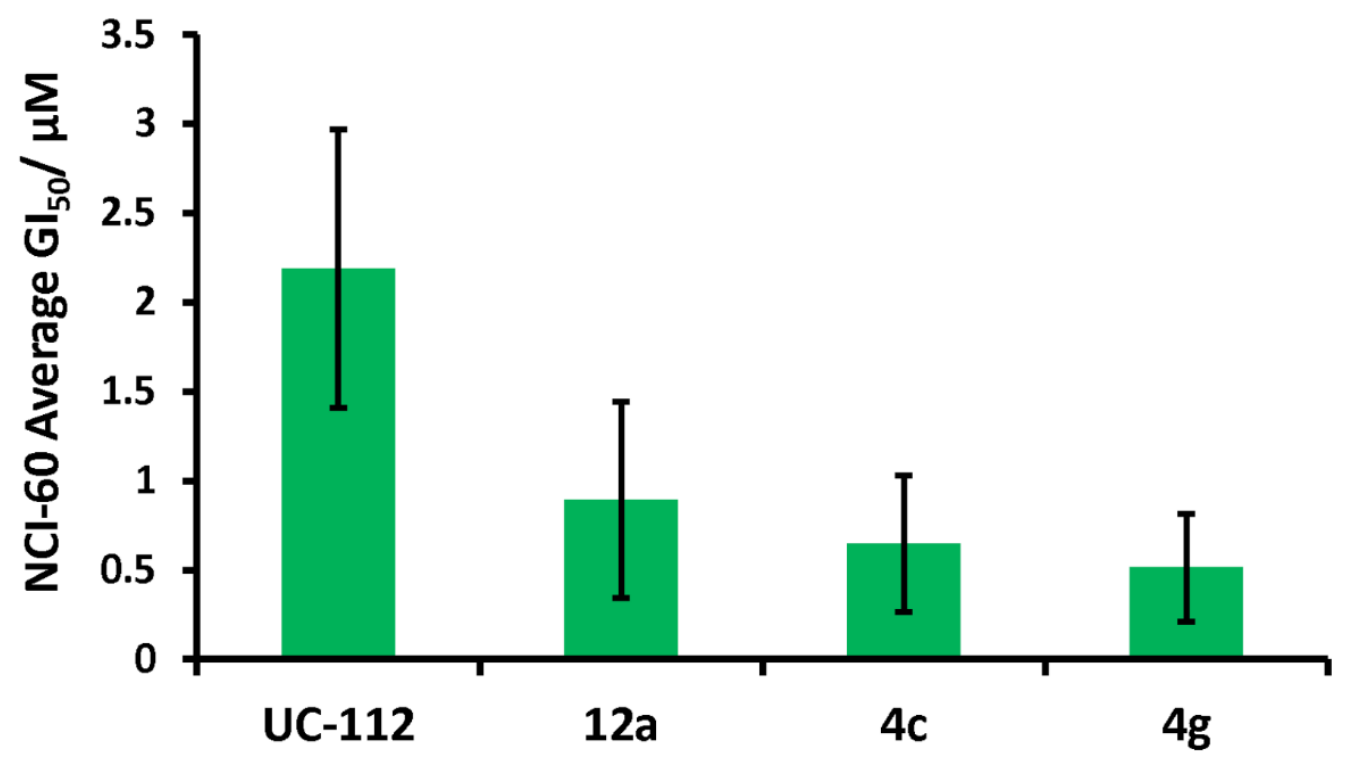

Figure 5-7 Average GI50 data for UC-112, compound 12c, 4c and $4 \mathrm{~g}$ tested in NCI-60 anti-proliferative screening

Data is shown with mean \pm SD as bar graph. 


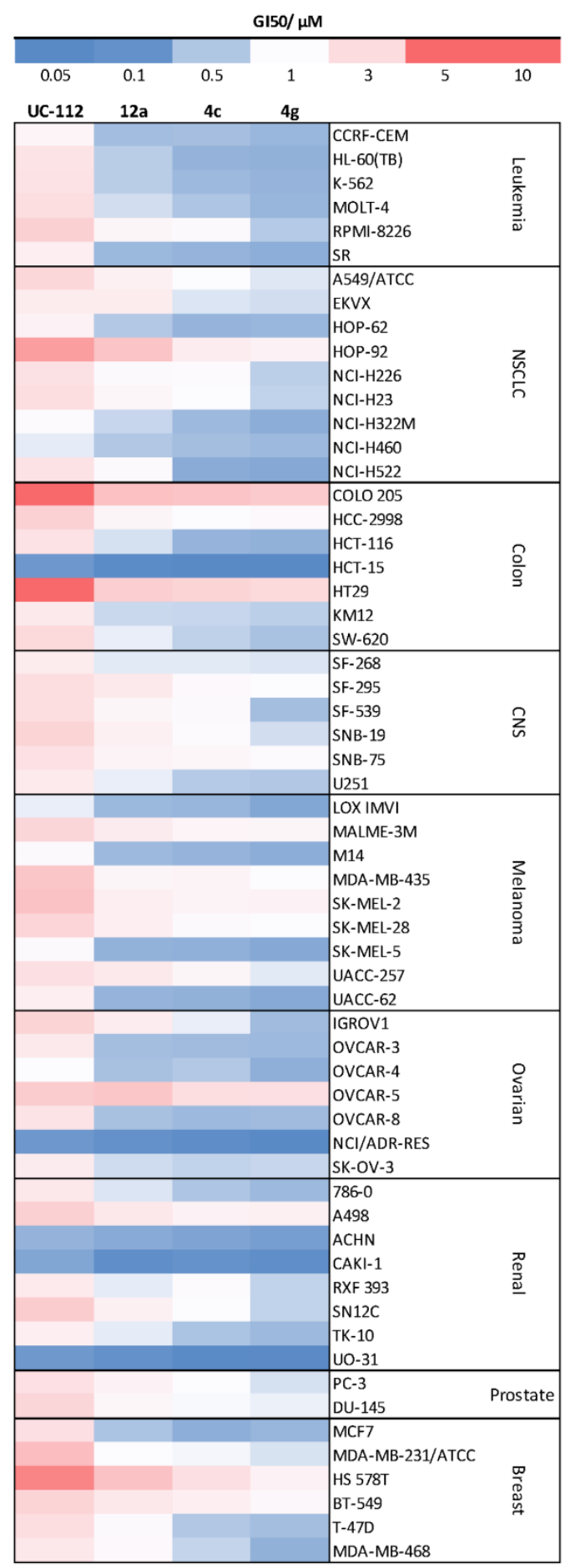

Figure 5-8. Heat map showing the GI50 values (nM) for UC-112 and three analogs in the NCI-60 screening

High intensity (blue) cells indicate high activity and low intensity (red) cells indicate low activity. Average $\mathrm{GI}_{50}$ values were calculated for each compound, separately. 


\section{Compound 4g Possesses Good Drug-Like Properties}

Adsorption, distribution, metabolism and elimination (ADME) properties are key elements in small molecule drug development. Poor ADME property is one of the major contributors of failure in advancing new compounds towards drug approval. To preliminarily evaluate the overall drug-like properties for the UC-112 scaffold, we sent our best compound $\mathbf{4 g}$ to an external contract research company (Eurofins Panlabs Inc., Redmond, WA) to determine its aqueous solubility and in vitro ADME properties. The aqueous solubility for compound $\mathbf{4 g}$ was tested in PBS solution at pH 7.4 (Table 5-6) and the result showed that compound $\mathbf{4 g}$ had very good aqueous solubility of $148.7 \mu \mathrm{M}$. The in vitro microsomal stability for compound $\mathbf{4 g}$ was determined in human liver microsomes. The result showed that it had a reasonable half life time at 51 minutes with a medium clearance rate at $136.6 \mu \mathrm{L} / \mathrm{min} / \mathrm{mg}$. Drug metabolism studies using cytochrome P450 inhibition by compound $\mathbf{4 g}$ (Table 5-7) showed weak inhibition for most cytochrome P450 enzymes (less than 30\%) except CYP2D6. This study suggests that the UC-112 scaffold demonstrated by compound $\mathbf{4 g}$ has good drug-like properties, which clearly warrants its further development.

\section{Mechanism of Action Studies}

In our recently report, [180] UC-112 induces apoptosis by selectively inhibiting the expression of survivin in cancer cells. In order to determine whether the new UC-112 analogs maintained the same mechanism of action, we performed the caspases activation and Western blotting assay for two potent new analogs $\mathbf{4 f}$ and $\mathbf{4 g}$ in two cancer cell lines (Figure 5-9). Both compounds $\mathbf{4 f}$ and $\mathbf{4 g}$ dose-dependently suppressed survivin level in these two cancer cell lines, while the levels of other IAPs were minimally affected. The presence of compound $\mathbf{4 g}$ at $300 \mathrm{nM}$ reduced survivin levels over $50 \%$ in both A375 and PC-3 cells as shown in the lane density data quantified by Image J software. The $\mathrm{IC}_{50}$ values for survivin inhibition were estimated to be in the low nano-molar range.

Furthermore, incubation of compound 12a, $4 \mathbf{c}$ or $4 \mathbf{g}$ at concentration of $1 \mu \mathrm{M}$ for $24 \mathrm{~h}$ significantly activated the executioner caspases $3 / 7$ up to 4 folds higher than the DMSO control group (Figure 5-10). This is consistent with the expected enhanced apoptosis induction capability due to survivin inhibition.

\section{Molecular Modeling Study}

To understand the observed improvement in potency of compound $\mathbf{4 g}$ over its parental compound UC-112, we developed a molecular model and performed the molecular docking study using the complex of human survivin-SMAC AVPI (PDB entry: 3UIH). As shown in Figure 5-11, UC-112 displayed several interesting interactions with the survivin protein BIR domain: (1) two hydrogen bonding interactions between the A/B-ring of UC-112 and residue Asp71; (2) one hydrogen bonding interaction between the D-ring nitrogen and residue Glu68; and (3) an $\pi$ - $\pi$ stacking interaction between the A/B-ring of UC-112 and residue Typ67 (Figure 5-11A). Examination of this proposed 
Table 5-6 Aqueous solubility and in vitro metabolism properties of compound $4 \mathrm{~g}$

\begin{tabular}{cccc}
\hline ID & $\begin{array}{c}\text { Solubility a }^{\text {a }} \\
(\boldsymbol{\mu M})\end{array}$ & Half-Life $^{\mathrm{b}}(\mathbf{m i n})$ & $\begin{array}{c}\mathbf{C l} \text { int } \\
(\boldsymbol{\mu L} / \mathbf{m i n} / \mathbf{m g})\end{array}$ \\
\hline $\mathbf{4 g}$ & 148.7 & 51.0 & 136.6 \\
\hline
\end{tabular}

Note: a: test concentration is $200 \mu \mathrm{M}$; b: test concentration is $100 \mathrm{nM}$. Eurofins Panlabs Inc. performed the experiments in this table.

Table 5-7. Cytochrome P450 inhibition effects of compound 4g

\begin{tabular}{ccc}
\hline CYP enzyme & Substrate & $\begin{array}{c}\text { \% Inhibition of } \\
\text { Control Values }\end{array}$ \\
\hline CYP1A & phenacetin & 18 \\
CYP2B6 & bupropion & 21 \\
CYP2C8 & paclitaxel & 21 \\
CYP2C9 & diclofenac & 17 \\
CYP2C19 & omeprazole & 45 \\
CYP2D6 & dextromethorphan & 87 \\
CYP3A & midazolam & 3 \\
CYP3A & testosterone & 29 \\
\hline
\end{tabular}

Note: Eurofins Panlabs Inc. performed the experiments in this table. 


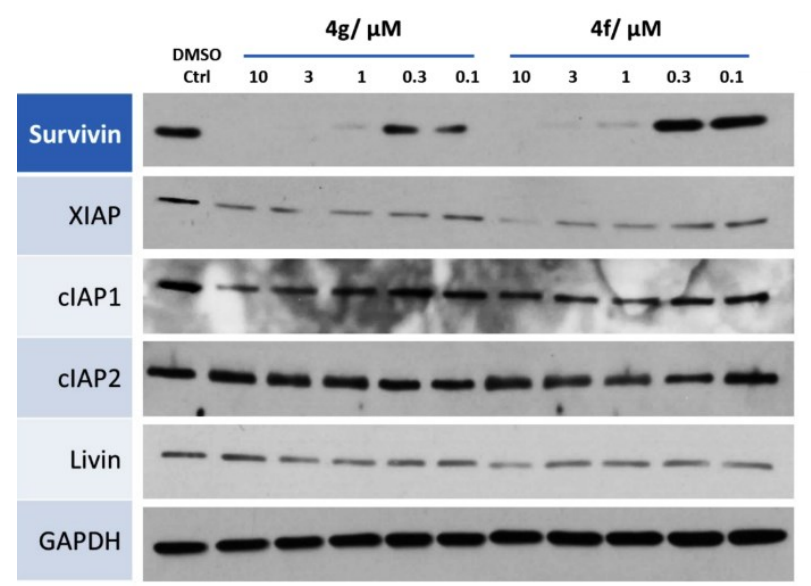

A375

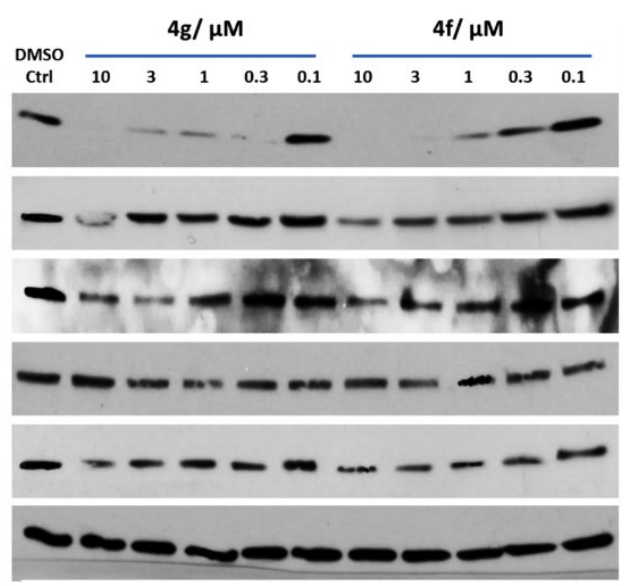

PC-3

Figure 5-9 Western blotting assay of A375 and PC-3 cells treated with gradient increasing dose of $4 \mathrm{f}$ or $\mathbf{4 g}$ for $24 \mathrm{~h}$

Left panel is in A375 cancer cell line. Right panel is in PC-3 cancer cell line. Note: Dr. Jin Wang performed the experiments for this figure. 


\section{A375 $24 \mathrm{~h}$}
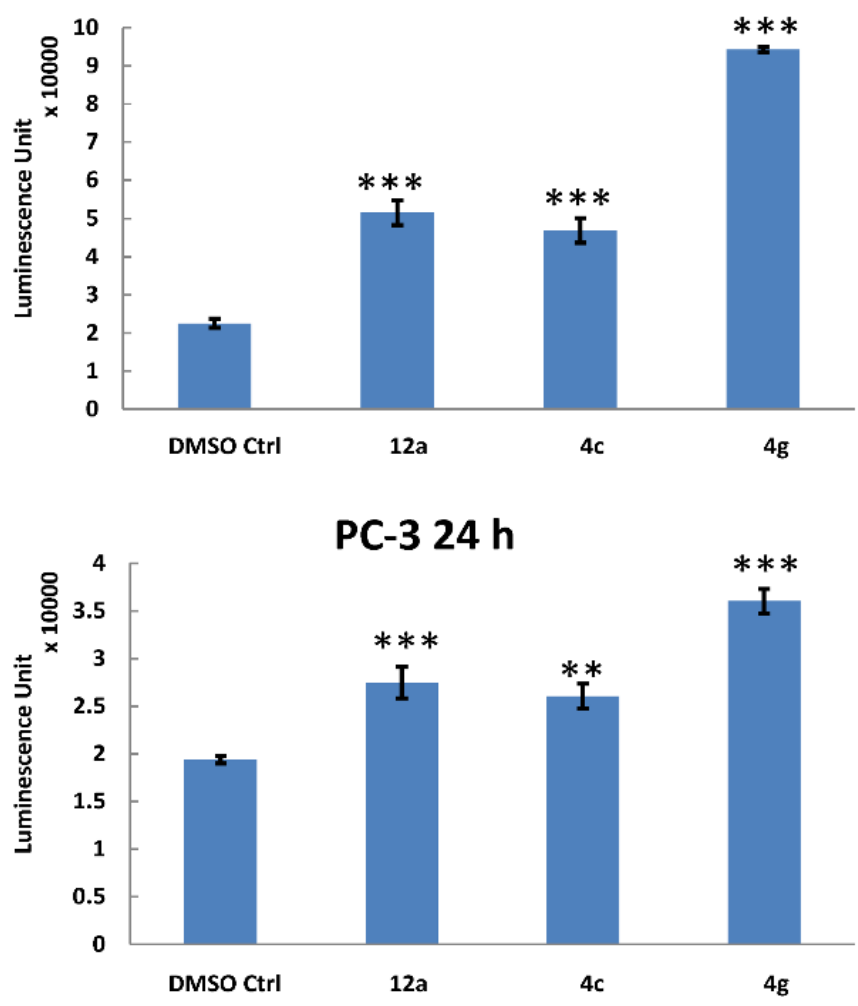

Figure 5-10. Relative in vitro caspases 3/7 activity of human melanoma A375 or human prostate cancer PC-3 cells were evaluated after treatment of UC-112 analogs ( $1 \mu \mathrm{M})$ for $24 \mathrm{~h}(\mathrm{~N}=3)$

The luminescence unit data was adjusted according to the cell viability results read from the same well in 96 -well plate. ${ }^{* * *} P<0.001,{ }^{* *} P<0.01$ compared with corresponded results from control group.

Note: Dr. Jin Wang performed the experiments for this figure. 

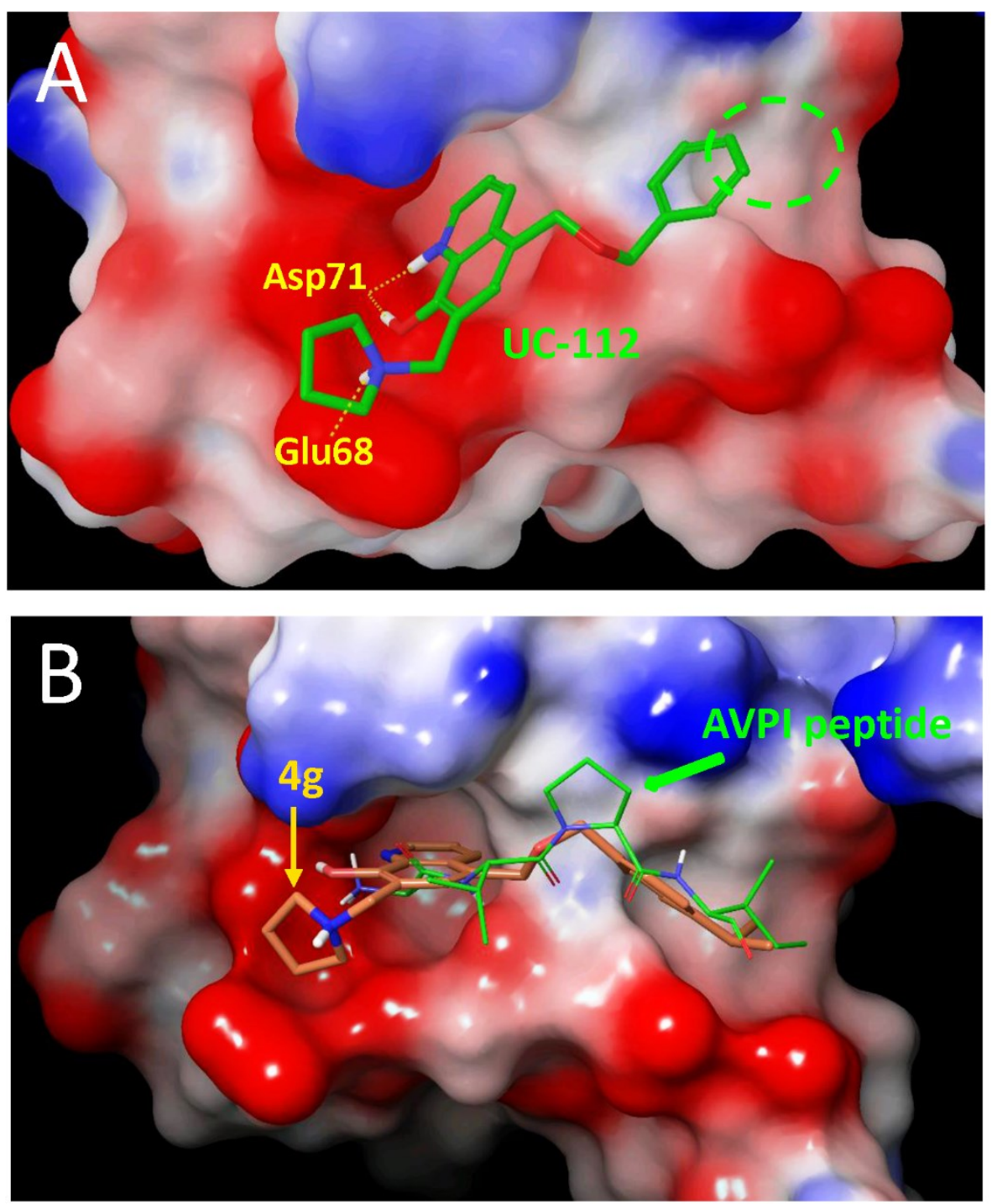

Figure 5-11. Potential binding pose of UC-112 and compound $4 \mathrm{~g}$ in the SMAC Nterminus tetra-peptide AVPI binding site of survivin crystal structure (PDB entry: 3UIH)

The surface of AVPI binding site in survivin was colored according to residue charge (blue for positive while red for negative). (a) UC-112 (green tube) formed hydrogen bonds with residue Asp71 and Glu68 on the survivin protein BIR domain. (b) Compound $\mathbf{4 g}$ (orange tube) displayed similar binding pose with UC-112 but had better occupied the grove toward the $\mathrm{N}$-terminus of survivin protein. And this pose was overlapping well with the binding mode of native ligand, SMAC AVPI (green stick).

Note: Dr. Jin Wang performed the experiments for this figure. 
binding pose clearly suggests that the un-substituted phenyl ring of UC-112 failed to occupy a hydrophobic groove (cycled with green dash line in Figure 5-11A), and a properly sized, non-polar para-substitution (e.g., an isopropyl moiety as in compound $\mathbf{4 g}$ ) to this ring would fill this groove and also provide excellent overlap with the bioactive AVPI peptide (Figure 5-11B). This is consistent with our experimental observations. Further refinement to this model, and ultimately an X-ray crystal structure will greatly facilitate the future optimization of this scaffold.

\section{Drug Affinity Responsive Target Stability (DARTS) Assay}

To investigate that whether the survivin down-regulation effect is caused by direct interaction between survivin protein and UC-112 analogs, we performed DARTS assay which is a well-established target identification method [242-245]. DARTS assay relies on the increasing of proteolysis resistance of the target protein generated by the interaction with small molecular ligand. We utilized immunoblotting to detect the abundances of several proteins including survivin in MDA-MB-435 or A375 cell lysates either undigested or digested by different concentrations of pronase. Representative data shown in Figure 5-12 clearly indicated that the protease susceptibility of survivin is significantly reduced in cell lysates pre-treated with $20 \mu \mathrm{M} \mathrm{4g}$, comparing with the GAPDH control group. Consistent with its selective survivin inhibition, $\mathbf{4} \mathbf{g}$ has negligible effects to protease susceptibility for other IAPs such as XIAP, cIAP1 or cIAP2. This observation suggested a possible direct interaction between $\mathbf{4 g}$ and survivin protein in cell lysates that will be confirmed by X-ray crystallography in the future.

\section{In Vivo Anti-Tumor Efficacy Assessment}

Since our in vitro study showed that compound $\mathbf{4 g}$ has the highest antiproliferative potency in this series of UC-112 analogs, we selected $\mathbf{4 g}$ to test its in vivo efficacy against tumor growth in a human melanoma A375 xenograft model through i.p injection. As shown in Figure 5-13A, compound 4g inhibited the growth of A375 xenograft tumor in a dose-dependent manner during the three weeks of continuous treatment. The tumor growth in compound $4 \mathrm{~g} 20 \mathrm{mg} / \mathrm{kg}$ and $40 \mathrm{mg} / \mathrm{kg}$ treatment group is $53 \%$ and $79 \%$ slower than the vehicle control group, respectively. Furthermore, Western blotting analysis revealed that the expression levels of survivin and XIAP protein decreased in tumor tissues which were freshly collected from compound $\mathbf{4 g}$ treated groups (Figure 5-13B). Terminal deoxynucleotidyl transferase dUTP nick end labeling (TUNEL) assay, which measured the nuclear DNA fragmentation, showed that a high dose $(40 \mathrm{mg} / \mathrm{kg}$ ) of compound $\mathbf{4 g}$ treatment caused the widely-spread cell apoptosis inside the tumor tissues (Figure 5-13C). 


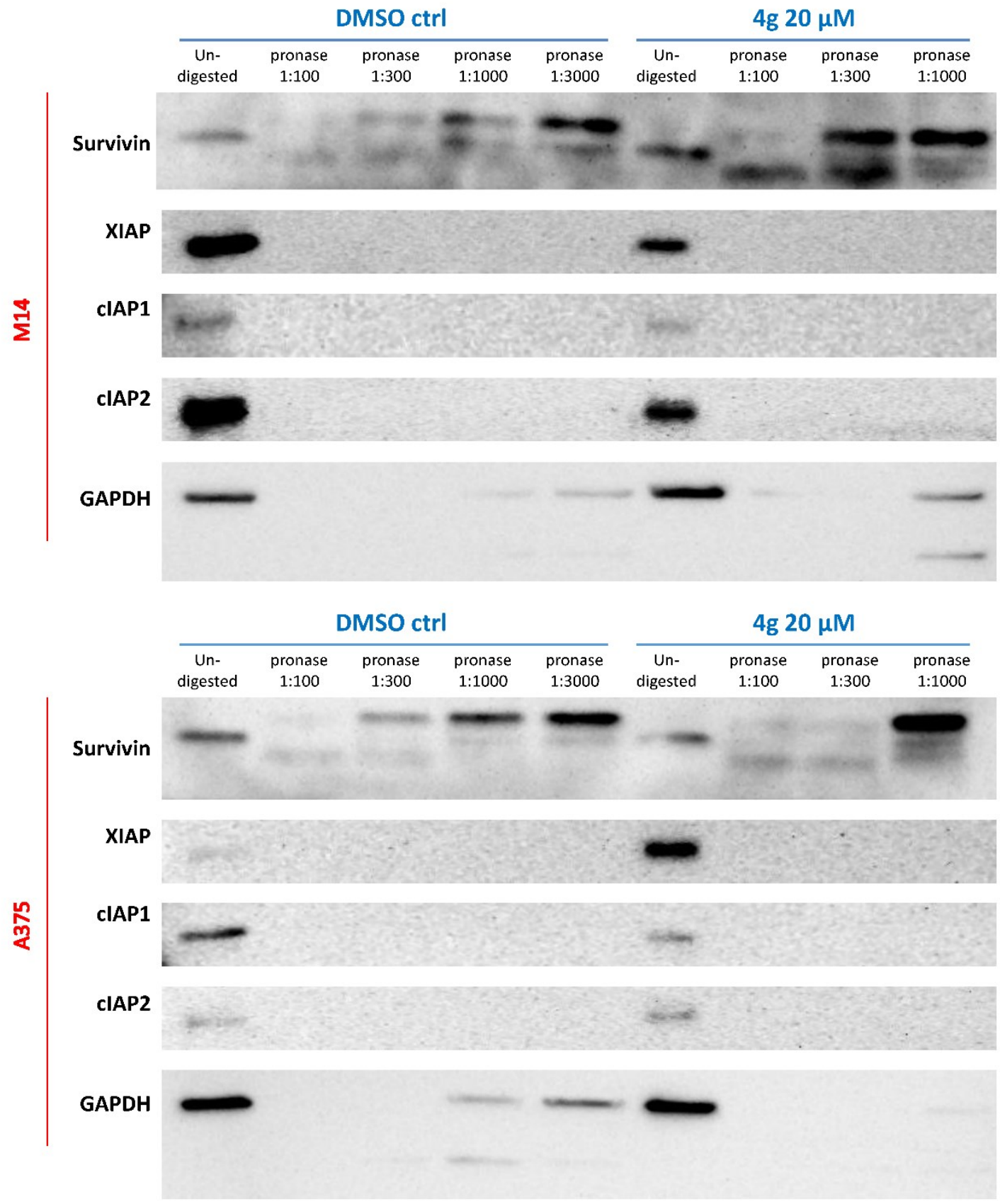

Figure 5-12. Representative drug affinity responsive target stability (DARTS) results for pronase-digested A375 or M14 cell lysates

Immunoblotting showed protection of the target protein, survivin, by incubation with compound $\mathbf{4 g}$ at the concentration of $20 \mu \mathrm{M}$, whereas digestion of the non-target proteins like GAPDH was unchanged.

Note: Dr. Jin Wang performed the experiments for this figure. 

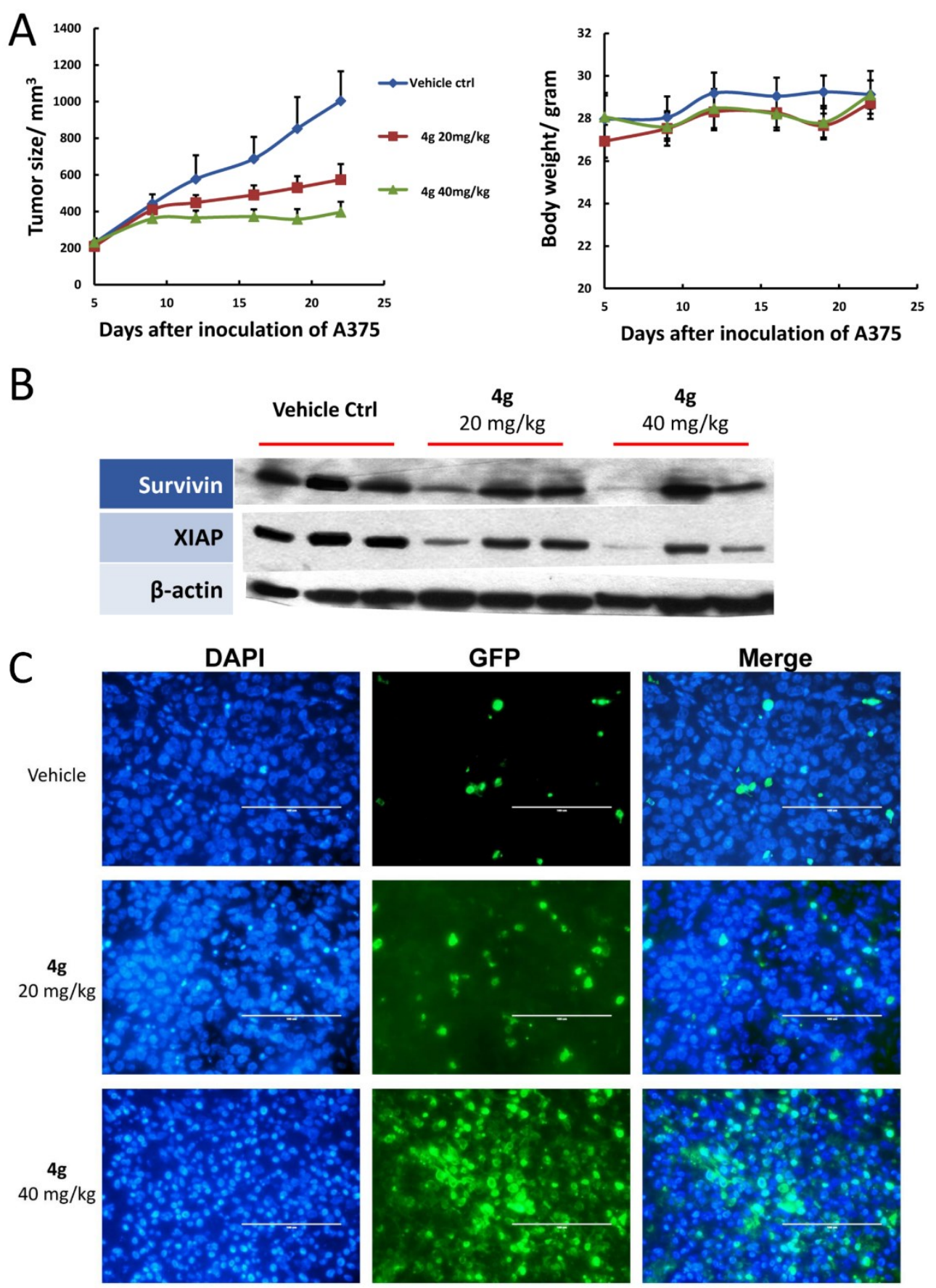

Figure 5-13. In vivo anti-tumor efficacy of compound $4 \mathrm{~g}(\mathrm{~N}=6)$

(a) $\mathbf{4 g}$ effectively inhibited the growth of A375 xenograft tumor after three weeks continuous treatment (i.p. injection) in a dose-dependent manner (left panel) without causing obvious decrease of mice body weight (right panel). (b) Western blotting results on the A375 xenograft tumor tissues (each lane represents one single mice). (c) Representative images of TUNEL assay using the formalin-fixed tumor sections. Note: Dr. Jin Wang performed the experiments for this figure. 


\section{Experimental Section}

\section{General}

All animal studies described in this manuscript have been approved by the IACUC at the University of Tennessee Health Science Center. All reagents were purchased from Sigma-Aldrich Chemical Co., Alfa Aesar (Ward Hill, MA), and AK Scientific (Mountain View, CA) and were used without further purification. Routine thin layer chromatography (TLC) was performed on aluminum-backed Uniplates (Analtech, Newark, DE). NMR spectra were obtained on a Varian Inova-500 spectrometer (Agilent Technologies, Santa Clara, CA) or a Bruker Ascend 400 (Billerica, MA) spectrometer. Chemical shifts are reported as parts per million (ppm) relative to TMS in $\mathrm{CDCl}_{3}$. High Resolution Mass spectra were collected in positive detection mode on a Waters Xevo G2$\mathrm{S}$ Tof instrument equipped with an electron-spray ionization (ESI) source (Milford, MA).

\section{Preparation of 5-Chloromethyl-8-Quinolinol Hydrochloride (2)}

A mixture of $5.84 \mathrm{~g}(40.0 \mathrm{mmol})$ of 8 -quinolinol, $50 \mathrm{ml}$ of concentrated hydrochloric acid, and $6.4 \mathrm{ml}$ of $37 \%$ formaldehyde was treated with $0.6 \mathrm{~g}$ of zinc chloride and stirred for $12 \mathrm{~h}$. The mixture was filtered, washed with copious acetone and dried to give compound 2 as a yellow solid (7.2g, 78\%). ${ }^{1} \mathrm{H}$ NMR (400 MHz, Deuterium Oxide) $\delta 9.12(\mathrm{dd}, J=8.7,1.4 \mathrm{~Hz}, 1 \mathrm{H}), 8.88(\mathrm{dd}, J=5.5,1.4 \mathrm{~Hz}, 1 \mathrm{H}), 7.97(\mathrm{dd}, J=8.7$, $5.4 \mathrm{~Hz}, 1 \mathrm{H}), 7.59$ (d, $J=8.0 \mathrm{~Hz}, 1 \mathrm{H}), 7.24$ (d, $J=7.9 \mathrm{~Hz}, 1 \mathrm{H}), 4.93$ (s, 2H).

\section{General Procedure for the Preparation of Compounds (3a-31)}

Method A (only for 3a,3f and 3g): 5-chloromethyl-8-quinolinol hydrochloride 2 (1.15 g, $5 \mathrm{mmol}$ ) was suspended in substituted benzyl alcohol $\mathbf{3}(25 \mathrm{mmol})$ and the mixture was heated at $90^{\circ} \mathrm{C}$ for $2 \mathrm{~h}$, during which time the solution became completely homogeneous. The solution was then poured to $200 \mathrm{ml}$ diethyl ether. The corresponding hydrochloride salt was recovered by filtration as a bright yellow solid. The yellow solid was then suspended in diethyl ether and aqueous $\mathrm{NH}_{4} \mathrm{OH}(2.5 \% \mathrm{v} / \mathrm{v}, 7.5 \mathrm{~mL}, \sim 1.2$ equiv.) was added drop by drop under vigorous stirring until the aqueous phase was basic $(\mathrm{pH} 8$ 10). The organic phase was washed with water, dried with anhydrous sodium sulfate and evaporated to dryness to afford the desired ethers.

Method B ( for 3b-e and 3h-l): To a solution of substituted benzyl alcohol $\mathbf{3}$ (6 $\mathrm{mmol})$ in anhydrous THF $(30 \mathrm{ml})$ was added sodium hydride $(60 \%$ dispersion in mineral oil, $0.72 \mathrm{~g}, 18 \mathrm{mmol})$ at $0{ }^{\circ} \mathrm{C}$. The suspension was stirred at $0{ }^{\circ} \mathrm{C}$ for 30 minutes. Salt 2 $(1.15 \mathrm{~g}, 5 \mathrm{mmol})$ was added to the suspension. The mixture was stirred at r.t for 3 hours. Water was added to the suspension, the mixture became homogeneous. The mixture was extracted by ethyl acetate and washed with brine, dried over anhydrous sodium sulfate 
and concentrated to get the crude. The crude compound was purified by flash chromatography (ethyl acetate: hexane 3:1).

5-(((4-Fluorobenzyl)oxy)methyl)quinolin-8-ol(3a). ${ }^{1} \mathrm{H}$ NMR $(400 \mathrm{MHz}$, Chloroform- $d$ ) $\delta 8.81(\mathrm{dd}, J=4.2,1.6 \mathrm{~Hz}, 1 \mathrm{H}), 8.47(\mathrm{dd}, J=8.5,1.5 \mathrm{~Hz}, 1 \mathrm{H}), 7.49(\mathrm{dd}, J$ $=8.5,4.2 \mathrm{~Hz}, 1 \mathrm{H}), 7.41(\mathrm{~d}, J=7.8 \mathrm{~Hz}, 1 \mathrm{H}), 7.32-7.27(\mathrm{~m}, 2 \mathrm{H}), 7.11(\mathrm{~d}, J=7.7 \mathrm{~Hz}$, $1 \mathrm{H}), 7.06-6.98(\mathrm{~m}, 2 \mathrm{H}), 4.87(\mathrm{~s}, 2 \mathrm{H}), 4.50(\mathrm{~s}, 2 \mathrm{H})$.

5-(((4-Chlorobenzyl)oxy)methyl)quinolin-8-ol(3b). ${ }^{1} \mathrm{H}$ NMR $(400 \mathrm{MHz}$, Chloroform- $d$ ) $\delta 8.83(\mathrm{dd}, J=4.2,1.6 \mathrm{~Hz}, 1 \mathrm{H}), 8.51(\mathrm{dd}, J=8.5,1.6 \mathrm{~Hz}, 1 \mathrm{H}), 7.52(\mathrm{dd}, J$ $=8.5,4.2 \mathrm{~Hz}, 1 \mathrm{H}), 7.44(\mathrm{~d}, J=7.7 \mathrm{~Hz}, 1 \mathrm{H}), 7.36-7.31(\mathrm{~m}, 5 \mathrm{H}), 7.14(\mathrm{~d}, J=7.7 \mathrm{~Hz}$, $1 \mathrm{H}), 4.90(\mathrm{~s}, 2 \mathrm{H}), 4.53(\mathrm{~s}, 2 \mathrm{H})$.

5-(((4-Bromobenzyl)oxy)methyl)quinolin-8-ol(3c). ${ }^{1} \mathrm{H}$ NMR $(400 \mathrm{MHz}$, Chloroform- $d$ ) $\delta 8.81(\mathrm{dd}, J=4.2,1.6 \mathrm{~Hz}, 1 \mathrm{H}), 8.47(\mathrm{dd}, J=8.5,1.6 \mathrm{~Hz}, 1 \mathrm{H}), 7.51-7.45$ $(\mathrm{m}, 3 \mathrm{H}), 7.41(\mathrm{~d}, J=7.7 \mathrm{~Hz}, 1 \mathrm{H}), 7.22-7.17(\mathrm{~m}, 2 \mathrm{H}), 7.11(\mathrm{~d}, J=7.7 \mathrm{~Hz}, 1 \mathrm{H}), 4.87$ (s, $2 \mathrm{H}), 4.48(\mathrm{~s}, 2 \mathrm{H})$.

5-(((4-(Trifluoromethyl)benzyl)oxy)methyl)quinolin-8-ol(3d). ${ }^{1} \mathrm{H}$ NMR (400 MHz, Chloroform- $d$ ) $\delta 8.75(\mathrm{dd}, J=4.2,1.6 \mathrm{~Hz}, 1 \mathrm{H}), 8.45(\mathrm{dd}, J=8.5,1.6 \mathrm{~Hz}, 1 \mathrm{H}), 7.56$ $-7.49(\mathrm{~m}, 2 \mathrm{H}), 7.45(\mathrm{dd}, J=8.5,4.3 \mathrm{~Hz}, 1 \mathrm{H}), 7.36$ (ddd, $J=7.8,2.0,1.2 \mathrm{~Hz}, 3 \mathrm{H}), 7.08$ $(\mathrm{d}, J=7.7 \mathrm{~Hz}, 1 \mathrm{H}), 4.85(\mathrm{~s}, 2 \mathrm{H}), 4.51(\mathrm{~s}, 2 \mathrm{H})$.

5-(((4-Methylbenzyl)oxy)methyl)quinolin-8-ol(3e). ${ }^{1} \mathrm{H}$ NMR $(500 \mathrm{MHz}$, Chloroform- $d$ ) $\delta 8.72(\mathrm{dd}, J=4.2,1.6 \mathrm{~Hz}, 1 \mathrm{H}), 8.40(\mathrm{dd}, J=8.5,1.6 \mathrm{~Hz}, 1 \mathrm{H}), 7.40(\mathrm{dd}, J$ $=8.5,4.1 \mathrm{~Hz}, 1 \mathrm{H}), 7.34(\mathrm{~d}, J=7.7 \mathrm{~Hz}, 1 \mathrm{H}), 7.15(\mathrm{~d}, J=7.9 \mathrm{~Hz}, 2 \mathrm{H}), 7.09(\mathrm{~d}, J=7.8 \mathrm{~Hz}$, 2H), $7.03(\mathrm{~d}, J=7.7 \mathrm{~Hz}, 1 \mathrm{H}), 4.78(\mathrm{~s}, 2 \mathrm{H}), 4.44(\mathrm{~s}, 2 \mathrm{H}), 2.28(\mathrm{~s}, 3 \mathrm{H})$.

5-(((4-Ethylbenzyl)oxy)methyl)quinolin-8-ol(3f). ${ }^{1} \mathrm{H}$ NMR $(400 \mathrm{MHz}$, Chloroform- $d$ ) $\delta 8.72(\mathrm{dd}, J=4.2,1.6 \mathrm{~Hz}, 1 \mathrm{H}), 8.41(\mathrm{dd}, J=8.5,1.5 \mathrm{~Hz}, 1 \mathrm{H}), 7.40(\mathrm{dd}, J$ $=8.5,4.2 \mathrm{~Hz}, 1 \mathrm{H}), 7.35(\mathrm{~d}, J=7.7 \mathrm{~Hz}, 1 \mathrm{H}), 7.17(\mathrm{~d}, J=2.1 \mathrm{~Hz}, 2 \mathrm{H}), 7.11(\mathrm{~d}, J=8.0 \mathrm{~Hz}$, 2H), $7.03(\mathrm{~d}, J=7.7 \mathrm{~Hz}, 1 \mathrm{H}), 4.79(\mathrm{~s}, 2 \mathrm{H}), 4.44(\mathrm{~s}, 2 \mathrm{H}), 2.58(\mathrm{q}, J=7.6 \mathrm{~Hz}, 2 \mathrm{H}), 1.16$ (t, $J=7.6 \mathrm{~Hz}, 3 \mathrm{H})$.

5-(((4-Isopropylbenzyl)oxy)methyl)quinolin-8-ol(3g). ${ }^{1} \mathrm{H}$ NMR (400 MHz, Chloroform- $d$ ) $\delta 8.72(\mathrm{dd}, J=4.2,1.6 \mathrm{~Hz}, 1 \mathrm{H}), 8.41(\mathrm{dd}, J=8.5,1.6 \mathrm{~Hz}, 1 \mathrm{H}), 7.40(\mathrm{dd}, J$ $=8.5,4.2 \mathrm{~Hz}, 1 \mathrm{H}), 7.35(\mathrm{~d}, J=7.7 \mathrm{~Hz}, 1 \mathrm{H}), 7.18(\mathrm{~d}, J=4.2 \mathrm{~Hz}, 2 \mathrm{H}), 7.14(\mathrm{~d}, J=8.2 \mathrm{~Hz}$, 2H), $7.03(\mathrm{~d}, J=7.7 \mathrm{~Hz}, 1 \mathrm{H}), 4.80(\mathrm{~s}, 2 \mathrm{H}), 4.44$ (s, 2H), 2.83 (p, J=6.9 Hz, 1H), 1.17 (d, $J=7.0 \mathrm{~Hz}, 6 \mathrm{H})$.

5-(((4-(Tert-butyl)benzyl)oxy)methyl)quinolin-8-ol(3h). ${ }^{1} \mathrm{H}$ NMR $(400 \mathrm{MHz}$, Chloroform-d) $\delta 8.67(\mathrm{dd}, J=4.2,1.6 \mathrm{~Hz}, 1 \mathrm{H}), 8.37(\mathrm{dd}, J=8.5,1.6 \mathrm{~Hz}, 1 \mathrm{H}), 7.35(\mathrm{dd}, J$ $=8.5,4.2 \mathrm{~Hz}, 1 \mathrm{H}), 7.31(\mathrm{~d}, J=7.7 \mathrm{~Hz}, 1 \mathrm{H}), 7.25(\mathrm{~d}, J=8.5 \mathrm{~Hz}, 2 \mathrm{H}), 7.17-7.13(\mathrm{~m}$, 2H), $6.98(\mathrm{~d}, J=7.7 \mathrm{~Hz}, 1 \mathrm{H}), 4.76(\mathrm{~s}, 2 \mathrm{H}), 4.40(\mathrm{~s}, 2 \mathrm{H}), 1.20(\mathrm{~s}, 9 \mathrm{H})$. 
5-(((4-Methoxybenzyl)oxy)methyl)quinolin-8-ol(3i). ${ }^{1} \mathrm{H}$ NMR $(400 \mathrm{MHz}$, Chloroform- $d$ ) $\delta 8.80(\mathrm{dd}, J=4.2,1.6 \mathrm{~Hz}, 1 \mathrm{H}), 8.47(\mathrm{dd}, J=8.5,1.6 \mathrm{~Hz}, 1 \mathrm{H}), 7.48(\mathrm{dd}, J$ $=8.5,4.2 \mathrm{~Hz}, 1 \mathrm{H}), 7.41(\mathrm{~d}, J=7.8 \mathrm{~Hz}, 1 \mathrm{H}), 7.28-7.23(\mathrm{~m}, 2 \mathrm{H}), 7.10(\mathrm{~d}, J=7.7 \mathrm{~Hz}$, $1 \mathrm{H}), 6.93-6.82(\mathrm{~m}, 2 \mathrm{H}), 4.84(\mathrm{~s}, 2 \mathrm{H}), 4.48(\mathrm{~s}, 2 \mathrm{H}), 3.81(\mathrm{~s}, 3 \mathrm{H})$.

5-(((4-(Benzyloxy)benzyl)oxy)methyl)quinolin-8-ol(3j). ${ }^{1} \mathrm{H}$ NMR $(500 \mathrm{MHz}$, Chloroform- $d$ ) $\delta 8.84(\mathrm{~d}, J=4.2 \mathrm{~Hz}, 1 \mathrm{H}), 8.51(\mathrm{~d}, J=8.5 \mathrm{~Hz}, 1 \mathrm{H}), 7.53-7.41(\mathrm{~m}, 6 \mathrm{H})$, $7.37(\mathrm{t}, J=7.3 \mathrm{~Hz}, 1 \mathrm{H}), 7.34-7.27(\mathrm{~m}, 2 \mathrm{H}), 7.16(\mathrm{~d}, J=7.6 \mathrm{~Hz}, 1 \mathrm{H}), 7.06-6.98(\mathrm{~m}$, $2 \mathrm{H}), 5.12(\mathrm{~s}, 2 \mathrm{H}), 4.89(\mathrm{~s}, 2 \mathrm{H}), 4.53(\mathrm{~s}, 2 \mathrm{H})$.

N-(4-(((8-Hydroxyquinolin-5-yl)methoxy)methyl)phenyl)acetamide(3k). ${ }^{1} \mathrm{H}$ NMR (400 MHz, DMSO-d6) $\delta 9.93(\mathrm{~s}, 1 \mathrm{H}), 9.86(\mathrm{~s}, 1 \mathrm{H}), 8.87(\mathrm{dd}, J=4.1,1.6 \mathrm{~Hz}, 1 \mathrm{H})$, $8.47(\mathrm{dd}, J=8.6,1.6 \mathrm{~Hz}, 1 \mathrm{H}), 7.60(\mathrm{dd}, J=8.6,4.2 \mathrm{~Hz}, 1 \mathrm{H}), 7.57-7.52(\mathrm{~m}, 2 \mathrm{H}), 7.44$ $(\mathrm{d}, J=7.8 \mathrm{~Hz}, 1 \mathrm{H}), 7.28-7.21(\mathrm{~m}, 2 \mathrm{H}), 7.02(\mathrm{~d}, J=7.7 \mathrm{~Hz}, 1 \mathrm{H}), 4.83(\mathrm{~s}, 2 \mathrm{H}), 4.47$ (s, $2 \mathrm{H}), 2.03(\mathrm{~s}, 3 \mathrm{H})$.

5-(((3,4,5-Trimethoxybenzyl)oxy)methyl)quinolin-8-ol (3I). ${ }^{1} \mathrm{H}$ NMR (400 $\mathrm{MHz}$, Chloroform- $d$ ) $\delta 8.85(\mathrm{dd}, J=4.3,1.5 \mathrm{~Hz}, 1 \mathrm{H}), 8.57(\mathrm{dd}, J=8.5,1.5 \mathrm{~Hz}, 1 \mathrm{H}), 7.53$ $(\mathrm{dd}, J=8.5,4.2 \mathrm{~Hz}, 1 \mathrm{H}), 7.47$ (d, $J=7.8 \mathrm{~Hz}, 1 \mathrm{H}), 7.19$ (d, $J=7.6 \mathrm{~Hz}, 1 \mathrm{H}), 6.56(\mathrm{~s}, 2 \mathrm{H})$, $4.92(\mathrm{~s}, 2 \mathrm{H}), 4.50(\mathrm{~s}, 2 \mathrm{H}), 3.86(\mathrm{~s}, 3 \mathrm{H}), 3.84(\mathrm{~s}, 6 \mathrm{H})$

\section{General Procure for the Preparation of Compounds (4a-4l)}

An equimolar mixture of the substrates $\mathbf{3}$, paraformaldehyde, and the pyrrolidine in anhydrous ethanol $(30 \mathrm{~mL})$ was refluxed for 4 hours under argon. After cooling, the solvent was evaporated under reduced pressure. The crude compound was purified by flash chromatography (Dichloromethane: methanol 20: 1).

5-(((4-Fluorobenzyl)oxy)methyl)-7-(pyrrolidin-1-ylmethyl)quinolin-8-ol(4a). ${ }^{1} \mathrm{H}$ NMR (400 MHz, Chloroform- $d$ ) $\delta 8.91$ (dd, $\left.J=4.1,1.6 \mathrm{~Hz}, 1 \mathrm{H}\right), 8.40$ (dd, $J=8.5,1.7$ $\mathrm{Hz}, 1 \mathrm{H}), 7.44(\mathrm{dd}, J=8.5,4.2 \mathrm{~Hz}, 1 \mathrm{H}), 7.35-7.30(\mathrm{~m}, 2 \mathrm{H}), 7.26(\mathrm{~s}, 1 \mathrm{H}), 7.10-6.97$ (m, 2H), $4.87(\mathrm{~s}, 2 \mathrm{H}), 4.55(\mathrm{~s}, 2 \mathrm{H}), 4.02(\mathrm{~s}, 2 \mathrm{H}), 2.84-2.61(\mathrm{~m}, 4 \mathrm{H}), 2.01-1.79(\mathrm{~m}, 4 \mathrm{H})$. HRMS (ESI): $\mathrm{m} / \mathrm{z}$ calculated for $\mathrm{C}_{22} \mathrm{H}_{23} \mathrm{FN}_{2} \mathrm{O}_{2}+\mathrm{H}^{+}\left[\mathrm{M}+\mathrm{H}^{+}\right]$: 367.1822; Found: 367.1828 .

5-(((4-Chlorobenzyl)oxy)methyl)-7-(pyrrolidin-1-ylmethyl)quinolin-8-ol(4b). ${ }^{1} \mathrm{H}$ NMR (400 MHz, Chloroform- $d$ ) $\delta 8.82(\mathrm{dd}, J=4.1,1.6 \mathrm{~Hz}, 1 \mathrm{H}), 8.30(\mathrm{dd}, J=8.5,1.7$ $\mathrm{Hz}, 1 \mathrm{H}), 7.34(\mathrm{dd}, J=8.5,4.1 \mathrm{~Hz}, 1 \mathrm{H}), 7.27-7.22(\mathrm{~m}, 2 \mathrm{H}), 7.21-7.17$ (m, 2H), 7.15 (s, 1H), 4.77 (s, 2H), $4.45(\mathrm{~s}, 2 \mathrm{H}), 3.92(\mathrm{~s}, 2 \mathrm{H}), 2.70-2.56(\mathrm{~m}, 4 \mathrm{H}), 1.88-1.74(\mathrm{~m}, 4 \mathrm{H})$. HRMS (ESI): $\mathrm{m} / \mathrm{z}$ calculated for $\mathrm{C}_{22} \mathrm{H}_{23} \mathrm{ClN}_{2} \mathrm{O}_{2}+\mathrm{H}^{+}\left[\mathrm{M}+\mathrm{H}^{+}\right]: 383.1526$; Found: 383.1521 .

5-(((4-Bromobenzyl)oxy)methyl)-7-(pyrrolidin-1-ylmethyl)quinolin-8-ol(4c). ${ }^{1} \mathrm{H}$ NMR $(400 \mathrm{MHz}$, Chloroform- $d$ ) $\delta 8.89(\mathrm{dd}, J=4.2,1.7 \mathrm{~Hz}, 1 \mathrm{H}), 8.38(\mathrm{dd}, J=8.5,1.7$ $\mathrm{Hz}, 1 \mathrm{H}), 7.49-7.44(\mathrm{~m}, 2 \mathrm{H}), 7.42(\mathrm{dd}, J=8.5,4.1 \mathrm{~Hz}, 1 \mathrm{H}), 7.25(\mathrm{~s}, 1 \mathrm{H}), 7.23-7.17$ (m, 
2H), $4.85(\mathrm{~s}, 2 \mathrm{H}), 4.51(\mathrm{~s}, 2 \mathrm{H}), 4.01(\mathrm{~s}, 2 \mathrm{H}), 2.84-2.64(\mathrm{~m}, 4 \mathrm{H}), 1.97-1.81(\mathrm{~m}, 4 \mathrm{H})$. HRMS (ESI): $\mathrm{m} / \mathrm{z}$ calculated for $\mathrm{C}_{22} \mathrm{H}_{23} \mathrm{BrN}_{2} \mathrm{O}_{2}+\mathrm{H}^{+}\left[\mathrm{M}+\mathrm{H}^{+}\right]: 427.1021$; Found: 427.1015 .

\section{7-(Pyrrolidin-1-ylmethyl)-5-(((4-} (trifluoromethyl)benzyl)oxy)methyl)quinolin-8-ol(4d). ${ }^{1} \mathrm{H}$ NMR $(500 \mathrm{MHz}$, Chloroform- $d$ ) $\delta 8.91(\mathrm{dd}, J=4.1,1.6 \mathrm{~Hz}, 1 \mathrm{H}), 8.42(\mathrm{dd}, J=8.5,1.7 \mathrm{~Hz}, 1 \mathrm{H}), 7.61(\mathrm{~d}, J$ $=8.0 \mathrm{~Hz}, 2 \mathrm{H}), 7.49-7.40(\mathrm{~m}, 3 \mathrm{H}), 7.27(\mathrm{~d}, J=3.1 \mathrm{~Hz}, 1 \mathrm{H}), 4.90(\mathrm{~s}, 2 \mathrm{H}), 4.62(\mathrm{~s}, 2 \mathrm{H})$, $4.02(\mathrm{~s}, 2 \mathrm{H}), 2.82-2.68(\mathrm{~m}, 4 \mathrm{H}), 1.97-1.85$ (m, 4H). HRMS (ESI): m/z calculated for $\mathrm{C}_{23} \mathrm{H}_{23} \mathrm{~F}_{3} \mathrm{~N}_{2} \mathrm{O}_{2}+\mathrm{H}^{+}\left[\mathrm{M}+\mathrm{H}^{+}\right]$: 417.1790; Found: 417.1792.

5-(((4-Methylbenzyl)oxy)methyl)-7-(pyrrolidin-1-ylmethyl)quinolin-8-ol(4e). ${ }^{1} \mathrm{H}$ NMR (500 MHz, Chloroform- $d$ ) $\delta 8.80(\mathrm{dd}, J=4.2,1.7 \mathrm{~Hz}, 1 \mathrm{H}), 8.31(\mathrm{dd}, J=8.5,1.7$ $\mathrm{Hz}, 1 \mathrm{H}), 7.34(\mathrm{dd}, J=8.5,4.1 \mathrm{~Hz}, 1 \mathrm{H}), 7.23(\mathrm{~s}, 1 \mathrm{H}), 7.16(\mathrm{~d}, J=7.9 \mathrm{~Hz}, 2 \mathrm{H}), 7.09$ (d, $J=$ $7.7 \mathrm{~Hz}, 2 \mathrm{H}), 4.75(\mathrm{~s}, 2 \mathrm{H}), 4.46(\mathrm{~s}, 2 \mathrm{H}), 3.96(\mathrm{~s}, 2 \mathrm{H}), 2.80-2.65(\mathrm{~m}, 4 \mathrm{H}), 2.28(\mathrm{~s}, 3 \mathrm{H})$, $1.88-1.78$ (m, 4H). HRMS (ESI): $\mathrm{m} / \mathrm{z}$ calculated for $\mathrm{C}_{23} \mathrm{H}_{26} \mathrm{~N}_{2} \mathrm{O}_{2}+\mathrm{H}^{+}\left[\mathrm{M}+\mathrm{H}^{+}\right]$: 363.2073; Found: 363.2078.

5-(((4-Ethylbenzyl)oxy)methyl)-7-(pyrrolidin-1-ylmethyl)quinolin-8-ol(4f). ${ }^{1} \mathrm{H}$ NMR (400 MHz, Chloroform- $d$ ) $\delta 8.81(\mathrm{dd}, J=4.2,1.7 \mathrm{~Hz}, 1 \mathrm{H}), 8.30(\mathrm{dd}, J=8.5,1.7$ $\mathrm{Hz}, 1 \mathrm{H}), 7.33(\mathrm{dd}, J=8.5,4.1 \mathrm{~Hz}, 1 \mathrm{H}), 7.20(\mathrm{~s}, 1 \mathrm{H}), 7.18(\mathrm{~d}, J=5.4 \mathrm{~Hz}, 2 \mathrm{H}), 7.12(\mathrm{~d}, J=$ $8.1 \mathrm{~Hz}, 2 \mathrm{H}), 4.76(\mathrm{~s}, 2 \mathrm{H}), 4.47(\mathrm{~s}, 2 \mathrm{H}), 3.93(\mathrm{~s}, 2 \mathrm{H}), 2.70-2.62(\mathrm{~m}, 4 \mathrm{H}), 2.58(\mathrm{q}, J=7.6$ $\mathrm{Hz}, 2 \mathrm{H}), 1.88-1.74 \mathrm{~m}, 4 \mathrm{H}), 1.16(\mathrm{t}, J=7.6 \mathrm{~Hz}, 3 \mathrm{H})$. HRMS (ESI): $\mathrm{m} / \mathrm{z}$ calculated for $\mathrm{C}_{24} \mathrm{H}_{28} \mathrm{~N}_{2} \mathrm{O}_{2}+\mathrm{H}^{+}\left[\mathrm{M}+\mathrm{H}^{+}\right]$: 377.2229; Found: 377.2240.

5-(((4-Isopropylbenzyl)oxy)methyl)-7-(pyrrolidin-1-ylmethyl)quinolin-8ol(4g). ${ }^{1} \mathrm{H}$ NMR (400 MHz, Chloroform- $d$ ) $\delta 8.89$ (dd, $\left.J=4.1,1.6 \mathrm{~Hz}, 1 \mathrm{H}\right), 8.38$ (dd, $J=$ 8.5, $1.6 \mathrm{~Hz}, 1 \mathrm{H}), 7.40(\mathrm{dd}, J=8.5,4.1 \mathrm{~Hz}, 1 \mathrm{H}), 7.29(\mathrm{~s}, 1 \mathrm{H}), 7.26-7.20(\mathrm{~m}, 4 \mathrm{H}), 4.85$ (s, $2 \mathrm{H}), 4.55(\mathrm{~s}, 2 \mathrm{H}), 4.00(\mathrm{~s}, 2 \mathrm{H}), 2.92(\mathrm{p}, J=6.9 \mathrm{~Hz}, 1 \mathrm{H}), 2.78-2.60(\mathrm{~m}, 4 \mathrm{H}), 1.96-1.80$ $(\mathrm{m}, 4 \mathrm{H}), 1.25(\mathrm{~d}, J=6.9 \mathrm{~Hz}, 6 \mathrm{H})$. HRMS (ESI): $\mathrm{m} / \mathrm{z}$ calculated for $\mathrm{C}_{25} \mathrm{H}_{30} \mathrm{~N}_{2} \mathrm{O}_{2}+\mathrm{H}^{+}[\mathrm{M}$ $+\mathrm{H}^{+}$]: 391.2386; Found: 391.2377.

5-(((4-(Tert-butyl)benzyl)oxy)methyl)-7-(pyrrolidin-1-ylmethyl)quinolin-8ol(4h). ${ }^{1} \mathrm{H}$ NMR (400 MHz, Chloroform- $d$ ) $\delta 8.81$ (dd, $\left.J=4.1,1.6 \mathrm{~Hz}, 1 \mathrm{H}\right), 8.31$ (dd, $J=$ 8.5, $1.7 \mathrm{~Hz}, 1 \mathrm{H}), 7.36-7.28(\mathrm{~m}, 3 \mathrm{H}), 7.23-7.19(\mathrm{~m}, 2 \mathrm{H}), 4.78(\mathrm{~s}, 2 \mathrm{H}), 4.47$ (s, 2H), $3.94(\mathrm{~s}, 2 \mathrm{H}), 2.77-2.50(\mathrm{~m}, 4 \mathrm{H}), 1.90-1.74(\mathrm{~m}, 4 \mathrm{H}), 1.25(\mathrm{~s}, 9 \mathrm{H})$. HRMS (ESI): m/z calculated for $\mathrm{C}_{26} \mathrm{H}_{32} \mathrm{~N}_{2} \mathrm{O}_{2}+\mathrm{H}^{+}\left[\mathrm{M}+\mathrm{H}^{+}\right]$: 405.2542 ; Found: 405.2535.

5-(((4-Methoxybenzyl)oxy)methyl)-7-(pyrrolidin-1-ylmethyl)quinolin-8-ol(4i). ${ }^{1} \mathrm{H}$ NMR (500 MHz, Chloroform-d) $\delta 8.89(\mathrm{dd}, J=4.1,1.7 \mathrm{~Hz}, 1 \mathrm{H}), 8.38(\mathrm{dd}, J=8.5,1.7$ $\mathrm{Hz}, 1 \mathrm{H}), 7.41(\mathrm{dd}, J=8.5,4.1 \mathrm{~Hz}, 1 \mathrm{H}), 7.30-7.27(\mathrm{~m}, 2 \mathrm{H}), 7.25(\mathrm{~s}, 1 \mathrm{H}), 6.97-6.83$ (m, $2 \mathrm{H}), 4.83(\mathrm{~s}, 2 \mathrm{H}), 4.52(\mathrm{~s}, 2 \mathrm{H}), 4.01(\mathrm{~s}, 2 \mathrm{H}), 3.82(\mathrm{~s}, 3 \mathrm{H}), 2.86-2.62(\mathrm{~m}, 4 \mathrm{H}), 1.96-$ 1.79 (m, 4H). HRMS (ESI): $\mathrm{m} / \mathrm{z}$ calculated for $\mathrm{C}_{23} \mathrm{H}_{26} \mathrm{~N}_{2} \mathrm{O}_{3}+\mathrm{H}^{+}\left[\mathrm{M}+\mathrm{H}^{+}\right]: 379.2022$; Found: 379.2025 . 
5-(((4-(Benzyloxy)benzyl)oxy)methyl)-7-(pyrrolidin-1-ylmethyl)quinolin-8ol(4j). ${ }^{1} \mathrm{H}$ NMR (400 MHz, Chloroform- $d$ ) $\delta 8.80$ (dd, $\left.J=4.1,1.6 \mathrm{~Hz}, 1 \mathrm{H}\right), 8.30$ (dd, $J=$ 8.5, $1.7 \mathrm{~Hz}, 1 \mathrm{H}), 7.39-7.29(\mathrm{~m}, 5 \mathrm{H}), 7.28-7.20(\mathrm{~m}, 4 \mathrm{H}), 6.94-6.85(\mathrm{~m}, 2 \mathrm{H}), 5.00(\mathrm{~s}$, 2H), $4.75(\mathrm{~s}, 2 \mathrm{H}), 4.44(\mathrm{~s}, 2 \mathrm{H}), 3.97(\mathrm{~s}, 2 \mathrm{H}), 2.80-2.60(\mathrm{~m}, 4 \mathrm{H}), 1.90-1.76(\mathrm{~m}, 4 \mathrm{H})$. HRMS (ESI): $\mathrm{m} / \mathrm{z}$ calculated for $\mathrm{C}_{29} \mathrm{H}_{30} \mathrm{~N}_{2} \mathrm{O}_{3}+\mathrm{H}^{+}\left[\mathrm{M}+\mathrm{H}^{+}\right]$: 455.2335; Found: 455.2335 .

N-(4-(((8-Hydroxy-7-(pyrrolidin-1-ylmethyl)quinolin-5-yl)methoxy) methyl)phenyl)acetamide(4k). ${ }^{1} \mathrm{H}$ NMR $(400 \mathrm{MHz}$, Chloroform- $d) \delta 8.81(\mathrm{dd}, J=4.1$, $1.7 \mathrm{~Hz}, 1 \mathrm{H}), 8.30(\mathrm{dd}, J=8.5,1.7 \mathrm{~Hz}, 1 \mathrm{H}), 7.42(\mathrm{~d}, J=8.4 \mathrm{~Hz}, 2 \mathrm{H}), 7.34(\mathrm{dd}, J=8.5,4.1$ $\mathrm{Hz}, 1 \mathrm{H}), 7.25-7.20(\mathrm{~m}, 2 \mathrm{H}), 7.18(\mathrm{~s}, 1 \mathrm{H}), 4.75$ (s, 2H), $4.46(\mathrm{~s}, 2 \mathrm{H}), 3.94(\mathrm{~s}, 2 \mathrm{H}), 2.76-$ $2.66(\mathrm{~m}, 4 \mathrm{H}), 2.11(\mathrm{~s}, 3 \mathrm{H}), 1.88-1.76(\mathrm{~m}, 4 \mathrm{H})$. HRMS (ESI): $\mathrm{m} / \mathrm{z}$ calculated for $\mathrm{C}_{24} \mathrm{H}_{27} \mathrm{~N}_{3} \mathrm{O}_{3}+\mathrm{H}^{+}\left[\mathrm{M}+\mathrm{H}^{+}\right]$: 406.2131; Found: 406.2136.

7-(Pyrrolidin-1-ylmethyl)-5-(((3,4,5-trimethoxybenzyl)oxy)methyl)quinolin-8ol(4l). ${ }^{1} \mathrm{H}$ NMR (400 MHz, Chloroform- $d$ ) $\delta 8.82(\mathrm{dd}, J=4.1,1.6 \mathrm{~Hz}, 1 \mathrm{H}), 8.34$ (dd, $J=$ 8.5, 1.7 Hz, 1H), 7.34 (dd, $J=8.5,4.1 \mathrm{~Hz}, 1 \mathrm{H}), 7.19(\mathrm{~s}, 1 \mathrm{H}), 6.48(\mathrm{~s}, 2 \mathrm{H}), 4.79(\mathrm{~s}, 2 \mathrm{H})$, $4.42(\mathrm{~s}, 2 \mathrm{H}), 3.93(\mathrm{~s}, 2 \mathrm{H}), 3.77(\mathrm{~s}, 3 \mathrm{H}), 3.76(\mathrm{~s}, 6 \mathrm{H}), 2.78-2.48(\mathrm{~m}, 4 \mathrm{H}), 1.89-1.66(\mathrm{~m}$, $4 \mathrm{H})$. HRMS (ESI): $\mathrm{m} / \mathrm{z}$ calculated for $\mathrm{C}_{25} \mathrm{H}_{30} \mathrm{~N}_{2} \mathrm{O}_{5}+\mathrm{H}^{+}\left[\mathrm{M}+\mathrm{H}^{+}\right]$: 439.2233; Found: 439.2245.

\section{General Procure for the Preparation of Compounds (5a-5g)}

Method A (for 5a-5d): To a solution of alcohols $(6 \mathrm{mmol})$ in anhydrous THF $(30 \mathrm{ml})$ was added sodium hydride (60\% dispersion in mineral oil, $0.72 \mathrm{~g}, 18 \mathrm{mmol})$ at $0{ }^{\circ} \mathrm{C}$. The suspension was stirred at $0{ }^{\circ} \mathrm{C}$ for 30 minutes. Salt $2(1.15 \mathrm{~g}, 5 \mathrm{mmol})$ was added to the suspension. The mixture was stirred at r.t for 3 hours. Water was added to the suspension, the mixture became homogeneous. The mixture was extracted by ethyl acetate and washed with brine, dried over anhydrous sodium sulfate and concentrated to get the crude. The crude compound was purified by flash chromatography (ethyl acetate: hexane $3: 1)$.

Method B (for 5e-5g): 5-chloromethyl-8-quinolinol hydrochloride 2 (1.15 g, 5 mmol) was suspended in different alcohols $(25 \mathrm{mmol})$ and the mixture was heated at 90 ${ }^{\circ} \mathrm{C}$ for $2 \mathrm{~h}$, during which time the solution became completely homogeneous. The solution was then poured to $200 \mathrm{ml}$ diethyl ether. The corresponding hydrochloride salt was recovered by filtration as a bright yellow solid. The yellow solid was then suspended in diethyl ether and aqueous $\mathrm{NH}_{4} \mathrm{OH}(2.5 \% \mathrm{v} / \mathrm{v}, 7.5 \mathrm{~mL}, \sim 1.2$ equiv. $)$ was added drop by drop under vigorous stirring until the aqueous phase was basic $(\mathrm{pH} 8-10)$. The organic phase was washed with water, dried with anhydrous sodium sulfate and evaporated to dryness to afford the desired products.

5-((Furan-2-ylmethoxy)methyl)quinolin-8-ol(5a). ${ }^{1} \mathrm{H}$ NMR $(400 \mathrm{MHz}$, Chloroform- $d$ ) $\delta 8.72(\mathrm{dd}, J=4.3,1.6 \mathrm{~Hz}, 1 \mathrm{H}), 8.37$ (dd, $J=8.5,1.5 \mathrm{~Hz}, 1 \mathrm{H}), 7.41$ (dd, $J$ 
$=8.5,4.2 \mathrm{~Hz}, 1 \mathrm{H}), 7.38-7.33(\mathrm{~m}, 2 \mathrm{H}), 7.03(\mathrm{~d}, J=7.7 \mathrm{~Hz}, 1 \mathrm{H}), 6.32-6.24(\mathrm{~m}, 2 \mathrm{H})$, $4.79(\mathrm{~s}, 2 \mathrm{H}), 4.42(\mathrm{~s}, 2 \mathrm{H})$.

5-((Thiophen-2-ylmethoxy)methyl)quinolin-8-ol(5b). ${ }^{1} \mathrm{H}$ NMR $(400 \mathrm{MHz}$, Chloroform- $d$ ) $\delta 8.80(\mathrm{dd}, J=4.2,1.6 \mathrm{~Hz}, 1 \mathrm{H}), 8.48(\mathrm{dd}, J=8.5,1.6 \mathrm{~Hz}, 1 \mathrm{H}), 7.48(\mathrm{dd}, J$ $=8.5,4.2 \mathrm{~Hz}, 1 \mathrm{H}), 7.42(\mathrm{~d}, J=7.7 \mathrm{~Hz}, 1 \mathrm{H}), 7.31(\mathrm{dd}, J=4.8,1.5 \mathrm{~Hz}, 1 \mathrm{H}), 7.10(\mathrm{~d}, J=$ $7.7 \mathrm{~Hz}, 1 \mathrm{H}), 7.00-6.97(\mathrm{~m}, 2 \mathrm{H}), 4.88(\mathrm{~s}, 2 \mathrm{H}), 4.70(\mathrm{~s}, 2 \mathrm{H})$.

5-((Pyridin-2-ylmethoxy)methyl)quinolin-8-ol(5c). ${ }^{1} \mathrm{H}$ NMR $(400 \mathrm{MHz}$, Chloroform- $d$ ) $\delta 8.80(\mathrm{dd}, J=4.2,1.6 \mathrm{~Hz}, 1 \mathrm{H}), 8.58-8.52(\mathrm{~m}, 2 \mathrm{H}), 7.67(\mathrm{td}, J=7.7,1.8$ $\mathrm{Hz}, 1 \mathrm{H}), 7.50(\mathrm{dd}, J=8.5,4.2 \mathrm{~Hz}, 1 \mathrm{H}), 7.46(\mathrm{~d}, J=7.7 \mathrm{~Hz}, 1 \mathrm{H}), 7.40$ (dt, $J=7.8,1.0 \mathrm{~Hz}$, $1 \mathrm{H}), 7.21-7.16(\mathrm{~m}, 1 \mathrm{H}), 7.11(\mathrm{~d}, J=7.7 \mathrm{~Hz}, 1 \mathrm{H}), 4.98(\mathrm{~s}, 2 \mathrm{H}), 4.70(\mathrm{~s}, 2 \mathrm{H})$.

5-((Cyclohexylmethoxy)methyl)quinolin-8-ol(5d). ${ }^{1} \mathrm{H}$ NMR $(400 \mathrm{MHz}$, Chloroform-d) $\delta 8.72(\mathrm{dd}, J=4.2,1.6 \mathrm{~Hz}, 1 \mathrm{H}), 8.43(\mathrm{dd}, J=8.5,1.6 \mathrm{~Hz}, 1 \mathrm{H}), 7.42(\mathrm{dd}, J$ $=8.5,4.2 \mathrm{~Hz}, 1 \mathrm{H}), 7.34(\mathrm{~d}, J=7.7 \mathrm{~Hz}, 1 \mathrm{H}), 7.02(\mathrm{~d}, J=7.7 \mathrm{~Hz}, 1 \mathrm{H}), 4.73(\mathrm{~s}, 2 \mathrm{H}), 3.21$ $(\mathrm{d}, J=6.5 \mathrm{~Hz}, 2 \mathrm{H}), 1.79-1.41(\mathrm{~m}, \mathrm{H}), 1.23-0.97(\mathrm{~m}, 3 \mathrm{H}), 0.91-0.73(\mathrm{~m}, 2 \mathrm{H})$.

5-(Ethoxymethyl)quinolin-8-ol(5e). ${ }^{1} \mathrm{H}$ NMR (400 MHz, Chloroform- $d$ ) $\delta 8.73$ $(\mathrm{dd}, J=4.2,1.6 \mathrm{~Hz}, 1 \mathrm{H}), 8.43(\mathrm{dd}, J=8.5,1.6 \mathrm{~Hz}, 1 \mathrm{H}), 7.42(\mathrm{dd}, J=8.5,4.2 \mathrm{~Hz}, 1 \mathrm{H})$, 7.35 (d, $J=7.6 \mathrm{~Hz}, 1 \mathrm{H}), 7.03$ (d, $J=7.7 \mathrm{~Hz}, 1 \mathrm{H}), 4.76(\mathrm{~s}, 2 \mathrm{H}), 3.50$ (q, $J=7.0 \mathrm{~Hz}, 2 \mathrm{H})$, $1.16(\mathrm{t}, J=7.0 \mathrm{~Hz}, 3 \mathrm{H})$.

5-(Propoxymethyl)quinolin-8-ol(5f). ${ }^{1} \mathrm{H}$ NMR (400 MHz, Chloroform- $d$ ) $\delta 8.72$ $(\mathrm{dd}, J=4.1,1.6 \mathrm{~Hz}, 1 \mathrm{H}), 8.44(\mathrm{dd}, J=8.5,1.6 \mathrm{~Hz}, 1 \mathrm{H}), 7.42(\mathrm{dd}, J=8.6,4.2 \mathrm{~Hz}, 1 \mathrm{H})$, $7.34(\mathrm{~d}, J=7.7 \mathrm{~Hz}, 1 \mathrm{H}), 7.02(\mathrm{~d}, J=7.7 \mathrm{~Hz}, 1 \mathrm{H}), 4.75(\mathrm{~s}, 2 \mathrm{H}), 3.38$ (t, $J=6.7 \mathrm{~Hz}, 2 \mathrm{H})$, $1.55(\mathrm{dtd}, J=14.0,7.4,6.7 \mathrm{~Hz}, 2 \mathrm{H}), 0.83(\mathrm{t}, J=7.4 \mathrm{~Hz}, 3 \mathrm{H})$.

5-(Butoxymethyl)quinolin-8-ol(5g). ${ }^{1} \mathrm{H}$ NMR (400 MHz, Chloroform- $d$ ) $\delta 8.72$ $(\mathrm{dd}, J=4.2,1.6 \mathrm{~Hz}, 1 \mathrm{H}), 8.43(\mathrm{dd}, J=8.5,1.6 \mathrm{~Hz}, 1 \mathrm{H}), 7.42(\mathrm{dd}, J=8.6,4.2 \mathrm{~Hz}, 1 \mathrm{H})$, $7.34(\mathrm{~d}, J=7.7 \mathrm{~Hz}, 1 \mathrm{H}), 7.02(\mathrm{~d}, J=7.7 \mathrm{~Hz}, 1 \mathrm{H}), 4.75(\mathrm{~s}, 2 \mathrm{H}), 3.42(\mathrm{t}, J=6.6 \mathrm{~Hz}, 2 \mathrm{H})$, 1.51 (ddt, $J=8.9,7.9,6.4 \mathrm{~Hz}, 2 \mathrm{H}), 1.34-1.22(\mathrm{~m}, 2 \mathrm{H}), 0.81(\mathrm{t}, J=7.4 \mathrm{~Hz}, 3 \mathrm{H})$.

\section{General Procure for the Preparation of Compounds (6a-6g)}

An equal molar mixture of the substrates 5, paraformaldehyde, and the pyrrolidine in anhydrous ethanol $(30 \mathrm{~mL})$ was refluxed for 4 hours under argon. After cooling, the solvent was evaporated under reduced pressure. The crude compound was purified by flash chromatography (dichloromethane: methanol 20:1) to generate pure products.

5-((Furan-2-ylmethoxy)methyl)-7-(pyrrolidin-1-ylmethyl)quinolin-8-ol(6a). ${ }^{1} \mathrm{H}$ NMR (400 MHz, Chloroform- $d$ ) $\delta 8.87$ (dd, $\left.J=4.1,1.6 \mathrm{~Hz}, 1 \mathrm{H}\right), 8.33(\mathrm{dd}, J=8.5,1.6$ $\mathrm{Hz}, 1 \mathrm{H}), 7.44(\mathrm{dd}, J=1.9,0.9 \mathrm{~Hz}, 1 \mathrm{H}), 7.40(\mathrm{dd}, J=8.5,4.1 \mathrm{~Hz}, 1 \mathrm{H}), 7.25(\mathrm{~s}, 1 \mathrm{H}), 4.83$ (s, 2H), 4.52 (s, 2H), 4.00 (s, 2H), 2.78-2.68 (m, 4H), 1.95 - 1.79 (m, 4H). HRMS (ESI): $\mathrm{m} / \mathrm{z}$ calculated for $\mathrm{C}_{20} \mathrm{H}_{22} \mathrm{~N}_{2} \mathrm{O}_{3}+\mathrm{H}^{+}\left[\mathrm{M}+\mathrm{H}^{+}\right]$: 339.1709; Found: 339.1711 . 
7-(Pyrrolidin-1-ylmethyl)-5-((thiophen-2-ylmethoxy)methyl)quinolin-8ol(6b). ${ }^{1} \mathrm{H}$ NMR (400 MHz, Chloroform- $d$ ) $\delta 8.88$ (dd, $\left.J=4.1,1.6 \mathrm{~Hz}, 1 \mathrm{H}\right), 8.37$ (dd, $J=$ 8.5, $1.7 \mathrm{~Hz}, 1 \mathrm{H}), 7.40(\mathrm{dd}, J=8.5,4.1 \mathrm{~Hz}, 1 \mathrm{H}), 7.31(\mathrm{dd}, J=4.9,1.3 \mathrm{~Hz}, 1 \mathrm{H}), 7.22(\mathrm{~s}$, $1 \mathrm{H}), 7.04-6.96(\mathrm{~m}, 2 \mathrm{H}), 4.85(\mathrm{~s}, 2 \mathrm{H}), 4.73(\mathrm{~s}, 2 \mathrm{H}), 3.99(\mathrm{~s}, 2 \mathrm{H}), 2.81-2.56(\mathrm{~m}, 4 \mathrm{H})$, $1.99-1.74(\mathrm{~m}, 4 \mathrm{H})$. HRMS (ESI): $\mathrm{m} / \mathrm{z}$ calculated for $\mathrm{C}_{20} \mathrm{H}_{22} \mathrm{~N}_{2} \mathrm{O}_{2} \mathrm{~S}+\mathrm{H}^{+}\left[\mathrm{M}+\mathrm{H}^{+}\right]$: 355.1480; Found: 355.1473.

5-((Pyridin-2-ylmethoxy)methyl)-7-(pyrrolidin-1-ylmethyl)quinolin-8-ol(6c). ${ }^{1} \mathrm{H}$ NMR (400 MHz, Chloroform- $d$ ) $\delta 8.89(\mathrm{dd}, J=4.2,1.6 \mathrm{~Hz}, 1 \mathrm{H}), 8.56(\mathrm{ddd}, J=4.9$, $1.8,0.9 \mathrm{~Hz}, 1 \mathrm{H}), 8.46(\mathrm{dd}, J=8.5,1.6 \mathrm{~Hz}, 1 \mathrm{H}), 7.67$ (td, $J=7.7,1.8 \mathrm{~Hz}, 1 \mathrm{H}), 7.45-7.39$ $(\mathrm{m}, 2 \mathrm{H}), 7.29(\mathrm{~s}, 1 \mathrm{H}), 7.18(\mathrm{ddd}, J=7.6,4.9,1.2 \mathrm{~Hz}, 1 \mathrm{H}), 4.96(\mathrm{~s}, 2 \mathrm{H}), 4.71(\mathrm{~s}, 2 \mathrm{H}), 4.02$ $(\mathrm{s}, 2 \mathrm{H}), 2.82-2.66(\mathrm{~m}, 4 \mathrm{H}), 1.95-1.84(\mathrm{~m}, 4 \mathrm{H})$. HRMS (ESI): $\mathrm{m} / \mathrm{z}$ calculated for $\mathrm{C}_{21} \mathrm{H}_{23} \mathrm{~N}_{3} \mathrm{O}_{2}+\mathrm{H}^{+}\left[\mathrm{M}+\mathrm{H}^{+}\right]: 350.1869$; Found: 350.1859 .

5-((Cyclohexylmethoxy)methyl)-7-(pyrrolidin-1-ylmethyl)quinolin-8-ol(6d). ${ }^{1} \mathrm{H}$ NMR (400 MHz, Chloroform- $d$ ) $\delta 8.80(\mathrm{dd}, J=4.1,1.7 \mathrm{~Hz}, 1 \mathrm{H}), 8.34(\mathrm{dd}, J=8.5,1.7$ $\mathrm{Hz}, 1 \mathrm{H}), 7.36(\mathrm{dd}, J=8.5,4.1 \mathrm{~Hz}, 1 \mathrm{H}), 7.24(\mathrm{~s}, 1 \mathrm{H}), 4.71(\mathrm{~s}, 2 \mathrm{H}), 3.98(\mathrm{~s}, 2 \mathrm{H}), 3.24(\mathrm{~d}, J$ $=6.5 \mathrm{~Hz}, 2 \mathrm{H}), 2.80-2.65(\mathrm{~m}, 4 \mathrm{H}), 1.92-1.78(\mathrm{~m}, 4 \mathrm{H}), 1.74-1.44(\mathrm{~m}, 6 \mathrm{H}), 1.25-1.00$ $(\mathrm{m}, 3 \mathrm{H}), 0.90-0.70(\mathrm{~m}, 2 \mathrm{H})$. HRMS (ESI): $\mathrm{m} / \mathrm{z}$ calculated for $\mathrm{C}_{22} \mathrm{H}_{30} \mathrm{~N}_{2} \mathrm{O}_{2}+\mathrm{H}^{+}[\mathrm{M}+$ $\left.\mathrm{H}^{+}\right]$: 355.2386; Found: 355.2385.

5-(Ethoxymethyl)-7-(pyrrolidin-1-ylmethyl)quinolin-8-ol(6e). ${ }^{1} \mathrm{H}$ NMR (400 $\mathrm{MHz}$, Chloroform- $d$ ) $\delta 8.90(\mathrm{dd}, J=4.2,1.6 \mathrm{~Hz}, 1 \mathrm{H}), 8.43(\mathrm{dd}, J=8.5,1.7 \mathrm{~Hz}, 1 \mathrm{H}), 7.45$ $(\mathrm{dd}, J=8.5,4.1 \mathrm{~Hz}, 1 \mathrm{H}), 7.29(\mathrm{~d}, J=1.2 \mathrm{~Hz}, 1 \mathrm{H}), 4.82(\mathrm{~s}, 2 \mathrm{H}), 4.03(\mathrm{~s}, 2 \mathrm{H}), 3.62$ (q, $J=$ $7.0 \mathrm{~Hz}, 2 \mathrm{H}), 2.88-2.61(\mathrm{~m}, 4 \mathrm{H}), 2.04-1.73(\mathrm{~m}, 4 \mathrm{H}), 1.27$ (t, $J=7.0 \mathrm{~Hz}, 3 \mathrm{H})$. HRMS (ESI): $\mathrm{m} / \mathrm{z}$ calculated for $\mathrm{C}_{17} \mathrm{H}_{22} \mathrm{~N}_{2} \mathrm{O}_{2}+\mathrm{H}^{+}\left[\mathrm{M}+\mathrm{H}^{+}\right]$: 287.1760 ; Found: 287.1753 .

5-(Propoxymethyl)-7-(pyrrolidin-1-ylmethyl)quinolin-8-ol(6f). ${ }^{1} \mathrm{H}$ NMR (400 MHz, Chloroform- $d$ ) $\delta 8.81(\mathrm{dd}, J=4.2,1.6 \mathrm{~Hz}, 1 \mathrm{H}), 8.34(\mathrm{dd}, J=8.5,1.7 \mathrm{~Hz}, 1 \mathrm{H}), 7.35$ $(\mathrm{dd}, J=8.5,4.1 \mathrm{~Hz}, 1 \mathrm{H}), 7.19(\mathrm{~s}, 1 \mathrm{H}), 4.72(\mathrm{~s}, 2 \mathrm{H}), 3.94(\mathrm{~s}, 2 \mathrm{H}), 3.41(\mathrm{t}, J=6.7 \mathrm{~Hz}, 2 \mathrm{H})$, $2.75-2.58(\mathrm{~m}, 4 \mathrm{H}), 1.87-1.76(\mathrm{~m}, 4 \mathrm{H}), 1.56(\mathrm{dtd}, J=14.0,7.4,6.6 \mathrm{~Hz}, 2 \mathrm{H}), 0.85(\mathrm{t}, J$ $=7.4 \mathrm{~Hz}, 3 \mathrm{H})$. HRMS (ESI): $\mathrm{m} / \mathrm{z}$ calculated for $\mathrm{C}_{18} \mathrm{H}_{24} \mathrm{~N}_{2} \mathrm{O}_{2}+\mathrm{H}^{+}\left[\mathrm{M}+\mathrm{H}^{+}\right]: 315.2073$; Found: 315.2059 .

5-(Butoxymethyl)-7-(pyrrolidin-1-ylmethyl)quinolin-8-ol(6g). ${ }^{1} \mathrm{H}$ NMR (400 MHz, Chloroform- $d$ ) $\delta 8.81$ (dd, $J=4.1,1.6 \mathrm{~Hz}, 1 \mathrm{H}), 8.34(\mathrm{dd}, J=8.5,1.7 \mathrm{~Hz}, 1 \mathrm{H}), 7.35$ $(\mathrm{dd}, J=8.5,4.1 \mathrm{~Hz}, 1 \mathrm{H}), 7.20(\mathrm{~s}, 1 \mathrm{H}), 4.72(\mathrm{~s}, 2 \mathrm{H}), 3.95(\mathrm{~s}, 2 \mathrm{H}), 3.45(\mathrm{t}, J=6.6 \mathrm{~Hz}, 2 \mathrm{H})$, $2.74-2.58(\mathrm{~m}, 4 \mathrm{H}), 1.90-1.73(\mathrm{~m}, 4 \mathrm{H}), 1.52(\mathrm{ddt}, J=8.9,7.9,6.4 \mathrm{~Hz}, 2 \mathrm{H}), 1.36-1.23$ $(\mathrm{m}, 2 \mathrm{H}), 0.82$ (t, $J=7.4 \mathrm{~Hz}, 3 \mathrm{H})$. HRMS (ESI): $\mathrm{m} / \mathrm{z}$ calculated for $\mathrm{C}_{19} \mathrm{H}_{26} \mathrm{~N}_{2} \mathrm{O}_{2}+\mathrm{H}^{+}[\mathrm{M}$ $+\mathrm{H}^{+}$]: 301.1916; Found: 301.1906.

\section{General Procure for the Preparation of Compounds (8a-8b)}

To a solution of compound 7 ( $1 \mathrm{mmol})$ was added paraformaldehyde $(1 \mathrm{mmol})$ and piperidine (1 $\mathrm{mmol}$ for $\mathbf{8 a}$ ) or morpholine $(1 \mathrm{mmol}$ for $\mathbf{8 b})$. The mixture was stirred 
under reflux for 4 hours. The solvent was then evaporated to get the crude product. The crude product was purified by flash chromatography (dichloromethane: methanol 20:1).

5-((Benzyloxy)methyl)-7-(piperidin-1-ylmethyl)quinolin-8-ol(8a). ${ }^{1} \mathrm{H}$ NMR (400 MHz, Chloroform- $d$ ) $\delta 8.82(\mathrm{dd}, J=4.1,1.7 \mathrm{~Hz}, 1 \mathrm{H}), 8.29(\mathrm{dd}, J=8.5,1.7 \mathrm{~Hz}, 1 \mathrm{H})$, $7.32(\mathrm{dd}, J=8.5,4.2 \mathrm{~Hz}, 1 \mathrm{H}), 7.29-7.20(\mathrm{~m}, 5 \mathrm{H}), 7.09(\mathrm{~s}, 1 \mathrm{H}), 4.76(\mathrm{~s}, 2 \mathrm{H}), 4.49$ (s, 2H), 3.77 (s, 2H), $2.52(\mathrm{~s}, 4 \mathrm{H}), 1.61$ (p, $J=5.6 \mathrm{~Hz}, 4 \mathrm{H}), 1.44(\mathrm{~s}, 2 \mathrm{H})$. HRMS (ESI): m/z calculated for $\mathrm{C}_{22} \mathrm{H}_{24} \mathrm{~N}_{2} \mathrm{O}_{3}+\mathrm{H}^{+}\left[\mathrm{M}+\mathrm{H}^{+}\right]$: 363.2073; Found: 363.2080.

5-((Benzyloxy)methyl)-7-(morpholinomethyl)quinolin-8-ol(8b). ${ }^{1} \mathrm{H}$ NMR (400 MHz, Chloroform- $d$ ) $\delta 8.88$ (dd, $J=4.1,1.6 \mathrm{~Hz}, 1 \mathrm{H}), 8.40$ (dd, $J=8.5,1.6 \mathrm{~Hz}, 1 \mathrm{H}), 7.43$ $(\mathrm{dd}, J=8.5,4.2 \mathrm{~Hz}, 1 \mathrm{H}), 7.38-7.29(\mathrm{~m}, 5 \mathrm{H}), 7.28(\mathrm{~s}, 1 \mathrm{H}), 4.85(\mathrm{~s}, 2 \mathrm{H}), 4.58(\mathrm{~s}, 2 \mathrm{H})$, $3.86(\mathrm{~s}, 2 \mathrm{H}), 3.81-3.75(\mathrm{~m}, 4 \mathrm{H}), 2.70-2.55(\mathrm{~m}, 4 \mathrm{H})$. HRMS (ESI): $\mathrm{m} / \mathrm{z}$ calculated for $\mathrm{C}_{23} \mathrm{H}_{26} \mathrm{~N}_{2} \mathrm{O}_{2}+\mathrm{H}^{+}\left[\mathrm{M}+\mathrm{H}^{+}\right]$: 365.1865; Found: 365.1850 .

\section{General Procure for the Preparation of Compounds (9a-9b)}

The method to make compounds $9 \mathbf{9}-9 \mathbf{b}$ was the same as the way to make compounds 5e-5g.

5-(Phenethoxymethyl)quinolin-8-ol(9a). ${ }^{1} \mathrm{H}$ NMR (400 MHz, Chloroform- $d$ ) $\delta$ $8.77(\mathrm{dd}, J=4.2,1.6 \mathrm{~Hz}, 1 \mathrm{H}), 8.30(\mathrm{dd}, J=8.5,1.5 \mathrm{~Hz}, 1 \mathrm{H}), 7.40-7.35(\mathrm{~m}, 2 \mathrm{H}), 7.28-$ $7.14(\mathrm{~m}, 5 \mathrm{H}), 7.07(\mathrm{~d}, J=7.7 \mathrm{~Hz}, 1 \mathrm{H}), 4.82(\mathrm{~s}, 2 \mathrm{H}), 3.72(\mathrm{t}, J=7.0 \mathrm{~Hz}, 2 \mathrm{H}), 2.90$ (t, $J=$ $7.0 \mathrm{~Hz}, 2 \mathrm{H})$.

5-((3-Phenylpropoxy)methyl)quinolin-8-ol(9b). ${ }^{1} \mathrm{H}$ NMR $(400 \mathrm{MHz}$, Chloroform- $d$ ) $\delta 8.80(\mathrm{dd}, J=4.2,1.6 \mathrm{~Hz}, 1 \mathrm{H}), 8.51(\mathrm{dd}, J=8.5,1.6 \mathrm{~Hz}, 1 \mathrm{H}), 7.50(\mathrm{dd}, J$ $=8.5,4.2 \mathrm{~Hz}, 1 \mathrm{H}), 7.41(\mathrm{~d}, J=7.7 \mathrm{~Hz}, 1 \mathrm{H}), 7.25-7.22(\mathrm{~m}, 2 \mathrm{H}), 7.20-7.14(\mathrm{~m}, 1 \mathrm{H})$, $7.13-7.08(\mathrm{~m}, 3 \mathrm{H}), 4.83(\mathrm{~s}, 2 \mathrm{H}), 3.50(\mathrm{t}, J=6.3 \mathrm{~Hz}, 2 \mathrm{H}), 2.65(\mathrm{t}, J=8.6 \mathrm{~Hz}, 2 \mathrm{H}), 1.97-$ $1.86(\mathrm{~m}, 2 \mathrm{H})$.

\section{General Procure for the Preparation of Compounds (10a-10b)}

An equimolar mixture of the substrates 9, paraformaldehyde, and the pyrrolidine in anhydrous ethanol $(30 \mathrm{~mL})$ was refluxed for 4 hours under argon. After cooling, the solvent was evaporated under reduced pressure. The crude product was purified by flash chromatography (dichloromethane: methanol 20:1) to generate pure products.

5-(Phenethoxymethyl)-7-(pyrrolidin-1-ylmethyl)quinolin-8-ol(10a). ${ }^{1} \mathrm{H}$ NMR (400 MHz, Chloroform- $d$ ) $\delta 8.86(\mathrm{dd}, J=4.2,1.7 \mathrm{~Hz}, 1 \mathrm{H}), 8.23(\mathrm{dd}, J=8.5,1.7 \mathrm{~Hz}, 1 \mathrm{H})$, $7.32(\mathrm{dd}, J=8.5,4.2 \mathrm{~Hz}, 1 \mathrm{H}), 7.27(\mathrm{~d}, J=2.4 \mathrm{~Hz}, 1 \mathrm{H}), 7.26-7.16(\mathrm{~m}, 5 \mathrm{H}), 4.80(\mathrm{~s}, 2 \mathrm{H})$, $3.98(\mathrm{~s}, 2 \mathrm{H}), 3.74(\mathrm{t}, J=7.0 \mathrm{~Hz}, 2 \mathrm{H}), 2.91(\mathrm{t}, J=7.0 \mathrm{~Hz}, 2 \mathrm{H}), 2.75-2.65(\mathrm{~m}, 4 \mathrm{H}), 1.95-$ 1.80 (m, 4H). HRMS (ESI): $\mathrm{m} / \mathrm{z}$ calculated for $\mathrm{C}_{23} \mathrm{H}_{26} \mathrm{~N}_{2} \mathrm{O}_{2}+\mathrm{H}^{+}\left[\mathrm{M}+\mathrm{H}^{+}\right]: 363.2073$;

Found: 363.2060 . 
5-((3-Phenylpropoxy)methyl)-7-(pyrrolidin-1-ylmethyl)quinolin-8-ol(10b). ${ }^{1} \mathrm{H}$ NMR (400 MHz, Chloroform- $d$ ) $\delta 8.89(\mathrm{dd}, J=4.1,1.7 \mathrm{~Hz}, 1 \mathrm{H}), 8.42(\mathrm{dd}, J=8.5,1.6$ $\mathrm{Hz}, 1 \mathrm{H}), 7.43(\mathrm{dd}, J=8.5,4.1 \mathrm{~Hz}, 1 \mathrm{H}), 7.26-7.19(\mathrm{~m}, 3 \mathrm{H}), 7.19-7.14(\mathrm{~m}, 1 \mathrm{H}), 7.14-$ $7.10(\mathrm{~m}, 2 \mathrm{H}), 4.80(\mathrm{~s}, 2 \mathrm{H}), 3.99(\mathrm{~s}, 2 \mathrm{H}), 3.53(\mathrm{t}, J=6.4 \mathrm{~Hz}, 2 \mathrm{H}), 2.75-2.64(\mathrm{~m}, 6 \mathrm{H})$, $1.99-1.83(\mathrm{~m}, 6 \mathrm{H})$. HRMS (ESI): $\mathrm{m} / \mathrm{z}$ calculated for $\mathrm{C}_{24} \mathrm{H}_{28} \mathrm{~N}_{2} \mathrm{O}_{2}+\mathrm{H}^{+}\left[\mathrm{M}+\mathrm{H}^{+}\right]$: 377.2229; Found: 377.2238.

\section{General Procure for the Preparation of Compounds (11a-11b)}

To a solution of benzyl mercaptan (6 mmol for 12a) or N-benzymethylamine (6 mmol for 12b) in anhydrous THF $(30 \mathrm{ml})$ was added sodium hydride $(60 \%$ dispersion in mineral oil, $0.72 \mathrm{~g}, 18 \mathrm{mmol}$ ) at $0{ }^{\circ} \mathrm{C}$. The suspension was stirred at $0{ }^{\circ} \mathrm{C}$ for 30 minutes. Salt $2(1.15 \mathrm{~g}, 5 \mathrm{mmol})$ was added to the suspension. The mixture was stirred at r.t for 3 hours. Water was added to the suspension, the mixture became homogeneous. The mixture was extracted by ethyl acetate and washed with brine, dried over anhydrous sodium sulfate and concentrated to get the crude. The crude product was purified by flash chromatography (ethyl acetate: hexane 3:1).

5-((Benzylthio)methyl)-7-(pyrrolidin-1-ylmethyl)quinolin-8-ol(11a). ${ }^{1} \mathrm{H}$ NMR (400 MHz, Chloroform- $d$ ) $\delta 8.78$ (dd, $J=4.2,1.6 \mathrm{~Hz}, 1 \mathrm{H}), 8.30$ (dd, $J=8.6,1.5 \mathrm{~Hz}, 1 \mathrm{H}$ ), $7.44(\mathrm{dd}, J=8.5,4.2 \mathrm{~Hz}, 1 \mathrm{H}), 7.37-7.26(\mathrm{~m}, 5 \mathrm{H}), 7.06(\mathrm{~d}, J=7.8 \mathrm{~Hz}, 1 \mathrm{H}), 3.96(\mathrm{~s}, 2 \mathrm{H})$, $3.65(\mathrm{~s}, 2 \mathrm{H})$.

5-((Benzyl(methyl)amino)methyl)quinolin-8-ol(11b). ${ }^{1} \mathrm{H}$ NMR $(400 \mathrm{MHz}$, Chloroform- $d$ ) $\delta 8.82(\mathrm{dd}, J=4.2,1.6 \mathrm{~Hz}, 1 \mathrm{H}), 8.62(\mathrm{dd}, J=8.5,1.6 \mathrm{~Hz}, 1 \mathrm{H}), 7.47(\mathrm{dd}, J$ $=8.6,4.2 \mathrm{~Hz}, 1 \mathrm{H}), 7.40(\mathrm{~d}, J=7.7 \mathrm{~Hz}, 1 \mathrm{H}), 7.37-7.32(\mathrm{~m}, 4 \mathrm{H}), 7.32-7.26(\mathrm{~m}, 1 \mathrm{H})$, $7.13(\mathrm{~d}, J=7.7 \mathrm{~Hz}, 1 \mathrm{H}), 3.85(\mathrm{~s}, 2 \mathrm{H}), 3.58(\mathrm{~s}, 2 \mathrm{H}), 2.20(\mathrm{~s}, 3 \mathrm{H})$.

\section{General Procure for the Preparation of Compounds (12a-12b)}

To a solution of compound $\mathbf{1 1}(1 \mathrm{mmol})$ was added paraformaldehyde $(1 \mathrm{mmol})$ and pyrrolidine( $1 \mathrm{mmol})$. The mixture was stirred under reflux for 4 hours. The solvent was then evaporated to get the crude product. The crude product was purified by flash chromatography (dichloromethane: methanol 20:1) to get a light yellow solid.

5-((Benzylthio)methyl)-7-(pyrrolidin-1-ylmethyl)quinolin-8-ol(12a). ${ }^{1} \mathrm{H}$ NMR (400 MHz, Chloroform- $d$ ) $\delta 8.78$ (dd, $J=4.2,1.6 \mathrm{~Hz}, 1 \mathrm{H}), 8.17$ (dd, $J=8.6,1.6 \mathrm{~Hz}, 1 \mathrm{H}$ ), $7.32(\mathrm{dd}, J=8.6,4.1 \mathrm{~Hz}, 1 \mathrm{H}), 7.28-7.15(\mathrm{~m}, 5 \mathrm{H}), 7.14(\mathrm{~s}, 1 \mathrm{H}), 3.97$ (s, 2H), 3.89 (s, $2 \mathrm{H}), 3.60(\mathrm{~s}, 2 \mathrm{H}), 2.82-2.65(\mathrm{~m}, 4 \mathrm{H}), 1.90-1.80(\mathrm{~m}, 4 \mathrm{H})$. HRMS (ESI): $\mathrm{m} / \mathrm{z}$ calculated for $\mathrm{C}_{22} \mathrm{H}_{24} \mathrm{~N}_{2} \mathrm{OS}+\mathrm{H}^{+}\left[\mathrm{M}+\mathrm{H}^{+}\right]$: 365.1688; Found: 365.1689 .

\section{5-((Benzyl(methyl)amino)methyl)-7-(pyrrolidin-1-ylmethyl)quinolin-8-} ol(12b). ${ }^{1} \mathrm{H}$ NMR (400 MHz, Chloroform- $d$ ) $\delta 8.87$ (dd, $\left.J=4.1,1.6 \mathrm{~Hz}, 1 \mathrm{H}\right), 8.57$ (dd, $J$ $=8.6,1.7 \mathrm{~Hz}, 1 \mathrm{H}), 7.43-7.31(\mathrm{~m}, 5 \mathrm{H}), 7.31-7.27(\mathrm{~m}, 1 \mathrm{H}), 7.24(\mathrm{~s}, 1 \mathrm{H}), 3.93(\mathrm{~s}, 2 \mathrm{H})$, 
$3.91(\mathrm{~s}, 2 \mathrm{H}), 3.68$ (s, 2H), 2.60-2.48 (m, 4H), 2.30 (s, 3H), 1.85- 1.70 (m, 4H). HRMS (ESI): $\mathrm{m} / \mathrm{z}$ calculated for $\mathrm{C}_{23} \mathrm{H}_{27} \mathrm{~N}_{3} \mathrm{O}+\mathrm{H}^{+}\left[\mathrm{M}+\mathrm{H}^{+}\right]$: 362.2232; Found: 362.2224 .

\section{Cell Culture and Cell Viability Assay}

The anti-proliferative effect of UC-112 and its analogs were tested in human melanoma (A375, MDA-MB-435 and MDA-MB-435/LCC6MDR1) and human prostate cancer (PC-3) cell lines. All the cell lines were purchased from ATCC (American Type Culture Collection, Manassas, VA). The cancer cells were cultured using the supplemented cell culture medium as described before [246] at $37^{\circ} \mathrm{C}$ in a humidified atmosphere containing $5 \% \mathrm{CO}_{2} .5000$ cells in logarithm growing phase were seeded overnight into each well of a 96-well plate. Then the cells were continuously incubated with sequential diluted compound solution $(10 \mathrm{nM}$ to $100 \mu \mathrm{M}, 100 \mu \mathrm{l}$ per well) in cell culture medium. After $48 \mathrm{~h}$ treatment, the cell viability was determined in MTS assay and $\mathrm{IC}_{50}$ was calculated $(n=4)$ as described before $[112,180]$.

\section{NCI-60 Screening}

Four compounds including the parental compound UC-112 were submitted to National Cancer Institute for its NCI-60 cell line screening, initially tested at one concentration $(10 \mu \mathrm{M})$, and subsequently selected for full five concentration testing following the standard protocols disclosed by NCI [247]. In brief, cells were plated into 96 well micro-titer plates $24 \mathrm{~h}$ prior to the treatment of compound solution for $48 \mathrm{~h}$, then the cell viability was read out through absorbance of sulforhodamine B (SRB) staining.

\section{Drug-Like Property Profiling for Compound 4g}

All these experiments were performed by a contract research service company, Eurofins Panlabs Inc. (Study Number 100017964). Aqueous solubility $(\mu \mathrm{M})$ was determined using the shake-flask method by comparing the peak area of the principal peak in a calibration standard $(200 \mu \mathrm{M})$ containing organic solvent (methanol/water, $60 / 40, v / v$ ) with the peak area of the corresponding peak in a buffer sample. Metabolic stability study was carried out by incubating compound $\mathbf{4 g}$ with human liver microsomes. Metabolic stability which is expressed as percent of the parent compound remaining, was calculated by comparing the peak area of the compound at the time point relative to that at time- 0 . The half-life (T1/2) was estimated from the slope of the initial linear range of the logarithmic curve of compound remaining (\%) vs. time. In the cytochrome P450 inhibition study, human liver microsomes $(0.1 \mathrm{mg} / \mathrm{mL})$ were incubated with different substrates and compound $\mathbf{4 g}$ for 10 minutes. After the incubation, peak areas corresponding to the metabolite of each substrate were recorded. The percent of control activity was then calculated by comparing the peak area obtained in the presence of compound $4 \mathrm{~g}$ to that obtained in the absence of compound $4 \mathrm{~g}$. Subsequently, the percent inhibition was calculated by subtracting the percent control activity from 100 . 


\section{Caspase Functional Assay}

The caspase 3/7 activity of cancer cells treated by DMSO control or compound of interest was analyzed using Glo Caspase-Glo 3/7 kit from Promega Corporation (Madison, WI) as per manufacturer's instructions in similar protocol as described before [180]. The readings of relative luminescence unit were normalized by the cell viability read from the same well determined by compatible CytoTox-Fluor Cytotoxicity assay kit (Promega, WI).

\section{Western Blotting}

Lysates of A375 cells treated by the compound solution for $24 \mathrm{~h}$ were used to determine the change of IAP protein levels through western blotting. Primary rabbit antibodies against survivin, XIAP, cIAP1, cIAP2, livin and GAPDH were purchased from Cell Signaling Technology, Inc. (Danvers, MA) and used according to manufacture instructions as reported previously[180]. Protein lane intensities were quantified by ImageJ software (US National Institutes of Health, Bethesda, MD).

\section{Molecular Modeling}

The molecular docking studies were performed following similar procedure as described before [180, 248] in Schrodinger Molecular Modeling Suite 2014 (Schrodinger Inc., Portland, OR). All the ligands were prepared to generate various conformation before being docked into the SMAC AVPI binding site of a human survivin crystal structure (Protein Data Bank entry: 3UIH). Molecular dynamic calculation was done after the docking to minimize the energy of potential ligand binding poses. Results were visualized using the Maestro interface of the Schrodinger software.

\section{DARTS Assay}

Drug affinity responsive target stability (DARTS) assay was performed to identify the protein targets of UC-112 analogs in A375 or MDA-MB-435 cell lysates following the protocols described in the literature [242-245]. Briefly, A375 or MDA-MB-435 lysates were prepared in non-denaturing M-PER lysis buffer (Thermo Fisher Scientific, Waltham, MA) with protease and phosphatase inhibitors. Then TNC (Tris, $\mathrm{NaCl}, \mathrm{CaCl}_{2}$ ) buffer was added into cell lysates before the total protein concentration of lysate being determined by BCA protein assay kit (Thermo Fisher Scientific, Waltham, MA). The lysates were split into two groups: one group was added with compound of interest solution, the other group was added with same amount of vehicle (DMSO). The samples were mixed thoroughly and incubated at room temperature for $1 \mathrm{~h}$. Then $10 \mathrm{mg} / \mathrm{mL}$ pronase stock solution was added into both compound treated or vehicle control groups to achieve the final dilution of 1:100,1:300,1:1000 and 1:3000. One aliquot of each group was kept as un-digested control. The proteolysis was performed at room temperature for 
30 min before ice cold protease inhibitor stock being added into the mixture. Then SDS loading buffer was added into all the samples and heated to $70^{\circ} \mathrm{C}$ for $10 \mathrm{~min}$. Finally, the results were analyzed by SDS-PAGE and immunoblotting.

\section{In Vivo Anti-tumor Efficacy}

$3 \times 10^{6}$ A 375 cells were implanted into the left-side dorsal flank of each nude mouse $(n=5)$ to establish the human melanoma A375 tumor xenograft model as described previously $[114,180]$. Compound $\mathbf{4 g}$ were first dissolved in DMSO then diluted by $2 \%$ methylcellulose PBS buffer. The proportion of DMSO in final solution was kept at lower than 5\%. Mice body weight and the size of tumor were closely monitored during the 3 week continuous treatment (i.p. injection, one dose per day, five days per week). At the end point of the treatment, mice were sacrificed after anesthesia. A375 tumor tissues were isolated then freshly lysed on ice to check the targeted protein levels through Western blotting.

\section{TUNEL Assay}

A375 tumor tissues collected from the in vivo efficacy study in the above were fixed in formalin phosphate buffer for one week. Then the tissues were processed to get paraffin embedded sections. TUNEL assay was performed using DeadEnd Fluorometric kit (Promega Corporation, Madison, WI) following manufacturer's instructions. By the end of the experiment, VECTASHIELD Hard Set mounting medium with DAPI (Vector Lab, Inc., Burlingame, CA) was used to mount the tumor slides and stain the nuclei. The final slides were analyzed immediately under a fluorescence microscope (EVOS FL Cell Imaging System, Thermo Fisher Scientific Inc., NY).

\section{Summary}

A series of novel analogs were designed and synthesized based on targeted structural modification of the lead compound UC-112. SAR (Figure 5-14) was investigated by making modifications to $\mathrm{C}$ ring, $\mathrm{D}$ ring and the linker. Several analogs showed excellent anti-proliferative activities and could also effectively overcome Pgpmediated multiple drug resistance. This scaffold as demonstrated by our most potent compound $\mathbf{4 g}$ has showed good drug-like properties which is important for further development. Preliminary studies of action mechanism confirmed that the new analogs maintain their mode of action by selectively down-regulating the level of survivin as the parent compound UC-112. Compound $\mathbf{4 g}$ effectively inhibited the growth of A375 xenograft tumor in vivo. Further optimization of this scaffold can be performed to generate more potent and selective survivin inhibitors based on this unique platform. 


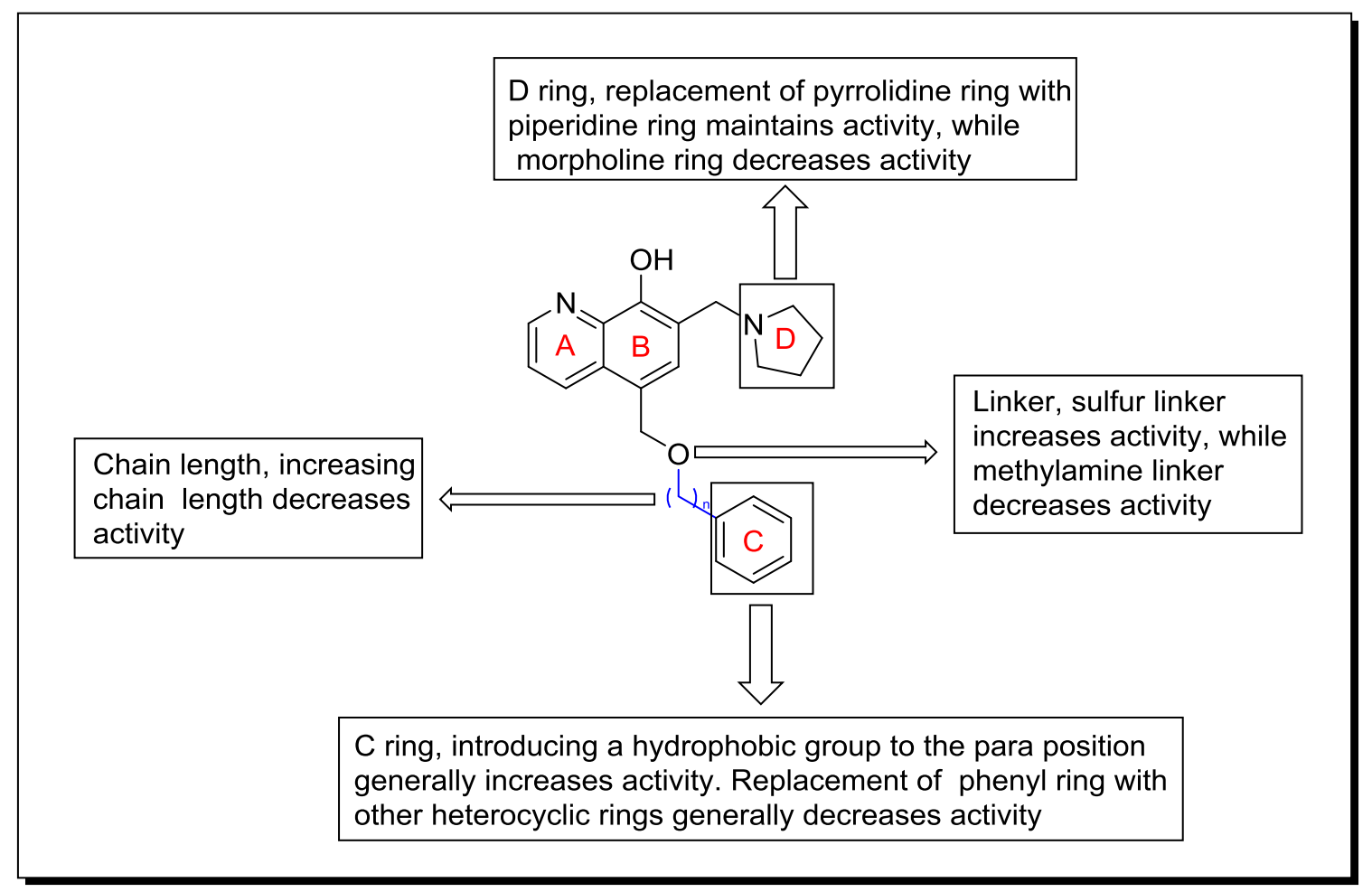

Figure 5-14.. Structure activity relationships of UC-112 analogs 


\section{CHAPTER 6. CONCLUSION}

Tubulin and survivin are two important cancer drug targets for a number of reasons that have been reviewed in details in previous chapters. My work in the past five years has been focusing on the development of novel tubulin polymerization inhibitors and survivin inhibitors for cancer treatment. Many active compounds with potent antiproliferative properties have been generated. These compounds have great promise to be further developed as effective anticancer agents. The thoughts for the development of these compounds are summarized here and future directions are discussed as well.

There are many drugs targeting tubulin that have been approved for cancer treatment, which makes tubulin a well-validated cancer target. Among the four best known tubulin binding sites, no colchicine site binder has been approved for cancer treatment. Thus, it is highly significant to develop novel tubulin targeting agents that interact with the colchicine binding site. Our group has done extensive work on the finding of new colchicine site binders and several series of important structures have been produced, such as SMART and ABI series.

For the tubulin project, we tried to further optimize the previously reported ABI scaffold in the beginning. There are three ring systems in the general structure of ABI scaffold. From a classical SAR point, we tackled the optimization by making modifications to the three ring systems. Extensive A ring modifications on the ABI scaffold had been done in the previous reported papers. The previous A ring modifications had tried to put many commonly used substitutions to the A ring. The results showed both electron donating groups and electron withdrawing groups increased activity compared to non-substituted A ring. Different positions of substitutions had also been tried on the A ring of ABI structure. It was found para-positon gave optimal activity. So we tried the A ring modification by putting additional substitutions that had not been used previously to the para position of A ring. The new substitutions did not improve activity compared with previous most active compounds. Because the additional A ring modifications did not generate more potent compounds and more importantly few modifications had been made on the B ring in the previous work, We focused our efforts on the $\mathrm{B}$ ring modification of $\mathrm{ABI}$ scaffold.

Our first thought about the B ring modification was that what if we changed the connection positions of the three ring systems. Based on this thought, we designed a new template structure which reversed the position of the two major substitution groups on the imidazole ring of ABI structure: the benzoyl group and the aryl group. By doing so, we generated a series of RABI compounds.

Some of these RABI compounds showed excellent antiproliferative activities in a panel of cancer cell lines including multidrug resistant cells. One appreciable advantage of the RABI compounds is that they can circumvent the multidrug resistance that is associated with existing tubulin targeting agents, such as paclitaxel, or vinblastine, as indicated by their similar activities in sensitive cancer cells and resistant cancer cells. 
Mechanism of actions studies showed RABI analogs maintained their ability to inhibit tubulin polymerization at colchicine binding site and arrest cells in G2/M phase, which demonstrated a similar mechanism of action as previous ABI analogs. The excellent activity of these compounds warranted their further development as effective anticancer agents.

The SAR of the new RABI template was extensively explored by introducing different substitutions to the three rings of this new structure. There are several interesting points in the SAR of RABI analogs, which provide us some insights into the design of tubulin polymerization inhibitors. First, the position switch of the benzoyl group and the phenyl group maintained the activity of most potent ABI analogs. Second, the 3, 4, 5-trimethoxy substituents were also required for the optimal activity in the RABI scaffold. These two points may suggest that the RABI analogs have similar binding mode as the previous ABI scaffold. Another interesting thing is that for RABI scaffold, the unsubstituted A ring was the best one, while in the ABI series, the substituted compounds showed better activity than unsubstituted $\mathrm{A}$ ring. This indicates that the $\mathrm{C}$ rings in both templates may bind to the same site, but the A rings of the two templates may bind to different areas of the pocket. The SAR of N1 position substitutions on the B ring brings an interesting question that what effect it will have on activity if we remove A ring. One possibility which comes from the modelling results is that A ring does not form any meaningful interaction with the binding pocket and thus removal of A ring does not affect activity. In this case, it is possible that removal of A ring makes the new structures better mimic the colchicine structure, which brings drug resistance issue that is associated with colchicine to the new structures. Another possibility is that A ring pushes the ring on the N1 position deep into the pocket for binding and thus removing A ring may decrease activity. Without the crystal structure of tubulin in complex with RABI compounds, it is hard to decide which possibility is true. The work to get the crystal structure of our RABI compounds bound with tubulin is currently ongoing, which will dramatically facilitate the design of novel tubulin polymerization inhibitors.

To further optimize the RABI scaffold, several modifications may be attempted. In the previous $\mathrm{ABI}$ analogs, the compound with 3-indole ring as $\mathrm{A}$ ring showed remarkable activity. Based on this result, different heterocyclic rings can be tried at the A ring position of the RABI structure, such as indole, benzofuran, and benzothiophene, which could form potential hydrogen bonds between the hetero atoms and surrounding residues. One big issue with previous $\mathrm{ABI}$ analogs is metabolic instability due to the carbonyl linker which can be easily reduced. To address this issue, the carbonyl linker may be incorporated into a ring system. For example we can use a pyridine ring to link B ring and $\mathrm{C}$ ring, which could still maintain the shape of the molecule but offer the advantage of stronger metabolic stability. For now only two rings have been tried on the $\mathrm{N} 1$ position of the imidazole ring in the RABI structure, thus different ring systems may be tried at that position for optimization.

The unique properties of survivin, such as the differential distribution of survivin in cancer cells and normal cells, the critical role of survivin in cell mitosis and survival, makes it a promising target for cancer treatment. Notable research work is ongoing to 
develop selective inhibitors of this promising target. We believe that targeting survivin has the potential to selectively treat cancer. Our interest in survivin began with the identification of UC-112, which turned out to be a potent and selective survivin inhibitor.

In order to generate more potent survivin inhibitor, we performed several targeted modifications to the structure of UC-112. The structure of UC-112 contains four rings and a linker. Our modifications mainly focused on $\mathrm{C}$ ring, $\mathrm{D}$ ring and the linker. We utilized traditional medicinal chemistry methodologies for the structural optimization, which include introduction of commonly used substituents, bioisosteric replacement, and homologation change. By doing those modifications, a set of new analogs with good antiproliferative activities were generated. Several compounds in this series had $\mathrm{IC}_{50}$ values in the nanomolar range. The success of our modifications was further supported by the NCI-60 cell line screening results which showed that our new compounds significantly improved growth inhibitory activity compared with parent compound UC112. The new scaffold provides a promising template for future development of effective survivin inhibitors, which will bring the benefit of selective cancer treatment.

Although the UC-112 analogs showed good activities, it has to be noted that most $\mathrm{IC}_{50}$ values are still in the micromolar range. The activity has to be further improved in order to be developed as effective anticancer agents. Several directions can be tried. The linkers between $\mathrm{B}$ ring and $\mathrm{C}$ ring in our analogs are very flexible, which could be unfavorable for activity considering the binding pocket of survivin is relatively small. Thus we can try more rigid linkers between $\mathrm{B}$ ring and $\mathrm{C}$ ring. For example, we can try carbonyl linker, olefin linker, and sulfonyl linker. Modelling results showed that the A ring of our analogs is residing in a negative site. We may try to shift the position of nitrogen on the A ring of UC-112 structure, which can form possible hydrogen bonds or ionic interactions with surrounding residues. In addition, we can try to put some amino acids on the D ring position of UC-112 structure, which could possibly better mimic the bioactive AVPI peptide.

To validate the target of these analogs, some preliminary mechanism of action studies were performed. The western blot results showed the new analogs selectively suppressed the level of survivin over other IAPs. Although this data demonstrated that survivin level was affected, several questions need to be answered before we can confirm survivin as our target. First question is that whether our compounds are inhibiting the upstream proteins of survivin or survivin itself. Second question is how our compounds downregulate survivin level, are they inhibiting the gene expression of survivin or promoting the degradation of survivin? Third question is that how does our compounds bind to survivin if they are truly targeting survivin. The X-ray crystal structure of our compounds bound to survivin may help answer the above questions. The work to resolve the crystal structure has been planned and will be performed in the near future. 


\section{LIST OF REFERENCES}

1. Coit, D. G.; Andtbacka, R.; Anker, C. J.; Bichakjian, C. K.; Carson, W. E., 3rd; Daud, A.; Dilawari, R. A.; Dimaio, D.; Guild, V.; Halpern, A. C.; Hodi, F. S., Jr.; Kelley, M. C.; Khushalani, N. I.; Kudchadkar, R. R.; Lange, J. R.; Lind, A.; Martini, M. C.; Olszanski, A. J.; Pruitt, S. K.; Ross, M. I.; Swetter, S. M.; Tanabe, K. K.; Thompson, J. A.; Trisal, V.; Urist, M. M.; National Comprehensive Cancer, N. Melanoma. J Natl Compr Canc Netw, 2012, 10(3), 366-400.

2. Leiter, U.; Garbe, C. Epidemiology of melanoma and nonmelanoma skin cancer-the role of sunlight. Adv Exp Med Biol, 2008, 624, 89-103.

3. Lo, J. A.; Fisher, D. E. The melanoma revolution: from UV carcinogenesis to a new era in therapeutics. Science, 2014, 346(6212), 945-949.

4. Bhatia, S.; Tykodi, S. S.; Thompson, J. A. Treatment of metastatic melanoma: an overview. Oncology (Williston Park), 2009, 23(6), 488-496.

5. Tsao, H.; Chin, L.; Garraway, L. A.; Fisher, D. E. Melanoma: from mutations to medicine. Genes Dev, 2012, 26(11), 1131-1155.

6. Read, J.; Wadt, K. A.; Hayward, N. K. Melanoma genetics. J Med Genet, 2015.

7. Cancer Genome Atlas, N. Genomic Classification of Cutaneous Melanoma. Cell, 2015, 161(7), 1681-1696.

8. Chapman, P. B.; Hauschild, A.; Robert, C.; Haanen, J. B.; Ascierto, P.; Larkin, J.; Dummer, R.; Garbe, C.; Testori, A.; Maio, M.; Hogg, D.; Lorigan, P.; Lebbe, C.; Jouary, T.; Schadendorf, D.; Ribas, A.; O'Day, S. J.; Sosman, J. A.; Kirkwood, J. M.; Eggermont, A. M.; Dreno, B.; Nolop, K.; Li, J.; Nelson, B.; Hou, J.; Lee, R. J.; Flaherty, K. T.; McArthur, G. A.; Group, B.-S. Improved survival with vemurafenib in melanoma with BRAF V600E mutation. $N$ Engl J Med, 2011, 364(26), 2507-2516.

9. Davies, H.; Bignell, G. R.; Cox, C.; Stephens, P.; Edkins, S.; Clegg, S.; Teague, J.; Woffendin, H.; Garnett, M. J.; Bottomley, W.; Davis, N.; Dicks, E.; Ewing, R.; Floyd, Y.; Gray, K.; Hall, S.; Hawes, R.; Hughes, J.; Kosmidou, V.; Menzies, A.; Mould, C.; Parker, A.; Stevens, C.; Watt, S.; Hooper, S.; Wilson, R.; Jayatilake, H.; Gusterson, B. A.; Cooper, C.; Shipley, J.; Hargrave, D.; Pritchard-Jones, K.; Maitland, N.; Chenevix-Trench, G.; Riggins, G. J.; Bigner, D. D.; Palmieri, G.; Cossu, A.; Flanagan, A.; Nicholson, A.; Ho, J. W.; Leung, S. Y.; Yuen, S. T.;

Weber, B. L.; Seigler, H. F.; Darrow, T. L.; Paterson, H.; Marais, R.; Marshall, C. J.; Wooster, R.; Stratton, M. R.; Futreal, P. A. Mutations of the BRAF gene in human cancer. Nature, 2002, 417(6892), 949-954.

10. Dhomen, N.; Marais, R. BRAF signaling and targeted therapies in melanoma. Hematol Oncol Clin North Am, 2009, 23(3), 529-545, ix.

11. Goldinger, S. M.; Murer, C.; Stieger, P.; Dummer, R. Targeted therapy in melanoma - the role of BRAF, RAS and KIT mutations. EJC Suppl, 2013, 11(2), 92-96.

12. Poulikakos, P. I.; Zhang, C.; Bollag, G.; Shokat, K. M.; Rosen, N. RAF inhibitors transactivate RAF dimers and ERK signalling in cells with wild-type BRAF.

Nature, 2010, 464(7287), 427-430. 
13. Rajalingam, K.; Schreck, R.; Rapp, U. R.; Albert, S. Ras oncogenes and their downstream targets. Biochimica et biophysica acta, 2007, 1773(8), 1177-1195.

14. Su, F.; Viros, A.; Milagre, C.; Trunzer, K.; Bollag, G.; Spleiss, O.; Reis-Filho, J. S.; Kong, X.; Koya, R. C.; Flaherty, K. T.; Chapman, P. B.; Kim, M. J.; Hayward, R.; Martin, M.; Yang, H.; Wang, Q.; Hilton, H.; Hang, J. S.; Noe, J.; Lambros, M.; Geyer, F.; Dhomen, N.; Niculescu-Duvaz, I.; Zambon, A.; Niculescu-Duvaz, D.; Preece, N.; Robert, L.; Otte, N. J.; Mok, S.; Kee, D.; Ma, Y.; Zhang, C.; Habets, G.; Burton, E. A.; Wong, B.; Nguyen, H.; Kockx, M.; Andries, L.; Lestini, B.; Nolop, K. B.; Lee, R. J.; Joe, A. K.; Troy, J. L.; Gonzalez, R.; Hutson, T. E.; Puzanov, I.; Chmielowski, B.; Springer, C. J.; McArthur, G. A.; Sosman, J. A.; Lo, R. S.; Ribas, A.; Marais, R. RAS mutations in cutaneous squamous-cell carcinomas in patients treated with BRAF inhibitors. N Engl J Med, 2012, 366(3), 207-215.

15. Carvajal, R. D.; Antonescu, C. R.; Wolchok, J. D.; Chapman, P. B.; Roman, R. A.; Teitcher, J.; Panageas, K. S.; Busam, K. J.; Chmielowski, B.; Lutzky, J.; Pavlick, A. C.; Fusco, A.; Cane, L.; Takebe, N.; Vemula, S.; Bouvier, N.; Bastian, B. C.; Schwartz, G. K. KIT as a therapeutic target in metastatic melanoma. JAMA, 2011, 305(22), 2327-2334.

16. Swanson, N. A.; Lee, K. K.; Gorman, A.; Lee, H. N. Biopsy techniques. Diagnosis of melanoma. Dermatol Clin, 2002, 20(4), 677-680.

17. Avril, M. F.; Aamdal, S.; Grob, J. J.; Hauschild, A.; Mohr, P.; Bonerandi, J. J.; Weichenthal, M.; Neuber, K.; Bieber, T.; Gilde, K.; Guillem Porta, V.; Fra, J.; Bonneterre, J.; Saiag, P.; Kamanabrou, D.; Pehamberger, H.; Sufliarsky, J.; Gonzalez Larriba, J. L.; Scherrer, A.; Menu, Y. Fotemustine compared with dacarbazine in patients with disseminated malignant melanoma: a phase III study. $J$ Clin Oncol, 2004, 22(6), 1118-1125.

18. Bedikian, A. Y.; Millward, M.; Pehamberger, H.; Conry, R.; Gore, M.; Trefzer, U.; Pavlick, A. C.; DeConti, R.; Hersh, E. M.; Hersey, P.; Kirkwood, J. M.; Haluska, F. G.; Oblimersen Melanoma Study, G. Bcl-2 antisense (oblimersen sodium) plus dacarbazine in patients with advanced melanoma: the Oblimersen Melanoma Study Group. J Clin Oncol, 2006, 24(29), 4738-4745.

19. Hodi, F. S.; O'Day, S. J.; McDermott, D. F.; Weber, R. W.; Sosman, J. A.; Haanen, J. B.; Gonzalez, R.; Robert, C.; Schadendorf, D.; Hassel, J. C.; Akerley, W.; van den Eertwegh, A. J.; Lutzky, J.; Lorigan, P.; Vaubel, J. M.; Linette, G. P.; Hogg, D.; Ottensmeier, C. H.; Lebbe, C.; Peschel, C.; Quirt, I.; Clark, J. I.; Wolchok, J. D.; Weber, J. S.; Tian, J.; Yellin, M. J.; Nichol, G. M.; Hoos, A.; Urba, W. J. Improved survival with ipilimumab in patients with metastatic melanoma. $N$ Engl J Med, 2010, 363(8), 711-723.

20. Topalian, S. L.; Hodi, F. S.; Brahmer, J. R.; Gettinger, S. N.; Smith, D. C.; McDermott, D. F.; Powderly, J. D.; Carvajal, R. D.; Sosman, J. A.; Atkins, M. B.; Leming, P. D.; Spigel, D. R.; Antonia, S. J.; Horn, L.; Drake, C. G.; Pardoll, D. M.; Chen, L.; Sharfman, W. H.; Anders, R. A.; Taube, J. M.; McMiller, T. L.; Xu, H.; Korman, A. J.; Jure-Kunkel, M.; Agrawal, S.; McDonald, D.; Kollia, G. D.; Gupta, A.; Wigginton, J. M.; Sznol, M. Safety, activity, and immune correlates of anti-PD-1 antibody in cancer. $N$ Engl J Med, 2012, 366(26), 2443-2454. 
21. Ascierto, P. A.; Marincola, F. M. 2015: The Year of Anti-PD-1/PD-L1s Against Melanoma and Beyond. EBioMedicine, 2015, 2(2), 92-93.

22. Ma, C.; Armstrong, A. W. Severe adverse events from the treatment of advanced melanoma: a systematic review of severe side effects associated with ipilimumab, vemurafenib, interferon alfa-2b, dacarbazine and interleukin-2. J Dermatolog Treat, 2014, 25(5), 401-408.

23. Atkins, M. B.; Lotze, M. T.; Dutcher, J. P.; Fisher, R. I.; Weiss, G.; Margolin, K.; Abrams, J.; Sznol, M.; Parkinson, D.; Hawkins, M.; Paradise, C.; Kunkel, L.; Rosenberg, S. A. High-dose recombinant interleukin 2 therapy for patients with metastatic melanoma: analysis of 270 patients treated between 1985 and 1993. $J$ Clin Oncol, 1999, 17(7), 2105-2116.

24. Ascierto, P. A.; Chiarion-Sileni, V.; Muggiano, A.; Mandala, M.; Pimpinelli, N.; Del Vecchio, M.; Rinaldi, G.; Simeone, E.; Queirolo, P. Interferon alpha for the adjuvant treatment of melanoma: review of international literature and practical recommendations from an expert panel on the use of interferon. $J$ Chemother, 2014, 26(4), 193-201.

25. Daponte, A.; Signoriello, S.; Maiorino, L.; Massidda, B.; Simeone, E.; Grimaldi, A. M.; Caraco, C.; Palmieri, G.; Cossu, A.; Botti, G.; Petrillo, A.; Lastoria, S.; Cavalcanti, E.; Aprea, P.; Mozzillo, N.; Gallo, C.; Comella, G.; Ascierto, P. A.; Southern Italy Cooperative Oncology, G. Phase III randomized study of fotemustine and dacarbazine versus dacarbazine with or without interferon-alpha in advanced malignant melanoma. $J$ Transl Med, 2013, 11, 38 .

26. Kidner, T. B.; Morton, D. L.; Lee, D. J.; Hoban, M.; Foshag, L. J.; Turner, R. R.; Faries, M. B. Combined intralesional Bacille Calmette-Guerin (BCG) and topical imiquimod for in-transit melanoma. J Immunother, 2012, 35(9), 716-720.

27. Long, G. V.; Menzies, A. M.; Nagrial, A. M.; Haydu, L. E.; Hamilton, A. L.; Mann, G. J.; Hughes, T. M.; Thompson, J. F.; Scolyer, R. A.; Kefford, R. F. Prognostic and clinicopathologic associations of oncogenic BRAF in metastatic melanoma. J Clin Oncol, 2011, 29(10), 1239-1246.

28. Stones, C. J.; Kim, J. E.; Joseph, W. R.; Leung, E.; Marshall, E. S.; Finlay, G. J.; Shelling, A. N.; Baguley, B. C. Comparison of responses of human melanoma cell lines to MEK and BRAF inhibitors. Front Genet, 2013, 4, 66.

29. Wan, P. T.; Garnett, M. J.; Roe, S. M.; Lee, S.; Niculescu-Duvaz, D.; Good, V. M.; Jones, C. M.; Marshall, C. J.; Springer, C. J.; Barford, D.; Marais, R.; Cancer Genome, P. Mechanism of activation of the RAF-ERK signaling pathway by oncogenic mutations of B-RAF. Cell, 2004, 116(6), 855-867.

30. Flaherty, K. T.; Puzanov, I.; Kim, K. B.; Ribas, A.; McArthur, G. A.; Sosman, J. A.; O'Dwyer, P. J.; Lee, R. J.; Grippo, J. F.; Nolop, K.; Chapman, P. B. Inhibition of mutated, activated BRAF in metastatic melanoma. N Engl J Med, 2010, 363(9), 809-819.

31. Falchook, G. S.; Long, G. V.; Kurzrock, R.; Kim, K. B.; Arkenau, T. H.; Brown, M. P.; Hamid, O.; Infante, J. R.; Millward, M.; Pavlick, A. C.; O'Day, S. J.; Blackman, S. C.; Curtis, C. M.; Lebowitz, P.; Ma, B.; Ouellet, D.; Kefford, R. F. Dabrafenib in patients with melanoma, untreated brain metastases, and other solid tumours: a phase 1 dose-escalation trial. Lancet, 2012, 379(9829), 1893-1901. 
32. Hauschild, A.; Grob, J. J.; Demidov, L. V.; Jouary, T.; Gutzmer, R.; Millward, M.; Rutkowski, P.; Blank, C. U.; Miller, W. H., Jr.; Kaempgen, E.; MartinAlgarra, S.; Karaszewska, B.; Mauch, C.; Chiarion-Sileni, V.; Martin, A. M.; Swann, S.; Haney, P.; Mirakhur, B.; Guckert, M. E.; Goodman, V.; Chapman, P. B. Dabrafenib in BRAF-mutated metastatic melanoma: a multicentre, open-label, phase 3 randomised controlled trial. Lancet, 2012, 380(9839), 358-365.

33. Falchook, G. S.; Lewis, K. D.; Infante, J. R.; Gordon, M. S.; Vogelzang, N. J.; DeMarini, D. J.; Sun, P.; Moy, C.; Szabo, S. A.; Roadcap, L. T.; Peddareddigari, V. G.; Lebowitz, P. F.; Le, N. T.; Burris, H. A., 3rd; Messersmith, W. A.; O'Dwyer, P. J.; Kim, K. B.; Flaherty, K.; Bendell, J. C.; Gonzalez, R.; Kurzrock, R.; Fecher, L. A. Activity of the oral MEK inhibitor trametinib in patients with advanced melanoma: a phase 1 dose-escalation trial. Lancet Oncol, 2012, 13(8), 782-789.

34. Kirkwood, J. M.; Bastholt, L.; Robert, C.; Sosman, J.; Larkin, J.; Hersey, P.; Middleton, M.; Cantarini, M.; Zazulina, V.; Kemsley, K.; Dummer, R. Phase II, open-label, randomized trial of the MEK1/2 inhibitor selumetinib as monotherapy versus temozolomide in patients with advanced melanoma. Clin Cancer Res, 2012, 18(2), 555-567.

35. Atefi, M.; von Euw, E.; Attar, N.; Ng, C.; Chu, C.; Guo, D.; Nazarian, R.; Chmielowski, B.; Glaspy, J. A.; Comin-Anduix, B.; Mischel, P. S.; Lo, R. S.; Ribas, A. Reversing melanoma cross-resistance to BRAF and MEK inhibitors by co-targeting the AKT/mTOR pathway. PLoS One, 2011, 6(12), e28973.

36. Haq, R.; Yokoyama, S.; Hawryluk, E. B.; Jonsson, G. B.; Frederick, D. T.; McHenry, K.; Porter, D.; Tran, T. N.; Love, K. T.; Langer, R.; Anderson, D. G.; Garraway, L. A.; Duncan, L. M.; Morton, D. L.; Hoon, D. S.; Wargo, J. A.; Song, J. S.; Fisher, D. E. BCL2A1 is a lineage-specific antiapoptotic melanoma oncogene that confers resistance to BRAF inhibition. Proc Natl Acad Sci US A, 2013, 110(11), 4321-4326.

37. Vin, H.; Ojeda, S. S.; Ching, G.; Leung, M. L.; Chitsazzadeh, V.; Dwyer, D. W.; Adelmann, C. H.; Restrepo, M.; Richards, K. N.; Stewart, L. R.; Du, L.; Ferguson, S. B.; Chakravarti, D.; Ehrenreiter, K.; Baccarini, M.; Ruggieri, R.; Curry, J. L.; Kim, K. B.; Ciurea, A. M.; Duvic, M.; Prieto, V. G.; Ullrich, S. E.; Dalby, K. N.; Flores, E. R.; Tsai, K. Y. BRAF inhibitors suppress apoptosis through off-target inhibition of JNK signaling. Elife, 2013, 2, e00969.

38. Roesch, A. Tumor heterogeneity and plasticity as elusive drivers for resistance to MAPK pathway inhibition in melanoma. Oncogene, 2015, 34(23), 2951-2957.

39. Yancovitz, M.; Litterman, A.; Yoon, J.; Ng, E.; Shapiro, R. L.; Berman, R. S.; Pavlick, A. C.; Darvishian, F.; Christos, P.; Mazumdar, M.; Osman, I.; Polsky, D. Intra- and inter-tumor heterogeneity of $\mathrm{BRAF}(\mathrm{V} 600 \mathrm{E}))$ mutations in primary and metastatic melanoma. PLoS One, 2012, 7(1), e29336.

40. Little, A. S.; Smith, P. D.; Cook, S. J. Mechanisms of acquired resistance to ERK1/2 pathway inhibitors. Oncogene, 2013, 32(10), 1207-1215.

41. Johannessen, C. M.; Boehm, J. S.; Kim, S. Y.; Thomas, S. R.; Wardwell, L.; Johnson, L. A.; Emery, C. M.; Stransky, N.; Cogdill, A. P.; Barretina, J.; Caponigro, G.; Hieronymus, H.; Murray, R. R.; Salehi-Ashtiani, K.; Hill, D. E.; Vidal, M.; Zhao, J. J.; Yang, X.; Alkan, O.; Kim, S.; Harris, J. L.; Wilson, C. J.; 
Myer, V. E.; Finan, P. M.; Root, D. E.; Roberts, T. M.; Golub, T.; Flaherty, K. T.; Dummer, R.; Weber, B. L.; Sellers, W. R.; Schlegel, R.; Wargo, J. A.; Hahn, W. C.; Garraway, L. A. COT drives resistance to RAF inhibition through MAP kinase pathway reactivation. Nature, 2010, 468(7326), 968-972.

42. Straussman, R.; Morikawa, T.; Shee, K.; Barzily-Rokni, M.; Qian, Z. R.; Du, J.; Davis, A.; Mongare, M. M.; Gould, J.; Frederick, D. T.; Cooper, Z. A.; Chapman, P. B.; Solit, D. B.; Ribas, A.; Lo, R. S.; Flaherty, K. T.; Ogino, S.; Wargo, J. A.; Golub, T. R. Tumour micro-environment elicits innate resistance to RAF inhibitors through HGF secretion. Nature, 2012, 487(7408), 500-504.

43. Nazarian, R.; Shi, H.; Wang, Q.; Kong, X.; Koya, R. C.; Lee, H.; Chen, Z.; Lee, M. K.; Attar, N.; Sazegar, H.; Chodon, T.; Nelson, S. F.; McArthur, G.; Sosman, J. A.; Ribas, A.; Lo, R. S. Melanomas acquire resistance to B-RAF(V600E) inhibition by RTK or N-RAS upregulation. Nature, 2010, 468(7326), 973-977.

44. Sanchez-Laorden, B.; Viros, A.; Girotti, M. R.; Pedersen, M.; Saturno, G.; Zambon, A.; Niculescu-Duvaz, D.; Turajlic, S.; Hayes, A.; Gore, M.; Larkin, J.; Lorigan, P.; Cook, M.; Springer, C.; Marais, R. BRAF inhibitors induce metastasis in RAS mutant or inhibitor-resistant melanoma cells by reactivating MEK and ERK signaling. Sci Signal, 2014, 7(318), ra30.

45. Fedorenko, I. V.; Gibney, G. T.; Sondak, V. K.; Smalley, K. S. Beyond BRAF: where next for melanoma therapy? Br J Cancer, 2015, 112(2), 217-226.

46. Marlier, J.; Cocquyt, V.; Brochez, L.; Van Belle, S.; Kruse, V. Ipilimumab, not just another anti-cancer therapy: hypophysitis as side effect illustrated by four case-reports. Endocrine, 2014, 47(3), 878-883.

47. Torino, F.; Barnabei, A.; Paragliola, R. M.; Marchetti, P.; Salvatori, R.; Corsello, S. M. Endocrine side-effects of anti-cancer drugs: mAbs and pituitary dysfunction: clinical evidence and pathogenic hypotheses. Eur J Endocrinol, 2013, $169(6)$, R153-164.

48. Mita, A. C.; Mita, M. M.; Nawrocki, S. T.; Giles, F. J. Survivin: key regulator of mitosis and apoptosis and novel target for cancer therapeutics. Clin Cancer Res, 2008, 14(16), 5000-5005.

49. Altieri, D. C. Survivin, cancer networks and pathway-directed drug discovery. Nat Rev Cancer, 2008, 8(1), 61-70.

50. Rosa, J.; Canovas, P.; Islam, A.; Altieri, D. C.; Doxsey, S. J. Survivin modulates microtubule dynamics and nucleation throughout the cell cycle. Mol Biol Cell, 2006, 17(3), 1483-1493.

51. Lu, J.; Tan, M.; Huang, W. C.; Li, P.; Guo, H.; Tseng, L. M.; Su, X. H.; Yang, W. T.; Treekitkarnmongkol, W.; Andreeff, M.; Symmans, F.; Yu, D. Mitotic deregulation by survivin in ErbB2-overexpressing breast cancer cells contributes to Taxol resistance. Clin Cancer Res, 2009, 15(4), 1326-1334.

52. Jordan, M. A.; Wilson, L. Microtubules as a target for anticancer drugs. Nat Rev Cancer, 2004, 4(4), 253-265.

53. Kaur, R.; Kaur, G.; Gill, R. K.; Soni, R.; Bariwal, J. Recent developments in tubulin polymerization inhibitors: An overview. Eur J Med Chem, 2014, 87, 89124.

54. Waterman-Storer, C. M.; Salmon, E. D. Microtubule dynamics: treadmilling comes around again. Curr Biol, 1997, 7(6), R369-372. 
55. Chen, W.; Zhang, D. Kinetochore fibre dynamics outside the context of the spindle during anaphase. Nat Cell Biol, 2004, 6(3), 227-231.

56. Dumontet, C.; Jordan, M. A. Microtubule-binding agents: a dynamic field of cancer therapeutics. Nat Rev Drug Discov, 2010, 9(10), 790-803.

57. Noble, R. L.; Beer, C. T.; Cutts, J. H. Role of chance observations in chemotherapy: Vinca rosea. Ann N Y Acad Sci, 1958, 76(3), 882-894.

58. Gigant, B.; Wang, C.; Ravelli, R. B.; Roussi, F.; Steinmetz, M. O.; Curmi, P. A.; Sobel, A.; Knossow, M. Structural basis for the regulation of tubulin by vinblastine. Nature, 2005, 435(7041), 519-522.

59. Hu, C. B.; Chen, C. P.; Yeh, T. K.; Song, J. S.; Chang, C. Y.; Chuu, J. J.; Tung, F. F.; Ho, P. Y.; Chen, T. W.; Lin, C. H.; Wang, M. H.; Chang, K. Y.; Huang, C. L.; Lin, H. L.; Li, W. T.; Hwang, D. R.; Chern, J. H.; Hwang, L. L.; Chang, J. Y.; Chao, Y. S.; Chen, C. T. BPR0C261 is a novel orally active antitumor agent with antimitotic and anti-angiogenic activities. Cancer Sci, 2011, 102(1), 182-191.

60. Li, W. T.; Hwang, D. R.; Chen, C. P.; Shen, C. W.; Huang, C. L.; Chen, T. W.; Lin, C. H.; Chang, Y. L.; Chang, Y. Y.; Lo, Y. K.; Tseng, H. Y.; Lin, C. C.; Song, J. S.; Chen, H. C.; Chen, S. J.; Wu, S. H.; Chen, C. T. Synthesis and biological evaluation of $\mathrm{N}$-heterocyclic indolyl glyoxylamides as orally active anticancer agents. J Med Chem, 2003, 46(9), 1706-1715.

61. Arthuis, M.; Pontikis, R.; Chabot, G. G.; Quentin, L.; Scherman, D.; Florent, J. C. Domino approach to 2-aroyltrimethoxyindoles as novel heterocyclic combretastatin A4 analogues. Eur J Med Chem, 2011, 46(1), 95-100.

62. Bacher, G.; Nickel, B.; Emig, P.; Vanhoefer, U.; Seeber, S.; Shandra, A.; Klenner, T.; Beckers, T. D-24851, a novel synthetic microtubule inhibitor, exerts curative antitumoral activity in vivo, shows efficacy toward multidrug-resistant tumor cells, and lacks neurotoxicity. Cancer Res, 2001, 61(1), 392-399.

63. El-Nakkady, S. S.; Hanna, M. M.; Roaiah, H. M.; Ghannam, I. A. Synthesis, molecular docking study and antitumor activity of novel 2-phenylindole derivatives. Eur J Med Chem, 2012, 47(1), 387-398.

64. Bohlin, L.; Rosen, B. Podophyllotoxin derivatives: Drug discovery and development. Drug Discov Today, 1996, 1(8), 343-351.

65. Wender, P. A.; Hegde, S. G.; Hubbard, R. D.; Zhang, L. Total synthesis of (-)laulimalide. J Am Chem Soc, 2002, 124(18), 4956-4957.

66. Pryor, D. E.; O'Brate, A.; Bilcer, G.; Diaz, J. F.; Wang, Y.; Wang, Y.; Kabaki, M.; Jung, M. K.; Andreu, J. M.; Ghosh, A. K.; Giannakakou, P.; Hamel, E. The microtubule stabilizing agent laulimalide does not bind in the taxoid site, kills cells resistant to paclitaxel and epothilones, and may not require its epoxide moiety for activity. Biochemistry, 2002, 41(29), 9109-9115.

67. Pettit, G. R.; Singh, S. B.; Hamel, E.; Lin, C. M.; Alberts, D. S.; Garcia-Kendall, D. Isolation and structure of the strong cell growth and tubulin inhibitor combretastatin A-4. Experientia, 1989, 45(2), 209-211.

68. Rustin, G. J.; Shreeves, G.; Nathan, P. D.; Gaya, A.; Ganesan, T. S.; Wang, D.; Boxall, J.; Poupard, L.; Chaplin, D. J.; Stratford, M. R.; Balkissoon, J.; Zweifel, M. A Phase Ib trial of CA4P (combretastatin A-4 phosphate), carboplatin, and paclitaxel in patients with advanced cancer. Br J Cancer, 2010, 102(9), 13551360. 
69. Fotsis, T.; Zhang, Y.; Pepper, M. S.; Adlercreutz, H.; Montesano, R.; Nawroth, P. P.; Schweigerer, L. The endogenous oestrogen metabolite 2-methoxyoestradiol inhibits angiogenesis and suppresses tumour growth. Nature, 1994, 368(6468), 237-239.

70. Seegers, J. C.; Aveling, M. L.; Van Aswegen, C. H.; Cross, M.; Koch, F.; Joubert, W. S. The cytotoxic effects of estradiol-17 beta, catecholestradiols and methoxyestradiols on dividing MCF-7 and HeLa cells. J Steroid Biochem, 1989, 32(6), 797-809.

71. Lottering, M. L.; Haag, M.; Seegers, J. C. Effects of 17 beta-estradiol metabolites on cell cycle events in MCF-7 cells. Cancer Res, 1992, 52(21), 5926-5932.

72. $\quad$ D'Amato, R. J.; Lin, C. M.; Flynn, E.; Folkman, J.; Hamel, E. 2Methoxyestradiol, an endogenous mammalian metabolite, inhibits tubulin polymerization by interacting at the colchicine site. Proc Natl Acad Sci US A, 1994, 91(9), 3964-3968.

73. Hamel, E.; Lin, C. M.; Flynn, E.; D'Amato, R. J. Interactions of 2methoxyestradiol, an endogenous mammalian metabolite, with unpolymerized tubulin and with tubulin polymers. Biochemistry, 1996, 35(4), 1304-1310.

74. Sweeney, C.; Liu, G.; Yiannoutsos, C.; Kolesar, J.; Horvath, D.; Staab, M. J.; Fife, K.; Armstrong, V.; Treston, A.; Sidor, C.; Wilding, G. A phase II multicenter, randomized, double-blind, safety trial assessing the pharmacokinetics, pharmacodynamics, and efficacy of oral 2-methoxyestradiol capsules in hormone-refractory prostate cancer. Clin Cancer Res, 2005, 11(18), 6625-6633.

75. James, J.; Murry, D. J.; Treston, A. M.; Storniolo, A. M.; Sledge, G. W.; Sidor, C.; Miller, K. D. Phase I safety, pharmacokinetic and pharmacodynamic studies of 2-methoxyestradiol alone or in combination with docetaxel in patients with locally recurrent or metastatic breast cancer. Invest New Drugs, 2007, 25(1), 4148.

76. Rajkumar, S. V.; Richardson, P. G.; Lacy, M. Q.; Dispenzieri, A.; Greipp, P. R.; Witzig, T. E.; Schlossman, R.; Sidor, C. F.; Anderson, K. C.; Gertz, M. A. Novel therapy with 2-methoxyestradiol for the treatment of relapsed and plateau phase multiple myeloma. Clin Cancer Res, 2007, 13(20), 6162-6167.

77. Yoshino, H.; Ueda, N.; Niijima, J.; Sugumi, H.; Kotake, Y.; Koyanagi, N.; Yoshimatsu, K.; Asada, M.; Watanabe, T.; Nagasu, T.; et al. Novel sulfonamides as potential, systemically active antitumor agents. $J$ Med Chem, 1992, 35(13), 2496-2497.

78. Yoshimatsu, K.; Yamaguchi, A.; Yoshino, H.; Koyanagi, N.; Kitoh, K. Mechanism of action of E7010, an orally active sulfonamide antitumor agent: inhibition of mitosis by binding to the colchicine site of tubulin. Cancer Res, 1997, 57(15), 3208-3213.

79. Yamamoto, K.; Noda, K.; Yoshimura, A.; Fukuoka, M.; Furuse, K.; Niitani, H. Phase I study of E7010. Cancer Chemother Pharmacol, 1998, 42(2), 127-134.

80. Michels, J.; Ellard, S. L.; Le, L.; Kollmannsberger, C.; Murray, N.; Tomlinson Guns, E. S.; Carr, R.; Chi, K. N. A phase IB study of ABT-751 in combination with docetaxel in patients with advanced castration-resistant prostate cancer. Ann Oncol, 2010, 21(2), 305-311. 
81. Hande, K. R.; Hagey, A.; Berlin, J.; Cai, Y.; Meek, K.; Kobayashi, H.; Lockhart, A. C.; Medina, D.; Sosman, J.; Gordon, G. B.; Rothenberg, M. L. The pharmacokinetics and safety of ABT-751, a novel, orally bioavailable sulfonamide antimitotic agent: results of a phase 1 study. Clin Cancer Res, 2006, 12(9), 2834-2840.

82. de Ines, C.; Leynadier, D.; Barasoain, I.; Peyrot, V.; Garcia, P.; Briand, C.; Rener, G. A.; Temple, C., Jr. Inhibition of microtubules and cell cycle arrest by a new 1deaza-7,8-dihydropteridine antitumor drug, CI 980, and by its chiral isomer, NSC 613863. Cancer Res, 1994, 54(1), 75-84.

83. Meyers, C. A.; Kudelka, A. P.; Conrad, C. A.; Gelke, C. K.; Grove, W.; Pazdur, R. Neurotoxicity of CI-980, a novel mitotic inhibitor. Clin Cancer Res, 1997, 3(3), 419-422.

84. Wienecke, A.; Bacher, G. Indibulin, a novel microtubule inhibitor, discriminates between mature neuronal and nonneuronal tubulin. Cancer Res, 2009, 69(1), 171177.

85. Lu, Y.; Chen, J.; Xiao, M.; Li, W.; Miller, D. D. An overview of tubulin inhibitors that interact with the colchicine binding site. Pharm Res, 2012, 29(11), 29432971.

86. Romagnoli, R.; Baraldi, P. G.; Brancale, A.; Ricci, A.; Hamel, E.; Bortolozzi, R.; Basso, G.; Viola, G. Convergent synthesis and biological evaluation of 2-amino4-(3',4',5'-trimethoxyphenyl)-5-aryl thiazoles as microtubule targeting agents. $J$ Med Chem, 2011, 54(14), 5144-5153.

87. Calliste, C. A.; Le Bail, J. C.; Trouillas, P.; Pouget, C.; Habrioux, G.; Chulia, A. J.; Duroux, J. L. Chalcones: structural requirements for antioxidant, estrogenic and anti-proliferative activities. Anticancer Res, 2001, 21(6A), 3949-3956.

88. Kumar, S. K.; Hager, E.; Pettit, C.; Gurulingappa, H.; Davidson, N. E.; Khan, S. R. Design, synthesis, and evaluation of novel boronic-chalcone derivatives as antitumor agents. J Med Chem, 2003, 46(14), 2813-2815.

89. Lahtchev, K. L.; Batovska, D. I.; Parushev, S. P.; Ubiyvovk, V. M.; Sibirny, A. A. Antifungal activity of chalcones: a mechanistic study using various yeast strains. Eur J Med Chem, 2008, 43(10), 2220-2228.

90. Ducki, S. Antimitotic chalcones and related compounds as inhibitors of tubulin assembly. Anticancer Agents Med Chem, 2009, 9(3), 336-347.

91. Sashidhara, K. V.; Kumar, A.; Kumar, M.; Sarkar, J.; Sinha, S. Synthesis and in vitro evaluation of novel coumarin-chalcone hybrids as potential anticancer agents. Bioorg Med Chem Lett, 2010, 20(24), 7205-7211.

92. Peyrot, V.; Leynadier, D.; Sarrazin, M.; Briand, C.; Menendez, M.; Laynez, J.; Andreu, J. M. Mechanism of binding of the new antimitotic drug MDL 27048 to the colchicine site of tubulin: equilibrium studies. Biochemistry, 1992, 31(45), 11125-11132.

93. Peyrot, V.; Leynadier, D.; Sarrazin, M.; Briand, C.; Rodriquez, A.; Nieto, J. M.; Andreu, J. M. Interaction of tubulin and cellular microtubules with the new antitumor drug MDL 27048. A powerful and reversible microtubule inhibitor. $J$ Biol Chem, 1989, 264(35), 21296-21301.

94. Boumendjel, A.; McLeer-Florin, A.; Champelovier, P.; Allegro, D.; Muhammad, D.; Souard, F.; Derouazi, M.; Peyrot, V.; Toussaint, B.; Boutonnat, J. A novel 
chalcone derivative which acts as a microtubule depolymerising agent and an inhibitor of P-gp and BCRP in in-vitro and in-vivo glioblastoma models. $B M C$ Cancer, 2009, 9, 242.

95. Risinger, A. L.; Westbrook, C. D.; Encinas, A.; Mulbaier, M.; Schultes, C. M.; Wawro, S.; Lewis, J. D.; Janssen, B.; Giles, F. J.; Mooberry, S. L. ELR510444, a novel microtubule disruptor with multiple mechanisms of action. J Pharmacol Exp Ther, 2011, 336(3), 652-660.

96. De Martino, G.; Edler, M. C.; La Regina, G.; Coluccia, A.; Barbera, M. C.; Barrow, D.; Nicholson, R. I.; Chiosis, G.; Brancale, A.; Hamel, E.; Artico, M.; Silvestri, R. New arylthioindoles: potent inhibitors of tubulin polymerization. 2. Structure-activity relationships and molecular modeling studies. $J$ Med Chem, 2006, 49(3), 947-954.

97. De Martino, G.; La Regina, G.; Coluccia, A.; Edler, M. C.; Barbera, M. C.; Brancale, A.; Wilcox, E.; Hamel, E.; Artico, M.; Silvestri, R. Arylthioindoles, potent inhibitors of tubulin polymerization. $J$ Med Chem, 2004, 47(25), 61206123.

98. Mahboobi, S.; Pongratz, H.; Hufsky, H.; Hockemeyer, J.; Frieser, M.; Lyssenko, A.; Paper, D. H.; Burgermeister, J.; Bohmer, F. D.; Fiebig, H. H.; Burger, A. M.; Baasner, S.; Beckers, T. Synthetic 2-aroylindole derivatives as a new class of potent tubulin-inhibitory, antimitotic agents. $J$ Med Chem, 2001, 44(26), 45354553.

99. Kuo, C. C.; Hsieh, H. P.; Pan, W. Y.; Chen, C. P.; Liou, J. P.; Lee, S. J.; Chang, Y. L.; Chen, L. T.; Chen, C. T.; Chang, J. Y. BPR0L075, a novel synthetic indole compound with antimitotic activity in human cancer cells, exerts effective antitumoral activity in vivo. Cancer Res, 2004, 64(13), 4621-4628.

100. Ambudkar, S. V.; Kimchi-Sarfaty, C.; Sauna, Z. E.; Gottesman, M. M. Pglycoprotein: from genomics to mechanism. Oncogene, 2003, 22(47), 7468-7485.

101. Thomas, H.; Coley, H. M. Overcoming multidrug resistance in cancer: an update on the clinical strategy of inhibiting p-glycoprotein. Cancer Control, 2003, 10(2), 159-165.

102. Geney, R.; Ungureanu 1, M.; Li, D.; Ojima, I. Overcoming multidrug resistance in taxane chemotherapy. Clin Chem Lab Med, 2002, 40(9), 918-925.

103. Canta, A.; Chiorazzi, A.; Cavaletti, G. Tubulin: a target for antineoplastic drugs into the cancer cells but also in the peripheral nervous system. Curr Med Chem, 2009, 16(11), 1315-1324.

104. Vats, T.; Buchanan, G.; Mehta, P.; Ragab, A.; Hvizdale, E.; Nitschke, R.; Link, M.; Beardsley, G. P.; Maybee, D.; Krischer, J. A study of toxicity and comparative therapeutic efficacy of vindesine-prednisone vs. vincristineprednisone in children with acute lymphoblastic leukemia in relapse. A Pediatric Oncology Group study. Invest New Drugs, 1992, 10(3), 231-234.

105. Swanton, C.; Nicke, B.; Schuett, M.; Eklund, A. C.; Ng, C.; Li, Q.; Hardcastle, T.; Lee, A.; Roy, R.; East, P.; Kschischo, M.; Endesfelder, D.; Wylie, P.; Kim, S. N.; Chen, J. G.; Howell, M.; Ried, T.; Habermann, J. K.; Auer, G.; Brenton, J. D.; Szallasi, Z.; Downward, J. Chromosomal instability determines taxane response. Proc Natl Acad Sci U S A, 2009, 106(21), 8671-8676. 
106. Bouchet, B. P.; Bertholon, J.; Falette, N.; Audoynaud, C.; Lamblot, C.; Puisieux, A.; Galmarini, C. M. Paclitaxel resistance in untransformed human mammary epithelial cells is associated with an aneuploidy-prone phenotype. Br J Cancer, 2007, 97(9), 1218-1224.

107. Lu, Y.; Li, C. M.; Wang, Z.; Ross, C. R., 2nd; Chen, J.; Dalton, J. T.; Li, W.; Miller, D. D. Discovery of 4-substituted methoxybenzoyl-aryl-thiazole as novel anticancer agents: synthesis, biological evaluation, and structure-activity relationships. J Med Chem, 2009, 52(6), 1701-1711.

108. Chen, J.; Wang, Z.; Li, C. M.; Lu, Y.; Vaddady, P. K.; Meibohm, B.; Dalton, J. T.; Miller, D. D.; Li, W. Discovery of novel 2-aryl-4-benzoyl-imidazoles targeting the colchicines binding site in tubulin as potential anticancer agents. $J$ Med Chem, 2010, 53(20), 7414-7427.

109. Lu, Y.; Li, C. M.; Wang, Z.; Chen, J.; Mohler, M. L.; Li, W.; Dalton, J. T.; Miller, D. D. Design, synthesis, and SAR studies of 4-substituted methoxylbenzoyl-arylthiazoles analogues as potent and orally bioavailable anticancer agents. $J$ Med Chem, 2011, 54(13), 4678-4693.

110. Xu, Q.; Qi, H.; Sun, M.; Zuo, D.; Jiang, X.; Wen, Z.; Wang, Z.; Wu, Y.; Zhang, W. Synthesis and Biological Evaluation of 3-Alkyl-1,5-Diaryl-1H-Pyrazoles as Rigid Analogues of Combretastatin A-4 with Potent Antiproliferative Activity. PLoS One, 2015, 10(6), e0128710.

111. Kanthou, C.; Tozer, G. M. Microtubule depolymerizing vascular disrupting agents: novel therapeutic agents for oncology and other pathologies. Int J Exp Pathol, 2009, 90(3), 284-294.

112. Chen, J.; Ahn, S.; Wang, J.; Lu, Y.; Dalton, J. T.; Miller, D. D.; Li, W. Discovery of novel 2-aryl-4-benzoyl-imidazole (ABI-III) analogues targeting tubulin polymerization as anti-proliferative agents. J Med Chem, 2012, 55(16), 72857289.

113. Li, C. M.; Lu, Y.; Chen, J.; Costello, T. A.; Narayanan, R.; Dalton, M. N.; Snyder, L. M.; Ahn, S.; Li, W.; Miller, D. D.; Dalton, J. T. Orally bioavailable tubulin antagonists for paclitaxel-refractory cancer. Pharm Res, 2012, 29(11), 3053-3063.

114. Wang, Z.; Chen, J.; Wang, J.; Ahn, S.; Li, C. M.; Lu, Y.; Loveless, V. S.; Dalton, J. T.; Miller, D. D.; Li, W. Novel tubulin polymerization inhibitors overcome multidrug resistance and reduce melanoma lung metastasis. Pharm Res, 2012, 29(11), 3040-3052.

115. Chen, J.; Li, C. M.; Wang, J.; Ahn, S.; Wang, Z.; Lu, Y.; Dalton, J. T.; Miller, D. D.; Li, W. Synthesis and anti-proliferative activity of novel 2-aryl-4-benzoylimidazole derivatives targeting tubulin polymerization. Bioorganic \& medicinal chemistry, 2011, 19(16), 4782-4795.

116. Li, C. M.; Chen, J.; Lu, Y.; Narayanan, R.; Parke, D. N.; Li, W.; Ahn, S.; Miller, D. D.; Dalton, J. T. Pharmacokinetic optimization of 4-substituted methoxybenzoyl-aryl-thiazole and 2-aryl-4-benzoyl-imidazole for improving oral bioavailability. Drug metabolism and disposition: the biological fate of chemicals, 2011, 39(10), 1833-1839. 
117. Khalili, B.; Tondro, T.; Hashemi, M. M. Novel one-pot synthesis of (4 or 5)-aryl2 -aryloyl-(1H)-imidazoles in water and tauto-isomerization study using NMR. Tetrahedron, 2009, 65(34), 6882-6887.

118. Parkinson, E. I.; Jason Hatfield, M.; Tsurkan, L.; Hyatt, J. L.; Edwards, C. C.; Hicks, L. D.; Yan, B.; Potter, P. M. Requirements for mammalian carboxylesterase inhibition by substituted ethane-1,2-diones. Bioorganic \& medicinal chemistry, 2011, 19(15), 4635-4643.

119. Pelphrey, P. M.; Popov, V. M.; Joska, T. M.; Beierlein, J. M.; Bolstad, E. S.; Fillingham, Y. A.; Wright, D. L.; Anderson, A. C. Highly efficient ligands for dihydrofolate reductase from Cryptosporidium hominis and Toxoplasma gondii inspired by structural analysis. $J$ Med Chem, 2007, 50(5), 940-950.

120. Riley, H. A. G., A. R. General procedure for synthesis of glyoxal derivatives. Organic Syntheses; Wiley \& Sons: New York, NY, 1943, 2, 509-510.

121. Corelli, F.; Summa, V.; Brogi, A.; Monteagudo, E.; Botta, M. Chiral Azole Derivatives .2. Synthesis of Enantiomerically Pure 1-Alkylimidazoles. J Org Chem, 1995, 60(7), 2008-2015.

122. Sabbah, M.; Soulere, L.; Reverchon, S.; Queneau, Y.; Doutheau, A. LuxR dependent quorum sensing inhibition by $\mathrm{N}, \mathrm{N}^{\prime}$-disubstituted imidazolium salts. Bioorganic \& medicinal chemistry, 2011, 19(16), 4868-4875.

123. Xi, Z. X.; Liu, F. H.; Zhou, Y. B.; Chen, W. Z. CuI/L (L = pyridinefunctionalized 1,3-diketones) catalyzed $\mathrm{C}-\mathrm{N}$ coupling reactions of aryl halides with NH-containing heterocycles. Tetrahedron, 2008, 64(19), 4254-4259.

124. Leonessa, F.; Green, D.; Licht, T.; Wright, A.; Wingate-Legette, K.; Lippman, J.; Gottesman, M. M.; Clarke, R. MDA435/LCC6 and MDA435/LCC6MDR1: ascites models of human breast cancer. Br J Cancer, 1996, 73(2), 154-161.

125. Vredenburg, M. R.; Ojima, I.; Veith, J.; Pera, P.; Kee, K.; Cabral, F.; Sharma, A.; Kanter, P.; Greco, W. R.; Bernacki, R. J. Effects of orally active taxanes on Pglycoprotein modulation and colon and breast carcinoma drug resistance. Journal of the National Cancer Institute, 2001, 93(16), 1234-1245.

126. Zhang, S.; Morris, M. E. Effects of the flavonoids biochanin A, morin, phloretin, and silymarin on P-glycoprotein-mediated transport. J Pharmacol Exp Ther, 2003, 304(3), 1258-1267.

127. Dong, X.; Mattingly, C. A.; Tseng, M. T.; Cho, M. J.; Liu, Y.; Adams, V. R.; Mumper, R. J. Doxorubicin and paclitaxel-loaded lipid-based nanoparticles overcome multidrug resistance by inhibiting P-glycoprotein and depleting ATP. Cancer Res, 2009, 69(9), 3918-3926.

128. Barbier, P.; Dorleans, A.; Devred, F.; Sanz, L.; Allegro, D.; Alfonso, C.; Knossow, M.; Peyrot, V.; Andreu, J. M. Stathmin and interfacial microtubule inhibitors recognize a naturally curved conformation of tubulin dimers. $J$ Biol Chem, 2010, 285(41), 31672-31681.

129. Dorleans, A.; Gigant, B.; Ravelli, R. B.; Mailliet, P.; Mikol, V.; Knossow, M. Variations in the colchicine-binding domain provide insight into the structural switch of tubulin. Proc Natl Acad Sci U S A, 2009, 106(33), 13775-13779.

130. Li, C. M.; Lu, Y.; Ahn, S.; Narayanan, R.; Miller, D. D.; Dalton, J. T. Competitive mass spectrometry binding assay for characterization of three binding sites of tubulin. J Mass Spectrom, 2010, 45(10), 1160-1166. 
131. Ambrosini, G.; Adida, C.; Altieri, D. C. A novel anti-apoptosis gene, survivin, expressed in cancer and lymphoma. Nature medicine, 1997, 3(8), 917-921.

132. de Almagro, M. C.; Vucic, D. The inhibitor of apoptosis (IAP) proteins are critical regulators of signaling pathways and targets for anti-cancer therapy. Experimental oncology, 2012, 34(3), 200-211.

133. Hunter, A. M.; LaCasse, E. C.; Korneluk, R. G. The inhibitors of apoptosis (IAPs) as cancer targets. Apoptosis : an international journal on programmed cell death, 2007, 12(9), 1543-1568.

134. Schimmer, A. D. Inhibitor of apoptosis proteins: translating basic knowledge into clinical practice. Cancer Res, 2004, 64(20), 7183-7190.

135. Fulda, S.; Vucic, D. Targeting IAP proteins for therapeutic intervention in cancer. Nat Rev Drug Discov, 2012, 11(2), 109-124.

136. Ryan, B. M.; O'Donovan, N.; Duffy, M. J. Survivin: a new target for anti-cancer therapy. Cancer treatment reviews, 2009, 35(7), 553-562.

137. Rauch, A.; Hennig, D.; Schafer, C.; Wirth, M.; Marx, C.; Heinzel, T.; Schneider, G.; Kramer, O. H. Survivin and YM155: how faithful is the liaison? Biochimica et biophysica acta, 2014, 1845(2), 202-220.

138. O'Connor, D. S.; Schechner, J. S.; Adida, C.; Mesri, M.; Rothermel, A. L.; Li, F.; Nath, A. K.; Pober, J. S.; Altieri, D. C. Control of apoptosis during angiogenesis by survivin expression in endothelial cells. The American journal of pathology, 2000, 156(2), 393-398.

139. Waligorska-Stachura, J.; Jankowska, A.; Wasko, R.; Liebert, W.; Biczysko, M.; Czarnywojtek, A.; Baszko-Blaszyk, D.; Shimek, V.; Ruchala, M. Survivin-prognostic tumor biomarker in human neoplasms--review. Ginekologia polska, 2012, 83(7), 537-540.

140. Kawasaki, H.; Toyoda, M.; Shinohara, H.; Okuda, J.; Watanabe, I.; Yamamoto, T.; Tanaka, K.; Tenjo, T.; Tanigawa, N. Expression of survivin correlates with apoptosis, proliferation, and angiogenesis during human colorectal tumorigenesis. Cancer, 2001, 91(11), 2026-2032.

141. Cheung, C. H.; Huang, C. C.; Tsai, F. Y.; Lee, J. Y.; Cheng, S. M.; Chang, Y. C.; Huang, Y. C.; Chen, S. H.; Chang, J. Y. Survivin - biology and potential as a therapeutic target in oncology. OncoTargets and therapy, 2013, 6, 1453-1462.

142. Yang, D.; Welm, A.; Bishop, J. M. Cell division and cell survival in the absence of survivin. Proc Natl Acad Sci U S A, 2004, 101(42), 15100-15105.

143. Vader, G.; Kauw, J. J.; Medema, R. H.; Lens, S. M. Survivin mediates targeting of the chromosomal passenger complex to the centromere and midbody. EMBO reports, 2006, 7(1), 85-92.

144. Ruchaud, S.; Carmena, M.; Earnshaw, W. C. The chromosomal passenger complex: one for all and all for one. Cell, 2007, 131(2), 230-231.

145. Ruchaud, S.; Carmena, M.; Earnshaw, W. C. Chromosomal passengers: conducting cell division. Nature reviews. Molecular cell biology, 2007, 8(10), 798-812.

146. Wiedemuth, R.; Klink, B.; Topfer, K.; Schrock, E.; Schackert, G.; Tatsuka, M.; Temme, A. Survivin safeguards chromosome numbers and protects from aneuploidy independently from p53. Molecular cancer, 2014, 13, 107. 
147. O'Connor, D. S.; Wall, N. R.; Porter, A. C.; Altieri, D. C. A p34(cdc2) survival checkpoint in cancer. Cancer cell, 2002, 2(1), 43-54.

148. Giodini, A.; Kallio, M. J.; Wall, N. R.; Gorbsky, G. J.; Tognin, S.; Marchisio, P. C.; Symons, M.; Altieri, D. C. Regulation of microtubule stability and mitotic progression by survivin. Cancer Res, 2002, 62(9), 2462-2467.

149. Altieri, D. C. The case for survivin as a regulator of microtubule dynamics and cell-death decisions. Current opinion in cell biology, 2006, 18(6), 609-615.

150. Tamm, I.; Wang, Y.; Sausville, E.; Scudiero, D. A.; Vigna, N.; Oltersdorf, T.; Reed, J. C. IAP-family protein survivin inhibits caspase activity and apoptosis induced by Fas (CD95), Bax, caspases, and anticancer drugs. Cancer Res, 1998, 58(23), 5315-5320.

151. Shin, S.; Sung, B. J.; Cho, Y. S.; Kim, H. J.; Ha, N. C.; Hwang, J. I.; Chung, C. W.; Jung, Y. K.; Oh, B. H. An anti-apoptotic protein human survivin is a direct inhibitor of caspase-3 and -7. Biochemistry, 2001, 40(4), 1117-1123.

152. Grossman, D.; Kim, P. J.; Blanc-Brude, O. P.; Brash, D. E.; Tognin, S.; Marchisio, P. C.; Altieri, D. C. Transgenic expression of survivin in keratinocytes counteracts UVB-induced apoptosis and cooperates with loss of p53. The Journal of clinical investigation, 2001, 108(7), 991-999.

153. Yamamoto, T.; Manome, Y.; Nakamura, M.; Tanigawa, N. Downregulation of survivin expression by induction of the effector cell protease receptor-1 reduces tumor growth potential and results in an increased sensitivity to anticancer agents in human colon cancer. European journal of cancer, 2002, 38(17), 2316-2324.

154. Dohi, T.; Okada, K.; Xia, F.; Wilford, C. E.; Samuel, T.; Welsh, K.; Marusawa, H.; Zou, H.; Armstrong, R.; Matsuzawa, S.; Salvesen, G. S.; Reed, J. C.; Altieri, D. C. An IAP-IAP complex inhibits apoptosis. J Biol Chem, 2004, 279(33), 34087-34090.

155. Marusawa, H.; Matsuzawa, S.; Welsh, K.; Zou, H.; Armstrong, R.; Tamm, I.; Reed, J. C. HBXIP functions as a cofactor of survivin in apoptosis suppression. The EMBO journal, 2003, 22(11), 2729-2740.

156. Duffy, M. J.; O'Donovan, N.; Brennan, D. J.; Gallagher, W. M.; Ryan, B. M. Survivin: a promising tumor biomarker. Cancer letters, 2007, 249(1), 49-60.

157. Li, Y.; Ma, X.; Wu, X.; Liu, X.; Liu, L. Prognostic Significance of Survivin in Breast Cancer: Meta-analysis. The breast journal, 2014.

158. Lv, S.; Dai, C.; Liu, Y.; Shi, R.; Tang, Z.; Han, M.; Bian, R.; Sun, B.; Wang, R. The Impact of Survivin on Prognosis and Clinicopathology of Glioma Patients: A Systematic Meta-Analysis. Molecular neurobiology, 2014.

159. Monzo, M.; Rosell, R.; Felip, E.; Astudillo, J.; Sanchez, J. J.; Maestre, J.; Martin, C.; Font, A.; Barnadas, A.; Abad, A. A novel anti-apoptosis gene: Re-expression of survivin messenger RNA as a prognosis marker in non-small-cell lung cancers. J Clin Oncol, 1999, 17(7), 2100-2104.

160. Tanaka, K.; Iwamoto, S.; Gon, G.; Nohara, T.; Iwamoto, M.; Tanigawa, N. Expression of survivin and its relationship to loss of apoptosis in breast carcinomas. Clin Cancer Res, 2000, 6(1), 127-134.

161. Satoh, K.; Kaneko, K.; Hirota, M.; Masamune, A.; Satoh, A.; Shimosegawa, T. Tumor necrosis factor-related apoptosis-inducing ligand and its receptor 
expression and the pathway of apoptosis in human pancreatic cancer. Pancreas, 2001, 23(3), 251-258.

162. Grossman, D.; McNiff, J. M.; Li, F.; Altieri, D. C. Expression and targeting of the apoptosis inhibitor, survivin, in human melanoma. The Journal of investigative dermatology, 1999, 113(6), 1076-1081.

163. Cheung, C. H.; Sun, X.; Kanwar, J. R.; Bai, J. Z.; Cheng, L.; Krissansen, G. W. A cell-permeable dominant-negative survivin protein induces apoptosis and sensitizes prostate cancer cells to TNF-alpha therapy. Cancer cell international, 2010, $10,36$.

164. Ling, X.; Calinski, D.; Chanan-Khan, A. A.; Zhou, M.; Li, F. Cancer cell sensitivity to bortezomib is associated with survivin expression and p53 status but not cancer cell types. Journal of experimental \& clinical cancer research : $C R$, 2010, 29, 8 .

165. He, S. Q.; Rehman, H.; Gong, M. G.; Zhao, Y. Z.; Huang, Z. Y.; Li, C. H.; Zhang, W. G.; Chen, X. P. Inhibiting survivin expression enhances TRAIL-induced tumoricidal activity in human hepatocellular carcinoma via cell cycle arrest. Cancer biology \& therapy, 2007, 6(8), 1247-1257.

166. Moriai, R.; Tsuji, N.; Moriai, M.; Kobayashi, D.; Watanabe, N. Survivin plays as a resistant factor against tamoxifen-induced apoptosis in human breast cancer cells. Breast cancer research and treatment, 2009, 117(2), 261-271.

167. Nomura, T.; Yamasaki, M.; Nomura, Y.; Mimata, H. Expression of the inhibitors of apoptosis proteins in cisplatin-resistant prostate cancer cells. Oncology reports, 2005, 14(4), 993-997.

168. Tirro, E.; Consoli, M. L.; Massimino, M.; Manzella, L.; Frasca, F.; Sciacca, L.; Vicari, L.; Stassi, G.; Messina, L.; Messina, A.; Vigneri, P. Altered expression of c-IAP1, survivin, and Smac contributes to chemotherapy resistance in thyroid cancer cells. Cancer Res, 2006, 66(8), 4263-4272.

169. Adisetiyo, H.; Liang, M.; Liao, C. P.; Aycock-Williams, A.; Cohen, M. B.; Xu, S.; Neamati, N.; Conway, E. M.; Cheng, C. Y.; Nikitin, A. Y.; Roy-Burman, P. Loss of survivin in the prostate epithelium impedes carcinogenesis in a mouse model of prostate adenocarcinoma. PLoS One, 2013, 8(7), e69484.

170. Mobahat, M.; Narendran, A.; Riabowol, K. Survivin as a preferential target for cancer therapy. International journal of molecular sciences, 2014, 15(2), 24942516.

171. Athanasoula, K.; Gogas, H.; Polonifi, K.; Vaiopoulos, A. G.; Polyzos, A.; Mantzourani, M. Survivin beyond physiology: orchestration of multistep carcinogenesis and therapeutic potentials. Cancer letters, 2014, 347(2), 175-182.

172. Ghanbari, P.; Mohseni, M.; Tabasinezhad, M.; Yousefi, B.; Saei, A. A.; Sharifi, S.; Rashidi, M. R.; Samadi, N. Inhibition of Survivin Restores the Sensitivity of Breast Cancer Cells to Docetaxel and Vinblastine. Applied biochemistry and biotechnology, 2014.

173. Wang, R.; Chen, D. Q.; Huang, J. Y.; Zhang, K.; Feng, B.; Pan, B. Z.; Chen, J.; De, W.; Chen, L. B. Acquisition of radioresistance in docetaxel-resistant human lung adenocarcinoma cells is linked with dysregulation of miR-451/c-Mycsurvivin/rad-51 signaling. Oncotarget, 2014. 
174. Sun, X. P.; Dong, X.; Lin, L.; Jiang, X.; Wei, Z.; Zhai, B.; Sun, B.; Zhang, Q.; Wang, X.; Jiang, H.; Krissansen, G. W.; Qiao, H.; Sun, X. Up-regulation of survivin by AKT and hypoxia-inducible factor 1alpha contributes to cisplatin resistance in gastric cancer. The FEBS journal, 2014, 281(1), 115-128.

175. Buchwald, P. Small-molecule protein-protein interaction inhibitors: therapeutic potential in light of molecular size, chemical space, and ligand binding efficiency considerations. IUBMB life, 2010, 62(10), 724-731.

176. Fuller, J. C.; Burgoyne, N. J.; Jackson, R. M. Predicting druggable binding sites at the protein-protein interface. Drug Discov Today, 2009, 14(3-4), 155-161.

177. Wishart, D. S.; Knox, C.; Guo, A. C.; Cheng, D.; Shrivastava, S.; Tzur, D.; Gautam, B.; Hassanali, M. DrugBank: a knowledgebase for drugs, drug actions and drug targets. Nucleic acids research, 2008, 36(Database issue), D901-906.

178. Lagane, B.; Garcia-Perez, J.; Kellenberger, E. Modeling the allosteric modulation of CCR5 function by Maraviroc. Drug discovery today. Technologies, 2013, 10(2), e297-305.

179. Bogan, A. A.; Thorn, K. S. Anatomy of hot spots in protein interfaces. Journal of molecular biology, 1998, 280(1), 1-9.

180. Wang, J.; Li, W. Discovery of novel second mitochondria-derived activator of caspase mimetics as selective inhibitor of apoptosis protein inhibitors. $J$ Pharmacol Exp Ther, 2014, 349(2), 319-329.

181. Du, J.; Kelly, A. E.; Funabiki, H.; Patel, D. J. Structural basis for recognition of H3T3ph and Smac/DIABLO N-terminal peptides by human Survivin. Structure, 2012, 20(1), 185-195.

182. Pennati, M.; Folini, M.; Zaffaroni, N. Targeting survivin in cancer therapy: fulfilled promises and open questions. Carcinogenesis, 2007, 28(6), 1133-1139.

183. Coumar, M. S.; Tsai, F. Y.; Kanwar, J. R.; Sarvagalla, S.; Cheung, C. H. Treat cancers by targeting survivin: just a dream or future reality? Cancer treatment reviews, 2013, 39(7), 802-811.

184. Nakahara, T.; Kita, A.; Yamanaka, K.; Mori, M.; Amino, N.; Takeuchi, M.; Tominaga, F.; Hatakeyama, S.; Kinoyama, I.; Matsuhisa, A.; Kudoh, M.; Sasamata, M. YM155, a novel small-molecule survivin suppressant, induces regression of established human hormone-refractory prostate tumor xenografts. Cancer Res, 2007, 67(17), 8014-8021.

185. Wall, N. R.; O'Connor, D. S.; Plescia, J.; Pommier, Y.; Altieri, D. C. Suppression of survivin phosphorylation on Thr34 by flavopiridol enhances tumor cell apoptosis. Cancer Res, 2003, 63(1), 230-235.

186. Meli, M.; Pennati, M.; Curto, M.; Daidone, M. G.; Plescia, J.; Toba, S.; Altieri, D. C.; Zaffaroni, N.; Colombo, G. Small-molecule targeting of heat shock protein 90 chaperone function: rational identification of a new anticancer lead. $\mathrm{J} \mathrm{Med} \mathrm{Chem,}$ 2006, 49(26), 7721-7730.

187. Wang, H. Q.; Jin, J. J.; Wang, J. Arctigenin enhances chemosensitivity to cisplatin in human nonsmall lung cancer H460 cells through downregulation of survivin expression. Journal of biochemical and molecular toxicology, 2014, 28(1), 39-45.

188. Huang, K.; Li, L. A.; Meng, Y. G.; You, Y. Q.; Fu, X. Y.; Song, L. Arctigenin Promotes Apoptosis in Ovarian Cancer Cells via the iNOS/NO/STAT3/Survivin Signalling. Basic \& clinical pharmacology \& toxicology, 2014. 
189. Hsiao, C. J.; Hsiao, G.; Chen, W. L.; Wang, S. W.; Chiang, C. P.; Liu, L. Y.; Guh, J. H.; Lee, T. H.; Chung, C. L. Cephalochromin induces G0/G1 cell cycle arrest and apoptosis in A549 human non-small-cell lung cancer cells by inflicting mitochondrial disruption. Journal of natural products, 2014, 77(4), 758-765.

190. Ling, X.; Cao, S.; Cheng, Q.; Keefe, J. T.; Rustum, Y. M.; Li, F. A novel small molecule FL118 that selectively inhibits survivin, Mcl-1, XIAP and cIAP2 in a p53-independent manner, shows superior antitumor activity. PLoS One, 2012, 7(9), e45571.

191. Zhao, J.; Ling, X.; Cao, S.; Liu, X.; Wan, S.; Jiang, T.; Li, F. Antitumor activity of FL118, a survivin, Mcl-1, XIAP, and cIAP2 selective inhibitor, is highly dependent on its primary structure and steric configuration. Molecular pharmaceutics, 2014, 11(2), 457-467.

192. O'Connor, D. S.; Grossman, D.; Plescia, J.; Li, F.; Zhang, H.; Villa, A.; Tognin, S.; Marchisio, P. C.; Altieri, D. C. Regulation of apoptosis at cell division by p34cdc2 phosphorylation of survivin. Proc Natl Acad Sci U S A, 2000, 97(24), 13103-13107.

193. Lee, H. G.; Baek, J. W.; Shin, S. J.; Kwon, S. H.; Cha, S. D.; Park, W. J.; Chung, R.; Choi, E. S.; Lee, G. H.; Cho, C. H. Antitumor Effects of Flavopiridol on Human Uterine Leiomyoma In Vitro and in a Xenograft model. Reproductive sciences, 2014.

194. Karp, J. E.; Garrett-Mayer, E.; Estey, E. H.; Rudek, M. A.; Smith, B. D.; Greer, J. M.; Drye, D. M.; Mackey, K.; Dorcy, K. S.; Gore, S. D.; Levis, M. J.; McDevitt, M. A.; Carraway, H. E.; Pratz, K. W.; Gladstone, D. E.; Showel, M. M.; Othus, M.; Doyle, L. A.; Wright, J. J.; Pagel, J. M. Randomized phase II study of two schedules of flavopiridol given as timed sequential therapy with cytosine arabinoside and mitoxantrone for adults with newly diagnosed, poor-risk acute myelogenous leukemia. Haematologica, 2012, 97(11), 1736-1742.

195. Bible, K. C.; Peethambaram, P. P.; Oberg, A. L.; Maples, W.; Groteluschen, D. L.; Boente, M.; Burton, J. K.; Gomez Dahl, L. C.; Tibodeau, J. D.; Isham, C. R.; Maguire, J. L.; Shridhar, V.; Kukla, A. K.; Voll, K. J.; Mauer, M. J.; Colevas, A. D.; Wright, J.; Doyle, L. A.; Erlichman, C.; Mayo Phase, C.; North Central Cancer Treatment, G. A phase 2 trial of flavopiridol (Alvocidib) and cisplatin in platin-resistant ovarian and primary peritoneal carcinoma: MC0261. Gynecologic oncology, 2012, 127(1), 55-62.

196. Emami, K. H.; Nguyen, C.; Ma, H.; Kim, D. H.; Jeong, K. W.; Eguchi, M.; Moon, R. T.; Teo, J. L.; Kim, H. Y.; Moon, S. H.; Ha, J. R.; Kahn, M. A small molecule inhibitor of beta-catenin/CREB-binding protein transcription [corrected]. Proc Natl Acad Sci U S A, 2004, 101(34), 12682-12687.

197. Azmi, A. S.; Aboukameel, A.; Bao, B.; Sarkar, F. H.; Philip, P. A.; Kauffman, M.; Shacham, S.; Mohammad, R. M. Selective inhibitors of nuclear export block pancreatic cancer cell proliferation and reduce tumor growth in mice.

Gastroenterology, 2013, 144(2), 447-456.

198. Etchin, J.; Sun, Q.; Kentsis, A.; Farmer, A.; Zhang, Z. C.; Sanda, T.; Mansour, M. R.; Barcelo, C.; McCauley, D.; Kauffman, M.; Shacham, S.; Christie, A. L.; Kung, A. L.; Rodig, S. J.; Chook, Y. M.; Look, A. T. Antileukemic activity of 
nuclear export inhibitors that spare normal hematopoietic cells. Leukemia, 2013, 27(1), 66-74.

199. Zhang, K.; Wang, M.; Tamayo, A. T.; Shacham, S.; Kauffman, M.; Lee, J.; Zhang, L.; Ou, Z.; Li, C.; Sun, L.; Ford, R. J.; Pham, L. V. Novel selective inhibitors of nuclear export CRM1 antagonists for therapy in mantle cell lymphoma. Experimental hematology, 2013, 41(1), 67-78 e64.

200. Wang, S.; Han, X.; Wang, J.; Yao, J.; Shi, Y. Antitumor effects of a novel chromosome region maintenance 1 (CRM1) inhibitor on non-small cell lung cancer cells in vitro and in mouse tumor xenografts. PLoS One, 2014, 9(3), e89848.

201. Tai, Y. T.; Landesman, Y.; Acharya, C.; Calle, Y.; Zhong, M. Y.; Cea, M.; Tannenbaum, D.; Cagnetta, A.; Reagan, M.; Munshi, A. A.; Senapedis, W.; SaintMartin, J. R.; Kashyap, T.; Shacham, S.; Kauffman, M.; Gu, Y.; Wu, L.; Ghobrial, I.; Zhan, F.; Kung, A. L.; Schey, S. A.; Richardson, P.; Munshi, N. C.; Anderson, K. C. CRM1 inhibition induces tumor cell cytotoxicity and impairs osteoclastogenesis in multiple myeloma: molecular mechanisms and therapeutic implications. Leukemia, 2014, 28(1), 155-165.

202. Xia, W.; Bisi, J.; Strum, J.; Liu, L.; Carrick, K.; Graham, K. M.; Treece, A. L.; Hardwicke, M. A.; Dush, M.; Liao, Q.; Westlund, R. E.; Zhao, S.; Bacus, S.; Spector, N. L. Regulation of survivin by ErbB2 signaling: therapeutic implications for ErbB2-overexpressing breast cancers. Cancer Res, 2006, 66(3), 1640-1647.

203. Kacan, T.; Altun, A.; Altun, G. G.; Kacan, S. B.; Sarac, B.; Seker, M. M.; Bahceci, A.; Babacan, N. Investigation of antitumor effects of sorafenib and lapatinib alone and in combination on MCF-7 breast cancer cells. Asian Pacific journal of cancer prevention : APJCP, 2014, 15(7), 3185-3189.

204. Robidoux, A.; Tang, G.; Rastogi, P.; Geyer, C. E., Jr.; Azar, C. A.; Atkins, J. N.; Fehrenbacher, L.; Bear, H. D.; Baez-Diaz, L.; Sarwar, S.; Margolese, R. G.; Farrar, W. B.; Brufsky, A. M.; Shibata, H. R.; Bandos, H.; Paik, S.; Costantino, J. P.; Swain, S. M.; Mamounas, E. P.; Wolmark, N. Lapatinib as a component of neoadjuvant therapy for HER2-positive operable breast cancer (NSABP protocol B-41): an open-label, randomised phase 3 trial. Lancet Oncol, 2013, 14(12), 11831192.

205. Baselga, J.; Bradbury, I.; Eidtmann, H.; Di Cosimo, S.; de Azambuja, E.; Aura, C.; Gomez, H.; Dinh, P.; Fauria, K.; Van Dooren, V.; Aktan, G.; Goldhirsch, A.; Chang, T. W.; Horvath, Z.; Coccia-Portugal, M.; Domont, J.; Tseng, L. M.; Kunz, G.; Sohn, J. H.; Semiglazov, V.; Lerzo, G.; Palacova, M.; Probachai, V.; Pusztai, L.; Untch, M.; Gelber, R. D.; Piccart-Gebhart, M.; Neo, A. S. T. Lapatinib with trastuzumab for HER2-positive early breast cancer (NeoALTTO): a randomised, open-label, multicentre, phase 3 trial. Lancet, 2012, 379(9816), 633-640.

206. Cheng, Y.; Zhang, Y.; Zhang, L.; Ren, X.; Huber-Keener, K. J.; Liu, X.; Zhou, L.; Liao, J.; Keihack, H.; Yan, L.; Rubin, E.; Yang, J. M. MK-2206, a novel allosteric inhibitor of Akt, synergizes with gefitinib against malignant glioma via modulating both autophagy and apoptosis. Molecular cancer therapeutics, 2012, 11(1), 154-164. 
207. Liu, R.; Liu, D.; Xing, M. The Akt inhibitor MK2206 synergizes, but perifosine antagonizes, the BRAF(V600E) inhibitor PLX4032 and the MEK1/2 inhibitor AZD6244 in the inhibition of thyroid cancer cells. The Journal of clinical endocrinology and metabolism, 2012, 97(2), E173-182.

208. Chowdhury, S.; Howell, G. M.; Rajput, A.; Teggart, C. A.; Brattain, L. E.; Weber, H. R.; Chowdhury, A.; Brattain, M. G. Identification of a novel TGFbeta/PKA signaling transduceome in mediating control of cell survival and metastasis in colon cancer. PLoS One, 2011, 6(5), e19335.

209. Agarwal, E.; Chaudhuri, A.; Leiphrakpam, P. D.; Haferbier, K. L.; Brattain, M. G.; Chowdhury, S. Akt inhibitor MK-2206 promotes anti-tumor activity and cell death by modulation of AIF and Ezrin in colorectal cancer. BMC Cancer, 2014, $14,145$.

210. Davies, T. G.; Bentley, J.; Arris, C. E.; Boyle, F. T.; Curtin, N. J.; Endicott, J. A.; Gibson, A. E.; Golding, B. T.; Griffin, R. J.; Hardcastle, I. R.; Jewsbury, P.; Johnson, L. N.; Mesguiche, V.; Newell, D. R.; Noble, M. E.; Tucker, J. A.; Wang, L.; Whitfield, H. J. Structure-based design of a potent purine-based cyclindependent kinase inhibitor. Nature structural biology, 2002, 9(10), 745-749.

211. Pennati, M.; Campbell, A. J.; Curto, M.; Binda, M.; Cheng, Y.; Wang, L. Z.; Curtin, N.; Golding, B. T.; Griffin, R. J.; Hardcastle, I. R.; Henderson, A.; Zaffaroni, N.; Newell, D. R. Potentiation of paclitaxel-induced apoptosis by the novel cyclin-dependent kinase inhibitor NU6140: a possible role for survivin down-regulation. Molecular cancer therapeutics, 2005, 4(9), 1328-1337.

212. Erkel, G.; Anke, T.; Sterner, O. Inhibition of NF-kappa B activation by panepoxydone. Biochemical and biophysical research communications, 1996, 226(1), 214-221.

213. Arora, R.; Yates, C.; Gary, B. D.; McClellan, S.; Tan, M.; Xi, Y.; Reed, E.; Piazza, G. A.; Owen, L. B.; Dean-Colomb, W. Panepoxydone targets NF-kB and FOXM1 to inhibit proliferation, induce apoptosis and reverse epithelial to mesenchymal transition in breast cancer. PLoS One, 2014, 9(6), e98370.

214. Yaffe, P. B.; Power Coombs, M. R.; Doucette, C. D.; Walsh, M.; Hoskin, D. W. Piperine, an alkaloid from black pepper, inhibits growth of human colon cancer cells via G1 arrest and apoptosis triggered by endoplasmic reticulum stress. Molecular carcinogenesis, 2014.

215. Stella, S.; Tirro, E.; Conte, E.; Stagno, F.; Di Raimondo, F.; Manzella, L.; Vigneri, P. Suppression of survivin induced by a BCR-ABL/JAK2/STAT3 pathway sensitizes imatinib-resistant CML cells to different cytotoxic drugs. Molecular cancer therapeutics, 2013, 12(6), 1085-1098.

216. Abdelhamed, S.; Yokoyama, S.; Refaat, A.; Ogura, K.; Yagita, H.; Awale, S.; Saiki, I. Piperine enhances the efficacy of TRAIL-based therapy for triplenegative breast cancer cells. Anticancer Res, 2014, 34(4), 1893-1899.

217. Iizuka, D.; Ogura, A.; Kuwabara, M.; Inanami, O. Purvalanol A induces apoptosis and downregulation of antiapoptotic proteins through abrogation of phosphorylation of JAK2/STAT3 and RNA polymerase II. Anti-cancer drugs, 2008, 19(6), 565-572.

218. Zaffaroni, N.; Pennati, M.; Colella, G.; Perego, P.; Supino, R.; Gatti, L.; Pilotti, S.; Zunino, F.; Daidone, M. G. Expression of the anti-apoptotic gene survivin 
correlates with taxol resistance in human ovarian cancer. Cellular and molecular life sciences: CMLS, 2002, 59(8), 1406-1412.

219. Cihalova, D.; Hofman, J.; Ceckova, M.; Staud, F. Purvalanol A, olomoucine II and roscovitine inhibit $\mathrm{ABCB} 1$ transporter and synergistically potentiate cytotoxic effects of daunorubicin in vitro. PLoS One, 2013, 8(12), e83467.

220. Plescia, J.; Salz, W.; Xia, F.; Pennati, M.; Zaffaroni, N.; Daidone, M. G.; Meli, M.; Dohi, T.; Fortugno, P.; Nefedova, Y.; Gabrilovich, D. I.; Colombo, G.; Altieri, D. C. Rational design of shepherdin, a novel anticancer agent. Cancer cell, 2005, 7(5), 457-468.

221. Hwu, J. R.; Tseng, W. N.; Gnabre, J.; Giza, P.; Huang, R. C. Antiviral activities of methylated nordihydroguaiaretic acids. 1. Synthesis, structure identification, and inhibition of tat-regulated HIV transactivation. J Med Chem, 1998, 41(16), 2994-3000.

222. Heller, J. D.; Kuo, J.; Wu, T. C.; Kast, W. M.; Huang, R. C. Tetra-O-methyl nordihydroguaiaretic acid induces $\mathrm{G} 2$ arrest in mammalian cells and exhibits tumoricidal activity in vivo. Cancer Res, 2001, 61(14), 5499-5504.

223. Chang, C. C.; Heller, J. D.; Kuo, J.; Huang, R. C. Tetra-O-methyl nordihydroguaiaretic acid induces growth arrest and cellular apoptosis by inhibiting Cdc2 and survivin expression. Proc Natl Acad Sci US A, 2004, 101(36), 13239-13244.

224. Sun, Y.; Giacalone, N. J.; Lu, B. Terameprocol (tetra-O-methyl nordihydroguaiaretic acid), an inhibitor of Sp1-mediated survivin transcription, induces radiosensitization in non-small cell lung carcinoma. Journal of thoracic oncology : official publication of the International Association for the Study of Lung Cancer, 2011, 6(1), 8-14.

225. Khanna, N.; Dalby, R.; Tan, M.; Arnold, S.; Stern, J.; Frazer, N. Phase I/II clinical safety studies of terameprocol vaginal ointment. Gynecologic oncology, 2007, 107(3), 554-562.

226. Grossman, S. A.; Ye, X.; Peereboom, D.; Rosenfeld, M. R.; Mikkelsen, T.; Supko, J. G.; Desideri, S.; Adult Brain Tumor, C. Phase I study of terameprocol in patients with recurrent high-grade glioma. Neuro-oncology, 2012, 14(4), 511517.

227. Koike, H.; Nitta, T.; Sekine, Y.; Arai, S.; Furuya, Y.; Nomura, M.; Matsui, H.; Shibata, Y.; Ito, K.; Oyama, T.; Suzuki, K. YM155 reverses rapamycin resistance in renal cancer by decreasing survivin. Journal of cancer research and clinical oncology, 2014.

228. Mir, R.; Stanzani, E.; Martinez-Soler, F.; Villanueva, A.; Vidal, A.; Condom, E.; Ponce, J.; Gil, J.; Tortosa, A.; Gimenez-Bonafe, P. YM155 sensitizes ovarian cancer cells to cisplatin inducing apoptosis and tumor regression. Gynecologic oncology, 2014, 132(1), 211-220.

229. Cheson, B. D.; Bartlett, N. L.; Vose, J. M.; Lopez-Hernandez, A.; Seiz, A. L.; Keating, A. T.; Shamsili, S.; Papadopoulos, K. P. A phase II study of the survivin suppressant YM155 in patients with refractory diffuse large B-cell lymphoma. Cancer, 2012, 118(12), 3128-3134.

230. Giaccone, G.; Zatloukal, P.; Roubec, J.; Floor, K.; Musil, J.; Kuta, M.; van Klaveren, R. J.; Chaudhary, S.; Gunther, A.; Shamsili, S. Multicenter phase II 
trial of YM155, a small-molecule suppressor of survivin, in patients with advanced, refractory, non-small-cell lung cancer. J Clin Oncol, 2009, 27(27), 4481-4486.

231. Iwai, M.; Minematsu, T.; Li, Q.; Iwatsubo, T.; Usui, T. Utility of P-glycoprotein and organic cation transporter 1 double-transfected LLC-PK1 cells for studying the interaction of YM155 monobromide, novel small-molecule survivin suppressant, with P-glycoprotein. Drug metabolism and disposition: the biological fate of chemicals, 2011, 39(12), 2314-2320.

232. Fukuda, S.; Pelus, L. M. Survivin, a cancer target with an emerging role in normal adult tissues. Molecular cancer therapeutics, 2006, 5(5), 1087-1098.

233. Satoh, K.; Kaneko, K.; Hirota, M.; Masamune, A.; Satoh, A.; Shimosegawa, T. Expression of survivin is correlated with cancer cell apoptosis and is involved in the development of human pancreatic duct cell tumors. Cancer, 2001, 92(2), 271278.

234. Conway, E. M.; Zwerts, F.; Van Eygen, V.; DeVriese, A.; Nagai, N.; Luo, W.; Collen, D. Survivin-dependent angiogenesis in ischemic brain: molecular mechanisms of hypoxia-induced up-regulation. The American journal of pathology, 2003, 163(3), 935-946.

235. Tu, S. P.; Jiang, X. H.; Lin, M. C.; Cui, J. T.; Yang, Y.; Lum, C. T.; Zou, B.; Zhu, Y. B.; Jiang, S. H.; Wong, W. M.; Chan, A. O.; Yuen, M. F.; Lam, S. K.; Kung, H. F.; Wong, B. C. Suppression of survivin expression inhibits in vivo tumorigenicity and angiogenesis in gastric cancer. Cancer Res, 2003, 63(22), 7724-7732.

236. Tsutsui, S.; Inoue, H.; Yasuda, K.; Suzuki, K.; Takeuchi, H.; Nishizaki, T.; Higashi, H.; Era, S.; Mori, M. Angiopoietin 2 expression in invasive ductal carcinoma of the breast: its relationship to the VEGF expression and microvessel density. Breast cancer research and treatment, 2006, 98(3), 261-266.

237. Yang, Y.; Zhang, Y.; Hao, S.; Kan, Q. Periodic mesoporous organosilicas with bis(8-quinolinolato) dioxomolybdenum(VI) inside the channel walls. Journal of colloid and interface science, 2011, 362(1), 157-163.

238. Farruggia, G.; Iotti, S.; Lombardo, M.; Marraccini, C.; Petruzziello, D.; Prodi, L.; Sgarzi, M.; Trombini, C.; Zaccheroni, N. Microwave assisted synthesis of a small library of substituted N,N'-bis((8-hydroxy-7-quinolinyl)methyl)-1,10-diaza-18crown-6 ethers. J Org Chem, 2010, 75(18), 6275-6278.

239. Himmi, B.; Joly, J. P.; Hlimi, F.; Soufiaoui, M.; Kitane, S.; Bahloul, A.; Eddaif, A.; Sebban, A. Synthesis of novel 5,7-disubstituted 8-hydroxyquinolines. $J$ Heterocyclic Chem, 2008, 45(4), 1023-1026.

240. Uchiyama-Kokubu, N.; Watanabe, T. Establishment and characterization of adriamycin-resistant human colorectal adenocarcinoma HCT-15 cell lines with multidrug resistance. Anti-cancer drugs, 2001, 12(9), 769-779.

241. Sangthong, S.; Ha, H.; Teerawattananon, T.; Ngamrojanavanich, N.; Neamati, N.; Muangsin, N. Overcoming doxorubicin-resistance in the NCI/ADR-RES model cancer cell line by novel anthracene-9,10-dione derivatives. Bioorg Med Chem Lett, 2013, 23(22), 6156-6160.

242. Derry, M. M.; Somasagara, R. R.; Raina, K.; Kumar, S.; Gomez, J.; Patel, M.; Agarwal, R.; Agarwal, C. Target identification of grape seed extract in colorectal 
cancer using drug affinity responsive target stability (DARTS) technique: role of endoplasmic reticulum stress response proteins. Current cancer drug targets, 2014, 14(4), 323-336.

243. Lomenick, B.; Hao, R.; Jonai, N.; Chin, R. M.; Aghajan, M.; Warburton, S.; Wang, J.; Wu, R. P.; Gomez, F.; Loo, J. A.; Wohlschlegel, J. A.; Vondriska, T. M.; Pelletier, J.; Herschman, H. R.; Clardy, J.; Clarke, C. F.; Huang, J. Target identification using drug affinity responsive target stability (DARTS). Proc Natl Acad Sci U S A, 2009, 106(51), 21984-21989.

244. Lomenick, B.; Jung, G.; Wohlschlegel, J. A.; Huang, J. Target identification using drug affinity responsive target stability (DARTS). Current protocols in chemical biology, 2011, 3(4), 163-180.

245. Pai, M. Y.; Lomenick, B.; Hwang, H.; Schiestl, R.; McBride, W.; Loo, J. A.; Huang, J. Drug affinity responsive target stability (DARTS) for small-molecule target identification. Methods in molecular biology, 2015, 1263, 287-298.

246. Xiao, M.; Ahn, S.; Wang, J.; Chen, J.; Miller, D. D.; Dalton, J. T.; Li, W. Discovery of 4-Aryl-2-benzoyl-imidazoles as tubulin polymerization inhibitor with potent anti-proliferative properties. J Med Chem, 2013, 56(8), 3318-3329.

247. Shoemaker, R. H. The NCI60 human tumour cell line anticancer drug screen. Nat Rev Cancer, 2006, 6(10), 813-823.

248. Lu, Y.; Chen, J.; Wang, J.; Li, C. M.; Ahn, S.; Barrett, C. M.; Dalton, J. T.; Li, W.; Miller, D. D. Design, synthesis, and biological evaluation of stable colchicine binding site tubulin inhibitors as potential anticancer agents. Journal of medicinal chemistry, 2014, 57(17), 7355-7366. 


\section{VITA}

Min Xiao was born in Anhui Province, China, in 1988. He entered East China University of Science and Technology in 2006 and earned a Bachelor of Science degree in Pharmaceutical Engineering in 2010. Then he joined Dr. Wei Li's lab at University of Tennessee Health Science Center in pursuit of a Ph.D. degree in Pharmaceutical Sciences. 